\title{
DEVELOPMENT OF A HYBRID SOLAR CASCADE HEAT PUMP HEATING SYSTEM
}

by

\author{
Jamie Fine
}

M.A.Sc., Aerospace Engineering, University of Toronto, Canada, 2014

B.Eng., Mechanical Engineering, Ryerson University, Canada, 2012

\author{
A dissertation \\ presented to Ryerson University \\ in partial fulfillment of the \\ requirements for the degree of \\ Doctor of Philosophy \\ in the program of \\ Mechanical and Industrial Engineering
}

Toronto, Ontario, Canada, 2018

(C) Jamie Fine, 2018 


\begin{abstract}
AUTHOR'S DECLARATION
I hereby declare that I am the sole author of this dissertation. This is a true copy of the dissertation, including any required final revisions, as accepted by my examiners.
\end{abstract}

I authorize Ryerson University to lend this dissertation to other institutions or individuals for the purpose of scholarly research.

I further authorize Ryerson University to reproduce this dissertation by photocopying or by other means, in total or in part, at the request of other institutions or individuals for the purpose of scholarly research.

I understand that my dissertation may be made electronically available to the public. 


\title{
DEVELOPMENT OF A HYBRID SOLAR CASCADE HEAT PUMP HEATING SYSTEM
}

\author{
Doctor of Philosophy, 2018 \\ Jamie Fine \\ Mechanical Engineering \\ Ryerson University
}

\begin{abstract}
Society's use of fossil fuels has led to increasingly high levels of $\mathrm{CO}_{2}$ in the atmosphere. These levels have been linked to global average temperature rises, and increases in the severity and frequency of major weather events. To combat these effects, nations around the world have committed to reducing their $\mathrm{CO}_{2}$ emissions, and transition to renewable energy. This thesis focuses on the development of a novel solar heating system, which combines a hybrid solar panel and cascade heat pump.
\end{abstract}

The thesis begins by presenting a high-level literature review of solar and heat pump technologies, followed by the initial design development of the system. Two design iterations are presented, illustrating that the final design was selected because it exhibits improved peak heat output, and reduced sensitivity to panel temperature.

Next, a manuscript-based chapter is presented that focuses on utilizing the proposed solar heating system for water distillation. Case studies are presented that compare the performance of the proposed system with a solar still at four different locations. The final conclusion from these 
studies is that using the proposed system offers area-based performance improvements of $780 \%$ compared to a basic solar still.

A second manuscript-based study is then presented, which focuses on utilizing the proposed solar heating system for domestic hot water production. Additional case studies are detailed that compare the proposed system to an evacuated tube design, and a single heat pump design. The conclusions from these studies are that the proposed system exceeds the performance of the evacuated tube system by up to $64 \%$, and that the proposed system is most beneficial during seasons with higher average dry-bulb temperatures, and increased solar irradiation.

A final manuscript-based study is then presented, which focuses on a methodology for improving alternate mode thermal performance estimates for hybrid solar panels. The conclusion from this study is that the proposed methodology can successfully estimate thermal performance within $5 \%$ of actual values. Each of these studies contributes to the project goal of developing a novel solar energy heating system, which can be further developed to reduce global $\mathrm{CO}_{2}$ emissions, and reduce the effects of climate change. 


\section{Acknowledgements}

I would like to thank:

$>$ Dr. Seth Dworkin and Dr. Jacob Friedman for providing me with the opportunity of joining their research teams and for their persistent and friendly support, encouragement, patience and advice in all steps of my $\mathrm{PhD}$.

$>$ Members of my dissertation committee: Dr. Wey Leong, Dr. Alan Fung, and Dr. Simon Furbo.

$>\quad$ Natural Sciences and Engineering Research Council of Canada (NSERC)

$>$ The Ontario Graduate Scholarship program

$>$ The Faculty of Engineering and Architectural Science at Ryerson University

$>$ Ryerson University, for the facilities and equipment provided for this research

$>$ Concordia University Centre for Zero Energy Building Studies, for the use of their solar simulator facility

$>$ Prof. Amin Ghobeity, Mechanical and Electrical Engineering \& Technology, Sheridan College, Brampton, Ontario, Canada, for helpful discussions and advice

$>$ The Canada Research Chairs program 
This dissertation is dedicated to my family and friends who have supported me through my entire education,

$$
\text { and }
$$

Kseniya, whose love and patience made this project possible. 


\section{Table of Contents}

AUTHOR'S DECLARATION...........................................................................................................

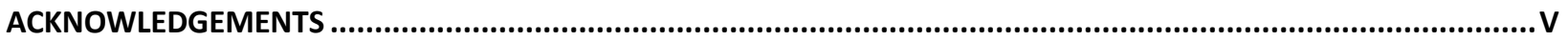

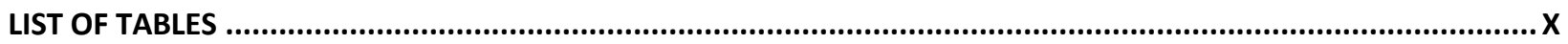

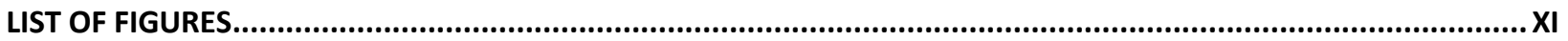

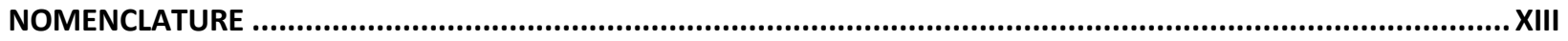

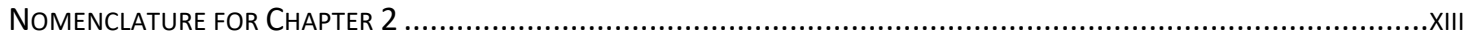

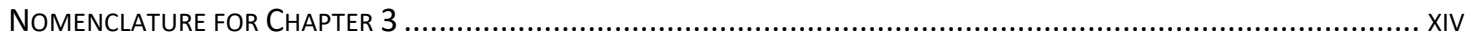

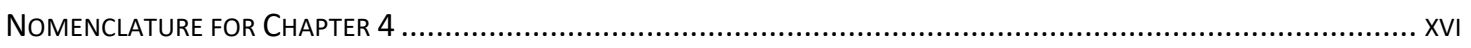

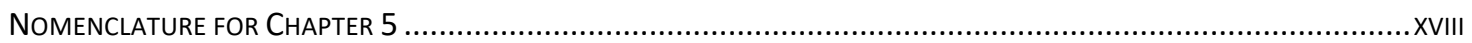

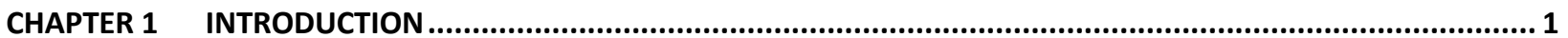

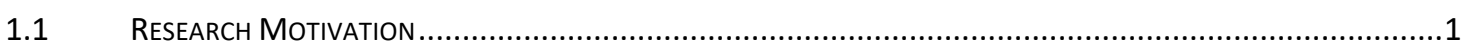

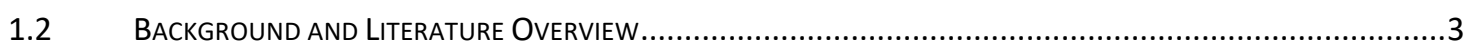

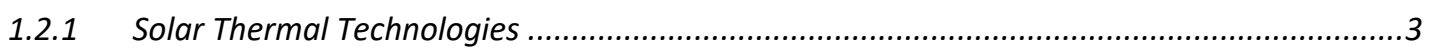

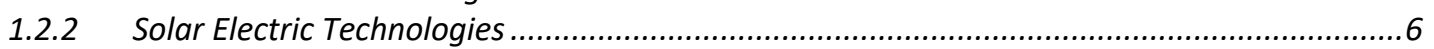

1.2.3 Hybrid Solar Technologies ......................................................................................... 11

1.2.4 Heat Pump Technologies........................................................................................ 13

1.3 OVERVIEW OF MANUSCRIPTS FROM DOCTORAL WORK .............................................................15

CHAPTER 2 INITIAL DEVELOPMENT OF THE HYBRID SOLAR CASCADE HEAT PUMP ..................................... 18

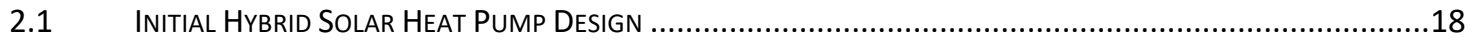

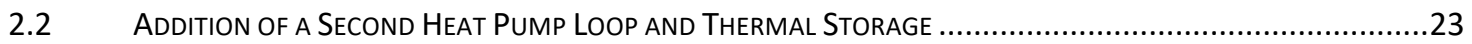

CHAPTER 3 TIME-STEPPING ANALYSIS OF A PHOTOVOLTAIC THERMAL HEAT INPUT PROCESS WITH THERMAL

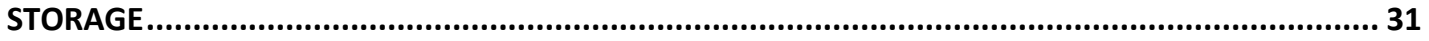

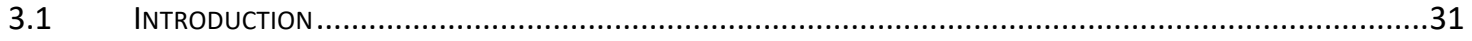

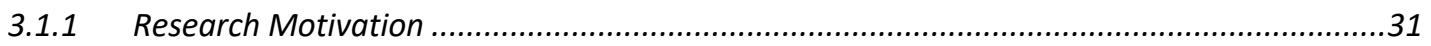

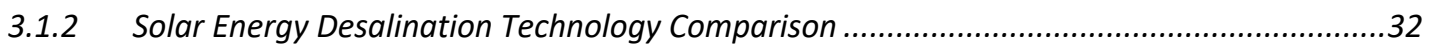

3.1.3 Solar Energy Coupled Heat Pump System Comparison ..................................................35

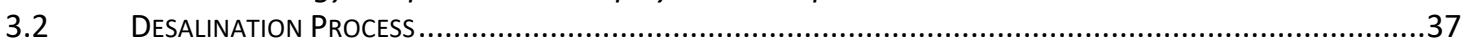

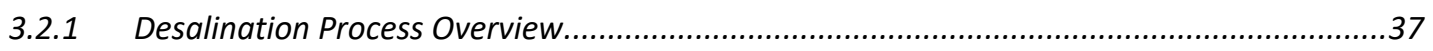

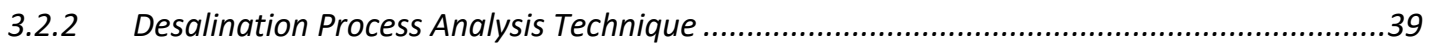

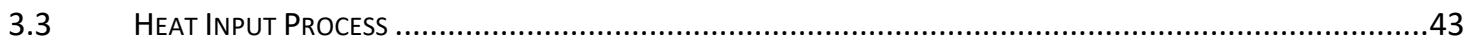

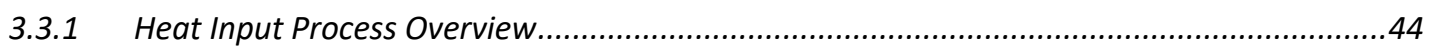

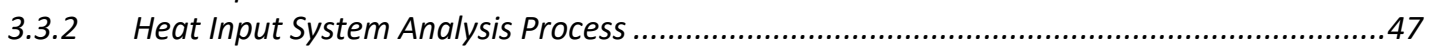

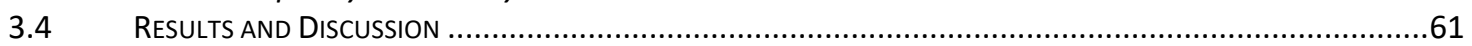

3.4.1 List of Assumptions.............................................................................................61

3.4.2 Multi-Effect System Simulation Results ...................................................................6. 62

3.4.3 Heat Input System Simulation Results .....................................................................6. 64

3.4.4 Comparisons with Existing Technologies..................................................................... 70

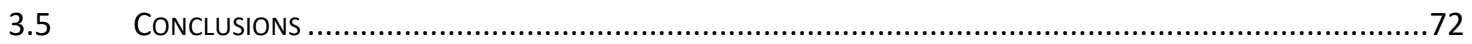

CHAPTER 4 DETAILED MODELING OF A NOVEL PHOTOVOLTAIC THERMAL CASCADE HEAT PUMP DOMESTIC

WATER HEATING SYSTEM.................................................................................... 74

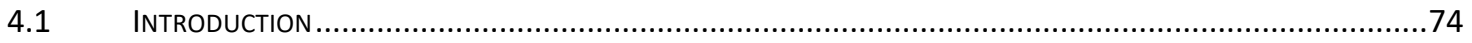

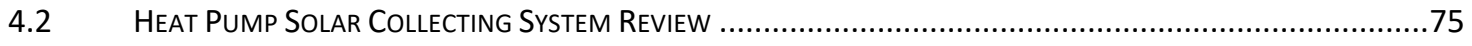

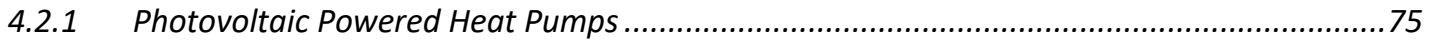

4.2.2 Solar Assisted Heat Pump......................................................................................... 76 


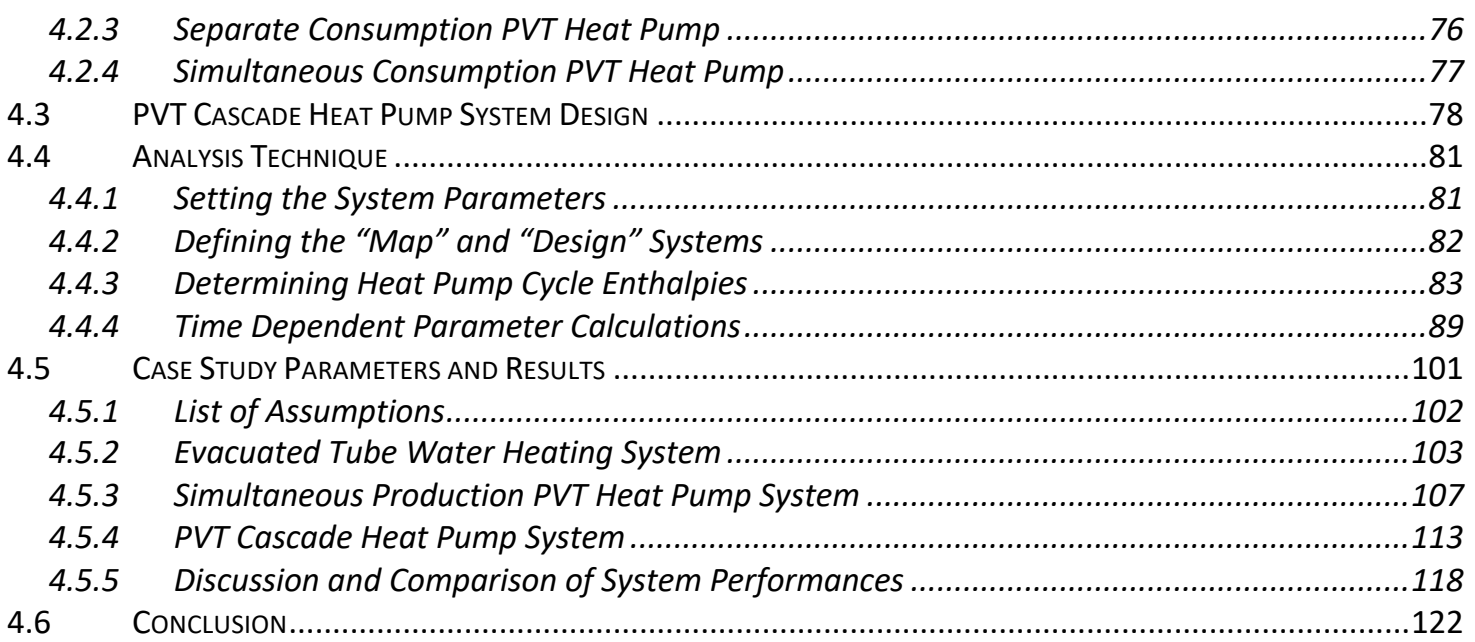

\section{CHAPTER 5 A METHODOLOGY FOR PREDICTING HYBRID SOLAR PANEL PERFORMANCE IN DIFFERENT}

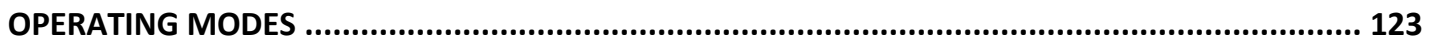

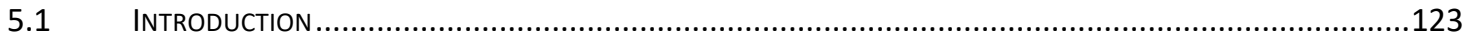

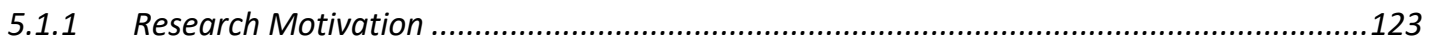

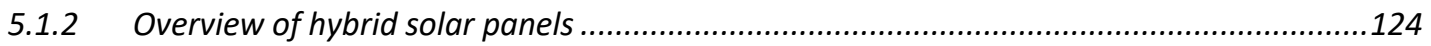

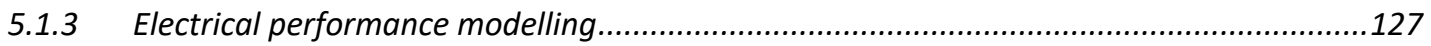

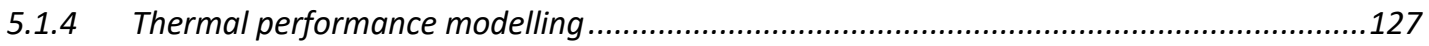

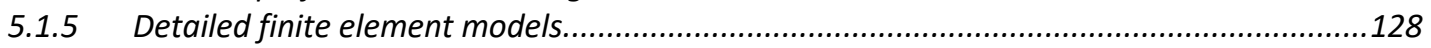

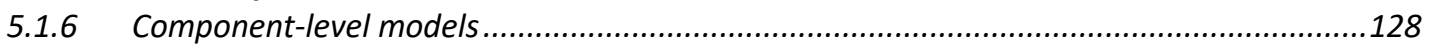

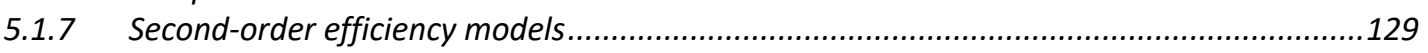

5.1.8 Effect of electrical energy generation on thermal performance ........................................131

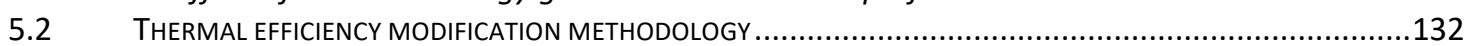

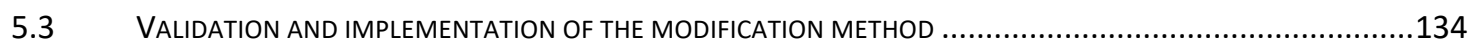

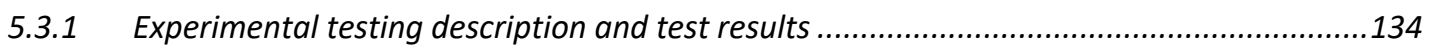

5.3.2 Comparison to Manufacturer Published Characterization Curves .....................................141

5.3.3 Application of the thermal performance modification technique .......................................144

5.3.4 Comparing the Proposed Method to an Alternative Modification Method ..........................149

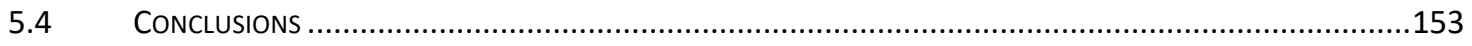

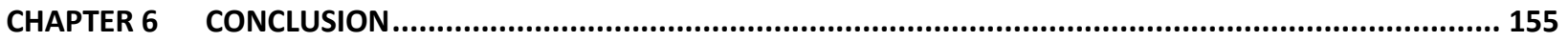

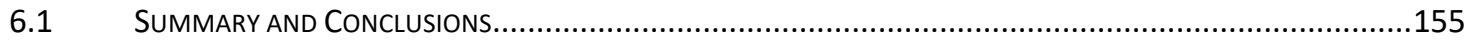

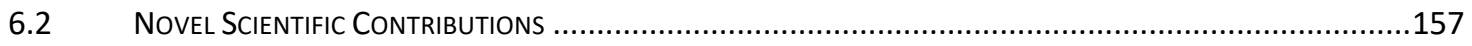

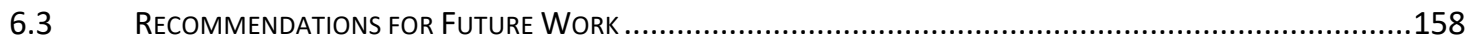

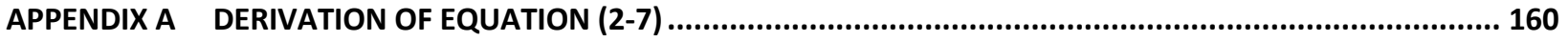

APPENDIX B SOLIMPEKS POWERTHERM PANEL MANUFACTURER SPECIFICATIONS ..................................... 162

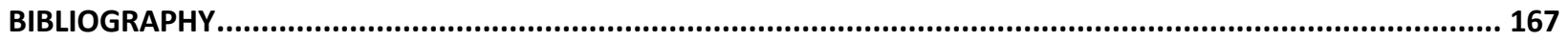




\section{List of Tables}

Table 3-1: Comparative Weather Data for Water Scarce Areas [44] ..........................................6 65

Table 3-2: Constant Design Input Parameters for System Case Study ............................................... 65

Table 3-3: Efficiency Summary of Solar Energy Driven Desalination Technologies.................... 71

Table 4-1: Case Study Locations with Climate Data................................................................. 102

Table 4-2: Design Input Parameters for Evacuated Tube System Case Study ............................ 104

Table 4-3: Evacuated Tube System Analysis Results................................................................... 106

Table 4-4: Design Input Parameters for PVT System Case Study ............................................ 108

Table 4-5: Simultaneous Consumption PVT Heat Pump System Optimization Results............. 112

Table 4-6: Design Input Parameters for PVT Cascade Heat Pump System Case Study ............. 113

Table 4-7: PVT Cascade Heat Pump Operating Mode Characteristics ..................................... 117

Table 4-8: PVT Cascade Heat Pump System Optimization Results............................................ 117

Table 4-9: Seasonal Comparison Between the PVT Heat Pump and Evacuated Tube systems. 119

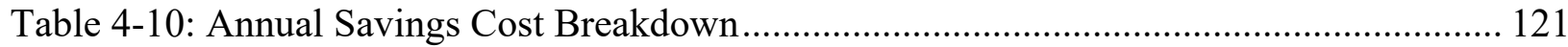

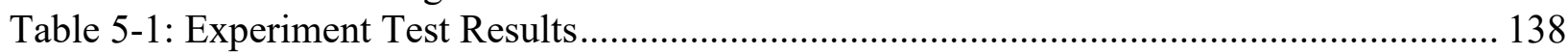

Table 5-2: Resulting Thermal and Electrical Efficiencies...................................................... 139

Table 5-3: Panel Efficiency Equation Coefficients from Test Results ........................................ 141

Table 5-4: Manufacturer Supplied Panel Efficiency Correlations [9, 41] ................................ 142

Table 5-5: Comparison of Measured Data to Estimates using Manufacturer Correlations......... 142

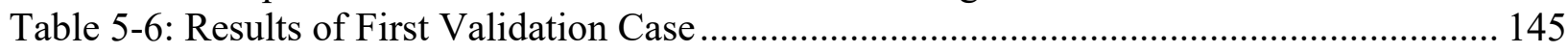

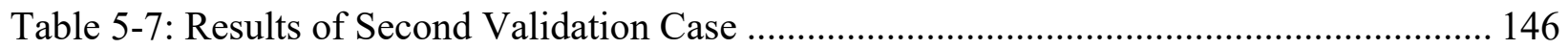

Table 5-8: Unmodified Performance Estimations for Comparison ........................................... 148

Table 5-9: First Validation Case Modification Results Using the IEA Method........................... 150

Table 5-10: Second Validation Case Modification Results Using the IEA Method ................... 151

Table 5-11: Results of Comparison between IEA Modification Method to Proposed Method.. 152 


\section{List of Figures}

Figure 1-1: Schematic of a Non-Concentrating Solar Collector [1] .......................................... 4

Figure 1-2: Schematic of a Concentrating Solar Collector [1] ............................................... 5

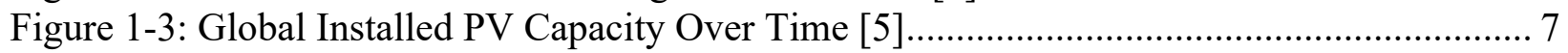

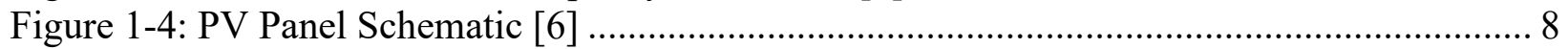

Figure 1-5: Theoretical Solar Cell Efficiency Limits for Different Materials [8] .......................... 9

Figure 1-6: Sample PV Panel Power Output as a Function of Temperature (measured) .............. 10

Figure 1-7: Liquid-Based Hybrid Panel Schematic [10] .............................................................. 11

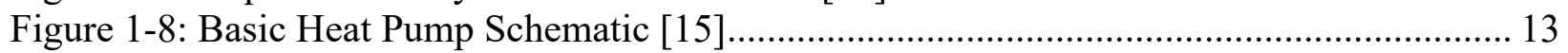

Figure 2-1: Schematic of Single Heat Pump Solar Heating System............................................ 18

Figure 2-2: (a) Initial Design Concept COP Balancing, (b) Initial Design Heat Output

(Condensation temperature $=80^{\circ} \mathrm{C}$, Solar flux $=1000 \mathrm{~W} / \mathrm{m}^{2}$, Ambient temperature $=20^{\circ} \mathrm{C}$ )

22

Figure 2-3: Schematic Second Design Iteration ........................................................................... 24

Figure 2-4: Plot of Cascade Heat Pump COP as a Function of Panel Temperature (Low pressure

evaporation temperature $=5^{\circ} \mathrm{C}$, High pressure condensation temperature $\left.=80^{\circ} \mathrm{C}\right) \ldots \ldots \ldots \ldots . .28$

Figure 2-5: Plot of the Thermal Performance and Cascade COP of the Final Design Concept

(Low pressure evaporation temperature $=5^{\circ} \mathrm{C}$, High pressure condensation temperature $=$

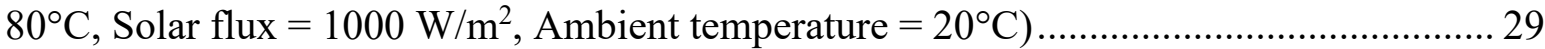

Figure 3-1: Desalination Process Used in Numerical Algorithm ................................................ 38

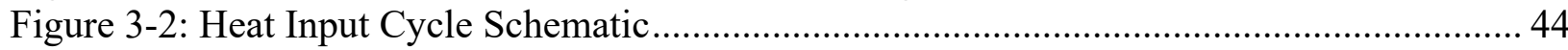

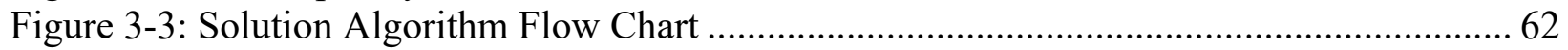

Figure 3-4: Plot of Required Thermal Energy vs. First Tank Saturation Temperature .................63 63

Figure 3-5: Average Daily Distillate Output per Unit Panel Area vs Design Heat Extraction Rate

through HX2 with Desalination First Tank Temperatures: (a) $40^{\circ} \mathrm{C}$, (b) $50^{\circ} \mathrm{C}$, (c) $60^{\circ} \mathrm{C}$, (d)

$70^{\circ} \mathrm{C}$

Figure 3-6: Average Daily Distillate Output per Unit Panel Area vs Design Heat Extraction Rate

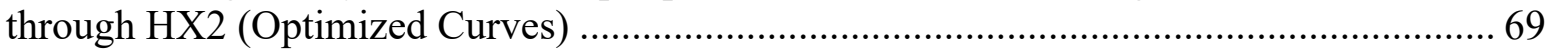

Figure 4-1: PVT Heat Pump System with Component Labels ..................................................... 79

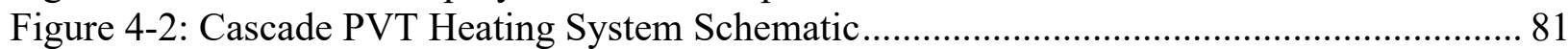

Figure 4-3: Heat Pump Schematic with Labelled States ........................................................... 84

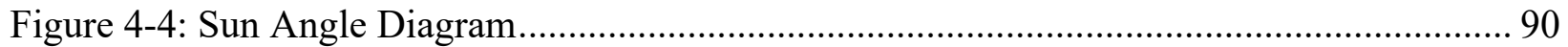

Figure 4-5: Evacuated Tube Heating System Schematic........................................................... 103

Figure 4-6: Evacuated Tube Annual Thermal Output vs. Panel Tilt Angle ................................ 105

Figure 4-7: Evacuated Tube Sample Thermal Power Output Profile .......................................... 106

Figure 4-8: Simultaneous Consumption PVT Heat Pump System Schematic ........................... 107

Figure 4-9: PVT Heat Pump System Optimization Process Flowchart ..................................... 109

Figure 4-10: Simultaneous Consumption PVT Heat Pump Sample Thermal Storage Tank

Temperature Profile for Toronto ...................................................................................... 110

Figure 4-11: Simultaneous Consumption PVT Heat Pump Sample Thermal Power Output Profile

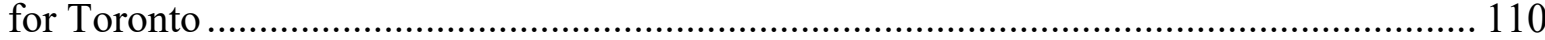

Figure 4-12: Simultaneous Consumption PVT Heat Pump Annual Energy Output Plots - (a)

Panel Tilt Angle Study, (b) Minimum Thermal Storage Tank Study .................................. 111 
Figure 4-13: PVT Cascade Heat Pump Sample Thermal Storage Tank Temperature Profile for

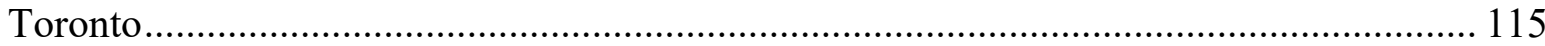

Figure 4-14: PVT Cascade Heat Pump Sample Thermal Power Output Profile for Toronto..... 115 Figure 4-15: PVT Cascade Heat Pump System Annual Energy Output Plots - (a) Panel Tilt

Angle Study, (b) Minimum Thermal Storage Tank Study .............................................. 116

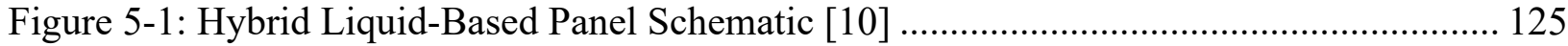

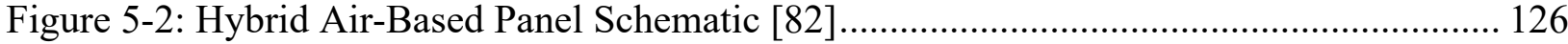

Figure 5-3: Photo of Panel on Solar Simulator Test Platform ................................................. 135

Figure 5-4: Thermal Test Results (a), Electrical Test Results (b) ........................................... 140

Figure 5-5: Manufacturer and Experimentally Produced Characterization Curves. (a) Thermal

Curves for Hybrid Operating Case, (b) Electrical Curves .................................................. 142 


\section{Nomenclature}

\section{Nomenclature for Chapter 2}

\begin{tabular}{|c|l|c|}
\hline Symbol & Description & Unit \\
\hline$\alpha$ & panel temperature coefficient & $\% / K$ \\
\hline$\eta_{0}$ & panel performance coefficient 1 & $\%$ \\
\hline$\eta_{e}$ & panel electrical efficiency & $\%$ \\
\hline$\eta_{e_{\text {ref }}}$ & $\begin{array}{l}\text { panel electrical power produced at the panel reference } \\
\text { temperature }\end{array}$ & \\
\hline$\eta_{t h}$ & panel thermal efficiency & $\%$ \\
\hline$A$ & solar panel area & $m^{2}$ \\
\hline$a_{1}$ & panel performance coefficient 2 & $W / m^{2} K$ \\
\hline$a_{2}$ & panel performance coefficient 3 & $W / m^{2} K^{2}$ \\
\hline$C O P$ & coefficient of performance of the single stage heat pump & - \\
\hline$C O P_{\text {cascade }}$ & COP of the cascade heat pump & - \\
\hline$\dot{E}_{\text {solar }}$ & electrical power generated & $W$ \\
\hline$G$ & solar flux incident on the solar panel & $W / m^{2}$ \\
\hline$\dot{Q}_{\text {in }}$ & heat input rate to the evaporator of the heat pump & $W$ \\
\hline$\dot{Q}_{\text {out }}$ & heat output at the condenser & $W$ \\
\hline$\dot{Q}_{\text {solar }}$ & thermal power generated & $W$ \\
\hline$T_{a}$ & ambient temperature & ${ }^{\circ} \mathrm{C}$ \\
\hline$T_{m}$ & mean panel temperature & ${ }^{\circ} \mathrm{C}$ \\
\hline$T_{\text {ref }}$ & panel reference temperature & ${ }^{\circ} \mathrm{C}$ \\
\hline$\dot{W}$ & work input to the compressor & $W$ \\
\hline
\end{tabular}


Nomenclature for Chapter 3

\begin{tabular}{|c|c|c|}
\hline Symbol & Description & Unit \\
\hline$\eta_{\text {elec }}$ & electrical efficiency of the solar collector & $\%$ \\
\hline$\eta_{t h}$ & thermal efficiency of the solar collector & $\%$ \\
\hline$A$ & total area of the solar collectors & $m^{2}$ \\
\hline$c_{p_{w}}$ & specific heat capacity of the working fluid in loop WA & $\mathrm{J} / \mathrm{kgK}$ \\
\hline$E_{\text {desal }_{i}}$ & $\begin{array}{l}\text { total electrical energy required by the desalination process over } \\
\text { time-step } i\end{array}$ & $J$ \\
\hline$E_{i}$ & electrical energy produced over time-step $i$ & $J$ \\
\hline$f$ & selected distillation fraction for the desalination cycle & $\%$ \\
\hline$h_{a_{n}}$ & enthalpy of the working fluid in loop RA at state $n$ & $\mathrm{~J} / \mathrm{kg}$ \\
\hline$h_{b_{n}}$ & enthalpy of the working fluid in loop RB at state $n$ & $\mathrm{~J} / \mathrm{kg}$ \\
\hline$h_{\text {brine }}$ & enthalpy of the brine & $\mathrm{J} / \mathrm{kg}$ \\
\hline$h_{\text {distillate }}$ & enthalpy of the distillate & $\mathrm{J} / \mathrm{kg}$ \\
\hline$h_{f e e d}$ & enthalpy of the feed water & $\mathrm{J} / \mathrm{kg}$ \\
\hline$h_{f g}$ & latent heat of condensation of distillate & $\mathrm{J} / \mathrm{kg}$ \\
\hline$h_{\text {ocean }}$ & enthalpy of the incoming ocean water & $\mathrm{J} / \mathrm{kg}$ \\
\hline$m_{a_{i}}$ & total mass flow of refrigerant in loop RA over time-step $i$ & $\mathrm{~kg}$ \\
\hline$m_{b_{i}}$ & total mass flow of refrigerant in loop RB over time-step $i$ & $\mathrm{~kg}$ \\
\hline$m_{\text {desal }}$ & total mass of distillate produced over time-step $i$ & $\mathrm{~kg}$ \\
\hline$m_{\text {tank }}$ & $\begin{array}{l}\text { mass of the thermal storage tank that contributes to the tank's } \\
\text { thermal mass }\end{array}$ & $\mathrm{kg}$ \\
\hline$\dot{m}_{\text {brine }_{i}}$ & mass flow rate of brine during time-step $i$ & $\mathrm{~kg} / \mathrm{s}$ \\
\hline$\dot{m}_{\text {cooling }_{i}}$ & $\begin{array}{l}\text { mass flow rate of ocean water for the final tank's condenser } \\
\text { during time-step } i\end{array}$ & $\mathrm{~kg} / \mathrm{s}$ \\
\hline$\dot{m}_{\text {distillate }_{i}}$ & mass flow rate of distillate during time-step $i$ & $\mathrm{~kg} / \mathrm{s}$ \\
\hline$\dot{m}_{f e e d}$ & mass flow rate of feed water during time-step $i$ & $\mathrm{~kg} / \mathrm{s}$ \\
\hline$\dot{m}_{\text {ocean }_{i}}$ & $\begin{array}{l}\text { total mass flow rate of ocean water taken in from the ocean } \\
\text { during time-step } i\end{array}$ & $\mathrm{~kg} / \mathrm{s}$ \\
\hline$\dot{m}_{\text {return }}$ & $\begin{array}{l}\text { total mass flow rate of water being returned to the ocean during } \\
\text { time-step } i\end{array}$ & $\mathrm{~kg} / \mathrm{s}$ \\
\hline$\dot{m}_{\text {solar }}$ & area specific mass flow rate of water in the solar collectors & $\mathrm{kg} / \mathrm{s}$ \\
\hline$\dot{m}_{w}$ & mass flow rate of fluid in loop WA & $\mathrm{kg} / \mathrm{s}$ \\
\hline$Q_{i}$ & $\begin{array}{l}\text { useful thermal energy absorbed by the working fluid in loop WA } \\
\text { over time-step } i\end{array}$ & $J$ \\
\hline$Q_{\text {desal }_{i}}$ & $\begin{array}{l}\text { total thermal energy transferred to the desalination process over } \\
\text { time-step } i\end{array}$ & $J$ \\
\hline$Q_{\text {ext }_{i}}$ & $\begin{array}{l}\text { total heat transfer from the external, low-temperature, heat source } \\
\text { over time-step } i\end{array}$ & $J$ \\
\hline$Q_{H X 1_{i}}$ & total heat transfer through $\mathrm{HX1}$ over time-step $i$ & $J$ \\
\hline
\end{tabular}




\begin{tabular}{|c|c|c|}
\hline$Q_{H X 2_{i}}$ & thermal energy transferred through $\mathrm{HX} 2$ over time-step $i$ & $J$ \\
\hline$\dot{Q}_{H X 2 \text { design }}$ & design heat transfer rate of $\mathrm{HX} 2$ & $W$ \\
\hline$\dot{Q}_{\text {in }_{i}}$ & $\begin{array}{l}\text { heat transfer rate into first tank from the external heat source } \\
\text { during time-step } i\end{array}$ & $W$ \\
\hline$Q_{\text {incident }_{i}}$ & total incident solar radiation energy over time-step $i$ & $W$ \\
\hline$\dot{q}_{\text {solar }_{i}}$ & solar flux during time-step $i$ & $W / m^{2}$ \\
\hline$Q_{\text {tank }_{i}}$ & net heat transfer into the thermal storage tank over time-step $i$ & $J$ \\
\hline$R_{e}$ & $\begin{array}{l}\text { amount of electrical energy required to produce one kilogram of } \\
\text { distillate from the desalination process }\end{array}$ & $\mathrm{J} / \mathrm{kg}$ \\
\hline$R_{t}$ & $\begin{array}{l}\text { mass of distillate produced per unit of thermal energy from the } \\
\text { desalination process }\end{array}$ & $\mathrm{kg} / \mathrm{J}$ \\
\hline$\Delta t_{\text {step }}$ & time-step length & $S$ \\
\hline$\Delta T_{H X 1}$ & $\begin{array}{l}\text { temperature difference between the saturation temperature of the } \\
\text { condenser in loop RA and the evaporators in loop RB }\end{array}$ & ${ }^{\circ} \mathrm{C}$ \\
\hline$\Delta T_{H X 2}$ & $\begin{array}{l}\text { temperature difference between the saturation temperature of the } \\
\text { evaporators in loop RB and the thermal storage tank minimum } \\
\text { temperature }\end{array}$ & ${ }^{\circ} \mathrm{C}$ \\
\hline$\Delta T_{H X 3}$ & $\begin{array}{l}\text { temperature difference between the saturation temperature of the } \\
\text { condenser in loop RB and the saturation temperature of the first } \\
\text { tank in the desalination process }\end{array}$ & ${ }^{\circ} \mathrm{C}$ \\
\hline$T_{a_{i}}$ & ambient air temperature during time-step $i$ & ${ }^{\circ} \mathrm{C}$ \\
\hline$T_{\text {cond }}{ }_{H X 1}$ & saturation temperature of the condenser in loop RA & ${ }^{\circ} \mathrm{C}$ \\
\hline$T_{\text {cond }_{H X 3}}$ & saturation temperature of the condenser in loop RB & ${ }^{\circ} \mathrm{C}$ \\
\hline$T_{\text {desal }}$ tank $1_{1}$ & saturation temperature of the first tank in the desalination process & ${ }^{\circ} \mathrm{C}$ \\
\hline$T_{\text {evap }_{H X 2}}$ & saturation temperature of the evaporators in loop RB & ${ }^{\circ} \mathrm{C}$ \\
\hline$T_{m_{i}}$ & mean temperature of the solar collector during time-step $i$ & ${ }^{\circ} \mathrm{C}$ \\
\hline$T_{r_{i}}$ & reduced temperature of the solar collector during time-step $i$ & $m^{2} K / W$ \\
\hline$T_{\text {solar }_{i n}}$ & $\begin{array}{l}\text { temperature of the fluid entering the solar collector during time- } \\
\text { step } i\end{array}$ & ${ }^{\circ} \mathrm{C}$ \\
\hline$T_{\text {solar }_{\text {out }}} i$ & $\begin{array}{l}\text { temperature of the fluid in loop WA leaving the solar collector } \\
\text { during time-step } i\end{array}$ & ${ }^{\circ} \mathrm{C}$ \\
\hline$T_{\text {tank }_{i}}$ & temperature of the thermal storage tank at time-step $i$ & ${ }^{\circ} \mathrm{C}$ \\
\hline$T_{\text {tank }_{\text {min }}}$ & $\begin{array}{l}\text { minimum allowable temperature of the thermal storage tank for } \\
\text { the heat input system to operate }\end{array}$ & ${ }^{\circ} \mathrm{C}$ \\
\hline$W_{a_{i}}$ & $\begin{array}{l}\text { electrical energy consumed by the compressor in loop RA over } \\
\text { time-step } i\end{array}$ & $J$ \\
\hline$W_{b_{i}}$ & $\begin{array}{l}\text { electrical energy consumed by the compressor in loop RB over } \\
\text { time-step } i\end{array}$ & $J$ \\
\hline
\end{tabular}




\section{Nomenclature for Chapter 4}

\begin{tabular}{|c|c|c|}
\hline Symbol & Description & Unit \\
\hline$\alpha_{s_{i}}$ & solar azimuth angle during time-step $i$ & degrees \\
\hline$\beta$ & panel tilt angle & degrees \\
\hline$\delta_{s_{\mathrm{i}}}$ & solar declination angle during time-step $i$ & degrees \\
\hline$\Delta t$ & time-step length & $S$ \\
\hline$\eta_{e_{i}}$ & electrical efficiency of the solar collector array during time-step $i$ & $\%$ \\
\hline$\eta_{t h_{i}}$ & thermal efficiency of the array during time-step $i$ & $\%$ \\
\hline$\theta_{b, l}$ & Beam irradiation incidence angle, longitudinal component & degrees \\
\hline$\theta_{b, t}$ & Beam irradiation incidence angle, transverse component & degrees \\
\hline$\theta_{d c}$ & Angle between panel normal and diffuse radiation vector & degrees \\
\hline$\theta_{g c}$ & Angle between panel normal and ground radiation vector & degrees \\
\hline$\theta_{x, i}$ & Angle of interest for IAM component $x$ at time-step $i$ & degrees \\
\hline$\rho_{i}$ & ground reflectivity during time-step $i$ & $\%$ \\
\hline$\rho_{n_{s y s}}$ & the density at State 1 for the corresponding system & $\mathrm{kg} / \mathrm{m}^{3}$ \\
\hline$A$ & total solar collector array absorber area & $m^{2}$ \\
\hline$a_{w}$ & panel azimuth angle & degrees \\
\hline$B_{i}$ & equation of time calculation parameter during time-step $i$ & degrees \\
\hline$C_{n}$ & corresponding compressor performance coefficient $n$ & - \\
\hline$c_{p}$ & specific heat capacity of solar array fluid & $\mathrm{J} / \mathrm{kgK}$ \\
\hline$D$ & $\begin{array}{l}\text { saturation temperature of the refrigerant on the discharge side of } \\
\text { the compressor }\end{array}$ & ${ }^{\circ} \mathrm{C}$ \\
\hline$E_{e_{i}}$ & total electrical energy generation over time-step $i$ & $J$ \\
\hline$E_{i}$ & total incident solar energy over time-step $i$ & $J$ \\
\hline$E_{t h_{i}}$ & total thermal energy generation over time-step $i$ & $J$ \\
\hline$E T_{i}$ & equation of time during time-step $i$ & minutes \\
\hline$F$ & chosen percentage of the theoretical mass flow rate increase & $\%$ \\
\hline$h_{n_{\text {sys }}}$ & the specific enthalpy at state $n$ for the corresponding system & $\mathrm{J} / \mathrm{kg}$ \\
\hline$i_{c_{i}}$ & solar incidence angle during time-step $i$ & degrees \\
\hline$I_{c_{i}}$ & total solar irradiation on the solar collector during time-step $i$ & $W / m^{2}$ \\
\hline$I_{d, h_{i}}$ & diffuse horizontal irradiation during time-step $i$ & $W / m^{2}$ \\
\hline$I_{h_{i}}$ & total horizontal irradiation during time-step $i$ & $W / m^{2}$ \\
\hline$I A M_{x, i}$ & $\begin{array}{l}\text { Solar array incident angle modifier for radiation component } x \\
\text { during time-step } i\end{array}$ & $\%$ \\
\hline$I A M_{i}$ & Solar array incident angle modifier during time-step $i$ & $\%$ \\
\hline$L$ & local latitude & degrees \\
\hline$l_{\text {local }}$ & local longitude & degrees \\
\hline$l_{S T}$ & longitude at the local corresponding standard time meridian & degrees \\
\hline$L S T_{i}$ & local standard time during time-step $i$ & minutes \\
\hline
\end{tabular}




\begin{tabular}{|c|c|c|}
\hline$m_{A_{i}}$ & total refrigerant mass flow over time-step $i$ in loop A & $\mathrm{kg}$ \\
\hline$m_{B_{i}}$ & total refrigerant mass flow over time-step $i$ in loop B & $\mathrm{kg}$ \\
\hline$\dot{M}_{\text {design }}$ & adjusted mass flow rate for the design system & $\mathrm{kg} / \mathrm{s}$ \\
\hline$\dot{m}_{f}$ & mass flow rate of fluid through the solar collector array & $\mathrm{kg} / \mathrm{s}$ \\
\hline$\dot{M}_{\text {map }}$ & mapped mass flow rate & $\mathrm{kg} / \mathrm{s}$ \\
\hline$\left(m c_{p}\right)_{\text {tank }}$ & thermal mass of the thermal storage tank & $J / K$ \\
\hline$n_{i}$ & day number during time-step $i$ & - \\
\hline$P_{\text {cond }}$ & saturation pressure of the refrigerant in the condenser & $P a$ \\
\hline$P_{\text {evap }}$ & evaporator saturation pressure & $P a$ \\
\hline$Q_{\text {cond }_{b_{i}}}$ & heat rejected through the condenser in loop B over time-step $i$ & $J$ \\
\hline$\dot{Q}_{H X 2 \text { design }}$ & design heat transfer rate for $\mathrm{HX} 2$ & $W$ \\
\hline$Q_{H X 2}$ elec $_{i}$ & $\begin{array}{l}\text { thermal energy transferred through HX2 over time-step } i \text { when } \\
\text { the system is operating with limited electricity }\end{array}$ & $J$ \\
\hline$Q_{H X 2_{\max }}$ & $\begin{array}{l}\text { maximum thermal energy that can be extracted from the thermal } \\
\text { storage tank over time-step } i\end{array}$ & $J$ \\
\hline$S$ & $\begin{array}{l}\text { saturation temperature of the refrigerant on the suction side of the } \\
\text { compressor }\end{array}$ & ${ }^{\circ} \mathrm{C}$ \\
\hline$s_{1_{\text {sys }}}$ & specific entropy at state 1 for the corresponding system & $J / k g K$ \\
\hline$S T_{i}$ & solar time during time-step $i$ & minutes \\
\hline$T_{a_{i}}$ & air dry bulb temperature during time-step $i$ & ${ }^{\circ} \mathrm{C}$ \\
\hline$T_{i n_{i}}$ & inlet temperature to the solar collector array during time-step $i$ & ${ }^{\circ} \mathrm{C}$ \\
\hline$T_{m_{i}}$ & mean temperature of the solar collector array during time-step $i$ & ${ }^{\circ} \mathrm{C}$ \\
\hline$T_{n_{s y s}}$ & temperature at state 1 for the corresponding system & ${ }^{\circ} \mathrm{C}$ \\
\hline$T_{\text {out }_{i}}$ & $\begin{array}{l}\text { temperature of the fluid exiting the solar collector array during } \\
\text { time-step } i\end{array}$ & ${ }^{\circ} \mathrm{C}$ \\
\hline$T_{r_{i}}$ & panel reduced temperature during time-step $i$ & $m^{2} K / W$ \\
\hline$T_{\text {tank }_{i}}$ & temperature of the thermal storage tank during time-step $i$ & ${ }^{\circ} \mathrm{C}$ \\
\hline$\dot{W}_{\text {design }}$ & corrected compressor power consumption & $W$ \\
\hline$\dot{W}_{\text {map }}$ & mapped power consumption & $W$ \\
\hline$\dot{W}_{\text {mod }}$ & modified compressor power consumption for the design system & $W$ \\
\hline$x_{n_{\text {sys }}}$ & quality of the working fluid at state $n$ in the corresponding system & $\%$ \\
\hline
\end{tabular}


Nomenclature for Chapter 5

\begin{tabular}{|c|c|c|}
\hline Symbol & Description & Unit \\
\hline$\alpha$ & panel temperature coefficient & $\% / K$ \\
\hline$\eta_{0}$ & panel performance coefficient 1 & $\%$ \\
\hline$\eta_{e}$ & electrical efficiency of the panel & $\%$ \\
\hline$\eta_{e_{\max }}$ & maximum electrical efficiency due to error propagation & $\%$ \\
\hline$\eta_{e_{\min }}$ & minimum electrical efficiency due to error propagation & $\%$ \\
\hline$\eta_{e_{r e f}}$ & $\begin{array}{l}\text { panel electrical power produced at the panel reference } \\
\text { temperature }\end{array}$ & $\%$ \\
\hline$\eta_{t h_{\max }}$ & maximum thermal efficiency due to error propagation & $\%$ \\
\hline$\eta_{t h_{\text {min }}}$ & minimum thermal efficiency due to error propagation & $\%$ \\
\hline$a_{1}$ & panel performance coefficient 2 & $W / m^{2} K$ \\
\hline$a_{2}$ & panel performance coefficient 3 & $W / m^{2} K^{2}$ \\
\hline$A_{\text {panel }}$ & panel area used in the thermal efficiency parameter determination & $m^{2}$ \\
\hline$c_{p}$ & specific heat capacity of the fluid in the panel & $\mathrm{J} / \mathrm{kg}$ \\
\hline$\dot{E}$ & electrical power generated by the panel & $W$ \\
\hline$G$ & incident solar flux & $W / m^{2}$ \\
\hline$G_{n}{ }^{\prime}$ & modified solar flux for modification case $n$ & $W / m^{2}$ \\
\hline$\dot{m}$ & mass flow rate of the fluid in the panel & $\mathrm{kg} / \mathrm{s}$ \\
\hline$\dot{Q}_{\text {panel }}$ & thermal power generated by the panel & $W$ \\
\hline$\dot{Q}_{\text {panel }}{ }^{\prime}$ & modified thermal power generated by the panel & $W$ \\
\hline$\dot{Q}_{\max }$ & maximum useful heat generated due to error propagation & $W$ \\
\hline$\dot{Q}_{\min }$ & minimum useful heat generated due to error propagation & $W$ \\
\hline$T_{a}$ & ambient temperature & ${ }^{\circ} \mathrm{C}$ \\
\hline$T_{\text {in }}$ & inlet fluid temperature & ${ }^{\circ} \mathrm{C}$ \\
\hline$T_{m}$ & mean panel temperature & ${ }^{\circ} \mathrm{C}$ \\
\hline$T_{\text {out }}$ & outlet fluid temperature & ${ }^{\circ} \mathrm{C}$ \\
\hline$T_{\text {panel }}$ & panel temperature of interest & ${ }^{\circ} \mathrm{C}$ \\
\hline$T_{r}$ & panel reduced temperature & $m^{2} K / W$ \\
\hline$T_{r}{ }^{\prime}$ & modified panel reduced temperature & $m^{2} K / W$ \\
\hline$T_{r_{\max }}$ & maximum reduced temperature due to error propagation & $m^{2} K / W$ \\
\hline$T_{r_{\min }}$ & minimum reduced temperature due to error propagation & $m^{2} K / W$ \\
\hline$T_{r e f}$ & panel reference temperature & ${ }^{\circ} \mathrm{C}$ \\
\hline
\end{tabular}




\section{Chapter 1 Introduction}

\subsection{Research Motivation}

We have only one inhabitable planet, and it runs on solar energy. Plants use energy from the sun to grow and produce oxygen, while animals eat these plants and breathe the oxygen. We all depend on the sun for warmth. Without solar energy, life as we know it would not exist.

In recent years, human society has developed another dependency, fossil fuels. We have grown addicted to the convenience fossil fuels provide, and their ability to store concentrated energy. We use these fuels, directly or indirectly, to heat and cool our buildings, to power our industrial processes and vehicles, and to power the electronics we use throughout each day. However, our use of fossil fuels has led to increasingly high levels of $\mathrm{CO}_{2}$ in the atmosphere. This increase in $\mathrm{CO}_{2}$ levels has been linked to global climate change, which includes global average temperature rises, increases in the severity and frequency of major weather events, intensification of droughts, and surges in flooding. It is now becoming commonplace to break long-standing climate records almost every year, and the negative effects of climate change on society are only now beginning to become evident.

To combat the effects of climate change, nations around the world have agreed to start cutting back their use of fossil fuels, and transition to renewable energy sources. These renewable sources include solar, wind, hydroelectric, geothermal, and biomass. It is of interest to note that aside from geothermal energy, each of these renewable sources are driven directly or indirectly by the sun. However, given the widespread availability of direct solar energy, and due to recent decreases in the cost of solar energy collectors, solar energy has become a primary focus for 
researchers. Global research efforts in solar energy include the development of new and improved solar collectors, and the development of novel ways to integrate these solar collectors into systems for different applications.

The focus of this thesis is on the latter of these two research areas, and focuses on the development of a heating system that combines hybrid solar panels with a cascade heat pump. The details related to the development of this system will be presented using three manuscripts that were published as part of the $\mathrm{PhD}$. The underlying theme of each of these manuscripts was the development, simulation, and improvement of this hybrid solar heating system. The first manuscript focuses on the development of the initial simulation algorithm for the system, and the application of this system to water desalination. The second manuscript focuses on improving the accuracy of the initially developed algorithm, and using the system for domestic water heating. The third and final manuscript focuses on an experimental testing campaign that was carried out, which had the goal of increasing simulation accuracy for hybrid solar panels.

This work has resulted in the development of a custom simulation algorithm, and a detailed understanding of a hybrid solar heat pump heating system, which are both novel contributions to the scientific community. The tools that were developed have also been disseminated to the scientific community through the published journal manuscripts, which allows other researchers to more easily investigate their solar energy systems. As a result of this thesis, the scientific community has an improved understanding of the use of solar energy for heating applications.

This thesis will continue in Section 1.2 by presenting a literature review related to solar technologies and heat pumps. This review will provide the reader with a brief overview of the technologies that are available in these areas, which were the foundation for the first parts of this project. Following this review, a presentation of the initial development and selection of the hybrid 
solar heat pump system layout will be discussed, which is not covered in the aforementioned publications. This topic will be discussed in Chapter 2, and will give the reader an understanding of the motivation behind the selected design.

\subsection{Background and Literature Overview}

The work in this thesis focused on the application of both solar and heat pump technologies, and the purpose of this section is to provide a high-level overview of these technologies. Detailed application-specific literature reviews are included in each of the manuscript-based chapters of this thesis. This section begins by discussing solar thermal technologies, followed by solar electric, hybrid solar, and heat pump technologies.

1.2.1 Solar Thermal Technologies

Thermal collectors tend to be classified as either non-concentrating and concentrating. A schematic of a non-concentrating solar collector is presented in Figure 1-1. 


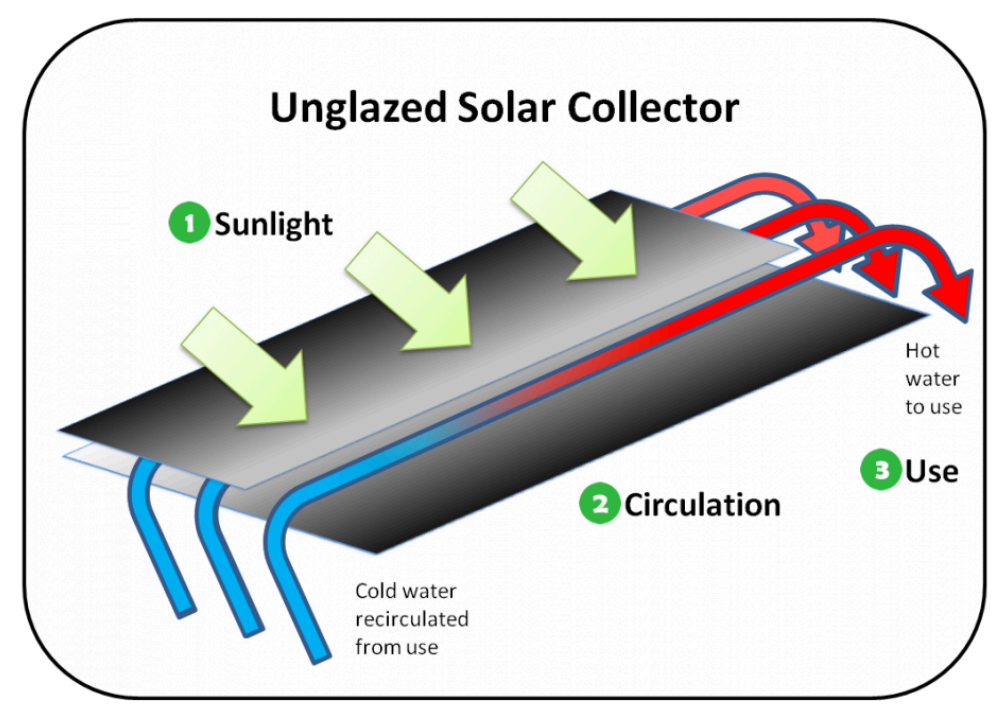

Figure 1-1: Schematic of a Non-Concentrating Solar Collector [1]

As shown in Figure 1-1, the incident solar radiation on a non-concentrating collector is directly received by a heat absorbing surface, and no focusing of the incident radiation takes place. This collector design is often referred to as a flat plate collector, and is widely used in domestic and industrial applications. As fluid flows through the collector, it absorbs thermal energy from the collector surface, which typically results in a sensible energy increase of the fluid. This fluid can be a liquid or a gas, depending on the application [2]. This review will present details related to liquid-based systems since they were the focus of the thesis project.

For all solar thermal collectors, as the temperature of the panel increases, the efficiency decreases due to convective and radiative heat losses. Collectors are designed to include insulating features that attempt to minimize these heat losses, which can include vacuum chambers, foam or fibre-based insulation materials, and glass coverings. High performance panels tend to implement more advanced insulating strategies, which tends to increase the cost of these panels. Typically, the temperatures expected within the system will dictate the required level of insulation [3]. 
When liquid-based systems are used, antifreeze protection is required in cold or seasonal climates, which is often achieved by mixing water with antifreeze such as propylene glycol [4]. Liquid-based systems also require overpressure protection to ensure that if the pressure in the system exceeds safe limits, which is often caused by high temperatures, that a catastrophic failure does not occur. Overpressure protection is often achieved by including pressure relief valves, or an additional fluid storage tank that the fluid can empty into from the solar array during high pressure events to avoid fluid loss [4]. These panels are often used for domestic hot water production, pool heating, and space heating.

Concentrating solar thermal collectors can offer increased performance compared to nonconcentrating collectors. A schematic of a concentrating solar collector is shown in Figure 1-2.

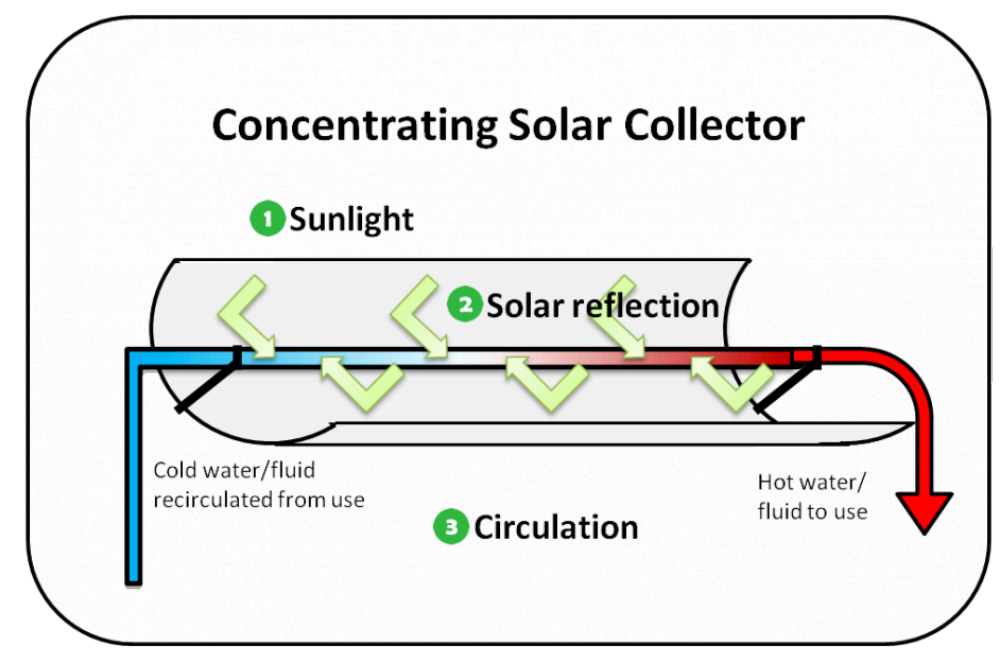

Figure 1-2: Schematic of a Concentrating Solar Collector [1]

These panels focus the incident solar radiation using a mirror or lens onto a smaller absorber area, which can result in higher system temperatures. These higher temperatures are 
achievable because the area for heat loss from the solar collector is minimized when compared to a non-concentrating collector. Therefore, even at elevated temperatures, heat loss is reduced compared to non-concentrating collectors, which allows for higher temperatures during operation [3].

If liquids are used, the same freezing and overpressure protections are needed for these systems compared to non-concentrating systems. However, concentrating systems also require that the reflecting or focusing mechanism is sufficiently pointed at the sun, to ensure that the absorbing surface remains within the focus point of the concentrating mechanism. If this pointing is not carried out, the performance of these collectors diminishes rapidly, and can fall below that of a non-concentrating collector [4]. This added complexity often results in these systems being more expensive to construct and maintain than non-concentrating systems, and diminishes the adoption of the technology.

This thesis applied the basic working principals of solar thermal collectors during the development of the hybrid solar heating system. The hybrid solar collector that was selected is comprised of a liquid-based, non-concentrating, solar thermal collector coupled with a solar electric panel. To continue, background information related solar electric technologies will be presented in Section 1.2.2.

\subsubsection{Solar Electric Technologies}

Generating electricity using solar energy is becoming more popular, especially as the cost of photovoltaic (PV) cells decreases and concerns related to GHG emissions increase. A plot of global installed PV capacity is presented in Figure 1-3. 


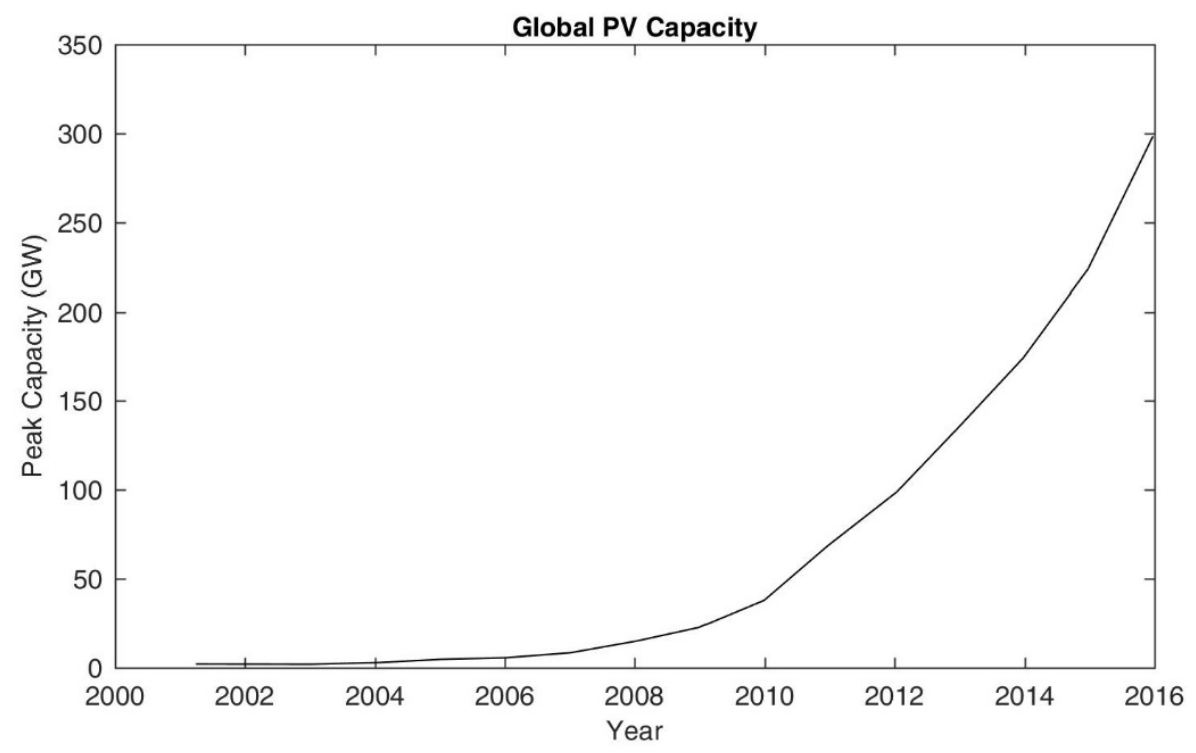

Figure 1-3: Global Installed PV Capacity Over Time [5]

As shown in Figure 1-3, the global installed PV capacity has risen from less than $10 \mathrm{GW}$ in 2006 to over $300 \mathrm{GW}$ in 2016. The increasing trend in PV capacity has also been accelerating over the past decade, which supports that interest in this technology is growing. At the end of 2016, the top three countries for global PV capacity were China with $78 \mathrm{GW}$, Japan with $43 \mathrm{GW}$, and Germany with $41 \mathrm{GW}$ [5]. Canada's installed capacity is approximately $2.7 \mathrm{GW}$, and ranks $18^{\text {th }}$ for installed PV capacity worldwide [5].

To continue, a schematic of a typical PV panel is presented in Figure 1-4, which shows the different components that are typically included. 


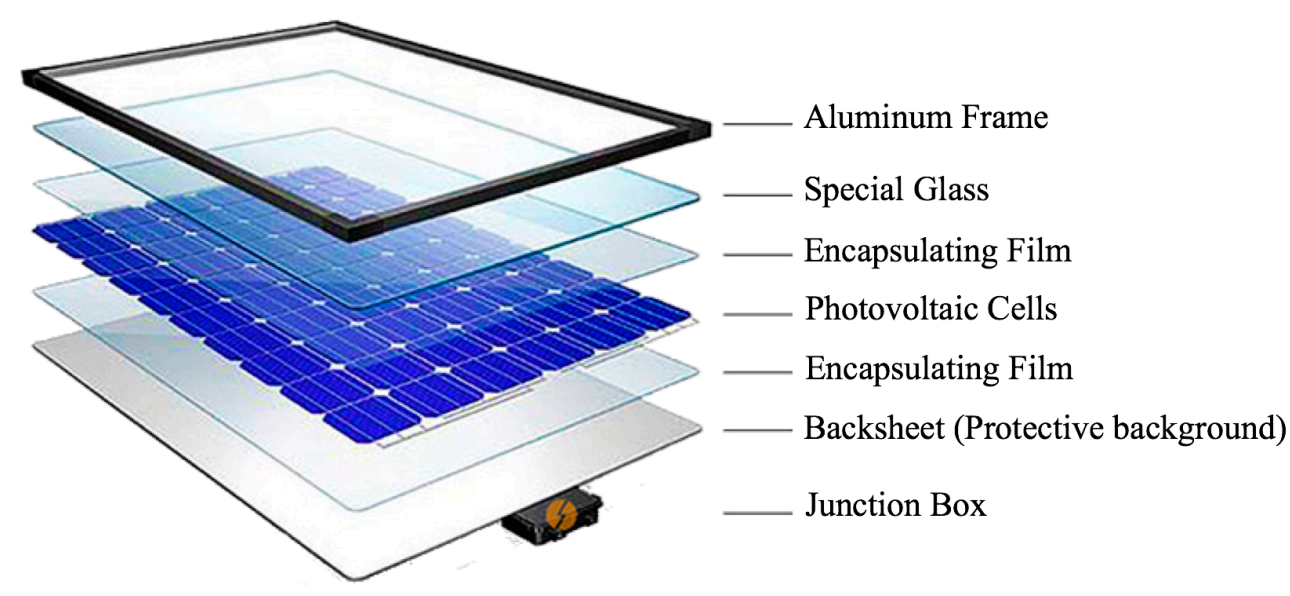

Figure 1-4: PV Panel Schematic [6]

As shown in Figure 1-4, the structure of a solar PV panel includes a frame, special protective cover glass, and a protective backsheet. These elements work together to protect the PV cells from mechanical loads, and provide a mounting interface. The internal elements of a solar electric panel are the encapsulating film and PV cells. The two film layers act as a soft interface between the structural elements of the panel and the PV cells, to ensure the cells are firmly held in place without concentrated forces that would crack the fragile cells. The junction box acts as the electrical connection point for the leads connected to each of the PV cells, and is where external electrical leads can also be connected to the panel.

Each of the PV cells in a panel are connected in series, which directly convert solar radiation into DC electrical power. Each PV cell is constructed from two different semi-conductor materials that are layered together, and electrical leads are connected to each of these layers. When photons are incident on the cell, electrons can be dislodged from the semi-conducting material and cause current to flow through a load connected to the panel leads. However, not all photons that are incident on the cell are able to dislodge an electron, and only photons with an energy level 
above a minimum threshold can generate electrical current. This minimum threshold is also referred to as the band gap energy, and different semiconductor material combinations result in different band gap energies [7]. This band gap energy, when combined with the energy distribution of the photons being emitted from a source, place a theoretical limit on the efficiency of a solar cell [8]. A plot of the theoretical limits for a variety of solar cell materials based upon the energy distribution of photons from the sun is presented in Figure 1-5.

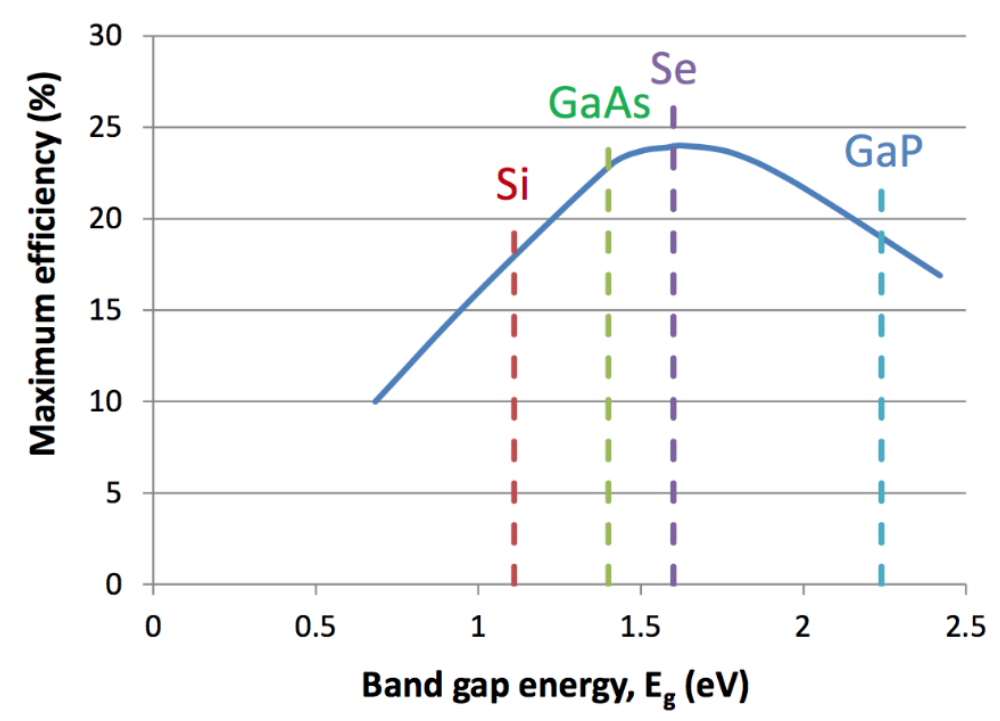

Figure 1-5: Theoretical Solar Cell Efficiency Limits for Different Materials [8]

The temperature of a PV cell also impacts its electrical production characteristics. A plot of the electrical power output of a PV panel as a function of panel temperature is presented in Figure 1-6. 


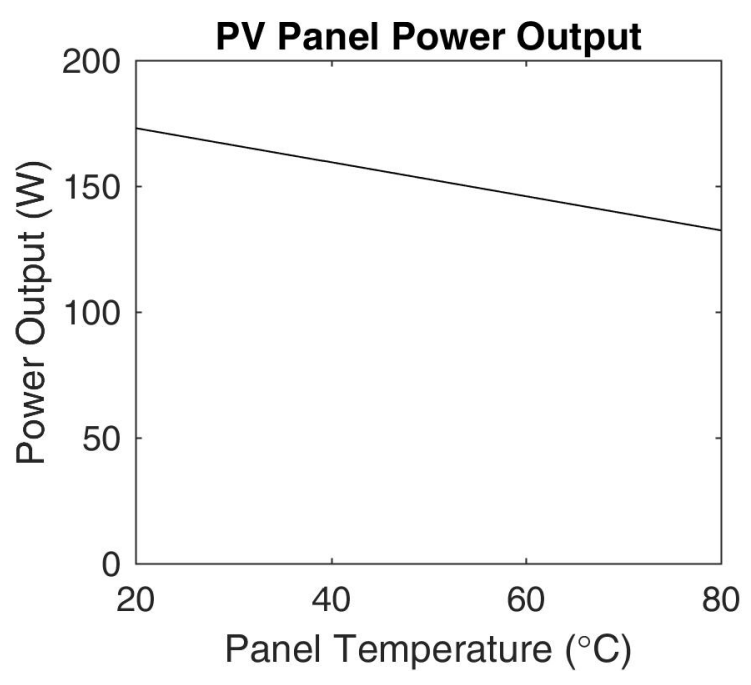

Figure 1-6: Sample PV Panel Power Output as a Function of Temperature (measured)

As shown in Figure 1-6, the power output of the panel decreases with increasing panel temperature. This trend occurs because of an electrical current that flows between the two semiconductor layers of the PV cells in the panel, even at room temperature, and is often referred to as "dark current". As the temperature of the cells increases, this current also increases, which reduces the electrical current available to an externally connected load. This phenomenon results in diminishing cell efficiency with increased temperature, which motivates designers to consider temperature reduction strategies for PV arrays. The effect of temperature on a PV panel is often characterized by manufacturers using a temperature coefficient, which is provided as part of the specification list for a panel [9].

Similar to the solar thermal technology, this thesis applied the basic working principals of solar electric collectors during the development of the hybrid solar heating system. The hybrid solar collector that was selected is a combination of a solar thermal and solar electric panel. To continue, background information related to hybrid solar panels will be presented in Section 1.2.3. 


\subsubsection{Hybrid Solar Technologies}

Hybrid solar panels can produce both heat and electricity, and are a combination of the two previously discussed solar technologies. A schematic of a liquid-based hybrid solar panel is shown in Figure 1-5.

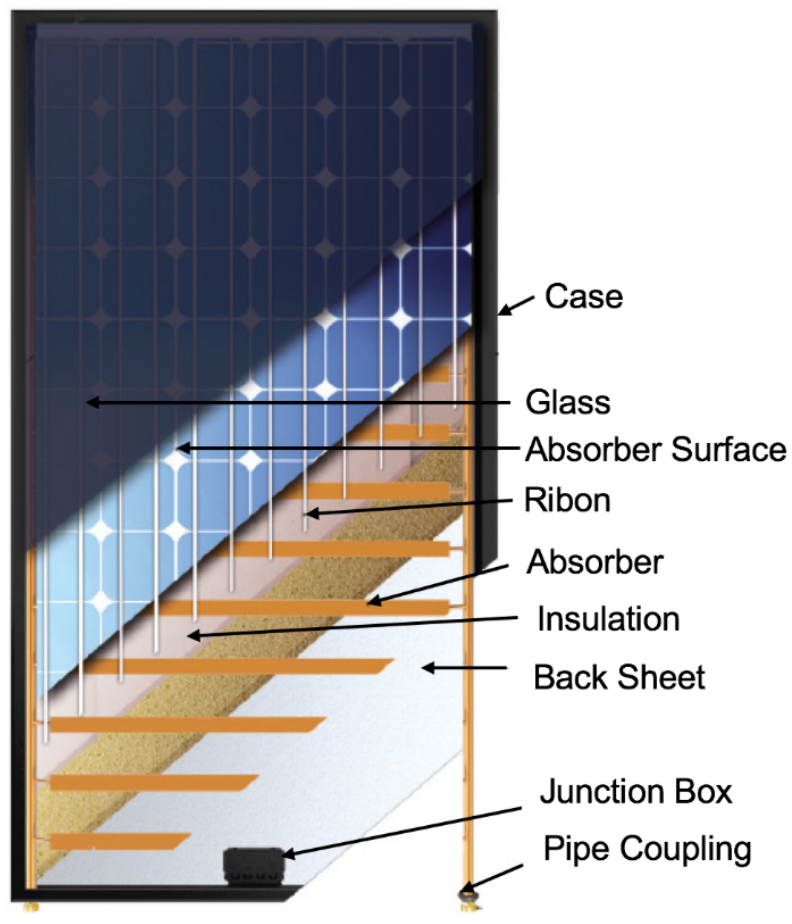

Figure 1-7: Liquid-Based Hybrid Panel Schematic [10]

There are two major benefits that result when using hybrid solar panels compared to thermal or electrical panels. The first benefit is a reduction in the total required panel area to produce both thermal and electrical energy [11]. As previously mentioned, hybrid panels can produce both energy streams from the same panel, which often results in a smaller required panel 
area when compared to having two independent arrays. Since many applications are constrained by the space available to mount solar collectors, such as when mounting solar panels on a roof of fixed size, the opportunity to reduce the size of a solar array is often of interest. The second benefit is that electrical efficiency improvements are often exhibited when compared to conventional PV panels. This improvement occurs because as heat is removed from the panel, the panel temperature decreases, which in turn reduces the PV cell temperature. As noted in Section 1.2.2, this decrease in cell temperature can result in improved electrical efficiency.

Many researchers are currently investigating new hybrid panel designs and system layouts. Research that focuses on panel design often investigates design features that can improve heat transfer, reduce heat loss, and improve panel thermal efficiency. The determination of the optimal quantity of PV cells on the panel is also a topic of interest since varying this quantity will have an effect on the ratio of thermal to electrical energy production. For example, a study by Tomar et al. [12] investigated different configurations of glass layers, PV cells, and ductwork to improve the performance of an air-based PVT collector. Alternatively, other researchers are investigating overall system optimization using existing hybrid solar panel designs. These groups often couple solar collectors with heat pumps to improve system flexibility and efficiency. A system proposed by Izquierdo et al. [13] uses a solar collector to charge a battery, which is then used by a compressor in a heat pump cycle. Another system proposed by Amin et al. [14] involves the use of a solar thermal panel as the thermal energy source for the heat pump cycle.

The use of hybrid solar technology is extensive throughout this thesis since these panels have the ability to offer improved total energy collection, and the ability to produce both thermal and electrical power. Coupling hybrid panels with heat pumps is also of key interest given the 
potential flexibility and efficiency improvements. To continue this literature review, a basic overview of heat pump technologies will be presented in Section 1.2.4.

\subsubsection{Heat Pump Technologies}

A heat pump is a system that moves heat from a low temperature heat source to a higher temperature heat sink [15]. Vapour compression heat pumps are the most common and use mechanical work to compress a working fluid. A schematic of a basic vapour compression heat pump is shown in Figure 1-8.

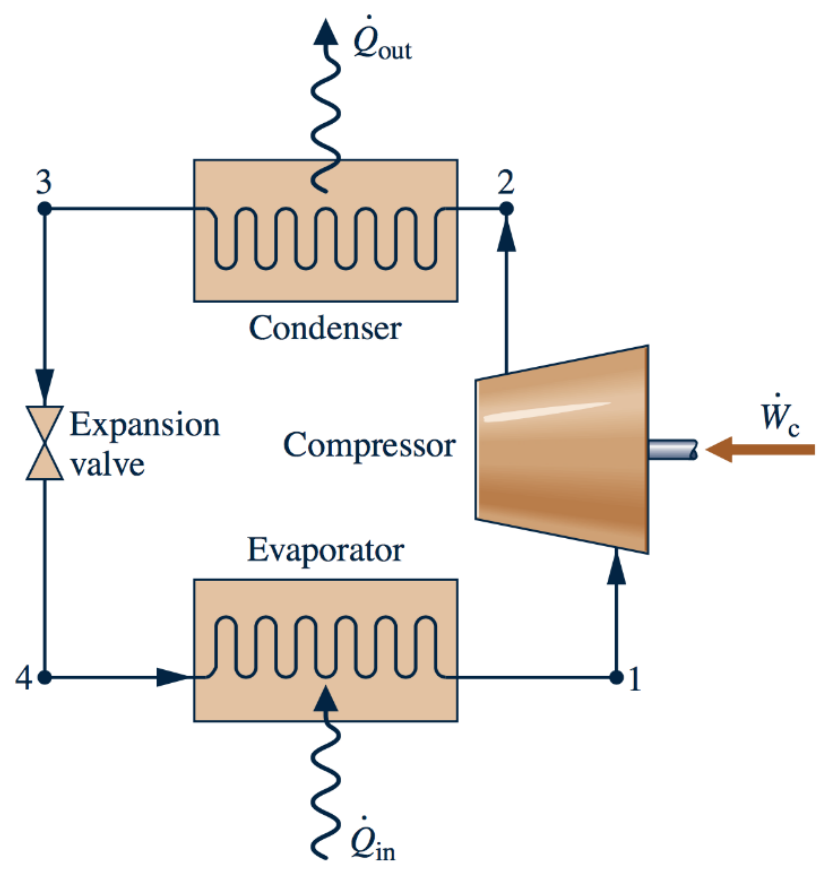

Figure 1-8: Basic Heat Pump Schematic [15] 
Refrigerant begins the cycle at state 1 as low-pressure vapour at the evaporator pressure. The refrigerant is then compressed by the compressor, which results in high pressure and high temperature vapour at state 2 , at the condenser pressure. This vapour then moves through the condenser where heat transfer occurs from the refrigerant to a heat sink until the refrigerant is a liquid at state 3. Finally, the refrigerant passes through an expansion valve that decreases the refrigerant pressure back to the evaporator pressure at state 4 , which also results in a decrease in refrigerant temperature. Heat is then transferred into the refrigerant from a heat source, through the evaporator, until the refrigerant is vaporized and begins the cycle again at state 1 [15].

These systems are useful because they can upgrade the quality of heat from a low-grade source, such as the ambient environment. This upgrade in heat quality only costs the input energy required to complete the upgrade, and the low-grade heat is typically viewed as being freely available. Due to the "upgrade cost" being viewed as the only energy cost for heat pumps, these systems are typically measured using a coefficient of performance (COP), which is the ratio of heat output from the condenser to energy input to the compressor [15].

For example, when these systems are implemented for space heating, they can take ambient outdoor heat and upgrade it to heat a home. Cold-climate heat pumps use heat from the ambient environment at $-25^{\circ} \mathrm{C}$, and upgrade it to heat a home at $22^{\circ} \mathrm{C}$ with a coefficient of performance of 1.9 [16]. This performance exceeds the theoretical maximum efficiency of any direct-heating system, such as electric resistance or fossil fuels, and is a major benefit of these systems.

Since heat pumps can increase the quality of heat being generated by a heat source, they are also of interest for coupling with solar technologies. As previously mentioned, all solar panels exhibit diminishing performance with increased temperature. Therefore, operating a solar panel at 
lower temperatures and using a heat pump to increase the quality of the heat from the panel was viewed as a design space with many optimization options. Using hybrid solar panels was also of key interest because these panels can produce the heat and electrical energy needed to operate a coupled heat pump system. This potential optimization was the motivation for this thesis project, and investigating different system designs from the perspective of optimizing heat output was the primary goal. A list of the publications that resulted from these investigations will be presented in Section 1.3.

\subsection{Overview of Manuscripts from Doctoral Work}

The work that was carried out as part of this $\mathrm{PhD}$ thesis resulted in the production of three journal manuscripts. The citations for all manuscripts written during the $\mathrm{PhD}$, along with a brief description of the contributions for each article, are presented in the list below:

1. J.P. Fine, J. Friedman, S.B. Dworkin, (2015) "Transient Analysis of a Photovoltaic Thermal Heat Input Process with Thermal Storage”. Applied Energy (160C), 308-320.

a. J.P. Fine developed the simulation algorithm, carried out the cases studies, and was primarily responsible for manuscript preparation and submission for this article, under the supervision of J. Friedman and S.B. Dworkin.

2. J.P. Fine, J. Friedman, S.B. Dworkin, (2017) "Detailed modeling of a novel photovoltaic thermal cascade heat pump domestic water heating system". Renewable Energy (101), 500513. 
a. J.P. Fine developed the simulation algorithm, carried out the cases studies, and was primarily responsible for manuscript preparation and submission for this article, under the supervision of J. Friedman and S.B. Dworkin.

3. J.P. Fine, S.B. Dworkin, J. Friedman, (2019) "A Methodology for Predicting Hybrid Solar Panel Performance in Different Operating Modes”. Renewable Energy (130), 1198-1206.

a. J.P. Fine developed the solar panel modelling methodology, the experimental testing campaign, carried out the experiments, and was primarily responsible for manuscript preparation and submission, under the supervision of S.B. Dworkin and J. Friedman.

These journal articles combine together to form the thesis project. The model developed as part of the first article served as the first step in devising a simulation algorithm for the hybrid solar cascade heat pump heating system. The case studies carried out as part of the first article also provided insight into the detailed operating characteristics of the system. The work completed as part of the second article resulted in improving the accuracy of the model developed as part of the first article, including the integration of solar tracking functionality, and improved heat pump performance calculation. The case studies carried out as part of the second article illustrated the effects of different climate zones on the performance of the system, along with providing insight into a second application for the system. Finally, the work contained within the third article focused on improving hybrid solar collector modelling accuracy. This hybrid solar collector model, and the validation of this model, built upon the concepts that were applied in the first two manuscripts, and focused on improving overall simulation accuracy. 
This thesis will continue by detailing the initial development of the hybrid solar heating system in Chapter 2. Manuscript-based chapters will then be presented in Chapter 3, Chapter 4, and Chapter 5, which are based upon list items 1, 2, and 3, respectively. To complete the document, a summary and concluding remarks are given in Chapter 6. 


\section{Chapter 2 Initial Development of the Hybrid Solar Cascade Heat Pump}

\subsection{Initial Hybrid Solar Heat Pump Design}

The development of the hybrid solar heating system began by investigating different system layouts that included hybrid solar panels and heat pumps. The selection of hybrid solar panels and heat pumps was made because the goal of this project was to develop a solar energybased heating system, and heat pumps are known to allow for the effective use of low-grade heat.

The first integration option that was investigated consisted of a hybrid solar panel array and a single heat pump loop. In this system, the solar array acts as both the heat and electrical energy source for the heat pump. A schematic of this process is shown in Figure 2-1.

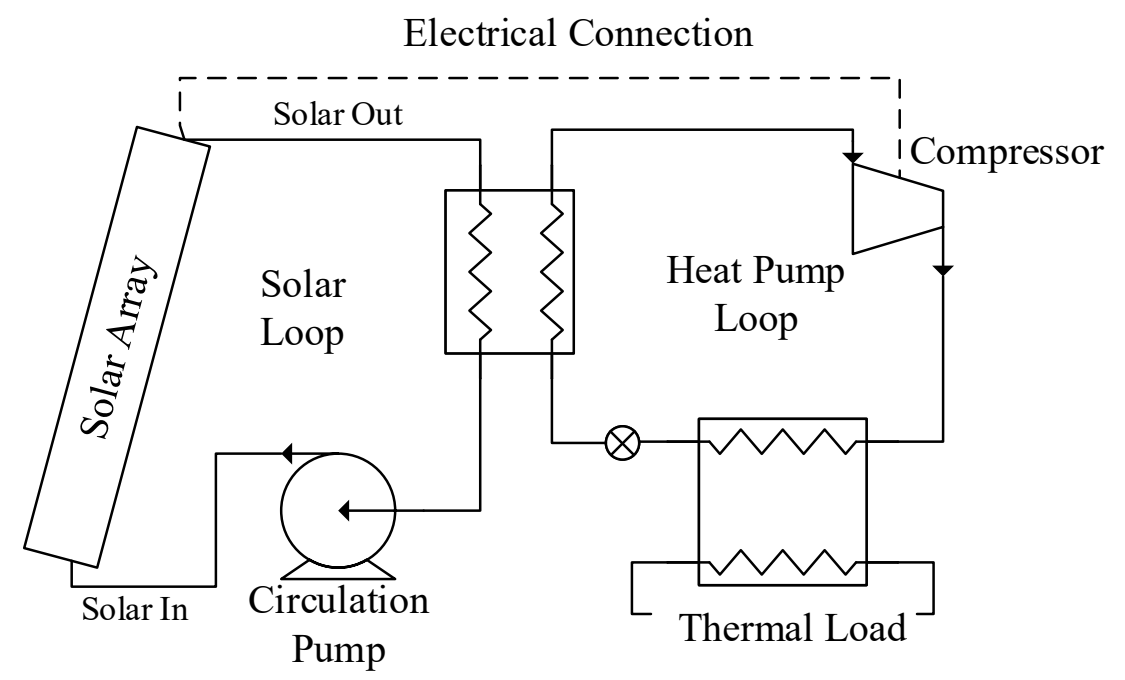

Figure 2-1: Schematic of Single Heat Pump Solar Heating System 
The operating principal of this system was to use the electrical energy generated by the solar array to increase the quality of the thermal energy generated by the same solar array. The temperature required by the heat sink was assumed to be constant, which implied that the saturation temperature of the refrigerant in the condenser was also constant. Therefore, at any given time, the heat pump was constrained by both the electrical and thermal power being generated by the panel. These constraints resulted in a steady state operating point where all the electrical and thermal energy generated by the array would be consumed by the heat pump, and no residual energy would remain.

To begin the evaluation of the system, the thermal and electrical power generated by the solar panel were found using manufacturer data, and the relationships used are shown in Equations $(2-1)$ and $(2-2)$.

$$
\begin{aligned}
& \dot{Q}_{\text {solar }}=\eta_{t h} G A \\
& \dot{E}_{\text {solar }}=\eta_{e} G A
\end{aligned}
$$

where $\dot{Q}_{\text {solar }}$ is the thermal power generated, $\dot{E}_{\text {solar }}$ is the electrical power generated, $\eta_{t h}$ is the panel thermal efficiency, $\eta_{e}$ is the panel electrical efficiency, $G$ is the solar flux incident on the solar panel, and $A$ is the solar panel area.

The determination of the thermal and electrical efficiencies were carried out using correlations that are typically provided by manufacturers with their panels. The thermal efficiency was calculated using the second-order thermal efficiency correlation, as shown in Equation (2-3), 
and the electrical efficiency was found using the temperature-dependant electrical efficiency correlation, as shown in Equation (2-4) [17].

$$
\begin{gathered}
\eta_{t h}=\eta_{0}+a_{1} \frac{\left(T_{m}-T_{a}\right)}{G}+a_{2} \frac{\left(T_{m}-T_{a}\right)^{2}}{G} \\
\eta_{e}=\eta_{e_{\text {ref }}}-\alpha\left(T_{m}-T_{r e f}\right)
\end{gathered}
$$

where $\eta_{0}, a_{1}, a_{2}, \eta_{e_{\text {ref }}}, \alpha$, and $T_{r e f}$ are the panel efficiency parameters provided by the manufacturer, $T_{m}$ is the panel mean temperature, and $T_{a}$ is the ambient temperature.

The heat pump in the system was characterized using the coefficient of performance (COP), which is the ratio of the heat output at the condenser $\left(\dot{Q}_{\text {out }}\right)$ to the work input to the compressor $(\dot{W})$. This relationship is presented in Equation (2-5) [15].

$$
C O P=\frac{\dot{Q}_{\text {out }}}{\dot{W}}=\frac{\dot{Q}_{\text {in }}+\dot{W}}{\dot{W}}
$$

where $\dot{Q}_{i n}$ is the heat input rate to the evaporator of the heat pump.

Since the electrical power generated by the solar panel is the only electrical energy source used to power the heat pump, and the thermal power generated by the solar panel is the only heat available to the heat pump, Equation (2-5) can be rewritten as shown in Equation (2-6).

$$
\mathrm{COP}=\frac{\dot{Q}_{\text {solar }}+\dot{E}_{\text {solar }}}{\dot{E}_{\text {solar }}}=\frac{\eta_{\text {th }} G A+\eta_{e} G A}{\eta_{e} G A}=\frac{\eta_{t h}+\eta_{e}}{\eta_{e}}=\frac{\eta_{t h}}{\eta_{e}}+1
$$


The COP found using Equation (2-6) represents the solar panel operating point where all of the thermal and electrical energy generated by the solar panel are being consumed. At steady state, this COP would also match the COP of the heat pump in the system. To determine the feasibility of such an operating point, a study was carried out to find the mean panel temperature that would be required for this balance of energy consumption and generation to take place.

This study required that the electrical and thermal efficiencies of the solar panel be determined, along with the COP of a heat pump. The determination of these parameters was found as a function of the mean panel temperature since this temperature impacts both the solar performance and heat pump performance. The saturation temperature of the condenser was held constant at $80^{\circ} \mathrm{C}$ for this study, which was selected based upon initial estimates of the temperature required for water distillation and will be discuss in Chapter 2 . A constant solar flux of $1000 \mathrm{~W} / \mathrm{m}^{2}$ was also used, which was based upon industry standards [18].

A sample solar panel was used for the study, which was the Solimpeks PowerTherm hybrid panel [10]. Similarly, a sample heat pump with a compressor isentropic efficiency of 70\% [19], and no super-heating or sub-cooling, was used to generate heat pump COP sample data. The saturation temperature of the evaporator varied as a function of the mean panel temperature, and was set to be $5^{\circ} \mathrm{C}$ below the mean panel temperature (i.e. $T_{\text {evap }}=T_{m}-5^{\circ} \mathrm{C}$ ) for all analysis cases. The refrigerant that was selected for analysis was R134a, which is currently being phased out due to environmental concerns, but was selected due to the availability of refrigerant properties within modelling software. No subcooling or superheating was used for the refrigerant in the cycle, and the ambient temperature was constant for all cases at $20^{\circ} \mathrm{C}$. 
The manufacturer-provided efficiency data for the solar panel was used to generate the result of Equation (2-6) as a function of panel temperature, using a custom MATLAB code. Similarly, an analysis of a sample heat pump that operated based upon the previously discussed assumptions was also carried out, and results were generated as a function of the same panel temperature. The area-normalized heat output, which is the heat output at the condenser of the heat pump, and the two COP results are presented in Figure 2-2.

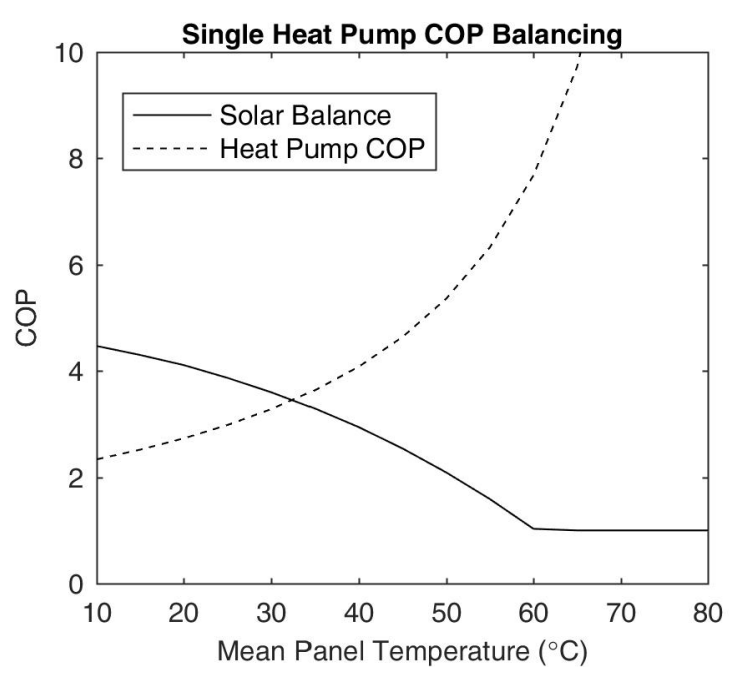

(a)

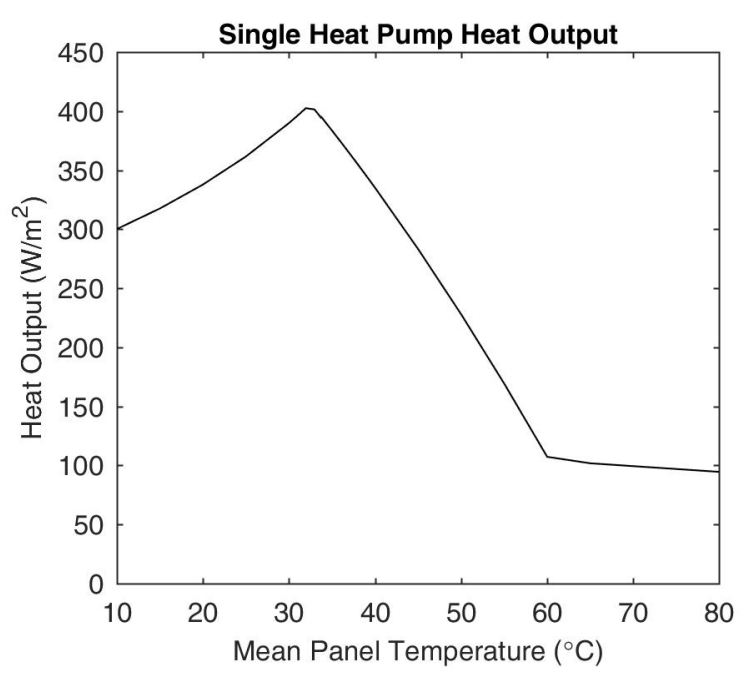

(b)

Figure 2-2: (a) Initial Design Concept COP Balancing, (b) Initial Design Heat Output (Condensation temperature = $80^{\circ} \mathrm{C}$, Solar flux $=1000 \mathrm{~W} / \mathrm{m}^{2}$, Ambient temperature $=20^{\circ} \mathrm{C}$ )

These results show that the heat pump COP and the COP required based upon Equation (26) are equal at a panel temperature of approximately $32^{\circ} \mathrm{C}$, which is the balance point for the system. This balance point results in a COP of approximately 3.5, and an area-normalized heat output of approximately $402 \mathrm{~W} / \mathrm{m}^{2}$. This temperature is within the typical operating range of the 
PowerTherm panel [10], and the heat pump COP is within typical values of 2 to 5 compared to off-the-shelf heat pump systems [19].

One concern that arose from these results, as shown by the heat output plot in Figure 2-2, is the steeply declining performance that is exhibited when operation occurs at panel temperatures that are different from this balance point value. For example, if a panel temperature of $40^{\circ} \mathrm{C}$ is used, the thermal output becomes $334 \mathrm{~W} / \mathrm{m}^{2}$, which is a drop of $17 \%$ compared to operation at the balance point. While balanced operation would be passively established by the system during steady state operation, this sensitivity to panel temperature was viewed as a concern given the highly-variable nature of the ambient conditions that a panel would normally experience. Therefore, design modifications were carried out with the goal of reducing the sensitivity of system performance to panel temperature, and to determine if peak performance could also be improved. The final design that resulted from these modifications will be presented in Section 2.2.

\subsection{Addition of a Second Heat Pump Loop and Thermal Storage}

The final design that was investigated involved adding a second heat pump loop and thermal storage to the initial design. A schematic of this design is presented in Figure 2-3. 


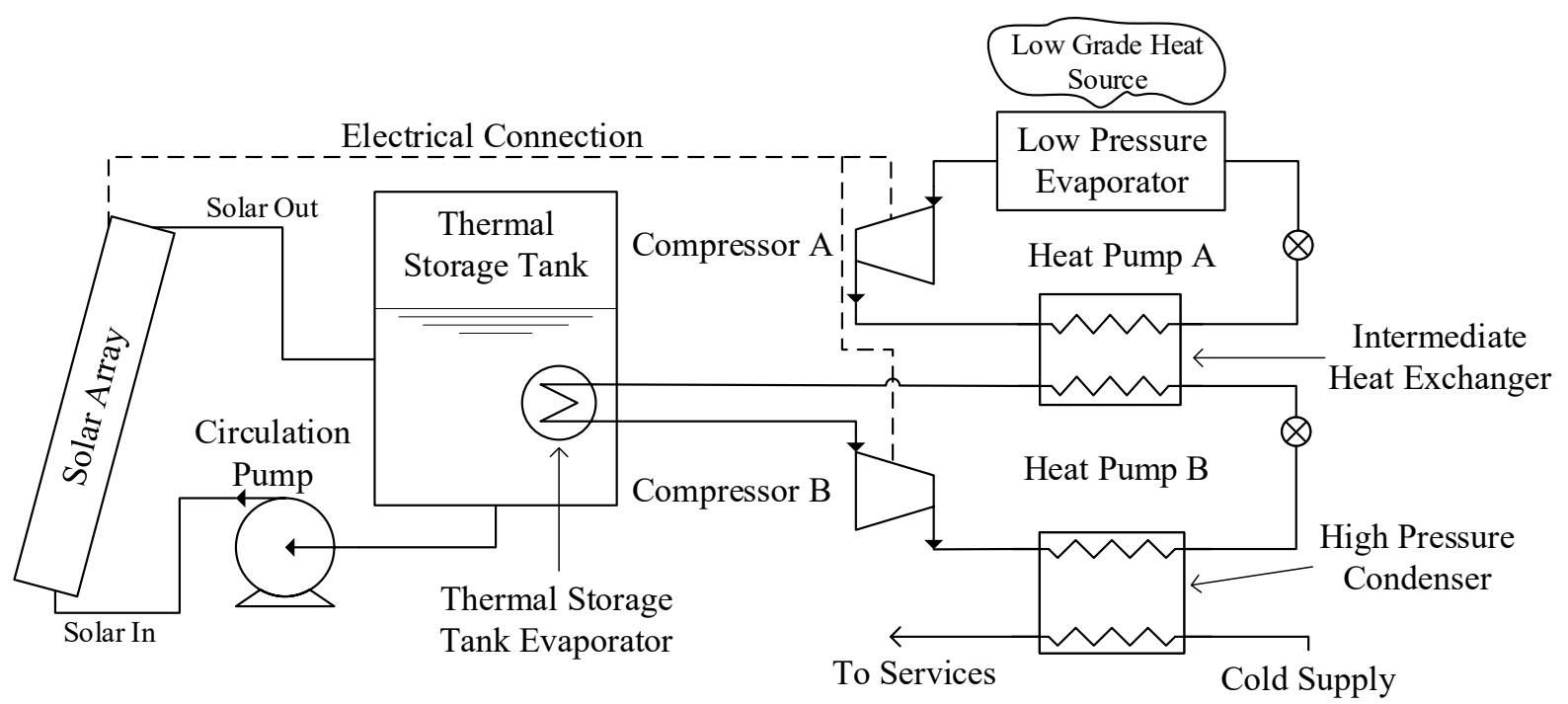

Figure 2-3: Schematic Second Design Iteration

Compared to the single heat pump design, there are two significant changes in how the system operates. The first change is a result of the addition of a second heat pump, which can provide an additional electrical energy sink when needed. This heat pump can be used at times when thermal energy production is low compared to electrical energy production, which allows for the thermal and electrical energy production of the solar array to be decoupled. The heat source for this heat pump could be a geo-exchange system, the ambient environment, or another lowgrade heat source.

The second change is a result of the added thermal storage tank, which can act as a thermal energy sink when needed. The thermal storage tank allows for thermal energy to be stored at times when electrical energy generation is low compared to thermal energy generation, which also allows for the energy production streams from the solar array to be decoupled. These two decoupling mechanisms allow for all energy being produced to either be consumed or stored, 
regardless of the ratio of thermal to electrical energy production, which was deemed necessary to improve the flexibility of the system.

While these added features and the decoupling they produced were the motivation for the modified design, the impacts they had on system performance still had to be quantified. This quantification began by deriving a relationship for the COP of a cascade heat pump system $\left(C O P_{\text {cascade }}\right)$ when moving heat from the low pressure evaporator to the high pressure condenser. This relationship assumes that no heat is being transferred from the thermal storage tank, and the result from this derivation is shown in Equation (2-7), with the derivation of this equation being presented in the Appendix of this thesis. It is important to note that in this case, a cascade heat pump system refers to two separate heat pump loops connected in series, which is the typical definition of a cascade heat pump system in the HVAC industry. It is also important to note that the COP of a heat pump system is always greater than or equal to unity, which ensures that the energy balance of the system is valid based upon the assumption that there is no heat loss from the system.

$$
C O P_{\text {cascade }}=\frac{C O P_{A} C O P_{B}}{C O P_{A}+C O P_{B}-1}
$$

When utilizing a cascade heat pump, it is important to note that the overall COP of the cascade system will typically be lower than the COP's of the individual stages. For example, if the COP of each stage is three, the COP of the cascade system will 1.8. This result is due to the fact that two work inputs are being used to move heat from the initial heat source to the final heat sink, while only one work input is being used to move heat across each stage. However, the benefit of a cascade system can be exhibited when the single stage COP for a heat pump that connects the 
low pressure evaporator to the final condenser is low due to the very large temperature lift. In this case, the relatively high COP's of the two single stages that only complete partial temperature lifts, compared to a single stage that completes a full temperature lift, allows for the use of a cascade system to be beneficial. This result will be further illustrated in the proceeding text.

To estimate the performance of the system, a control strategy was used that gave heat pump loop B priority and minimized cascade heat pump operation. This strategy was used because the temperature difference between the evaporator and condenser in heat pump loop B was always equal to or less than the temperature difference between the evaporator in loop A, and the condenser in loop B. Therefore, given these relative temperature differences, the COP of loop B was always greater than the COP of the cascade system, and giving heat pump loop B priority would then result in optimal system performance.

This control strategy resulted in two operating cases for the system. The first case is when the thermal energy being produced by the panel is equal to or more than the thermal energy required by heat pump loop B, if loop B were to consume all of the electrical energy produced by the panel. In this case, the heat output of the system is a function of the electrical energy produced by the solar array, along with the COP of loop B. The thermal energy that is not consumed is stored in the thermal storage tank.

The second case occurs when the thermal energy being produced by the panel is not sufficient to meet the heat input needs of heat pump loop B, if all of the electrical energy were also consumed by heat pump loop B. In this case, heat pump loop B is operated such that all of the thermal energy produced by the panel is consumed, and then the remaining electrical energy is split between heat pump loops A and B. To determine thermal performance in this case, it is mathematically equivalent to model the system as if two separate heat pump loops are operating. 
The first loop is a single-stage heat pump that utilizes only the evaporator in the thermal storage tank, and only the high pressure condenser. The second loop is a cascade heat pump that utilizes the low pressure evaporator, an intermediate condensing/evaporating heat exchanger, and the high pressure condenser. The evaporator in the intermediate heat exchanger is at the same temperature as the evaporator in the single stage heat pump loop, and the condenser in the intermediate heat exchanger is at the same temperature as the thermal storage tank. The heat output from the overall system can then be modelled as the combined heat output from the single stage heat pump, which is constrained by the solar thermal energy production, and the additional heat output from the cascade heat pump, which results from the splitting of the remaining electrical energy, and is dependent on the result of Equation (2-7).

To complete the analysis, the total heat output and the cascade heat pump COP were determined as a function of the panel mean temperature. The evaporation temperature for heat pump loop A was set constant at $5^{\circ} \mathrm{C}$, assuming that heat could be freely obtained from a $10^{\circ} \mathrm{C}$ source, such as a geo-exchange loop, and the condensation temperature of heat pump loop B was set constant at $80^{\circ} \mathrm{C}$. The temperature difference between each heat source and heat sink was set to $5^{\circ} \mathrm{C}$. These temperatures were selected to be consistent with the temperatures used to generate the results shown in Figure 2-2. The condensation temperature in heat pump loop A was assumed to be the same as the panel mean temperature. The evaporation temperature for heat pump loop B was assumed to be $5^{\circ} \mathrm{C}$ below the mean panel temperature. R134a was again used as the refrigerant with no subcooling or superheating. The ambient temperature was constant for all cases at $20^{\circ} \mathrm{C}$. The effect of varying the panel mean temperature on the cascade heat pump COP is shown in Figure 2-4. 


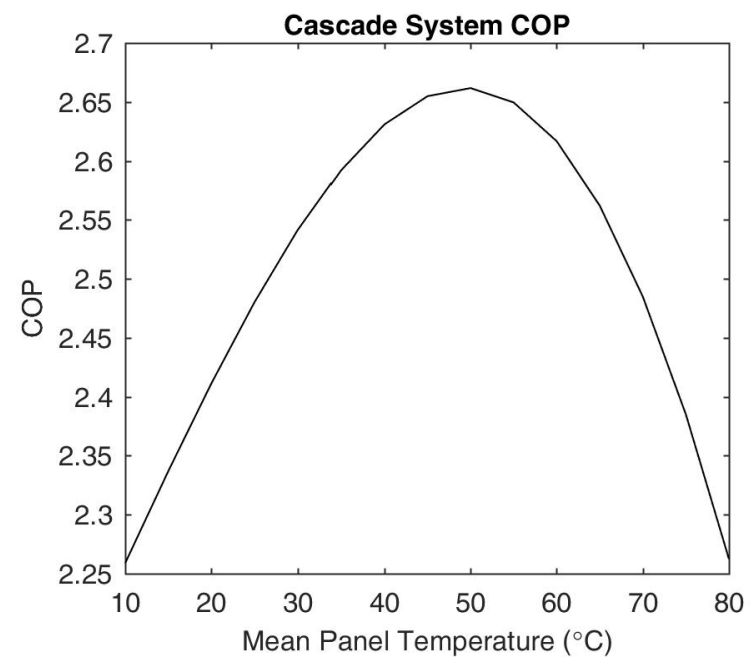

Figure 2-4: Plot of Cascade Heat Pump COP as a Function of Panel Temperature (Low pressure evaporation temperature $=5^{\circ} \mathrm{C}$, High pressure condensation temperature $=80^{\circ} \mathrm{C}$ )

As shown in Figure 2-4, the COP of the cascade heat pump ranges from 2.25 to 2.65 as a function of the panel mean temperature, which is equal to the intermediate heat exchanger condensation temperature. For comparison, a single stage heat pump would operate with a COP of 2.33 to achieve the same temperature lift (i.e. from $5^{\circ} \mathrm{C}$ to $80^{\circ} \mathrm{C}$ ). Therefore, these results show that for panel temperatures between $20^{\circ} \mathrm{C}$ and $70^{\circ} \mathrm{C}$, a cascade heat pump COP exceeds that of a single stage heat pump, which supports the selection of a cascade heat pump arrangement for the system.

To continue, the total heat output from the system is shown in Figure 2-5, which also includes the single heat pump design results from Figure 2-2 for comparison. 


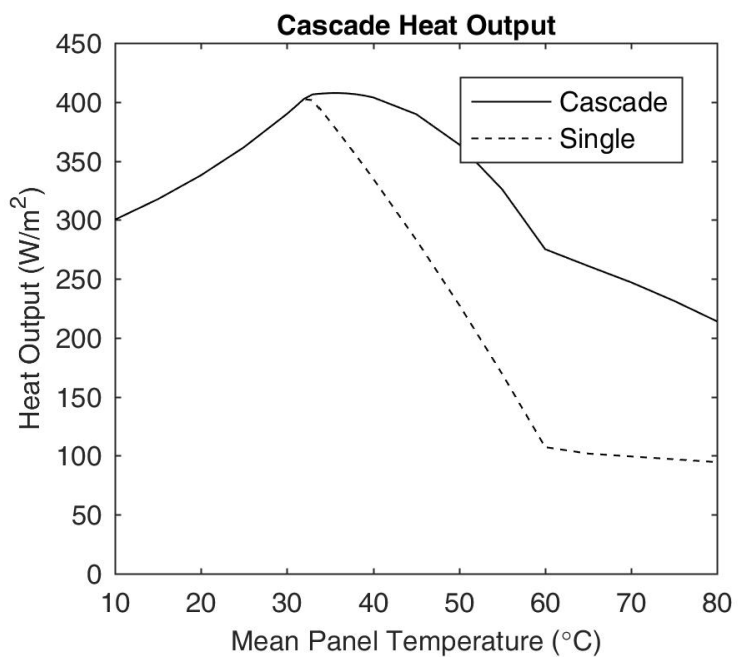

Figure 2-5: Plot of the Thermal Performance and Cascade COP of the Final Design Concept (Low pressure evaporation temperature $=5^{\circ} \mathrm{C}$, High pressure condensation temperature $=80^{\circ} \mathrm{C}$, Solar flux $=1000 \mathrm{~W} / \mathrm{m}^{2}$, Ambient temperature $=20^{\circ} \mathrm{C}$ )

The data presented in Figure 2-5 shows that the peak heat output of the cascade system is $408 \mathrm{~W} / \mathrm{m}^{2}$, which slightly exceeds the peak heat output from the single heat pump system of 402 $\mathrm{W} / \mathrm{m}^{2}$. At the peak heat output operating point, the efficiency of the system is approximately $40 \%$ relative to the incident solar irradiation. As the temperature of the panel increases, heat transfer from the low grade heat sources remains at zero for all panel temperatures lower than $33^{\circ} \mathrm{C}$, to a maximum $270 \mathrm{~W}$ at a panel temperature of $50^{\circ} \mathrm{C}$. The results also show that the heat output from the cascade system consistently exceeds the heat output from the single heat pump system at panel temperatures of $33^{\circ} \mathrm{C}$ or greater.

Based on the results of this comparative study, the cascade heat pump design was shown to slightly improve peak system heat output, and more importantly reduce the sensitivity of the system to panel operating temperature. At panel temperatures below the balance point, additional thermal energy from the panel can be stored in the thermal storage tank, and at panel temperatures 
above the balance point, additional thermal energy can be supplied by the low grade heat source. Both of these features were viewed as favourable for the cascade system, and these preliminary comparisons were deemed sufficient to proceed with more detailed studies. It is important to note that the cascade system contains an additional heat source compared to the single heat pump case. However, since the comparison between these two systems focuses on the thermal output as a function of panel area, and because this additional heat source is assumed to be low grade and freely available, the cost of the additional thermal energy is not considered in the performance comparison.

The first study that was carried out was utilizing the proposed solar heating system for water distillation, which will be discussed in Chapter 3. A second study focuses on improving the accuracy of the initially developed algorithm, using the system for domestic water heating, and will be discussed in Chapter 4. The third and final study focuses on an experimental testing campaign that was carried out, which had the goal of increasing simulation accuracy for hybrid solar panels, and will be discussed in Chapter 5 . 


\section{Chapter 3 Time-Stepping Analysis of a Photovoltaic Thermal Heat Input Process with Thermal Storage}

This chapter is based on the following journal manuscript:

J. P. Fine, J. Friedman and S. B. Dworkin, "Transient analysis of a photovoltaic thermal heat input process with thermal storage," Appied Energy, vol. 160, pp. 308-320, 2015.

\subsection{Introduction}

\subsubsection{Research Motivation}

As the population of the world increases, so does stress on natural fresh water sources. Potable water throughout the world is not evenly distributed, which results in many areas facing water shortages. One solution to this issue is to use desalination technology for saline water such that the population can consume it safely.

The most common desalination process today is the reverse osmosis membrane process, which involves pumping the ocean water to a high pressure and passing it through a membrane $[20,21,22,23]$. As for distillation, there are several processes in use today and all of these processes require thermal energy to drive the phase change of the ocean water. This thermal energy usually comes from the burning of fossil fuels, or from waste heat from other industrial processes, which also usually originates from fossil fuel combustion [20]. Both of these methods are usually implemented using large-scale plants that require significant infrastructure and are often too expensive for sparsely populated regions [24].

Using fossil fuels to drive desalination, while currently more cost effective than using a renewable energy source, can have drawbacks related to the environment and in some cases related 
to the logistics of the desalination plant. Fossil fuels, when burned, produce greenhouse gasses that contribute to global climate change, which can increase drought in many areas. Also, over time fossil fuel supplies worldwide are becoming more expensive as the world reserves are being depleted. Finally, fossil fuels may not always be readily and reliably available in remote areas. Therefore, using fossil fuels as a long-term solution for desalination is not always viable.

Alternatively, using renewable energy to power the desalination process can be much more viable in the long-term. Typically, areas that have water shortages are situated in parts of the world that have abundant and untapped renewable energy sources [24]. Additionally, renewable energy sources can be used reliably in remote areas that do not have conventional energy infrastructure in place [25].

This paper will focus on the use of solar energy as the renewable energy source for a distillation process. Hybrid photovoltaic / thermal (PV/T) panels that are coupled with heat pumps were selected as the energy source because of their ability to provide both the necessary electrical and thermal energy over a suitable temperature range. The proposed system's novel use of two heat pump loops allows for optimal use of the electrical and thermal energy generated by the PVT panel compared to existing systems.

\subsubsection{Solar Energy Desalination Technology Comparison}

Currently, most solar energy-based desalination systems are implemented in research-scale setups, or in small scale pilot projects [26]. The most basic solar energy-driven desalination system is the solar still, which utilizes a large pool that is covered by a transparent screen. The water that evaporates condenses onto the screen and is then collected. These systems, while inexpensive to 
set up and maintain, require very large areas to produce distillate, which is their major drawback. Typically, basic solar still systems produce distillate at a maximum rate of $3.5 \mathrm{~kg} / \mathrm{m}^{2} /$ day, which assumes a location of Daytona Beach, USA [25].

George et al. [27] have been working on a simple improvement of the basic solar still, which incorporates a slowly rotating hollow cylinder. The cylinder is placed horizontally such that the rotation axis is aligned with the long dimension of the cylinder. A portion of the surface of the cylinder that is below the rotation axis is then held below the water's surface. As the cylinder's surface rotates into and out of the water, water adheres to the inner and outer surfaces of the cylinder, which increases the surface area available for evaporation. This increase in surface area then results in an increase of the overall evaporation rate of the system. Using this system, the research group has shown evaporation rates of $9 \mathrm{~kg} / \mathrm{m}^{2} /$ day in Beirut, Lebanon, with a marginal increase to the system's cost [27].

Liu et al. [28] have developed a low-cost, passive, portable distillation system that sits on top of an open body of water. This system utilizes a hydrophilic and porous paper, coated in black carbon powder, which is contained within a transparent housing. The bottom side of the paper sits on the water surface, which allows for the absorption of saline water. The absorbed water then travels through the paper to the top, where it is exposed to solar radiation. This design reduces heat transfer to the water body below, and improves the evaporation rate of the water from the upper surface of the paper. Liu et al. state that this system can offer a thermal efficiency of up to $88.2 \%$, and they also state that a basic solar still has a thermal efficiency of $16.7 \%$ [28]. Therefore, their design can offer a distillate output of up to $18.5 \mathrm{~kg} / \mathrm{m}^{2} /$ day in Buffalo, USA, assuming a basic solar still output of $3.5 \mathrm{~kg} / \mathrm{m}^{2} /$ day [25]. This value will be used for comparison in Section 3.4 .4 of this study. 
Singh et al. [29] have built a system that combines a solar still with PVT panels. Their system utilizes thermal energy from the PVT panels to preheat the water in the solar still basin, and utilizes the electrical energy that is produced to operate the pumps in the cycle. This configuration allows for a fully off-grid system, and can offer increased distillate outputs compared to a passive solar still. Their system utilized a double slope solar still with a basin area of $2 \mathrm{~m}^{2}$ and an additional $2 \mathrm{~m}^{2}$ of PVT collectors. A distillate production rate of $7.54 \mathrm{~kg} /$ day in Ghaziabad, India, was achieved with their system, which results in an area specific flow rate of $1.26 \mathrm{~kg} / \mathrm{m}^{2} /$ day based on their total solar collector area. This area specific production rate is lower than a basic solar still's maximum production rate of $3.5 \mathrm{~kg} / \mathrm{m}^{2} /$ day [25] because of the additional area that must be considered from the added solar collectors. Therefore, this system will not be considered in further desalination technology comparisons in this paper.

Chafidz et al. [30] have been working on a small scale membrane desalination system that uses both solar thermal collectors and photovoltaic collectors to desalinate water. Their system has the added benefit of being off-grid and portable, since it was designed to operate within a standard shipping container. However, their system is more complex than the basic or enhanced solar stills. The small scale membrane distillation system has been tested and resulted in an optimal output of 99.6 liters of distillate in one day [30]. The system includes $18 \mathrm{~m}^{2}$ of evacuated tube solar collector area, and approximately $20.5 \mathrm{~m}^{2}$ of PV collector area [30]. This distillate output coupled with the total solar collector area results in a per unit area daily output of $2.6 \mathrm{~kg} / \mathrm{m}^{2} /$ day in Riyadh, Saudi Arabia. Although this specific output is lower than the solar still, this system has the added benefit of being portable, which must also be considered when comparing designs.

Finally, simulations completed by Bilton et al. [31] were focused on coupling reverse osmosis with solar photovoltaic collectors. This coupling has the benefit of being able to exploit 
the high energy efficiency of the reverse osmosis desalination process, and uses the electricity produced by photovoltaic panels directly. However, reverse osmosis desalination systems require large initial investment, highly skilled maintenance staff, a large amount of pre-treatment for the feed water compared to other distillation techniques, and the efficiency of the cycle is sensitive to the feed water salinity [25]. It was stated that the average energy requirement for distillate production using a reverse osmosis system with energy recovery is $4 \mathrm{kWh} / \mathrm{m}^{3}$ [31]. A calculation was then completed that resulted in a distillate output of $216 \mathrm{~kg} / \mathrm{m}^{2} / \mathrm{day}$, which assumed an average solar panel efficiency of $15 \%$, and used weather data from Phoenix, Arizona, USA. This large specific distillate output is far greater than the outputs of the previously mentioned thermal distillation processes, but the drawbacks related to reverse osmosis desalination may not allow this technology to be used in many locales.

\subsubsection{Solar Energy Coupled Heat Pump System Comparison}

Currently, there are several research groups investigating the coupling of heat pump systems with solar collectors for improved energy extraction. Four different methods of coupling these technologies that have been identified through literature review.

The first method involves the use of a PV panel as the power source for a heat pump system [13]. These systems do not utilize the heat from the solar collector, and only use the solar collector as the electrical energy source for the compressor in the heat pump system. The system proposed by Izquierdo et al. [13] uses a solar collector to charge a battery, which is then discharged by a compressor in a heat pump cycle. A drawback to this system is that there is un-utilized thermal 
energy generated by the PV panel. This unused thermal energy causes the temperature of the PV panel to rise, which lowers its efficiency, resulting in lower electrical energy outputs [32].

The second method involves the use of a solar thermal panel as the thermal energy source for the heat pump cycle [14]. These systems do not include PV cells in the system, and therefore the electrical power supplied to the compressor must be supplied by an external source. Therefore, the requirement for an external energy source is the main drawback of this system.

The third method involves the use of a PVT panel, but the heat pump cycle only utilizes the thermal energy from the panel, and the electrical energy is provided from an external source $[32,33,34,35]$. These systems are concerned with both the thermal and electrical outputs of the solar collectors, but the consumption of these energy streams are by separate systems. These systems can operate with refrigerant flowing through the PVT panel, which results in the PVT panel acting as the evaporator in the heat pump cycle. Alternatively, a non-evaporating working fluid can be passed through the PVT panel, and the extracted heat can be used later in the heat pump cycle. The requirement for an external energy source is the main drawback of this system. Finally, the research being carried out on these systems is concerned with optimization of the PVT panel design such that optimal thermal and electrical energy extraction can occur [32, 33, 34, 35].

The fourth method involves using a PVT panel to provide both thermal energy and electrical energy to a heat pump cycle $[36,37,38]$. The system being investigated by Zhang et al. [36] couples a heat pump with an array of PVT panels, and the compressor in the heat pump is powered directly off of the panels. The electrical energy consumption of the heat pump compressor is dependent on the useful thermal energy produced by the PVT panel, along with the selected working fluid states in the heat pump loop. In cases where all available thermal energy from the panel is extracted, and excess electrical energy remains, Zhang et al. anticipate that the excess 
electricity will be sold to the grid or stored in a battery [36]. The main drawback of this system, compared to the other methods, is its complexity. Another drawback is that in systems where the excess electricity cannot be used externally, it would be wasted. However, Zhang et al. have shown that the system is highly efficient and has environmental and economic benefits [38].

\subsection{Desalination Process}

This section discusses the desalination process that was selected for our analysis, and the techniques that were used are also presented here.

\subsubsection{Desalination Process Overview}

The desalination process that was selected for this study was a multi-effect distillation (MED) process. The MED process was selected because, compared to other distillation methods, it is typically the most energy efficient, it operates at the lowest temperature, it is the most adaptable to fluctuating energy inputs, it requires less maintenance, and it requires the least water pre-treatment [25].

To analyze this process, the first law of thermodynamics was used. Heat loss to the environment was not considered and neither were boiling point elevation (BPE) effects, which increase the boiling temperature of salt and water solutions. Heat loss was neglected at this point in the analysis as it can be accounted for using a factor of safety as needed, and because component insulation can be purchased to minimize the effect. The BPE effects were also neglected at this 
point in the analysis because typical distillation fractions for MED systems (i.e. the mass fraction of distillate produced per unit of sea water intake), result in BPE's of less than one degree Celsius [39]. However, the BPE effects will be considered when selecting the temperature differences within the MED system, and when sizing the required heat exchangers.

A numerical algorithm was developed to analyze the proposed MED cycle that allowed for easy manipulation of cycle parameters. The schematic in Figure 3-1 was used as the basis for the code.

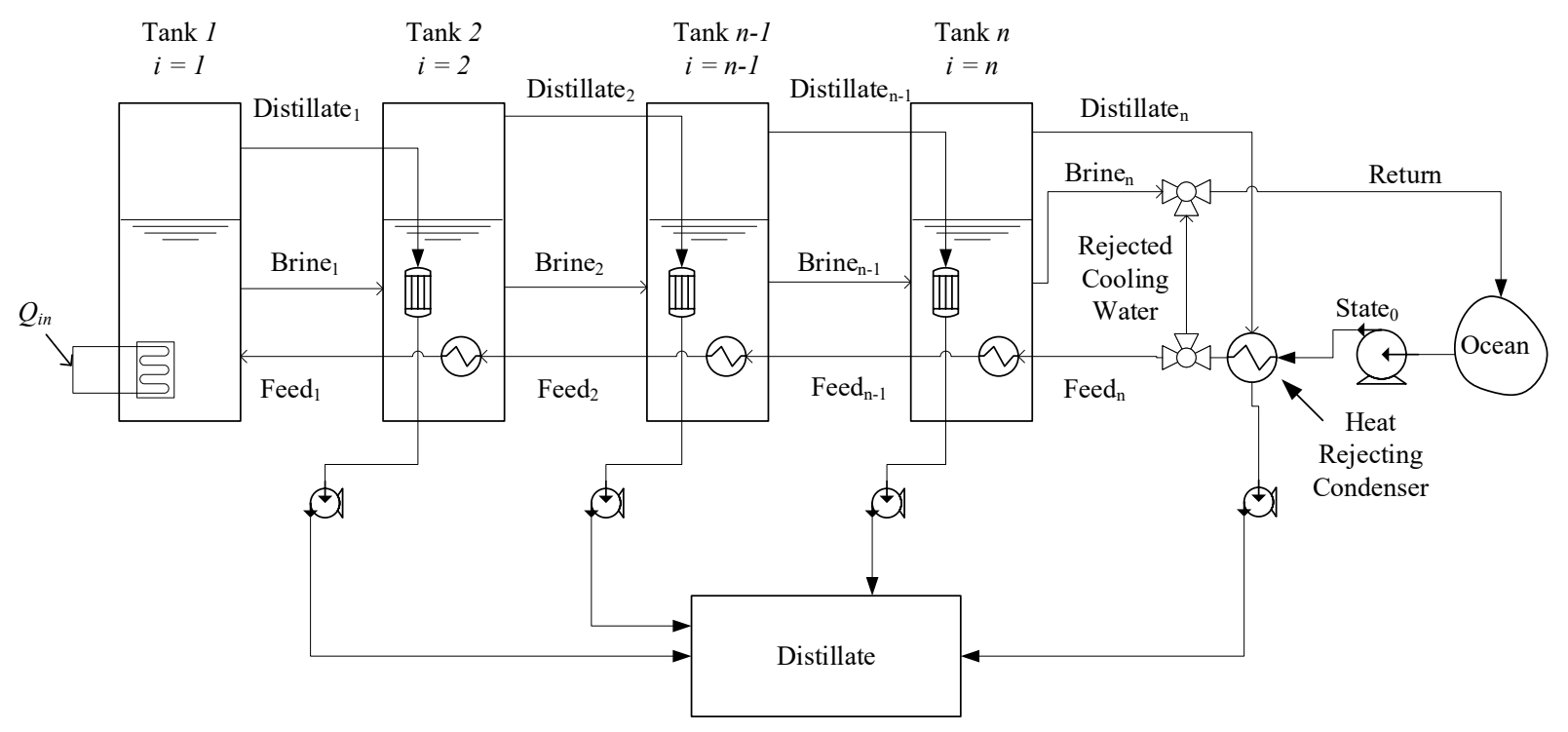

Figure 3-1: Desalination Process Used in Numerical Algorithm

Salt water is first pumped to a heat exchanger that acts as a condenser for the final tank (i.e. tank ' $n$ '). The initial flow rate of ocean water includes both cooling fluid for the final condenser, and the feed water that will be introduced into the desalination cycle. After the water leaves the first heat exchanger, a portion is mixed with the brine from the final tank, and then the 
mixture is sent back to the ocean. The portion of the ocean water that is not rejected is then sent towards the first tank in the process (i.e. tank 1) as feed water. As the feed water goes towards the first tank it passes through pre-heating heat exchangers contained within each of the other tanks.

As feed water is being pumped into the first tank, an external heat source is used to heat and boil a fraction of the brine contained within the first tank. The evaporated brine, which is now $\mathrm{H}_{2} \mathrm{O}$ distillate, passes through a condensing heat exchanger in the next tank of the process, which is held at a lower temperature. As the distillate condenses it transfers heat to the brine surrounding the heat exchanger, which causes evaporation within the tank. This process is repeated for each tank in the process until the final tank, where the condenser is the heat exchanger that uses the feed water as the cooling medium.

The first tank in the system is assumed to be held at the highest pressure, and the remaining tanks are held at progressively lower pressures. The vapour leaving each tank is assumed to be saturated vapour and the brine leaving each tank is assumed to be saturated liquid at the corresponding tank pressure. Since the tanks are held at progressively lower pressures there will also be a difference in the saturation temperature for each tank. The amount of feed water preheating can be adjusted during the design of the distillation process, and can also be set to zero if no feed water heating is desired for a specific iteration of the design.

\subsubsection{Desalination Process Analysis Technique}

Each tank in the system is given an index number. The highest-pressure tank is given index 1 , the tank at the next lower pressure 2, etc. For the first tank, the steady state mass flow rate balance is given by Equation (3-1). 


$$
\dot{m}_{\text {feed }}-\dot{m}_{\text {brine }_{1}}-\dot{m}_{\text {distillate }_{1}}=0
$$

where $\dot{m}_{f e e d}$ is the mass flow rate of feed water being injected into the first tank, $\dot{m}_{\text {brine }_{1}}$ is the mass flow rate of brine exiting the first tank, and $\dot{m}_{\text {distillate }_{1}}$ is the mass flow rate of distillate exiting the first tank.

The steady state energy balance for the first tank is given by Equation (3-2).

$$
h_{\text {feed }_{1}} \dot{m}_{\text {feed }}-h_{\text {brine }_{1}} \dot{m}_{\text {brine }_{1}}-h_{\text {distillate }_{1}} \dot{m}_{\text {distillate }_{1}}+\dot{Q}_{\text {in }}=0
$$

where $h_{\text {feed }_{1}}$ is the enthalpy of the feed water entering the first tank, $h_{\text {brine }_{1}}$ is the enthalpy of the brine exiting the first tank, $h_{\text {distillate }_{1}}$ is the enthalpy of the distillate exiting the first tank, and $\dot{Q}_{\text {in }}$ is the heat transfer rate into first tank from the external heat source.

Equations (3-1) and (3-2) are only the mass and energy balance equation for the first tank. This is because the first tank is the only tank with feed water being injected directly into it, it is the only tank with an external heat source, and it is the only tank without a condenser inside it. Each of the remaining tanks have one brine inlet, one brine outlet, one distillate outlet, one feed water heater, and a condenser. The steady state mass balance for a tank with index $2,3 \ldots, \mathrm{n}$, where $\mathrm{n}$ is the total number of tanks in the system, is shown in Equation (3-3).

$$
\dot{m}_{\text {brine }_{i-1}}-\dot{m}_{\text {brine }_{i}}-\dot{m}_{\text {distillate }_{i}}=0
$$


where $\dot{m}_{\text {brine }_{i-1}}$ is the mass flow rate of brine exiting tank $i-1, \dot{m}_{\text {brine }_{i}}$ is the mass flow rate of brine exiting tank $i$, and $\dot{m}_{\text {distillate }_{i}}$ is the mass flow rate of distillate exiting tank $i$.

The steady state energy balance for the tanks with index $2 \leq i \leq \mathrm{n}$ is shown in Equation (34).

$$
\begin{gathered}
h_{\text {brine }_{i-1}} \dot{m}_{\text {brine }_{i-1}}+\dot{m}_{\text {distillate }_{i-1}} h_{\text {fg }_{i-1}}- \\
\dot{m}_{\text {feed }}\left(h_{\text {feed }_{i-1}}-h_{\text {feed }_{i}}\right)-h_{\text {brine }_{i}} \dot{m}_{\text {brine }_{i}}-h_{\text {distillate }_{i}} \dot{m}_{\text {distillate }_{i}}=0
\end{gathered}
$$

where $h_{\text {brine }_{i-1}}$ is the enthalpy of the brine exiting tank $i-1, h_{\text {brine }_{i}}$ is the enthalpy of the brine exiting tank $i, h_{f g_{i-1}}$ is the latent heat of condensation of the distillate exiting tank $i-1, h_{\text {distillate }_{i}}$ is the enthalpy of the distillate exiting tank $i, h_{\text {feed }_{i-1}}$ is the enthalpy of the feed water entering tank $i-1$, and $h_{\text {feed }}$ is the enthalpy of the brine entering tank $i$.

There are then five remaining equations left that are used to characterize the system. These five equations are derived from overall system mass and energy balances, not just from individual tanks. The first equation states that the sum of all distillate streams for all tank is equal to the system's distillate fraction, multiplied by the total feed water mass flow rate. This relationship is shown in Equation (3-5).

$$
f \times \dot{m}_{\text {feed }}-\sum_{i=1}^{n} \dot{m}_{\text {distillate }_{i}}=0
$$

where $f$ is the selected distillation fraction for the desalination cycle.

The second of the five equations relates the total distillate produced to the distillate produced in each tank. This relationship is shown in Equation (3-6). 


$$
\sum_{i=1}^{n} \dot{m}_{\text {distillate }_{i}}=\dot{m}_{\text {distillate }_{\text {total }}}
$$

The third of the five equations is a mass balance for the entire system and relates the total incoming mass flow rate from the ocean to the total distillate flow rate and the return flow rate. This relationship is shown in Equation (3-7).

$$
\dot{m}_{\text {ocean }}-\dot{m}_{\text {return }}=\dot{m}_{\text {distillate }_{\text {total }}}
$$

where $\dot{m}_{\text {ocean }}$ is the total mass flow rate of ocean water taken in from the ocean, and $\dot{m}_{\text {return }}$ is the total mass flow rate of water being returned to the ocean.

The fourth of the five equations relates the amount of cooling water required for the heat rejection condenser to the heat rejection condenser stream enthalpies. This relationship is shown in Equation (3-8).

$$
\dot{m}_{\text {distillate }_{n}}\left(h_{f g_{n}}\right)-\dot{m}_{\text {ocean }}\left(h_{\text {feed }_{n}}-h_{\text {ocean }}\right)=0
$$

where $h_{\text {ocean }}$ is the enthalpy of the incoming ocean water.

The fifth of the five equations relates the return mass flow rate to the rejected brine flow rate, and cooling water flow rate. This relationship is shown in Equation (3-9).

$$
\dot{m}_{\text {brine }_{n}}-\dot{m}_{\text {return }}+\dot{m}_{\text {cooling }}=0
$$


where $\dot{m}_{\text {cooling }}$ is the mass flow rate of ocean water that is taken as cooling water for the final tank's condenser.

A linear system can be set up to include Equations (3-1) through (3-9), which can then be solved to yield the mass flow rates throughout the system and the required heat power input when the system is operating at steady state. The division of the total distillate output per unit time and the power input requirement yields the system's specific thermal energy requirement (i.e. $R_{T}$ ) in units of kilograms of distillate per kilojoule of input energy. The specific thermal energy requirement is then used in relating the heat input process to the desalination process, which will be discussed in Section 3.3.

Finally, although the majority of energy required for the MED process is thermal energy, there is still an electrical energy requirement that must be considered. This electrical energy requirement is due to the power requirements of the vacuum pumps that maintain the pressures in each tank, along with the power requirements of the pumps that draw liquid through the system. However, the recalculation of this requirement was outside the scope of this analysis so values from existing MED plants were used.

\subsection{Heat Input Process}

This section discusses the heat input process that is being proposed, along with the techniques that were used in analyzing the proposed process. The proposed heat input system uses a PVT panel as the electrical and thermal energy source for a heat pump cycle, similarly to Zhang et al. [36]. However, compared to Zhang et al.'s system, the proposed system uses an additional 
heat pump loop such that the cycle's heat output is not constrained by the thermal energy production of the PVT panel.

\subsubsection{Heat Input Process Overview}

The heat input process that is being investigated utilizes three working fluid loops and is shown in Figure 3-2.

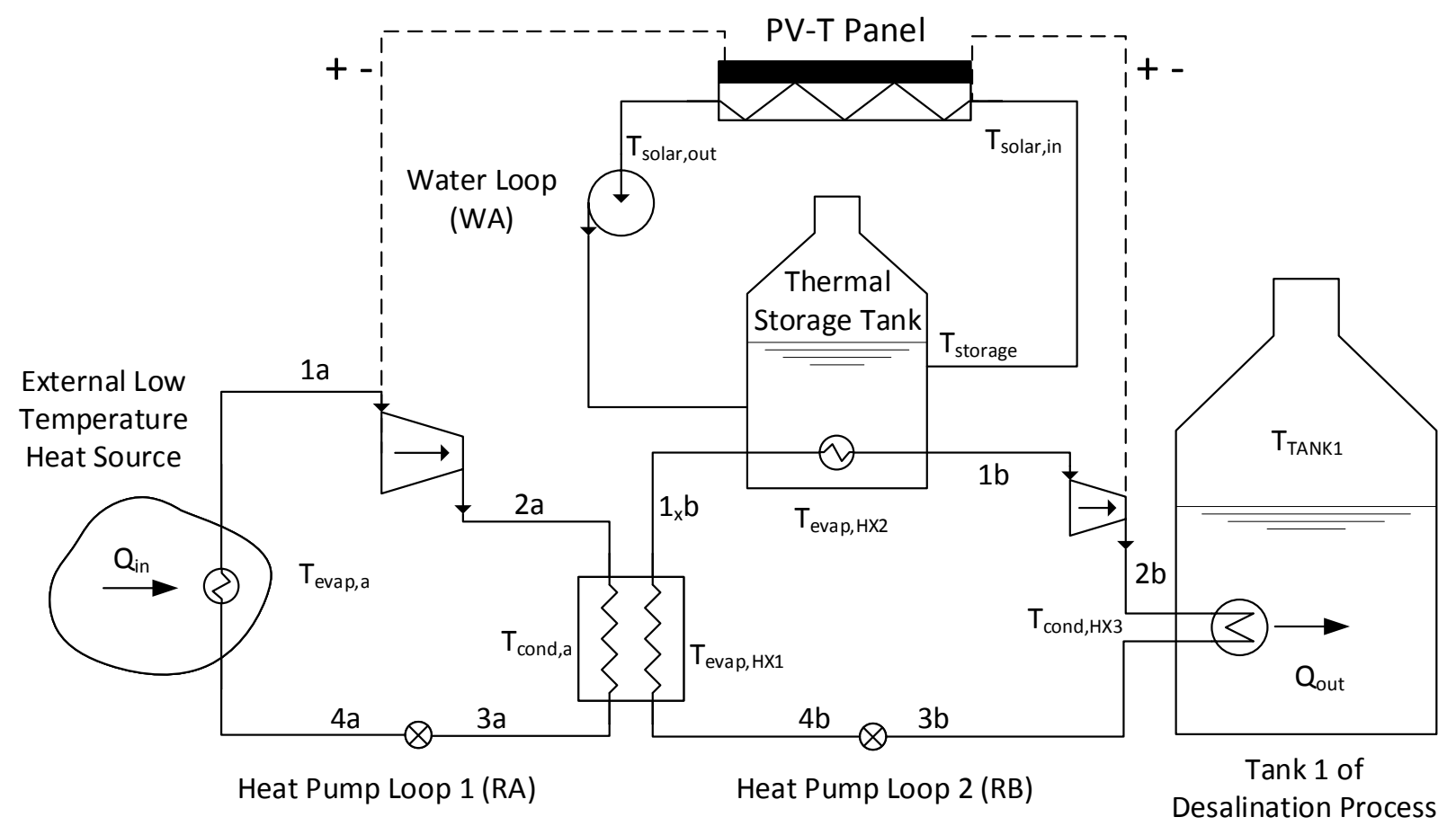

Figure 3-2: Heat Input Cycle Schematic 
The first working fluid loop that will be discussed is a heat pump cycle labelled as loop "RA" in Figure 3-2. Loop RA takes heat from an external low-temperature heat source and moves it into another heat pump loop (i.e. loop RB) that is within the overall heat input cycle. For the presented analysis, both heat pump loops in the heat input cycle are assumed to use refrigerant R134-a. The compressors are analyzed using an isentropic efficiency method, saturated vapour is assumed to exit the final evaporators in both cycles, saturated liquid is assumed to exit the condensers in both cycles, and the throttling processes are assumed to be constant-enthalpy [15].

The second loop, labelled as loop "WA" in Figure 3-2, contains photo-voltaic thermal (PVT) solar panels that produce utilizable heat and electrical energy from solar radiation. The working fluid in loop WA, which is currently assumed to be water, is pumped from the thermal storage tank through the panels at a constant flow rate when the system is operating. The fluid in loop WA then returns to the thermal storage tank, after being heated, which allows for thermal energy to be extracted from the solar collectors and moved into the thermal storage tank.

The third working fluid loop in the cycle, labelled as loop "RB" in Figure 3-2, is a second heat pump loop. Loop RB has two evaporators that are held at the same pressure. The first evaporator extracts heat from the condenser of loop RA, and the second evaporator extracts heat from the thermal storage tank, which is part of loop WA. The condenser in loop RB rejects heat to the first tank of the desalination process, which is the overall purpose of the three working fluid loop cycle.

The PVT panels that are in loop WA also produce electrical power that is used to run the compressors in both loops RA and RB. This electrical energy production, and consumption, occurs while thermal energy is also being extracted from the PVT panels. Electrical energy storage is not being used in this design, so the electrical power being consumed by the cycle follows the power 
generated by the solar panels. This variation in power is accounted for by adjusting the mass flow rates in the system.

The system is assumed to operate using an on-off control scheme, where the control parameter is the temperature of the thermal storage tank. A temperature control parameter is required because the saturation temperature of the evaporator contained within the thermal storage tank is assumed to be constant. Therefore, the temperature of the thermal storage tank must be monitored such that a positive temperature gradient is maintained between the tank and the evaporator (i.e. HX2) contained within the tank.

Finally, the motivation for selecting a double heat pump loop cycle is an improved thermodynamic efficiency. The first heat pump loop (RA) moves heat from a low temperature heat source (LTHS) to an intermediate condenser, which results in an evaporator-condenser saturation temperature difference of $\Delta T_{1}$. The second heat pump loop (RB) moves heat from the first heat pump loop's condenser, and the thermal storage tank, to the desalination process, which results in an evaporator-condenser saturation temperature difference of $\Delta T_{2}$. It should be noted that the system could be designed with a single heat pump loop with an evaporator that extracts heat from both the LTHS, and the thermal storage tank, and moves the heat to the condenser in the desalination process. However, this configuration would result in an evaporator-condenser saturation temperature difference of $\Delta T_{3}$, which would be greater than $\Delta T_{2}$. This increased temperature difference would then result in a reduced coefficient of performance (COP) for the single heat pump loop configuration, compared to the COP of loop RB. Therefore, given that the system should operate for an appreciable fraction of a typical year without drawing heat from the LTHS, which will be discussed in Section 3.3.2, the double heat pump loop configuration was found to increase the system's thermodynamic efficiency. 


\subsubsection{Heat Input System Analysis Process}

The analysis of the heat input cycle is carried out using a time-stepping method to generate results over a solution period. Hourly air dry-bulb temperatures and hourly solar flux weather data for a typical year in a selected location are used as the environmental condition inputs for the system. This data is made available by government organizations for many major cities in North America [40].

The efficiency and other design input parameters related to the solar collectors, such as the collector area, are used to simulate the solar collector's performance. These characteristics are usually provided by the manufacturer of the solar collector, but they can also be determined through testing a solar collector after purchase.

A simulation time-step size must be chosen at the beginning of the analysis as well. The length of the time-steps should be selected such that solution calculation time is not unreasonably long, and such that further reduction in the time-step length will not cause appreciable changes in the results. In this study, a time-step length of 1 minute was selected based upon sensitivity study results, to ensure time-step size independence of the presented solution.

Next, the solar collector area, mass of the thermal storage tank, compressor isentropic efficiencies, flow rate of solar collector cooling fluid, and specific heat capacity of the thermal storage tank must be chosen. These values remain constant through the simulation and are selected based on manufacturers' data along with the discretion of the designer.

The design temperature differences between the hot and cold sides of HX1, HX2, and HX3 are specified as well. The larger the temperature differences, the smaller the heat transfer area that will be required for the heat exchangers. However, large temperature differences also result in 
lower cycle efficiencies because of the increased compressor work requirements for the heat pump loops.

The saturation temperature of the first tank of the desalination process, the thermostat control temperature for the thermal storage tank, and the design heat transfer rate for HX2 should now be specified. The saturation temperature of the first tank in the desalination process will have an effect on the saturation temperatures of $\mathrm{HX} 1, \mathrm{HX} 2$, and $\mathrm{HX} 3$. The saturation temperature of the first tank in the desalination process will also have an effect on the specific thermal energy requirement to produce distillate, as detailed in Section 3.2.2. The thermostat control temperature is the minimum allowable temperature of the thermal storage tank, and when the thermal storage tank is below this temperature the system does not operate. The design heat transfer rate for HX2 is used, along with the $\mathrm{HX} 2$ design temperature difference, and the minimum thermal storage tank temperature, to determine the heat transfer area for HX2. The saturation temperature of the first tank of the desalination process, the thermostat control temperature for the thermal storage tank, and the design heat transfer rate for $\mathrm{HX} 2$ all have quite an appreciable effect on the performance of the system. Therefore, these three parameters were selected as the optimization parameters for the system.

The mass flow rate of fluid in loop WA, when the system is operating, can be found using Equation (3-10).

$$
\dot{m}_{w}=\dot{m}_{\text {solar }} \times A
$$

where $\dot{m}_{w}$ is the mass flow rate of fluid in loop WA, $\dot{m}_{\text {solar }}$ is the area specific mass flow rate of water in the solar collectors, and $A$ is the total area of the solar collectors. 
The saturation temperatures of the evaporators in loop RB can be found using Equation (3-

11).

$$
T_{\text {evap }_{H X 2}}=T_{\text {tank }_{\text {min }}}-\Delta T_{H X 2}
$$

where $T_{\text {evap }_{H X 2}}$ is the saturation temperature of the evaporators in loop RB, $T_{\text {tank }}$ min is the minimum allowable temperature of the thermal storage tank for the heat input system to operate, and $\Delta T_{H X 2}$ is the temperature difference between the saturation temperature of the evaporators in loop $\mathrm{RB}$ and the thermal storage tank minimum temperature.

The saturation temperature of the condenser in loop RB can then be found using Equation $(3-12)$.

$$
T_{\text {cond }_{H X 3}}=T_{\text {desal }} \text { tank1 }_{1}+\Delta T_{H X 3}
$$

where $T_{\text {cond }_{H X 3}}$ is the saturation temperature of the condenser in loop $\mathrm{RB}, T_{\text {desal }}$ tank1 is the saturation temperature of the first tank in the desalination process, and $\Delta T_{H X 3}$ is the temperature difference between the saturation temperature of the condenser in loop $\mathrm{RB}$ and the saturation temperature of the first tank in the desalination process.

The saturation temperature of the condenser in loop RA can then be found using Equation $(3-13)$.

$$
T_{\text {cond }_{H X 1}}=T_{\text {evap }_{H X 2}}+\Delta T_{H X 1}
$$


where $T_{\text {cond }_{H X 1}}$ is the saturation temperature of the condenser in loop RA, and $\Delta T_{H X 1}$ is the temperature difference between the condenser in loop RA and the evaporators in loop RB.

Next, the initial temperature of the working fluid in loop WA, denoted as $T_{\text {init }}$, is set to the thermostat control temperature for the thermal storage tank. This temperature should be the same temperature that the system reaches at the final time-step of the solution, or else the system is not in equilibrium. Therefore, this assumption is valid for a suitably designed system.

The enthalpies of the refrigerant in loops RA and RB at the different points in both of the cycles can now be found using the previously established saturation temperatures, along with the assumed compressor isentropic efficiencies. For loops RA and RB it is assumed that saturated vapour enters the compressors, saturated liquid leaves the condensers, and the throttling processes occur at constant working fluid enthalpy. The isentropic efficiencies along with the previously chosen component saturation temperatures are used to determine the enthalpy changes across the compressors.

Now, the operating profile of the system can be found. The following steps are repeated algorithmically for each solution time-step. First, the total incident solar radiation energy on the PVT panels during the current time-step is found using Equation (3-14).

$$
Q_{\text {incident }_{i}}=\dot{q}_{\text {solar }_{i}} \times A \times \Delta t_{\text {step }}
$$

where $Q_{\text {incident }_{i}}$ is the total incident solar radiation energy over time-step $i, \dot{q}_{\text {solar }_{i}}$ is the solar flux over the time-step $i$, and $\Delta t_{\text {step }}$ is the time-step length. 
Next, the temperature of the cooling fluid entering the solar panel for the current time-step is set to the temperature of the thermal storage tank from the previous time-step. This relationship is shown in Equation (3-15).

$$
T_{\text {solar }_{i n}}=T_{\text {tank }_{i-1}}
$$

where $T_{\text {solar }_{i n} i}$ is the temperature of the fluid entering the solar collector during time-step $i$, and $T_{\text {tank }_{i-1}}$ is the temperature of the thermal storage tank at time-step $i-1$.

The mean temperature of the solar collector is assumed to only be a function of the temperature of the incoming panel cooling fluid from the current time-step and the outgoing panel cooling fluid from the previous time-step. This relationship is shown in Equation (3-16).

$$
T_{m_{i}}=\frac{T_{\text {solar }_{i n_{i}}}+T_{\text {solar }_{\text {out }} \text { i-1 }}}{2}
$$

where $T_{m_{i}}$ is the mean temperature of the solar collector during time-step $i$, and $T_{\text {solar }_{\text {out }} \text { i- }}$ is the temperature of the fluid exiting the solar collector during time-step $i-1$.

The electrical efficiency of the solar collector for the current time-step is then found using Equation (3-17). Equation (3-17) is a linear solar collector electrical efficiency equation and was derived from provided solar collector test data for the Solimpeks PowerTherm PVT solar collector [9], and the datasheet for this solar collector is contained in the Appendix of this thesis.

$$
\eta_{\text {elec }_{i}}=\frac{186.59-0.6771 \times T_{m_{i}}}{1400}
$$


where $\eta_{\text {elec }}$ is the electrical efficiency of the solar collector during time-step $i$.

Using the electrical efficiency and incident solar energy from the current time-step, the electrical energy production over the time-step can be found using Equation (3-18).

$$
E_{i}=\eta_{\text {elec }_{i}} \times Q_{\text {incident }_{i}}
$$

where $E_{i}$ is the electrical energy produced over time-step $i$.

Now, the thermal efficiency of the panel can be found. First the panel reduced temperature must be calculated using Equation (3-19).

$$
T_{r_{i}}=\frac{T_{m_{i}}-T_{a_{i}}}{\dot{q}_{\text {solar }_{i}}}
$$

where $T_{r_{i}}$ is the reduced temperature of the solar collector during time-step $i$, and $T_{a_{i}}$ is the ambient air temperature during time-step $i$.

The thermal efficiency of the panel for the current time-step is then found using Equation (3-20). The constants in Equation (3-20) are also based on test data for the Solimpeks PowerTherm PVT solar collector [41].

$$
\eta_{t h_{i}}=0.493-4.086 \times T_{r_{i}}-0.068 \times \dot{q}_{\text {solar }_{i}} \times T_{r_{i}}^{2}
$$

where $\eta_{t h_{i}}$ is the thermal efficiency of the solar collector during time-step $i$. 
Since the thermal efficiency relationship for solar collectors includes a term that is related to the incident solar flux, and the solar flux can range from zero to values around $1000 \mathrm{~W} / \mathrm{m}^{2}$, there are issues when the solar flux is small (i.e. less than $100 \mathrm{~W} / \mathrm{m}^{2}$ ). This large range in solar flux values causes erroneously large variations of the thermal efficiency of the panel, and in the event that the solar flux is zero, Equation (3-20) does not have a real solution. Therefore, to accommodate for this large range in solar flux values a maximum and minimum allowable thermal efficiency were imposed on the system such that when a solution to Equation (3-20) results in a value outside of these limits the solution can be set to either the upper or lower limit. Therefore, when the thermal efficiency is found to be above the upper limit, the solution is forced to equal the upper limit. Similar, when the thermal efficiency was found to be below the lower limit, the solution is forced to equal the lower limit. Finally, the thermal efficiency is assumed to be zero during time-steps that have no solar radiation.

The total thermal energy absorbed by the working fluid passing through the solar collector in loop WA during a time-step, which is also equal to the thermal energy input to the thermal storage tank from the solar collector over a given time-step, is found using Equation (3-21).

$$
Q_{i}=\eta_{\text {th }_{i}} \times Q_{\text {incident }_{i}}
$$

where $Q_{i}$ is the useful thermal energy absorbed by the working fluid in loop WA over time-step $i$.

The temperature of the working fluid in loop WA leaving the solar panel during the current time-step is then found using Equation (3-22).

$$
T_{\text {solar }_{\text {out }}}=T_{\text {solar }_{i n_{i}}}+\frac{Q_{i}}{\Delta t_{\text {step }} \times \dot{m}_{w} \times c_{p_{w}}}
$$


where $T_{\text {solar }_{\text {out }}}$ is the temperature of the fluid in loop WA leaving the solar collector during timestep $i$, and $c_{p_{w}}$ is the specific heat capacity of the working fluid in loop WA.

Now, the heat extracted from the thermal storage tank over a time-step can begin to be considered. At the beginning of this analysis a design heat transfer rate for HX2 was selected, and based on this rate the heat extracted from the thermal storage tank can be found Equation (3-23).

$$
Q_{H X 2_{i}}=\dot{Q}_{H X 2_{\text {design }}} \times \Delta t_{\text {step }} \times\left(\frac{T_{\text {tank }_{i-1}}-T_{\text {evap }_{H X 2}}}{T_{\text {tank }_{\text {min }}}-T_{\text {evap }_{H X 2}}}\right)
$$

where $Q_{H X 2_{i}}$ is the thermal energy transferred through HX2 over time-step $i$, and $\dot{Q}_{H X 2 \text { design }}$ is the design heat transfer rate of $\mathrm{HX} 2$.

Equation (3-23) assumes that the heat transfer area and the convection coefficient for heat transfer between the thermal storage tank and the loop RB evaporator contained within the thermal storage tank are constant throughout the analysis. This assumption allows for the heat transfer over a time-step to be proportional to the designed heat transfer rate, time-step length, and the ratio of the designed HX2 temperature gradient and the current HX2 temperature gradient. However, during time-steps with low electrical energy production, referred to as the limited electricity state, there is not enough electrical energy to run the compressors and the desalination cycle if the heat extraction rate from the thermal storage tank (i.e. $Q_{i}$ ) is set equal to the result of Equation (3-23). Therefore, in time-steps during which the system operates in the limited electricity state, HX2 will have sufficient heat transfer potential to provide enough heat to balance the cycle. This case allows loop RA to be inactive, and the amount of heat that must be transferred through HX2 can be found using Equation (3-24). 


$$
Q_{H X 2_{i}}=\frac{\left(h_{b 1}-h_{b 4}\right) E_{i}}{\left(h_{b 2}-h_{b 1}\right)+R_{e} R_{t}\left(h_{b 2}-h_{b 3}\right)}
$$

where $h_{b 1}$ is the enthalpy of the working fluid in loop RB after HX2, $h_{b 2}$ is the enthalpy of the working fluid in loop RB after the compressor in loop RB, $h_{b 3}$ is the enthalpy of the working fluid in loop $\mathrm{RB}$ after $\mathrm{HX} 3, h_{b 4}$ is the enthalpy of the working fluid in loop RB after the throttling process in loop $\mathrm{RB}, R_{e}$ is the amount of electrical energy required to produce one kilogram of distillate from the desalination process, and $R_{t}$ is the mass of distillate produced per unit of thermal energy from the desalination process.

Therefore, when finding the heat transferred through HX2 over a given time-step, both Equations (3-23) and (3-24) must be solved. Then, if the result of Equation (3-24) is less than the result of Equation (3-23), the heat transfer rate is set to the result of Equation (3-24). Otherwise, the heat transfer rate is set to the result of Equation (3-23).

If the temperature of the thermal storage tank from the previous time-step is equal to or greater than the minimum thermal storage tank temperature (i.e. $T_{\operatorname{tank}_{i-1}} \geq T_{\operatorname{tank}_{\min }}$ ) then the heat input systems will operate. When the system operates, the net heat transfer for the thermal storage tank is found using Equation (3-25).

$$
Q_{\text {tank }_{i}}=Q_{i}-Q_{H X 2_{i}}
$$

where $Q_{\operatorname{tank}_{i}}$ is the net heat transfer into the thermal storage tank over time-step $i$. 
If the result of Equation (3-25) is positive, heat is being added to the thermal storage tank, and if the result is negative heat is being removed from the tank. When the system is not operating, the net heat transfer to the thermal storage tank is found using Equation (3-26).

$$
Q_{\text {tank }_{i}}=Q_{i}
$$

The temperature of the thermal storage tank at the current time-step is then found using Equation (3-27).

$$
T_{\text {tank }_{i}}=T_{\text {tank }_{i-1}}+\frac{Q_{\text {tank }_{i}}}{m_{\text {tank }} \times c_{p_{\text {tank }}}}
$$

where $m_{\operatorname{tank}}$ is the mass of the thermal storage tank that contributes to the tank's thermal mass.

Now, the operating characteristics of the overall system can be found for the given timestep, and there are three main states that the system can occupy. The first state is when there is no solar irradiation, or the thermal storage tank is below the control temperature. The system does not operate in this state, and the solution process can move to the next time-step. The second state is when the system is active but there is limited electricity, which results in heat pump loop RA being inactive. This state results in a linear system of equations that can be solved directly. Lastly, the third state occurs when the system is operating, and there is sufficient electricity. When the third state occurs, a non-linear system solution must be carried out.

In the second state, when the system is operating with limited electricity, the total mass flow of the working fluid in loop RB is found using Equation (3-28). 


$$
m_{b_{i}}=\frac{Q_{H X 2 i}}{h_{b 1}-h_{b 4}}
$$

where $m_{b_{i}}$ is the total mass flow of refrigerant in loop RB over time-step $i$.

Next, the electrical energy consumed by the compressor in loop RB over the time-step is found using Equation (3-29).

$$
W_{b_{i}}=m_{b_{i}}\left(h_{b 2}-h_{b 1}\right)
$$

where $W_{b_{i}}$ is the electrical energy consumed by the compressor in loop RB over time-step $i$.

The heat transferred through HX3 to the desalination process is then found using Equation $(3-30)$.

$$
Q_{\text {desal }_{i}}=m_{b_{i}}\left(h_{b 2}-h_{b 3}\right)
$$

where $Q_{\text {desal }}$ is the total thermal energy transferred to the desalination process over time-step $i$.

Finally, the mass of distillate produced over the time-step is found using Equation (3-31).

$$
m_{\text {desal }_{i}}=R_{t} Q_{\text {desal }_{i}}
$$

where $m_{\text {desal }_{i}}$ is the total mass of distillate produced over time-step $i$.

Unlike the limited electricity state where loop RA is assumed to be non-operational, which allows for a direct solution of the system, the third state requires the simultaneous solution of ten 
equations, of which one is non-linear. The first equation, shown in Equation (3-32), relates the mass of refrigerant flow through loop RB over the time-step to the heat transfer rate through HX1 over the time-step. Equation (3-32) is the non-linear equation in the system because $m_{b_{i}}$, and $h_{b 1_{x_{i}}}$ are unknown, and they are multiplied.

$$
Q_{H X 1_{i}}=m_{b_{i}}\left(h_{b 1_{x_{i}}}-h_{b 4}\right)
$$

where $Q_{H X 1_{i}}$ is the total heat transfer through HX1 over time-step $i$, and $h_{b 1_{x_{i}}}$ is the enthalpy of the working fluid in loop RB after HX1 during time-step $i$.

The second relationship, shown in Equation (3-33), relates the mass of refrigerant flow through loop RB during the time-step to the heat transfer through HX2 during the time-step.

$$
Q_{H X 2_{i}}=m_{b_{i}}\left(h_{b 1}-h_{b 1_{x_{i}}}\right)
$$

The third relationship, shown in Equation (3-34), relates the mass of refrigerant flow through loop RB over the time-step, to the electrical energy required to run the compressor in loop RB over the time-step.

$$
W_{b_{i}}=m_{b_{i}}\left(h_{b 2}-h_{b 1}\right)
$$

The fourth relationship, shown in Equation (3-35), relates the mass of refrigerant flow through loop RB over the time-step, to the heat transfer into the desalination process over the timestep. 


$$
Q_{\text {desal }_{i}}=m_{b_{i}}\left(h_{b 2}-h_{b 3}\right)
$$

The fifth relationship, shown in Equation (3-36), relates the mass of refrigerant flow through loop RA over the time-step, to the heat transfer from the external heat source to the evaporator in loop RA over the time-step.

$$
Q_{\text {ext }_{i}}=m_{a_{i}}\left(h_{a 1}-h_{a 4}\right)
$$

where $Q_{\text {ext }}$ is the total heat transfer from the external, low-temperature, heat source over timestep $i, m_{a_{i}}$ is the total mass flow of refrigerant in loop RA over time-step $i, h_{a 1}$ is the enthalpy of the working fluid in loop RA after the evaporator, and $h_{a 4}$ is the enthalpy of the working fluid in loop RA after the throttling process.

The sixth relationship, shown in Equation (3-37), relates the mass of refrigerant flow through loop RA over the time-step, to the electrical energy required to run the compressor in loop RA over the time-step.

$$
W_{a_{i}}=m_{a_{i}}\left(h_{a 2}-h_{a 1}\right)
$$

where $W_{a_{i}}$ is the electrical energy consumed by the compressor in loop RA over time-step $i$, and $h_{a 2}$ is the enthalpy of the working fluid in loop RA after the compressor in loop RA.

The seventh relationship, shown in Equation (3-38), relates the mass of refrigerant flow through loop RA over the time-step, to the heat transfer through HX1 over the time-step. 


$$
Q_{H X 11_{i}}=m_{a_{i}}\left(h_{a 2}-h_{a 3}\right)
$$

The eighth relationship, shown in Equation (3-39), relates the heat transfer to the desalination process over the time-step, to the mass of distillate produced over the time-step.

$$
m_{\text {desal }_{i}}=R_{T} \times Q_{\text {desal }_{i}}
$$

The ninth relationship, shown in Equation (3-40), relates the mass of distillate output over the time-step, to the electrical energy required by the desalination process over the time-step.

$$
E_{\text {desal }_{i}}=R_{E} \times m_{\text {desal }_{i}}
$$

where $E_{\text {desal }_{i}}$ is the total electrical energy required by the desalination process over time-step $i$.

The tenth relationship, shown in Equation (3-41), relates the total electrical energy production from the solar panel over the time-step, to the total required electrical energy for the cycle. The total electrical energy required for the cycle over the time-step is the sum of the compressor electrical energy requirements for both loops RA and RB, along with the electrical energy required by the desalination process.

$$
E_{i}=W_{a_{i}}+W_{b_{i}}+E_{\text {desal }_{i}}
$$


The unknown quantities in Equations (3-32) to (3-41) are $Q_{H X 1_{i}}, Q_{\text {desal }_{i}}, Q_{e x t_{i}}, W_{a_{i}}, W_{b_{i}}$, $m_{a_{i}}, m_{b_{i}}, h_{b 1_{x_{i}}}, m_{\text {desal }_{i}}$, and $E_{\text {desal }}$. The input quantities are the enthalpies of the working fluids in loops RA and RB, $Q_{H X 2_{i}}, E_{i}, R_{t}$, and $R_{e}$.

To solve this system of equations a Newton-Raphson solution method was implemented [42], which solved for all variables in the solution vector simultaneously. The initial guess for the solution corresponded to $50 \%$ of the evaporation of the working fluid in loop RB occurring in HX1. This guess allowed for the determination of the enthalpy of the working fluid in loop RB after HX1, which linearized the system for the initial guess. The system was considered converged when the relative absolute change of the solution vector between iterations, which includes all of the unknown quantities, was less than $1 \times 10^{-6}$. This process was repeated for each time-step in the solution period until all system parameters of interest were obtained.

\subsection{Results and Discussion}

This section will present the results of the simulations that were carried out using the model that was developed. A comparison with the other existing desalination systems will also be given.

\subsubsection{List of Assumptions}

The following assumptions were used when analyzing the desalination and heat input cycles as part of this study:

1. Heat loss from the tanks and the piping in the system is neglected. 
2. The solar loop circulation pump energy requirement is neglected.

3. There is infinite demand for desalinated water at all time-steps, ensuring that all heat produced by the heating system is consumed by the desalination process.

\subsubsection{Multi-Effect System Simulation Results}

To begin the simulation, the inputs for the desalination cycle analysis must be selected, as shown in Figure 3-3 (i). Next, the desalination system analysis must be completed, which produces a set of results including the thermal energy requirement that is needed for the heat input cycle analysis, as shown in Figure 3-3 (ii). Then, the heat input cycle analysis is completed using the desalination cycle analysis results and other input parameters, as shown in Figure 3-3 (iii). Lastly, after running the heat input cycle analysis, the distillate production profile is generated for the system, as indicated in Figure 3-3 (iv).

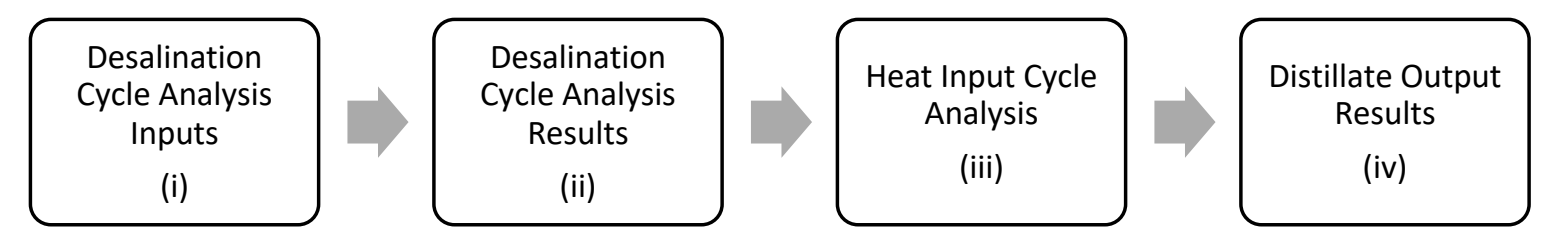

Figure 3-3: Solution Algorithm Flow Chart

For the study that was completed, the following input parameters were selected for the desalination cycle analysis: 
1. The temperature difference between tanks was $5^{\circ} \mathrm{C}$.

2. The final tank (i.e. lowest pressure/temperature tank) saturation temperature and pressure were $20^{\circ} \mathrm{C}$ and 0.023 bar respectively.

3. Feed water heating was used such that the incoming fluid leaves each pre-heating heat exchanger at a temperature of $2^{\circ} \mathrm{C}$ cooler than the tank in which the heat exchanger is contained [43].

4. The distillation fraction was set to $40 \%$.

5. The terminal temperature difference in the heat rejection heat exchanger (i.e. the heat exchanger that is not contained within a distillation effect) was set to $1^{\circ} \mathrm{C}$.

The results of this calculation are shown in Figure 3-4 and were used in sizing the heat addition system for the process.

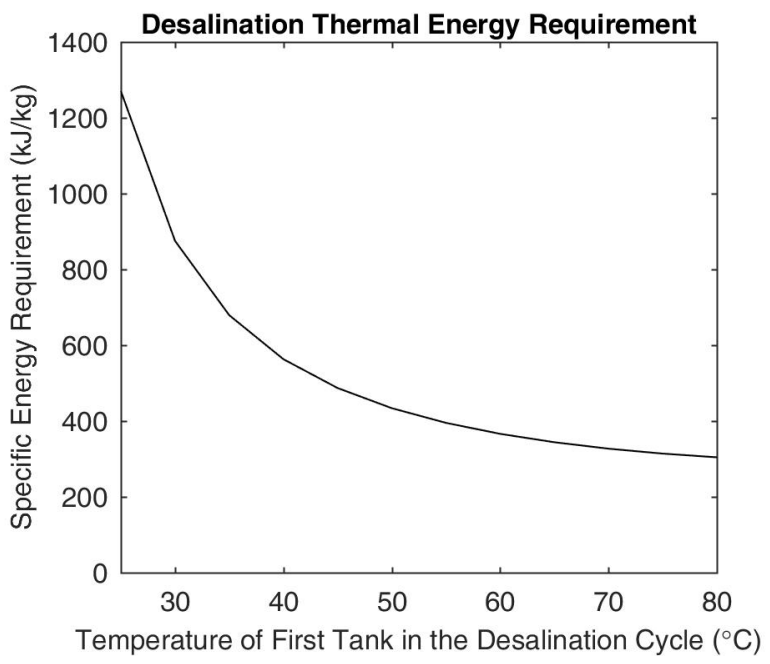

Figure 3-4: Plot of Required Thermal Energy vs. First Tank Saturation Temperature 
In Figure 3-4, the horizontal axis represents the saturation temperature of the first tank in the desalination process, and the vertical axis represents the thermal energy that must be supplied to the first tank in the process to produce one kilogram of distillate. In analysing the trend in Figure 3-4 one must recall that the number of effects in the cycle increases by one effect for each $5^{\circ} \mathrm{C}$ temperature increase of the first tank. Therefore, the results of this analysis show an inverse proportional relationship between the temperature of the first tank and the specific energy requirement. This relationship occurs because the latent heat from one effect can be re-used by further effects as the saturation temperature of the first tank increases.

\subsubsection{Heat Input System Simulation Results}

Following the completion of the MED system simulation, the simulation of the heat input system was carried out. Simulations of the proposed system were completed using weather data for Phoenix, Arizona, USA. This location was selected because Phoenix is an arid region, with large amounts solar radiation, which is representative of the areas in which this system would be most effective. Table 3-1 presents comparative weather data for several water stressed areas around the world to illustrate the similarity between the regions. Weather data from the National Solar Radiation Database was used for the analysis, which included air dry bulb temperature and total horizontal solar irradiance for each hour of the years 1961-1990 [40]. An average over all available years, for a specific hour, for each of the required parameters was then found and was used in the analysis. 
Table 3-1: Comparative Weather Data for Water Scarce Areas [44]

\begin{tabular}{|c|c|c|}
\hline Location (City, Country) & $\begin{array}{c}\text { Total Annual Horizontal } \\
\text { Radiation }\left(\mathrm{kWh} / \mathrm{m}^{2} / \text { year }\right)\end{array}$ & $\begin{array}{c}\text { Annual Average Dry } \\
\text { Bulb Temperature }\left({ }^{\circ} \mathrm{C}\right)\end{array}$ \\
\hline Phoenix, USA & 2094 & 23.8 \\
\hline Los Angeles, USA & 1825 & 16.8 \\
\hline Miami, USA & 1753 & 24.5 \\
\hline Houston, USA & 1627 & 20.4 \\
\hline Tripoli, Libya & 1864 & 20.3 \\
\hline Abu Dhabi, UAE & 2205 & 27.1 \\
\hline Cairo, Egypt & 1912 & 22.3 \\
\hline Algiers, Africa & 1683 & 17.7 \\
\hline Cape Town, South Africa & 1901 & 16.5 \\
\hline Riyadh, Saudi Arabia & 2232 & 26.2 \\
\hline Tehran, Iran & 2140 & 17.3 \\
\hline
\end{tabular}

A constraint was imposed that the size of the desalination plant would be approximately the size of a standard shipping container, or smaller. This constraint guided the dimensions of many of the components that were in the system, such as the thermal storage tank, and solar collector panel area. The following input parameters were used for the analysis.

Table 3-2: Constant Design Input Parameters for System Case Study

\begin{tabular}{|c|c|}
\hline Parameter & Value \\
\hline$\Delta t_{\text {step }}$ & 60 seconds \\
\hline$A$ & $8.4 \mathrm{~m}^{2}$ \\
\hline$m_{\text {tank }}$ & $4000 \mathrm{~kg}$ \\
\hline$\eta_{\text {comp }}$ & $0.5[45]$ \\
\hline$c_{p_{\text {tank }}}$ & $4.18 \frac{\mathrm{kJ}}{\mathrm{kg} \mathrm{K}}$ \\
\hline$\Delta T_{H X 1}, \Delta T_{H X 2}, \Delta T_{H X 3}$ & $5{ }^{\circ} \mathrm{C}$ \\
\hline$\dot{m}_{\text {solar }}$ & $0.021 \frac{\mathrm{kg}}{\mathrm{m}^{2} \mathrm{~s}}$ \\
\hline
\end{tabular}


A one-year simulation of the system was carried out using the Phoenix, Arizona weather data, which simulated the performance of the system with changing solar irradiation and air dry bulb temperature. The solar fluid pumping energy requirement was neglected as this power requirement is small compared to compressor energy consumption. Optimization of the system with respect to the distillate output per unit of solar panel area was then carried out, which will here in be referred to as the system's efficiency. This form of efficiency was selected for two reasons. The first is because the end goal of this system is to produce potable water. The second is because the driving cost of the system is likely the solar collectors. Therefore, the amount of water produced per unit cost can be represented by this efficiency.

The parameters that were left as optimization parameters were the minimum temperature of the thermal storage tank (i.e. $T_{\operatorname{tank}_{\min }}$ ), the saturation temperature of the first tank in the desalination process (i.e. $T_{\text {desal } a n k 1}$ ), and the design heat extraction rate through HX2 (i.e. $\dot{Q}_{H X 2 \text { design }}$ ). The plots shown in Figure 3-5 present the results for four different desalination first tank saturation temperatures (i.e. $40^{\circ} \mathrm{C}, 50^{\circ} \mathrm{C}, 60^{\circ} \mathrm{C}$, and $70^{\circ} \mathrm{C}$ ), with up to four different thermal storage tank minimum temperatures for each desalination first tank temperature. 


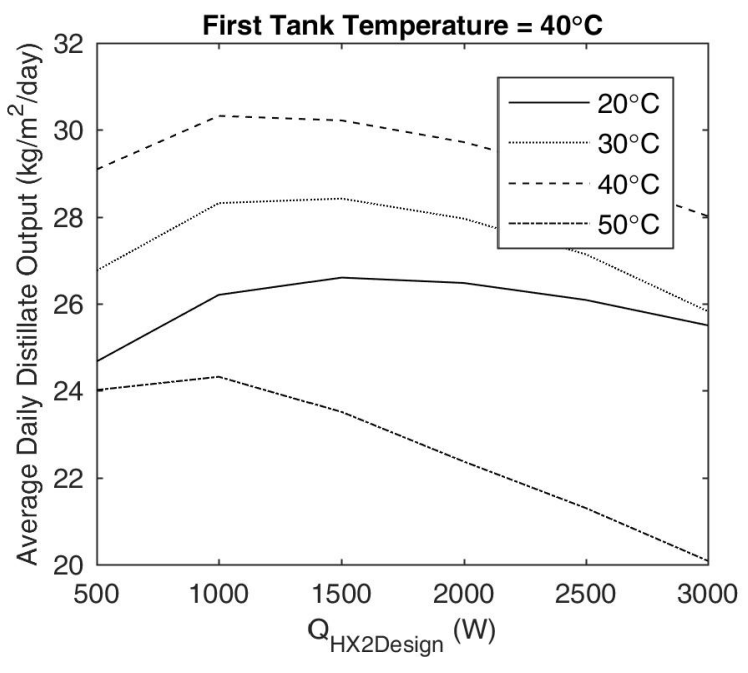

(a)

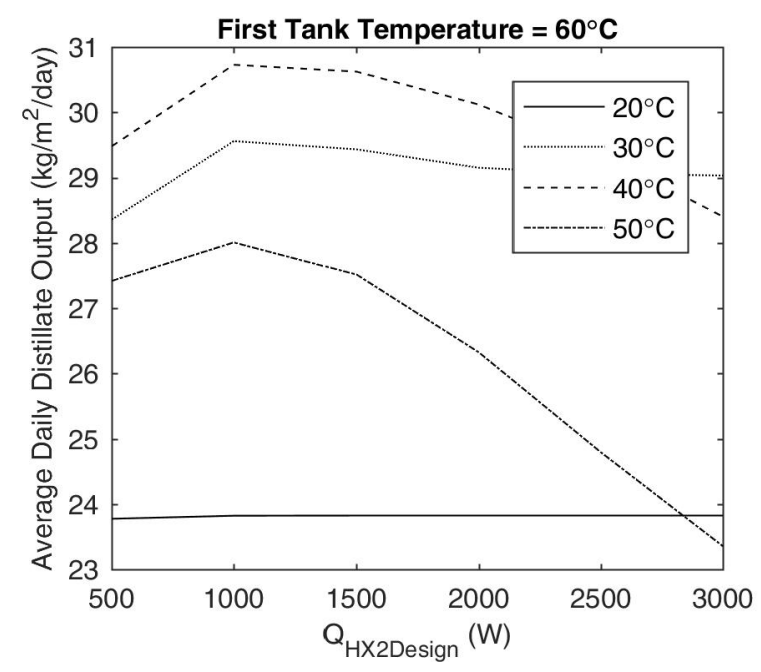

(c)

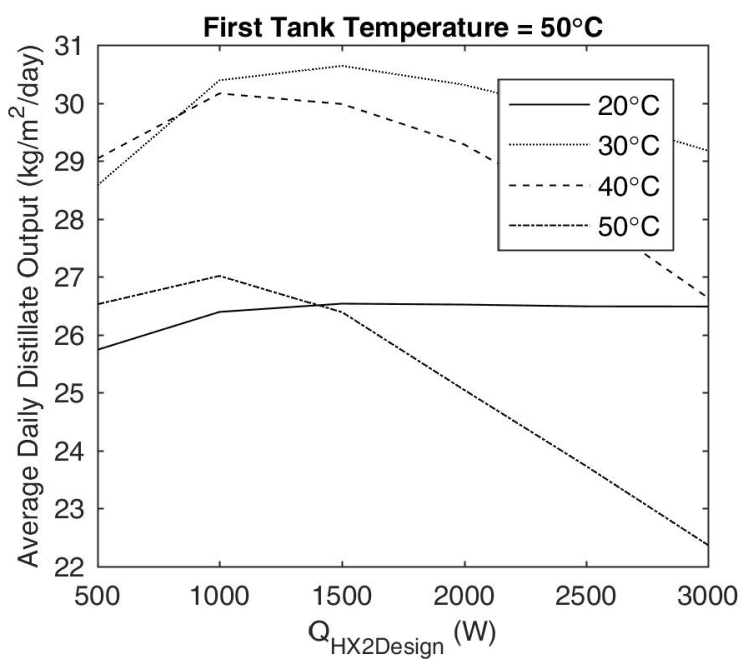

(b)

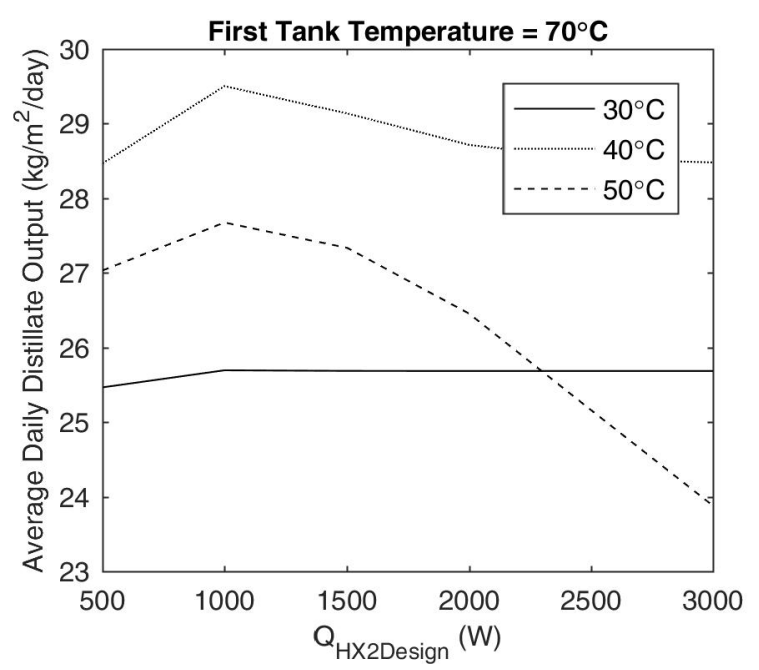

(d)

Figure 3-5: Average Daily Distillate Output per Unit Panel Area vs Design Heat Extraction Rate through HX2 with Desalination First Tank Temperatures: (a) $40^{\circ} \mathrm{C}$, (b) $50^{\circ} \mathrm{C}$, (c) $60^{\circ} \mathrm{C}$, (d) $70^{\circ} \mathrm{C}$

In Figure 3-5, the design heat extraction rate from the thermal storage tank is the parameter shown on the horizontal axis and the average daily distillate output per unit solar collector area is shown on the vertical axis. Finally, each curve in Figure 3-5 represents a different minimum thermal storage tank set point temperature. 
The optimal design heat extraction rate from the thermal storage tank for each thermal storage tank minimum temperature corresponds to the maximum of each curve in Figure 3-5. For example, when the desalination system first tank saturation temperature is $50^{\circ} \mathrm{C}$, the optimal distillate output is $30.6 \mathrm{~kg} / \mathrm{m}^{2} /$ day. This optimal output is shown on the " $30^{\circ} \mathrm{C}$ " curve, which is the optimal curve when the first tank in the desalination process is $50^{\circ} \mathrm{C}$. The corresponding design heat transfer rate from the thermal storage tank is approximately 1500 Watts for this output.

The trends in each curve result from the complex relationships between the parameters in the system. For example, as the minimum temperature of the thermal storage tank is increased, the saturation temperature of the evaporators in loop RB are also increased. This results in the saturation temperatures of the evaporators in loop RB being closer to the saturation temperature of the condenser in loop RB. This decreasing temperature difference improves the loop RB coefficient of performance (COP). However, the increased saturation temperatures of the evaporators in loop RB also results in an increased temperature of the condenser in loop RA, which lowers the COP of loop RA. Therefore, balancing these competing effects will result in an optimal system.

The relationship between the design heat extraction rate from the thermal storage tank also has a complex effect on the cycle performance. When the design heat extraction rate is below the optimal value, the evaporator contained within the thermal storage tank cannot follow the heat input by the solar collector. Referring to Figure 3-2, this situation results in a more frequent than optimal use of loop RA, which operates at a lower COP than loop RB, and still requires the loop RA heat to pass through loop RB. Therefore, when a below optimal design heat extraction rate is selected, there is a double penalty. However, when the design heat extraction rate is too large, the temperature of the thermal storage tank begins to fall below the minimum allowable temperature 
because of the large heat extraction rate, which results in the system turning off. Therefore, these competing effects must also be balanced in an optimal system.

The optimal curve for each desalination first tank temperature plot was selected using the process that was previously described. These optimal curves were then combined and are plotted in Figure 3-6.

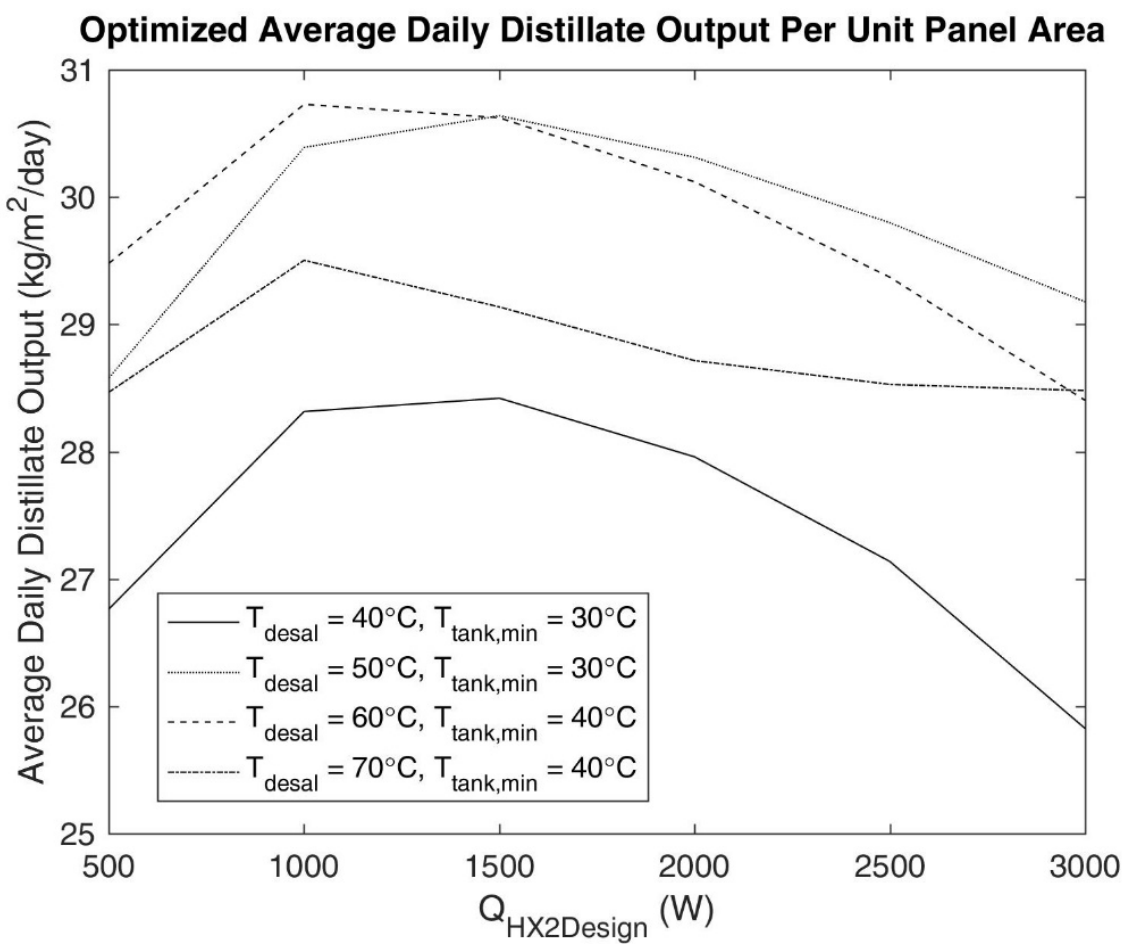

Figure 3-6: Average Daily Distillate Output per Unit Panel Area vs Design Heat Extraction Rate through HX2 (Optimized Curves)

Each of the curves in Figure 3-6 represents the output when the optimal thermal storage tank minimum temperature is selected for different saturation temperatures of the first tank in the 
desalination process. Therefore, the optimal curve in Figure 3-6 represents the system's overall optimal operating condition.

Given the study's selected weather location, the optimal operating condition for the system occurs when the desalination first tank saturation temperature is set to $60^{\circ} \mathrm{C}$. This desalination first-tank saturation temperature results in rejected brine with a salinity increase of approximately $1.6 \mathrm{psu}$, which is considered acceptable from an environmental standpoint [46]. The corresponding thermal storage tank minimum temperature is $40^{\circ} \mathrm{C}$, and the design heat extraction rate through HX2 is approximately 1100 Watts. The resulting distillate output is then approximately 30.7 $\mathrm{kg} / \mathrm{m}^{2} /$ day. The system operates during $47 \%$ of the time-steps annually, with $40 \%$ of the operational steps being in the limited electricity state, and $60 \%$ of the operational time-steps being fully operational.

\subsubsection{Comparisons with Existing Technologies}

A summary table that presents the area based efficiencies of the systems that were introduced in Section 3.1.2, along with the efficiency of the proposed system is given in Table 3-3. 
Table 3-3: Efficiency Summary of Solar Energy Driven Desalination Technologies

\begin{tabular}{|c|c|c|c|}
\hline Method & Location & $\begin{array}{c}\text { Typical } \\
\text { Distillate Output } \\
\left(\mathrm{kg} / \mathrm{m}^{2} / \text { day }\right)\end{array}$ & $\begin{array}{c}\text { Improvement } \\
\text { Compared to } \\
\text { Basic Still (\%) }\end{array}$ \\
\hline Basic Solar Still & $\begin{array}{c}\text { Daytona Beach, } \\
\text { USA }\end{array}$ & $3.5[25]$ & -- \\
\hline $\begin{array}{c}\text { Solar Still with } \\
\text { Rotating Cylinder }\end{array}$ & Beirut, Lebanon & $9[27]$ & $160 \%$ \\
\hline $\begin{array}{c}\text { Carbon Paper } \\
\text { Solar Still }\end{array}$ & Buffalo, USA & $18.5[28]$ & $430 \%$ \\
\hline $\begin{array}{c}\text { Portable Solar } \\
\text { Powered } \\
\text { Membrane }\end{array}$ & $\begin{array}{c}\text { Riyadh, Saudi } \\
\text { Arabia }\end{array}$ & $2.6[30]$ & $57 \%$ \\
\hline $\begin{array}{c}\text { Photovoltaic } \\
\text { Reverse Osmosis }\end{array}$ & Phoenix, USA & $216[31]$ & $6070 \%$ \\
\hline Proposed System & Phoenix, USA & 30.7 & $780 \%$ \\
\hline
\end{tabular}

Based on the results shown in Table 3-3 it can be seen that the model predicts that the proposed system has a distillate output per unit of solar collector area improvement of $780 \%$ when compared to the basic solar still. Similarly, compared to the carbon paper solar still, which is the next leading thermally-driven solar distillation system, an improvement of $65 \%$ is exhibited. These improvements in distillate output would help combat the main issue with solar still technologies, which is that they take up prohibitively large amounts of land. However, the basic and carbon paper stills both quote low setup and maintenance costs, since they can be passive systems.

When a photovoltaic reverse osmosis system is compared with the model's predictions for the proposed system, the model predicts approximately one seventh of the distillate output per unit of solar collector area based upon the assumptions given in Section 3.1.2. However, to reiterate, reverse osmosis systems have large start-up costs, require more maintenance, and are subject to sensitivity to the quality of the feed water for their performance [25]. 
Once the proposed system is in production it is expected to be economically viable compared to other portable, solar powered, desalination systems. The energy collection method that is proposed contains many similar components incorporated in other portable systems described in the literature, as discussed in Section 3.1.2, and the added cost of the additional heat pump components is expected to be low in comparison to the cost of the solar collectors, and the associated benefits. Finally, the capital and maintenance costs associated with MED systems is typically lower than those for RO systems, which also supports the anticipated economic viability.

\subsection{Conclusions}

One possible solution worth exploring to the problem of water scarcity is to desalinate ocean water such that it can be consumed. However, most desalination techniques today rely on conventional energy sources, require highly skilled labour, or require extensive existing infrastructure to operate. The proposed solution uses solar energy to distill ocean water, which is typically abundant in areas with water scarcity. PVT panels, coupled with heat pumps, were selected as the energy collection method because they can provide heat efficiently over a suitable temperature range. A double heat pump loop system was selected as the final configuration of the heat input system because it results in an increased thermodynamic efficiency compared to a single heat pump loop configuration. The system is designed to be an off-grid solution, and will be a small scale installation that can fit into a standard shipping container. The system was also designed such that highly skilled labour would not be required for its operation or maintenance, as is the case with reverse osmosis systems. 
A model has been developed that carries out a time-stepping analysis of the proposed system. The overall goal of the model was to determine the distillate output of the proposed system given different operating conditions. The model used a time-stepping method, which involved solving systems of linear and non-linear equations. The equations used in the model were based on the first-law of thermodynamics, along with manufacturer's data for the selected solar collector.

The model predicts that the optimized average daily distillate output, normalized by the solar collector area, is $30.7 \mathrm{~kg} / \mathrm{m}^{2} /$ day. This output rate is approximately $780 \%$ more than a basic solar still's area normalized daily output rate. These results assume that the system operates in Phoenix, Arizona, USA, with an array of Solimpeks PowerTherm PVT solar collectors. Experimental validation of the model will be carried out to verify and improve the model's accuracy. 


\section{Chapter 4 Detailed Modeling of a Novel Photovoltaic Thermal Cascade Heat Pump Domestic Water Heating System}

This chapter is based on the following journal manuscript:

J. P. Fine, J. Friedman and S. B. Dworkin, "Detailed modeling of a novel photovoltaic thermal cascade heat pump domestic water heating system," Renewable Energy, no. 101, pp. 500-513, 2017.

\subsection{Introduction}

The use of solar energy for water heating is becoming more popular as the cost of solar collectors fall and concerns over greenhouse gas (GHG) emissions increase around the world. However, most solar water heating systems still require an auxiliary heat source since the temperature of the fluid emerging from the solar collector may not meet the required hot water supply temperature $[47,48,49]$. Alternatively, if a system is set up such that the outlet temperature of the fluid from the collector is constrained to be sufficient for hot water production, the system will operate with lower thermal efficiency.

Along with investigations into using solar energy for domestic hot water production, there are also several ongoing studies investigating the use of heat pump systems for domestic water heating. However, in cold climates, the coefficient of performance of these heat pump systems are diminished because of the large temperature differences between the evaporating and condensing heat exchangers in these systems $[50,51]$. Therefore, a novel solution to low system efficiencies is discussed in this paper.

This novel solution implements a hybrid photovoltaic thermal (PVT) collector, coupled with two heat pump loops, which are in a cascade arrangement. The electrical energy generated 
by the solar collector is used to power the compressors in both of the heat pumps, and the heat pumps upgrade the temperature of the thermal energy generated by the solar collector, along with a secondary low quality heat source

First, a review of existing studies into solar collector heat pump systems will be presented in Section 4.2. In Sections 4.3 and 4.4, the PVT cascade heat pump system, and the analysis technique developed to analyze this system, will be presented. Finally, the results of a comparative case study between a conventional solar water heating system and the PVT heat pump system will be presented in Section 4.5.

\subsection{Heat Pump Solar Collecting System Review}

An investigation into existing methods for coupling heat pumps with solar collectors was carried out at the beginning of this study. Four different methods were identified during this literature review, which are photovoltaic powered heat pumps, solar assisted heat pumps, separate consumption PVT heat pumps, and simultaneous consumption PVT heat pumps. These methods will be discussed below.

\subsubsection{Photovoltaic Powered Heat Pumps}

The first method involves powering the compressor in a heat pump cycle with a PV panel $[2,13]$. These systems do not utilize the waste heat generated on the solar collector, and only use the solar collector as an electrical energy source. A study carried out by Izquierdo et al. [13] used 
a PV panel to charge a battery, which then powered a compressor in a heat pump cycle. One drawback to this system is that there is wasted thermal energy generated by the PV panel, which not only could be harnessed, but also causes the temperature of the PV panel to rise, resulting in lower PV electrical energy outputs [32]. Another drawback of this system is the inefficiency associated with charging and discharging the system's battery [52]. Overall, a heat output equal to $18 \%$ of the incident solar irradiation was realized at the condenser in this system [13].

\subsubsection{Solar Assisted Heat Pump}

The second method involves the use of a solar thermal collector as a thermal energy source for a heat pump cycle $[2,14,53]$. These systems can use the solar thermal collector as the primary thermal energy source, or as a secondary thermal energy source. This system type does not include $\mathrm{PV}$ cells, and therefore the electrical power supplied to the compressor must be provided by an external source. A reduction in external electrical energy consumption of $12 \%$ can be realized when using this system type for domestic hot water production [53].

\subsubsection{Separate Consumption PVT Heat Pump}

The third method involves the use of a PVT panel, but the heat pump cycle only utilizes the thermal energy from the panel, while the electrical energy generated by the panel is consumed by an external system, and the electricity that powers the compressor is provided from another external system $[32,33,34,35]$. These systems attempt to optimize both the thermal and electrical energy outputs of the PVT panel, but these energy streams are consumed by separate systems. 
These systems can operate with refrigerant flowing through the PVT panel, which results in the PVT panel acting as the evaporator in the heat pump cycle. Alternatively, a non-evaporating working fluid can be passed through the PVT panel, and the refrigerant in the heat pump can be evaporated in a second heat exchanger. The research being carried out on these systems is concerned with optimization of the detailed mechanical design of the PVT panel, such that optimal thermal and electrical energy extraction can occur $[32,33,34,35]$. Finally, studies show that $40-$ $60 \%$ of the total solar energy incident on the solar collector can be used with this system arrangement [34].

\subsubsection{Simultaneous Consumption PVT Heat Pump}

The fourth method involves using a PVT panel to provide both thermal energy and electrical energy to a heat pump cycle $[36,37,38]$. The system being investigated by Zhang et al. [36] couples a heat pump with an array of PVT panels, and the compressor in the heat pump is powered directly from the array's generated electricity. The electrical energy consumption of the heat pump compressor is entirely dependent on the useful thermal energy produced by the PVT panel, along with the selected working fluid states in the heat pump loop. In cases where all available thermal energy from the panel is extracted, and excess electrical energy remains, Zhang et al. anticipate that the excess electricity will be sold to the grid, or stored in a battery [36]. The main drawback of this system, compared to the three previously mentioned methods, is its complexity. Another drawback is that in systems where the excess electricity cannot be used externally, it would be wasted. However, Zhang et al. have shown that this system has 
environmental and economic benefits, and can produce a heat output equal to $50 \%$ of the incident solar irradiation at its condenser [37, 38].

The design discussed in this paper builds on the simultaneous consumption PVT heat pump system proposed by Zhang et al. by adding a secondary heat pump loop. The use of two heat pump loops is a novel system arrangement, and allows for system parameter optimization to maximize thermal energy output [17]. The feasibility of this system is supported by the common and successful implementation of cascade heat pumps in industry [50], along with the successful implementation of the simultaneous consumption PVT heat pump system by Zhang et al. [36].

\subsection{PVT Cascade Heat Pump System Design}

The PVT cascade heat pump system in this study uses both the heat and electrical energy generated by the PVT panel in the heat pump. However, unlike the PVT heat pump system mentioned in Section 4.2.4, the system in this paper contains a secondary heat pump loop. The addition of a secondary heat pump loop allows for all of the electrical energy generated by the PVT panel to be usefully consumed within the system, instead of wasting energy, relying on a battery for electrical energy storage, or relying on a grid connection for energy sale [17]. A schematic of the PVT cascade heat pump system is shown in Figure 4-1. 


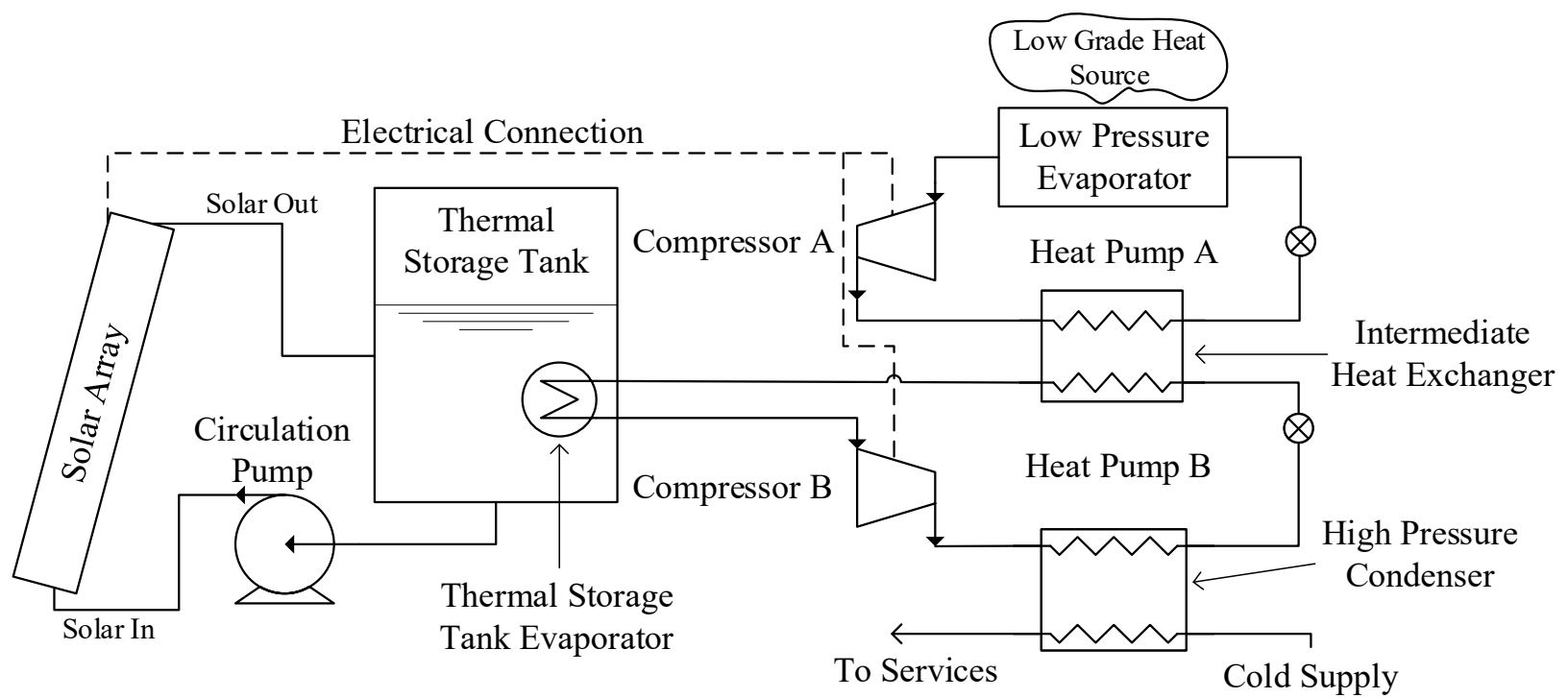

Figure 4-1: PVT Heat Pump System with Component Labels

A coolant fluid is circulated through the PVT array, which extracts thermal energy and adds it to the thermal storage tank. The coolant is assumed to circulate only when the thermal efficiency of the array is greater than zero, and it operates using an on/off control scheme. Therefore, the flowrate through the panel is either zero, or a constant value that is determined based on manufacture guidelines. The thermal energy that is injected into the thermal storage tank then causes the temperature of the tank to increase, while the mass of fluid within the tank is kept constant.

A heat pump loop (heat pump B) evaporator contained within the thermal storage tank is used to extract heat from the thermal storage tank. This evaporator is assumed to be maintained at a constant pressure, and therefore its evaporation temperature can be taken as constant. It follows that heat can only be removed from the thermal storage tank when the temperature of the tank is sufficiently above this constant evaporator temperature, which is defined as the minimum thermal 
storage tank temperature. When the thermal storage tank is below this minimum temperature, the heat pump loops are deemed inoperable.

At times when the thermal storage tank is at or above the minimum temperature, the heat pump loops become operational. The compressors in each heat pump loop are assumed to be powered directly from the electrical energy generated by the PVT array. Heat pump loop B is given priority to consume this electrical energy, which results in scenarios where only loop B is operating if there is not enough electricity to also power loop A. However, at times when there is sufficient electrical power for both heat pump loops, then heat is taken from another low temperature heat source through a low pressure evaporator. This heat source can be the ambient environment, a geoexchange loop, or any other freely available low-grade heat source.

The heat from heat pump loop A is passed into heat pump loop B through the intermediate heat exchanger, which acts as the condenser for loop A and an evaporator for loop B. This heat, along with the heat from the thermal storage tank, passes though heat pump loop B, and is then used to heat water for domestic purposes at the condenser in loop B.

Since variable speed compressors are used in both heat pump loops, the mass flow rates of refrigerant in each heat pump loop are assumed to be variable, and are proportional to the electrical energy supplied to each heat pump loop's compressor. The mass flow rate of the cold supply water through the high pressure condenser in heat pump loop B is assumed to be sufficient to maintain thermal equilibrium within the system, based on the selected refrigerant states. Finally, the refrigerant used in the heat pump loops can be the same, or different, and would be selected based on the conditions in which the system will operate. 


\subsection{Analysis Technique}

The analysis of the PVT heat pump system was carried out using a time-stepping method. System equilibrium and constant system parameters were assumed during each time-step in the analysis. The schematic shown in Figure 4-2 includes labelled state locations, which will be used in the proceeding analysis description.

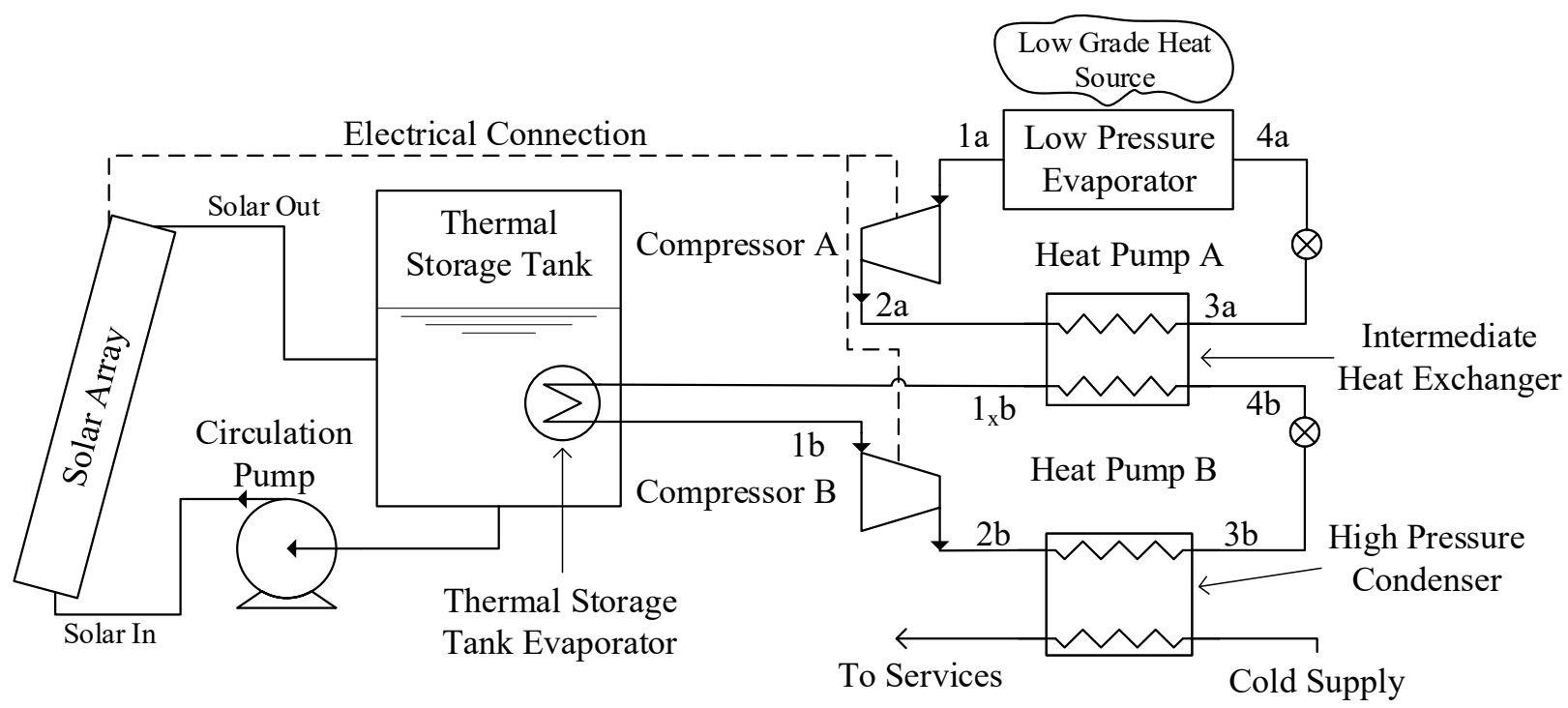

Figure 4-2: Cascade PVT Heating System Schematic

\subsubsection{Setting the System Parameters}

To begin the analysis, the geographical location of the simulated site must be selected. The local latitude $\left(L_{\text {local }}\right)$, and longitude $\left(l_{\text {local }}\right)$ must be determined. The longitude of the local standard time meridian $\left(l_{S T}\right)$ must also be determined. Weather data for the selected simulation 
site must be acquired, which must include the hourly total horizontal irradiation $\left(I_{h}\right)$, diffuse horizontal irradiation $\left(I_{d, h}\right)$, direct beam irradiation $\left(I_{b, n}\right)$, and air dry-bulb temperature $\left(T_{a}\right)$.

Next, the total solar collector area $(A)$, collector cooling fluid flow rate $\left(\dot{m}_{f}\right)$, solar collector array tilt angle from horizontal $(\beta)$, and the solar collector array azimuth angle $\left(a_{w}\right)$ must be set. The minimum operating temperature for the thermal storage tank $\left(T_{\text {tank }_{\text {min }}}\right)$, the design heat transfer rate for the evaporator within the thermal storage tank $\left(\dot{Q}_{H X 2_{\text {design }}}\right)$, and the thermal storage tank thermal mass $\left(m c_{p_{\text {tank }}}\right)$ are also set at this point.

Since heat pumps are required in the design, the heat pump refrigerant type must be set, along with the selection of the saturation temperatures for each of the heat exchangers within the heat pump loops. The desired degree of superheat of the refrigerant at the state before the compressor in each heat pump loop (i.e. states $1 a$ and $1 b$ in Figure 4-2), and the degree of subcooling of the refrigerant at the state exiting the condenser (i.e. states $3 a$ and $3 b$ in Figure 4-2), must also be set. Finally, the third-order compressor performance coefficients, along with the state information for the manufacturer test data, must be determined from manufacturer data for each of the compressors used in the system.

\subsubsection{Defining the "Map" and "Design" Systems}

The third-order compressor performance coefficients used in this analysis follow ANSI/AHRI standard 540 [54], and are used in a polynomial fit to compressor performance data based on manufacturer mapping tests. These tests are typically conducted using a prescribed amount of superheating and sub-cooling in the heat pump process, and the predicted compressor 
performance that is generated from the provided polynomial fit will effectively assume the same amounts of superheating and sub-cooling. Therefore, the compressor performance and corresponding heat pump state information that is found by directly using the manufacturer provided polynomial fits are referred to as the "map" system parameters because they inherently assume the same amounts of superheating and sub-cooling that the manufacture mapping tests assume.

However, the system parameter assumptions that generated the "map" states may differ from those that are desired. To account for these differences, an adjustment to the "map" compressor performance parameters can be carried out. This adjustment of the "map" performance parameters produces results that correspond to the desired system's design, and are therefore defined as the "design" system parameters.

\subsubsection{Determining Heat Pump Cycle Enthalpies}

Using the system parameters that were set in Section 4.4.1, the enthalpies of the refrigerant through the heat pump loops can be found. As shown in Figure 4-3, State 1 is defined as the state of the refrigerant before it enters the compressor, State 2 is defined as the state of the refrigerant as it exits the compressor, State 3 is defined as the state of the refrigerant as it exits the condenser, and State 4 is defined as the state of the refrigerant as it exits the throttling valve. Pressure changes through heat exchangers, along with the enthalpy changes through the piping that connects each component, are neglected in this analysis [55]. 


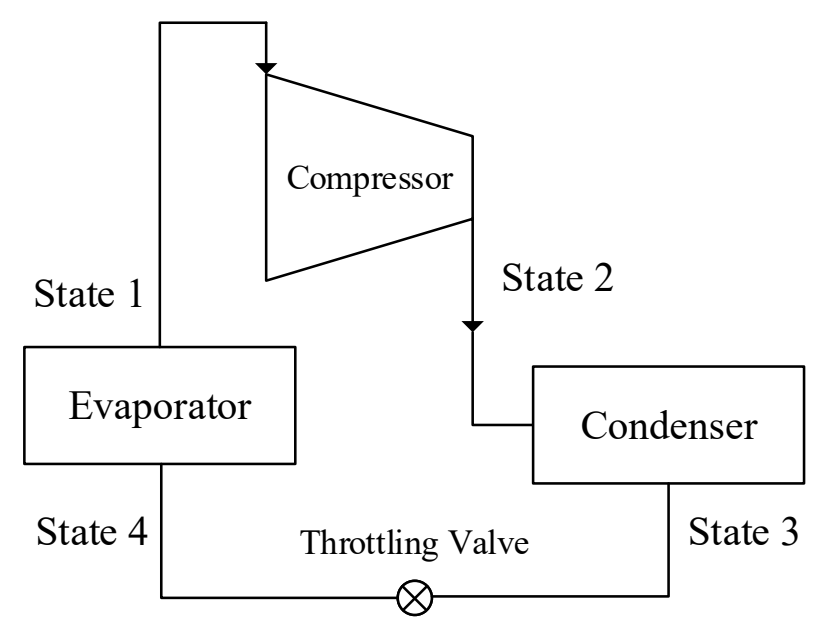

Figure 4-3: Heat Pump Schematic with Labelled States

Using the saturation temperatures that were set in Section 4.4.1, state information is found for both heat pump loops in the system. This state information must be found for both the mapped system, using "map" system state specifications, and design system, using "design" system state specifications. In the discussions that follow, since state parameters must be found for both the "design" and "map" systems, the subscript "sys" is used as a placeholder for "design" or "map" in variable subscripts.

If there is no superheating for State 1, then the enthalpy at State 1 must be found using Equation (4-1). However, if there is superheating, then Equation (4-2) must be used. Next, using the State 1 enthalpy result, Equations (4-3) and (4-4) can be used to find the density and specific entropy at State 1, respectively.

$$
\begin{aligned}
& h_{1_{\text {sys }}}=h\left(P_{\text {evap }}, x_{\text {sys }}\right) \\
& h_{1_{\text {sys }}}=h\left(P_{\text {evap }}, T_{1_{\text {sys }}}\right)
\end{aligned}
$$




$$
\begin{aligned}
& \rho_{1_{\text {sys }}}=\rho\left(P_{\text {evap }}, h_{1_{\text {sys }}}\right) \\
& s_{1_{\text {sys }}}=s\left(P_{\text {evap }}, h_{1_{\text {sys }}}\right)
\end{aligned}
$$

where $h_{1_{\text {sys }}}$ is the specific enthalpy at State 1 for the corresponding system (i.e. the "design" or "map" system), $P_{\text {evap }}$ is the saturation pressure at State $1, x_{s y s}$ is the vapour quality at State 1 for the corresponding system, $T_{1_{\text {sys }}}$ is the temperature at State 1 for the corresponding system, $\rho_{1_{\text {sys }}}$ is the density at State 1 for the corresponding system, and $s_{1_{\text {sys }}}$ is the specific entropy at State 1 for the corresponding system.

Next, the isentropic State 2 must be found for both the design system, and the map system, using Equation (4-5).

$$
h_{2 s_{\text {sys }}}=h\left(P_{\text {cond }}, s_{1_{\text {sys }}}\right)
$$

where $h_{2 s_{\text {sys }}}$ is the specific enthalpy of the isentropic State 2 for the corresponding system, and $P_{c o n d}$ is the saturation pressure of the refrigerant in the condenser. The isentropic State 2 represents the specific enthalpy of the working fluid after being compressed from the evaporator saturation pressure to the condenser saturation pressure, with constant entropy.

The mapped compressor power consumption and mass flow rate are calculated at this point. This calculation is completed using Equation (4-6), and using the compressor performance coefficients that were previously acquired from manufacturer data. 


$$
\begin{gathered}
X_{\text {map }}=C_{1}+C_{2} S+C_{3} D+C_{4} S^{2}+C_{5} S D+C_{6} D^{2}+C_{7} S^{3} \\
+C_{8} D S^{2}+C_{9} S D^{2}+C_{10} D^{3}
\end{gathered}
$$

where $X_{\text {map }}$ is the parameter being calculated (i.e. mapped power consumption $\left(\dot{W}_{\text {map }}\right)$ or mapped mass flow rate $\left.\left(\dot{M}_{\text {map }}\right)\right), S$ is the saturation temperature of the refrigerant on the suction side of the compressor, $D$ is the saturation temperature of the refrigerant on the discharge side of the compressor, and $C_{1}, C_{2}, \ldots, C_{10}$ are the corresponding compressor performance coefficients for the given parameter $X_{\text {map }}$.

Since the performance parameter that was calculated using Equation (4-6) corresponds to the performance at the mapped state, the previously mentioned adjustment to the performance parameter must be made. To complete this adjustment a new mass flow rate must first be calculated using Equation (4-7) [56].

$$
\dot{M}_{\text {design }}=\dot{M}_{\text {map }} \times\left(1+F\left(\frac{\rho_{1_{\text {design }}}}{\rho_{1_{\text {map }}}}-1\right)\right)
$$

where $\dot{M}_{\text {design }}$ is the adjusted mass flow rate for the design system, and $F$ is a chosen percentage of the theoretical mass flow rate increase. The chosen percentage of the theoretical mass flow rate increase can be taken as 0.75 based on findings in the literature [56].

Using the adjusted mass flow rate, and previously determined enthalpy values, a modified compressor power consumption can be found using Equation (4-8) [56].

$$
\dot{W}_{\text {mod }}=\dot{W}_{\text {map }} \times\left(\frac{\dot{M}_{\text {design }}}{\dot{M}_{\text {map }}}\right)\left(\frac{h_{2 s_{\text {design }}}-h_{1_{\text {design }}}}{h_{2 s, \text { map }}-h_{1, \text { map }}}\right)
$$


where $\dot{W}_{\text {mod }}$ is the modified compressor power consumption for the design system.

The result of Equation (4-8) typically over-predicts the change in power consumption from the mapped system to the design system by about $48 \%$, based on experimental data found in the literature [56]. According to Dabiri et al. [56], this over-prediction occurs because State 1, which is equal to the state at the evaporator outlet and compressor shell inlet, is used in Equation (4-8). However, more accurate results can be achieved if the state at the compressor suction port is used instead. The calculation of the state at the compressor suction port requires additional information about the compressor being analyzed, which is not typically available, and therefore the less accurate state value was selected for use in Equation (4-8). Therefore, a generalized correction to alleviate this over-prediction was used in this analysis, and is shown in Equation (4-9).

$$
\dot{W}_{\text {design }}=\dot{W}_{\text {map }}+\left(\dot{W}_{\text {mod }}-\dot{W}_{\text {map }}\right) \times 0.52
$$

where $\dot{W}_{\text {design }}$ is the corrected compressor power consumption.

At this point, the actual specific enthalpy of the working fluid after the compressor for the design system can be found using Equation (4-10).

$$
h_{2_{\text {design }}}=\left(\frac{\dot{W}_{\text {design }}}{\dot{M}_{\text {design }}}\right)+h_{1_{\text {design }}}
$$

where $h_{2 \text { design }}$ is the specific enthalpy of the working fluid after the compressor for the design system. 
It is prudent to check that the isentropic efficiency of the compressor does not exceed unity since this would indicate an error in the preceding analysis. The isentropic efficiency of the compressor in the corresponding system $\left(\eta_{s y s}\right)$ can be found using Equation (4-11).

$$
\eta_{s y s}=\frac{h_{2 s_{\text {sys }}}-h_{1_{\text {sys }}}}{h_{2_{\text {sys }}}-h_{1_{s y s}}}=\frac{h_{2 s_{\text {sys }}}-h_{1_{\text {sys }}}}{\dot{W}_{\text {sys }} / \dot{M}_{\text {sys }}}
$$

Now, the specific enthalpy of the working fluid at State 3 in the design system $\left(h_{3_{\text {design }}}\right)$ must be found using Equation (4-12) if there is no sub-cooling, or Equation (4-13) if there is subcooling.

$$
\begin{aligned}
& h_{3_{\text {design }}}=h\left(P_{\text {cond }}, x_{3_{\text {design }}}\right) \\
& h_{3_{\text {design }}}=h\left(P_{\text {cond }}, T_{3_{\text {design }}}\right)
\end{aligned}
$$

where $x_{3_{\text {design }}}$ is the quality of the working fluid at State 3 in the design system, and $T_{3 \text { design }}$ is the temperature of the working fluid at State 3 in the design system.

The last state in each heat pump loop, State 4, has the same specific enthalpy as State 3 (i.e. $h_{4 \text { design }}=h_{3_{\text {design }}}$ ). This equality is used because it is assumed that the throttling process from State 3 to State 4 is a constant enthalpy process [15]. 


\subsubsection{Time Dependent Parameter Calculations}

Once all location and heat pump enthalpy parameters are determined for the system, the time dependent parameters can be calculated. To begin this process, the initial conditions for the system must be set. The system is assumed to not operate during the first simulation time-step, and therefore the mass flow rates in all heat pump loops are set to zero (i.e. $m_{A_{1}}=m_{B_{1}}=0$ ). The temperature of the thermal storage tank, along with the solar panel fluid inlet, and outlet temperatures, are all set to the minimum thermal storage tank temperature (i.e. $T_{t a n k_{1}}=T_{i n_{1}}=$ $T_{\text {out }}=T_{\text {tank }_{\text {min }}}$, respectively).

Following setting the initial conditions for the system, the iterative segment of the simulation can begin. The goal of the following calculations is to determine the thermal storage tank temperature $\left(T_{\text {tank }}\right)$, and heat energy output from the condenser in loop B $\left(Q_{\text {cond }_{b}}\right)$ for each time-step in the simulation. Therefore, the proceeding parameters must all be determined at each time-step until the simulation is complete.

The process begins by first checking if there is solar irradiation at the current time-step. This determination is completed by checking if direct beam solar irradiation is present at the current time-step, based on the input weather data (i.e. check if $I_{b, n_{i}}>0$ ). If there is no direct beam irradiation, then the system does not operate, resulting in the heat output from the condenser in loop B being zero at the current time-step, and the thermal storage tank being set to the temperature from the previous time-step. The next time-step can then be started by again checking if direct beam solar irradiation is present. 
If there is direct beam solar irradiation present at the current time-step, the calculation of all system parameters is carried out. This calculation begins by first determining the solar altitude angle $(\alpha)$ and solar azimuth angle $\left(\alpha_{s}\right)$, which are shown in Figure 4-4.

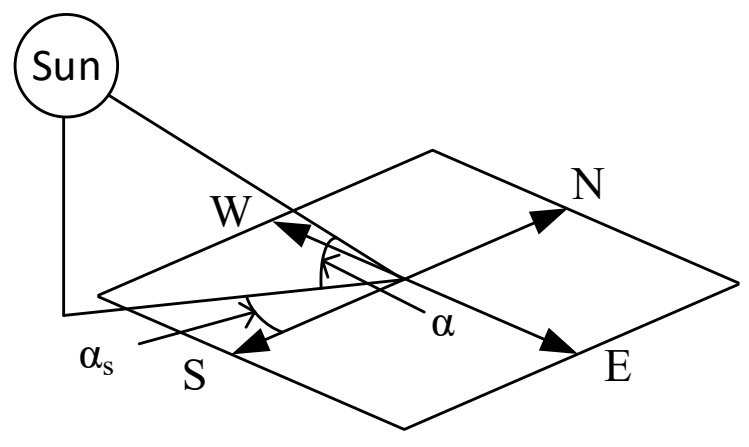

Figure 4-4: Sun Angle Diagram

To determine the solar altitude and azimuth angles, the solar declination angle $\left(\delta_{s_{\mathrm{i}}}\right)$ must first be determined using Equation (4-14) [57].

$$
\delta_{s_{\mathrm{i}}}=23.45^{\circ} \sin \left(360^{\circ} \times \frac{284+n_{i}}{365}\right)
$$

where $n_{i}$ is the day number at the current time-step. For the day number, January $1^{\text {st }}$ is defined as $n=1$.

At this point, the value of the equation of time $\left(E T_{i}\right)$ at the current time-step must be determined using Equation (4-15) and Equation (4-16) [57].

$$
E T_{i}=9.87 \sin \left(2 B_{i}\right)-7.53 \cos \left(B_{i}\right)-1.5 \sin \left(B_{i}\right)
$$




$$
B_{i}=360^{\circ} \times\left(\frac{n_{i}-81}{364}\right)
$$

Next, the solar time at the current time-step $\left(S T_{i}\right)$, which is the number of minutes before or after local solar noon, based on the standard time clock, must be determined using Equation (417) [57].

$$
S T_{i}=L S T_{i}+E T_{i}+\left(l_{S T}-l_{\text {local }}\right) \times 4\left(\frac{\text { minutes }}{\text { degree }}\right)
$$

where $L S T_{i}$ is the local standard time at the current time-step, $l_{S T}$ is the longitude at the local corresponding standard time meridian, and $l_{\text {local }}$ is the local longitude. Equation (4-17) assumes that a location in the Western hemisphere is used, and that Western longitude values are positive. Finally, for both the solar time and local standard time, a negative value is used at times before local solar noon, and a positive value is used at times after local solar noon.

The solar altitude angle at the current time-step $\left(\alpha_{i}\right)$ can now be found using Equation (418) [57].

$$
\sin \left(\alpha_{i}\right)=\sin (L) \times \sin \left(\delta_{s_{\mathrm{i}}}\right)+\cos (L) \times \cos \left(\delta_{s_{\mathrm{i}}}\right) \times \cos \left(\frac{S T_{i}}{4}\right)
$$

where $L$ is the local latitude.

The solar azimuth angle at the current time-step $\left(\alpha_{s_{i}}\right)$ can be found at this point by using both Equation (4-19) and Equation (4-20) [58]. 


$$
\begin{gathered}
\alpha_{s_{i}}=\operatorname{acos}\left[\frac{\sin (L) \sin \left(\alpha_{i}\right)-\sin \left(\delta_{s_{\mathrm{i}}}\right)}{\cos (L) \cos \left(\alpha_{i}\right)}\right] \\
\sin \left(\alpha_{s_{i}}\right)=\frac{\cos \left(\delta_{s_{i}}\right) \sin \left(\frac{S T_{i}}{4}\right)}{\cos \left(\alpha_{i}\right)}
\end{gathered}
$$

Two redundant equations are required to determine the solar azimuth angle such that the quadrant that the angle lies in can be determined. If the result of Equation (4-20) is positive, then the solar azimuth angle is set equal to the result of Equation (4-19). Alternatively, if the result of Equation (4-20) is negative, then the solar azimuth angle is set equal to the negative result of Equation (4-19).

Next, the angle between the solar collector array surface normal vector and the incident solar irradiation at the current time-step, which is defined as the solar incidence angle $\left(i_{c_{i}}\right)$, must be found using Equation (4-21) [57].

$$
i_{c_{i}}=\operatorname{acos}\left[\cos \left(\alpha_{i}\right) \cos \left(\alpha_{s_{i}}-a_{w}\right) \sin (\beta)+\sin \left(\alpha_{i}\right) \cos (\beta)\right]
$$

where $a_{w}$ is the panel azimuth angle, and $\beta$ is the panel tilt angle.

The total solar irradiation on the solar collector at the current time-step $\left(I_{c_{i}}\right)$ can be determined at this point. The total solar irradiation on the collector is composed of beam irradiation, diffuse sky irradiation, and reflected irradiation. The total collector irradiation can then be found based on this assumption using Equation (4-22).

$$
I_{c_{i}}=I_{b, n_{i}} \cos \left(i_{c_{i}}\right)+I_{d, h_{i}} \cos ^{2}\left(\frac{\beta}{2}\right)+\rho_{i} I_{h_{i}} \sin ^{2}\left(\frac{\beta}{2}\right)
$$


where $I_{d, h}$ is the diffuse horizontal irradiation at the current time-step from weather data, $\rho_{i}$ is the ground reflectivity at the current time-step from weather data, and $I_{h_{i}}$ is the total horizontal irradiation at the current time-step from weather data.

The total incident solar energy over the current time-step $\left(E_{i}\right)$ can be found at this point using Equation (4-23).

$$
E_{i}=I_{c_{i}} \times A \times \Delta t
$$

where $A$ is the total solar collector array absorber area, and $\Delta t$ is the time-step length.

Next, the fluid inlet temperature to the solar collector array at the current time-step $\left(T_{i n_{i}}\right)$, is set equal to the thermal storage tank temperature from the previous time-step, as shown in Equation (4-24).

$$
T_{\text {in } i}=T_{\text {tank }_{i-1}}
$$

where $T_{\text {tank }_{i-1}}$ is the temperature of the thermal storage tank from the previous time-step.

Next, the mean temperature of the solar collector array at the current time-step $\left(T_{m_{i}}\right)$ is found using Equation (4-25).

$$
T_{m_{i}}=\frac{T_{i n_{i}}+T_{\text {out }_{i-1}}}{2}
$$


where $T_{\text {out }}{ }_{i-1}$ is the temperature of the fluid exiting the solar collector array at the previous timestep.

The incident angle modifier (IAM) at the current time-step $\left(I A M_{i}\right)$, must now be found using the correlation provided by the panel manufacturer, and is a function of the solar incidence angle. This parameter represents the performance of the solar collector as a function of the solar incidence angle, and is required since many solar collectors exhibit varying performance given a constant solar flux and changing solar incidence angle. To determine the IAM, the angle between the panel normal and the diffuse radiation vector $\left(\theta_{d c}\right)$, along with the angle between the panel normal and the ground reflectance angle $\left(\theta_{g c}\right)$ must be determined using Equations (4-26) and (427) respectively [59].

$$
\begin{gathered}
\theta_{d c}=59.69-0.1388 \beta+0.001497 \beta^{2} \\
\theta_{g c}=90-0.5788 \beta+0.002693 \beta^{2}
\end{gathered}
$$

Next, the panel-dependant IAM value must be calculated for the beam, diffuse, and reflected radiation components of the incident radiation using Equation (4-28), which is the function that was derived for the Solimpeks PowerTherm PVT panel [41], and the datasheet for this solar collector is contained in the Appendix of this thesis.

$$
\begin{aligned}
I A M_{x, i}=- & 3.04 \times 10^{-8} \times\left|\theta_{i}\right|^{4}+2.63 \times 10^{-6} \times\left|\theta_{i}\right|^{3} \\
& -1.36 \times 10^{-4} \times\left|\theta_{i}\right|^{2}+2.02 \times 10^{-3} \times\left|\theta_{i}\right|+1
\end{aligned}
$$

where $I A M_{x, i}$ is the IAM component for each radiation component, and $\theta_{x, i}$ is the angle of interest for the IAM calculation. When determining the beam IAM (i.e. $I A M_{b c}$ ), $\theta_{i}$ is set to the solar 
incidence angle $\left(i_{c_{i}}\right)$. When determining the diffuse IAM (i.e. $\left.I A M_{d c}\right), \theta_{i}$ is set to the angle between the panel normal and the diffuse radiation vector $\left(\theta_{d c}\right)$. When determining the reflected radiation IAM (i.e. $I A M_{g c}$ ), $\theta_{i}$ is set to the angle between the panel normal and the ground reflectance angle $\left(\theta_{g c}\right)$.

Using the results of Equation (4-28), the overall panel IAM $\left(I A M_{i}\right)$ can be found using Equation (4-29) [59].

$$
I A M_{i}=\frac{I A M_{b c} I_{b, n}+I A M_{d c} I_{d, h}\left(\frac{1+\cos (\beta)}{2}\right)+I A M_{g c} \rho I_{h}\left(\frac{1-\cos (\beta)}{2}\right)}{I_{c}}
$$

When completing the IAM determination for an asymmetric solar collector, such as an evacuated tube collector, the transverse and longitudinal components of the incident radiation angle must also be considered and used with separate panel-dependant IAM correlations. To determine the transverse $\left(\theta_{b, t}\right)$ and longitudinal $\left(\theta_{b, l}\right)$ components of the incident beam angle, Equations (4-30) and (4-31) can be used [59]. The transverse components of the diffuse and ground angles are both equal to zero, and the longitudinal components of both of these angles are equal to the panel tilt angle.

$$
\begin{gathered}
\theta_{b, t}=\tan ^{-1}\left(\left|\frac{\sin \left(90-\alpha_{i}\right) \sin \left(\left|a_{w}-\alpha_{s}\right|\right)}{\cos \left(i_{c}\right)}\right|\right) \\
\theta_{b, l}=\left|\tan ^{-1}\left(\tan \left(90-\alpha_{i}\right) \cos \left(a_{w}-\alpha_{s}\right)\right)-\beta_{i}\right|
\end{gathered}
$$

Next, using the mean temperature of the solar array, along with correlations from manufacturer data, the electrical efficiency of the solar collector array at the current time-step $\left(\eta_{e_{i}}\right)$ 
can be found. Equation (4-32) is the function that was derived for Solimpeks PowerTherm PVT panel [9].

$$
\eta_{e_{i}}=I A M_{i} \times \frac{\left(186.6-0.6771 \times T_{m_{i}}\right)}{1400}
$$

After determining the electrical efficiency of the array, the thermal efficiency of the array at the current time-step $\left(\eta_{t h_{i}}\right)$ can be determined. The thermal efficiency is determined using a second order efficiency curve along with the panel reduced temperature $\left(T_{r_{i}}\right)$ at the current timestep. The panel reduced temperature is first determined using Equation (4-33).

$$
T_{r_{i}}=\frac{T_{m_{i}}-T_{a_{i}}}{I_{c_{i}}}
$$

where $T_{a_{i}}$ is the air dry bulb temperature at the current time-step from weather data.

Using the panel reduced temperature, the thermal efficiency of the array can be found using Equation (3-20), which is the function that was derived for the Solimpeks PowerTherm PVT panel [41].

$$
\eta_{t h_{i}}=I A M_{i} \times 0.493-4.086 \times T_{r_{i}}-0.068 \times I_{c_{i}} \times T_{r_{i}}^{2}
$$

In time-steps where the resulting array thermal efficiency is a negative value, the thermal efficiency is set to zero and the system is assumed to not operate. This case can occur when there is low thermal irradiation coupled with outdoor temperatures that are low compared to the panel temperature. 
Next, the total thermal energy generation $\left(E_{t h_{i}}\right)$ and electrical energy generation $\left(E_{e_{i}}\right)$ over the current time-step can be found using Equation (4-35) and Equation (4-36), respectively.

$$
\begin{gathered}
E_{t h_{i}}=\eta_{t h_{i}} \times E_{i} \\
E_{e_{i}}=\eta_{e_{i}} \times E_{i}
\end{gathered}
$$

Using the resulting thermal energy generated over a time-step, the outlet temperature of the fluid passing through the solar array over the current time-step $\left(T_{\text {out }}\right.$ ) can be determined with Equation (4-37).

$$
T_{\text {out }_{i}}=T_{i n_{i}}+\frac{E_{t h_{i}}}{\Delta t \dot{m}_{f} c_{p}}
$$

where $\dot{m}_{f}$ is the total mass flow rate of fluid through the solar collector array, and $c_{p}$ is the specific heat capacity of that fluid.

At this point, the heat extracted from the thermal storage tank over the time-step can be considered. Since the system is assumed to operate with a minimum thermal storage tank temperature, at times when the tank is below this temperature, the heat pump loops do not operate. This non-operating state results in the refrigerant total mass flows over the time-step in both heat pump loops A $\left(m_{A}\right)$ and B $\left(m_{B}\right)$ being set to zero. The amount of heat extracted through HX2 $\left(Q_{H X 2 a_{a c t u a l}}\right)$ and the amount of heat rejected through the condenser in loop B $\left(Q_{c_{c o n d}}\right)$ are then also set to zero. The temperature of the thermal storage tank at the current time-step $\left(T_{\text {tank }_{i}}\right)$ can 
then be found using Equation (4-38), which assumes there is no heat loss from the tank, and that the tank is fully mixed.

$$
T_{\text {tank }_{i}}=T_{\text {tank }_{i-1}}+\frac{E_{t h_{i}}}{\left(m c_{p}\right)_{t a n k}}
$$

where $\left(m c_{p}\right)_{\text {tank }}$ is the thermal mass of the thermal storage tank.

Alternatively, for the case when the thermal storage tank is of sufficient temperature, and there is solar irradiation present, the calculation of the heat pump operating parameters can be carried out. At the beginning of this analysis a design heat transfer rate for $\operatorname{HX} 2\left(\dot{Q}_{H X 2}\right.$ design $)$ was selected, and based on this rate the maximum thermal energy that can be extracted from the thermal storage tank over the current time-step $\left(Q_{H X 2_{\max _{i}}}\right)$ can be found using Equation (4-39).

$$
Q_{H X 2_{\text {max }_{i}}}=\dot{Q}_{H X 2_{\text {design }}} \times \Delta t_{\text {step }} \times\left(\frac{T_{\text {tank }_{i-1}}-T_{\text {evap }_{H X 2}}}{T_{\text {tank }_{\text {min }}}-T_{\text {evap }_{H X 2}}}\right)
$$

Equation (4-39) assumes that the heat transfer area and the convection coefficient for heat transfer between the thermal storage tank and the loop B evaporator contained within the thermal storage tank are constant throughout the analysis. This assumption allows for the heat transfer over a time-step to be proportional to the designed heat transfer rate, time-step length, and the ratio of the current temperature difference between the thermal storage tank and HX2 to the minimum temperature difference the thermal storage tank and HX2. However, during time-steps with low electrical energy production, referred to as the limited electricity state, there is not enough electrical energy to run the compressors in loop B if the actual heat extraction rate from the thermal storage tank is set equal to $Q_{H X 2_{\max _{i}}}$. Therefore, in time-steps during which the system operates 
in the limited electricity state, HX2 will have more than sufficient heat transfer potential to provide enough heat to balance the cycle. This case allows loop A to be inactive, and the amount of heat energy that can be transferred through HX2 can be found using Equation (4-40), which assumes that the compressor power consumption constrains the system.

$$
Q_{H X 2 \text { elec }_{i}}=E_{e_{i}} \frac{\left(h_{b 1}-h_{b 4}\right)}{\left(h_{b 2}-h_{b 1}\right)}
$$

where $Q_{H X 2 \text { elec }_{i}}$ is the quantity of thermal energy transferred through HX2 over the current timestep when the system is operating with limited electricity.

The determination whether the system operates with limited electricity, or is fully operational, is achieved by comparing $Q_{H X 2_{\max }}$ and $Q_{H X 2_{\text {elec }_{i}}}$. When $Q_{H X 2_{\text {elec }_{i}}}>Q_{H X 2_{\max }}$ the system is fully operational, and the actual heat transfer through $\mathrm{HX} 2\left(Q_{H X 2 \text { actual }_{i}}\right)$ is set to equal to $Q_{H X 2_{\max _{i}}}$. Alternatively, when $Q_{H X 2_{\text {elec }}} \leq Q_{H X 2_{\max }}$, the system operates in the limited electricity state, and the actual heat transfer through HX2 is set to be equal to $Q_{H X 2}$ elec $i_{i}$.

After the actual heat transfer through HX2 over the current time-step is determined, the mass flow rates of refrigerant, and heat transfer rates through the heat pump loops, can be calculated. When the system operates in the limited electricity case, only loop B operates, which allows for a direct solution of the total mass flow of refrigerant in loop B over the current timestep $\left(m_{B_{i}}\right)$ using Equation (4-41).

$$
m_{B i}=\frac{Q_{H X 2_{a c t u a l}}}{h_{b 1}-h_{b 4}}
$$


Next, the heat rejected at the condenser in loop B over the current time-step $\left(Q_{\text {cond }_{b_{i}}}\right)$ can be found using Equation (4-42).

$$
Q_{\text {cond }_{b_{i}}}=m_{B_{i}}\left(h_{b 2}-h_{b 3}\right)
$$

Alternatively, when the system is fully operational, Equation (4-43) and Equation (4-44) must be solved simultaneously for the total refrigerant mass flows over the current time-step, for both heat pump loops.

$$
\begin{gathered}
\left(h_{a 2}-h_{a 1}\right) m_{A_{i}}+\left(h_{b 2}-h_{b 1}\right) m_{B_{i}}=E_{e_{i}} \\
-\left(h_{a 2}-h_{a 3}\right) m_{A_{i}}+\left(h_{b 1}-h_{b 4}\right) m_{B_{i}}=E_{t h_{i}}
\end{gathered}
$$

Next, similar to the limited electricity case, the heat rejected at the condenser in loop B can be found using Equation (4-42), using the result of the solutions from Equation (4-43) and Equation (4-44).

Finally, the time-step concludes by determining the temperature of the thermal storage tank using Equation (4-45), which accounts for both the heat added by the solar collector fluid, and the heat removed through HX2. Similarly to Equation (4-38), Equation (4-45) assumes there is no heat loss from the tank, and that the tank is fully mixed

$$
T_{\text {tank }_{i}}=T_{\text {tank }_{i-1}}+\frac{E_{\text {th }_{i}}-Q_{H X 2_{a}}}{\left(m c_{p}\right)_{\text {tank }}}
$$


In Section 4.5, a case study that implemented the previously detailed analysis technique will be presented, such that the efficacy of the PVT cascade heat pump system can be discussed.

\subsection{Case Study Parameters and Results}

A case study was carried out that compared the total annual energy output from the PVT cascade heat pump system to the simultaneous consumption PVT heat pump system, and the next leading solar domestic hot water system in the market, which was found to be the evacuated tube water heating system [49]. The design parameters that were used in comparing all systems were suitable for $60^{\circ} \mathrm{C}$ domestic hot water production. The mass flow rate of the city supply water was assumed to be variable, such that the heat removed from the thermal storage tank by the city supply water would allow the temperature of the thermal storage tank to be kept constant. Finally, since the desired output of this analysis was the energy output profile to the city supply water, the resulting required mass flow rate and inlet temperature of the city supply water were not needed.

Several locations were used, such that the effects of different climate could be determined. Table 4-1 presents a summary of the locations that were considered, along with related basic climate data $[60,61]$. 
Table 4-1: Case Study Locations with Climate Data

\begin{tabular}{|c|c|c|c|}
\hline $\begin{array}{c}\text { Location } \\
\text { (City, Country) }\end{array}$ & $\begin{array}{c}\text { Location } \\
\text { Latitude }\end{array}$ & $\begin{array}{c}\text { Annual Average } \\
\text { Dry-Bulb } \\
\text { Temperature }\left({ }^{\circ} \mathrm{C}\right)\end{array}$ & $\begin{array}{c}\text { Total Annual Solar } \\
\text { Beam Irradiation } \\
\left(\mathrm{kWh} / \mathrm{m}^{2}\right)\end{array}$ \\
\hline Edmonton, Canada & $53.6^{\circ}$ & 2.8 & 1491 \\
\hline Toronto, Canada & $43.7^{\circ}$ & 7.4 & 1252 \\
\hline Washington DC, USA & $39.0^{\circ}$ & 12.7 & 1378 \\
\hline Phoenix, USA & $33.5^{\circ}$ & 23.8 & 2524 \\
\hline
\end{tabular}

The details and results of the evacuated tube analysis will be presented first, since they will be used as the base case for the comparison to the other two systems. The simulation results from the simultaneous consumption PVT heat pump system, and the PVT cascade heat pump system, will then be given.

\subsubsection{List of Assumptions}

The following assumptions were used when analyzing each of the solar water heating systems:

1. Heat loss from the thermal storage tanks is neglected.

2. Circulation pump energy requirements are neglected for the solar loops.

3. There is infinite demand for heated water at all time-steps, ensuring that all heat produced by the cycle is usefully consumed. 


\subsubsection{Evacuated Tube Water Heating System}

A schematic of the evacuated tube water heating system that was used in this study is shown in Figure 4-5.

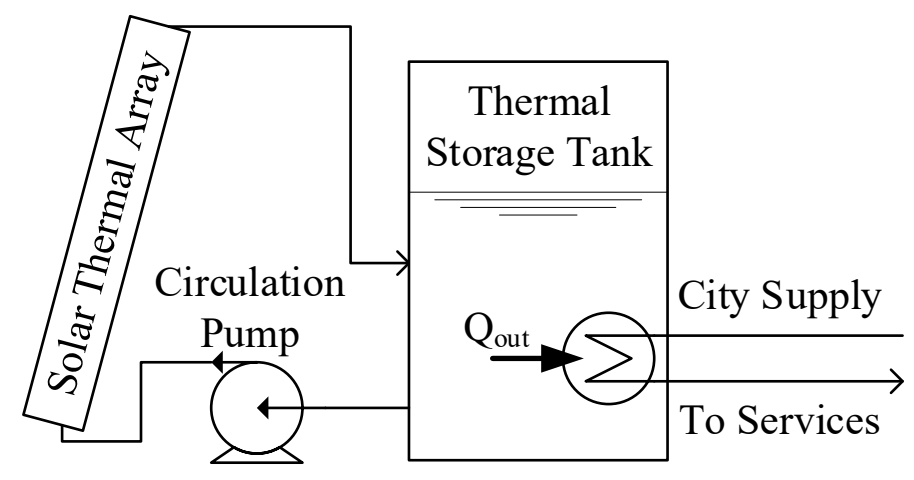

Figure 4-5: Evacuated Tube Heating System Schematic

The thermal storage tank in this system was assumed to have a constant temperature of $65^{\circ} \mathrm{C}$, which ensures that hot water at a temperature of $60^{\circ} \mathrm{C}$ can be produced from the city supply water that passes through the heat exchanger in the thermal storage tank. Typical solar water heating systems often utilize low flow rates, to promote thermal storage tank temperature stratification, which improves system efficiency. However, to remain consistent with the other system simulations in this study, a constant thermal storage tank temperature of $65^{\circ} \mathrm{C}$ was used such that no additional heat energy was required to achieve a water outlet temperature of $60^{\circ} \mathrm{C}$. This assumption results in the inlet temperature to the panel being constant at $65^{\circ} \mathrm{C}$ since the energy added to the tank by the solar collectors is simultaneously removed by the heat load at each time-step. Therefore, this modelling technique for the system results in only the solar thermal 
collector being accounted for, and variations in the temperature of the thermal storage tank are not included.

The analysis of the evacuated tube system was also carried out using the process that was described in Section 4.4, but neglecting the heat pump calculations since heat pumps were not included in this system. A Solar Panels Plus SPP-30 evacuated tube solar collector was used in this analysis, and the incidence angle modifier and thermal efficiency equations that were used to model this collector are shown in Equation (4-46) and Equation (4-47), respectively [62]. The remaining simulation input parameters for the evacuated tube analysis are shown in Table 4-2.

$$
\begin{aligned}
I A M_{i}=-4 \times 10^{-7} \times\left|i_{c_{i}}\right|^{4}+3 \times 10^{-5} \times\left|i_{c_{i}}\right|^{3} & \\
& \quad-6 \times 10^{-4} \times\left|i_{c_{i}}\right|^{2}+6.3 \times 10^{-3} \times\left|i_{c_{i}}\right|+1 \\
\eta_{t h_{i}}= & \varphi_{i} \times\left(0.477-0.9374 \times T_{r_{i}}-0.00655 \times I_{c_{i}} \times T_{r_{i}}^{2}\right)
\end{aligned}
$$

Table 4-2: Design Input Parameters for Evacuated Tube System Case Study

\begin{tabular}{|l|c|}
\hline \multicolumn{1}{|c|}{ Parameter } & Value \\
\hline Time-step length & $60 \mathrm{~s}$ \\
\hline Total array absorber area & $8.4 \mathrm{~m}^{2}$ \\
\hline Thermal storage tank volume & $4 \mathrm{~m}^{3}$ \\
\hline $\begin{array}{l}\text { Fluid mass flow rate through solar } \\
\text { collector array }\end{array}$ & $0.17 \frac{\mathrm{kg}}{\mathrm{s}}$ \\
\hline Panel azimuth angle & $0^{\circ}$ \\
\hline $\begin{array}{l}\text { Specific heat capacity of solar } \\
\text { array cooling fluid }\end{array}$ & $4180 \frac{\mathrm{J}}{\mathrm{kgK}}$ \\
\hline
\end{tabular}

The optimization process was carried out by running a simulation in each location using panel tilt angles ranging from $0^{\circ}$ to $90^{\circ}$, then, for each location, selecting the panel tilt angle that 
resulted in the maximum thermal energy output over the simulated year. A plot of the results from the tilt angle optimization is shown in Figure 4-6.

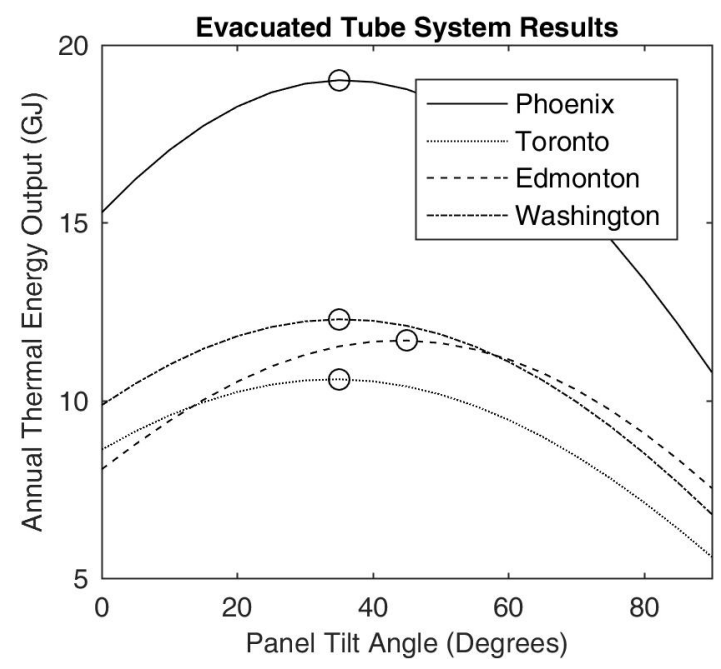

Figure 4-6: Evacuated Tube Annual Thermal Output vs. Panel Tilt Angle

For illustration purposes, a sample plot showing a resulting thermal power output profile for a simulated year in Toronto is shown in Figure 4-7, which was generated using a panel tilt angle of $35^{\circ}$. 


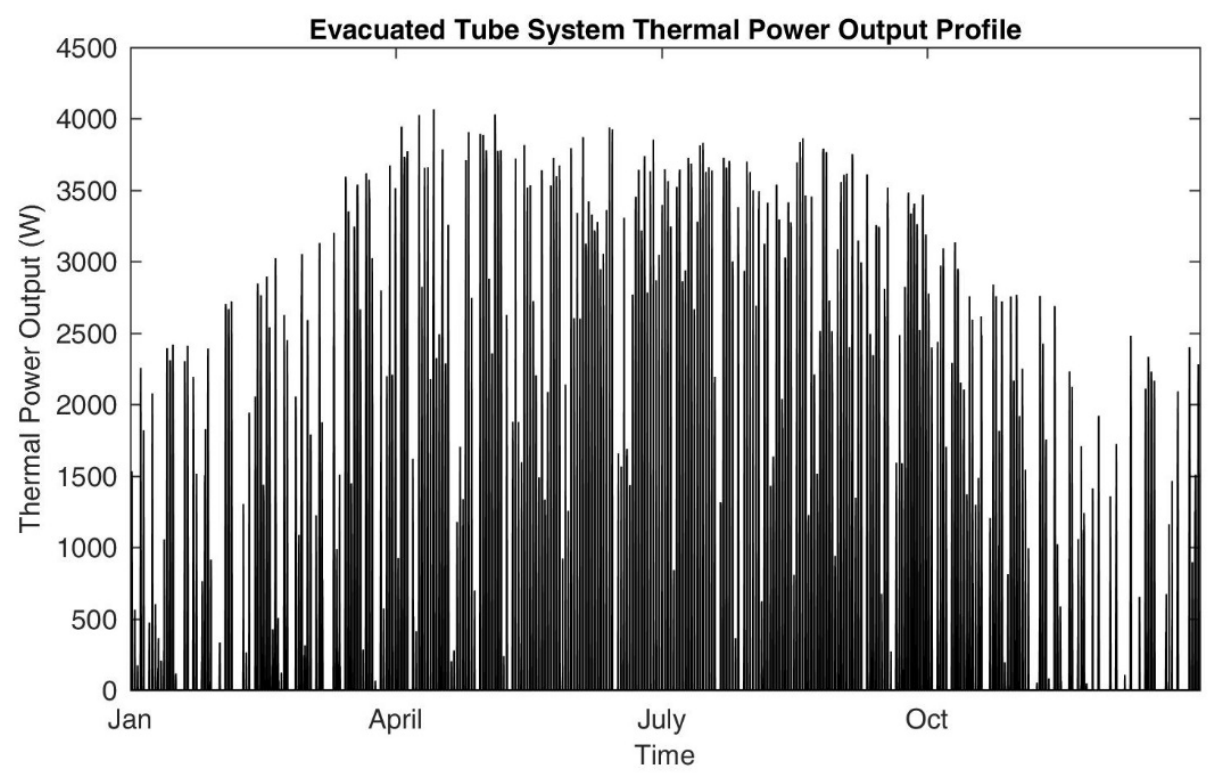

Figure 4-7: Evacuated Tube Sample Thermal Power Output Profile

After running the simulation at each location, and varying the panel tilt angle, the panel tilt angle that resulted in the maximum annual thermal energy output was determined. This optimal tilt angle is represented by the local maxima of each curve in Figure 4-6, and is marked on each curve in the plot for clarity. The resulting optimal tilt angle for each location, and the corresponding annual energy outputs, are presented in Table 4-3.

Table 4-3: Evacuated Tube System Analysis Results

\begin{tabular}{|c|c|c|}
\hline $\begin{array}{c}\text { Location } \\
\text { (City, Country) }\end{array}$ & $\begin{array}{c}\text { Optimal } \\
\text { Tilt Angle }\end{array}$ & $\begin{array}{c}\text { Corresponding Annual } \\
\text { Thermal Energy Output (GJ) }\end{array}$ \\
\hline Edmonton, Canada & $44^{\circ}$ & 11.9 \\
\hline Toronto, Canada & $34^{\circ}$ & 10.6 \\
\hline Washington DC, USA & $35^{\circ}$ & 12.3 \\
\hline Phoenix, USA & $36^{\circ}$ & 18.9 \\
\hline
\end{tabular}


The optimal tilt angles that were determined through this optimization process, along with the trends in total annual energy production, were verified using RETScreen software [63]. These results will be used for comparison against both of the PVT heat pump system annual energy outputs in Section 4.5.5.

\subsubsection{Simultaneous Production PVT Heat Pump System}

Several simulations of the simultaneous consumption PVT heat pump system were carried out to determine the operating parameters that result in the highest annual thermal energy output for each simulation location. A schematic that will be used to discuss the process is shown in Figure 4-8.

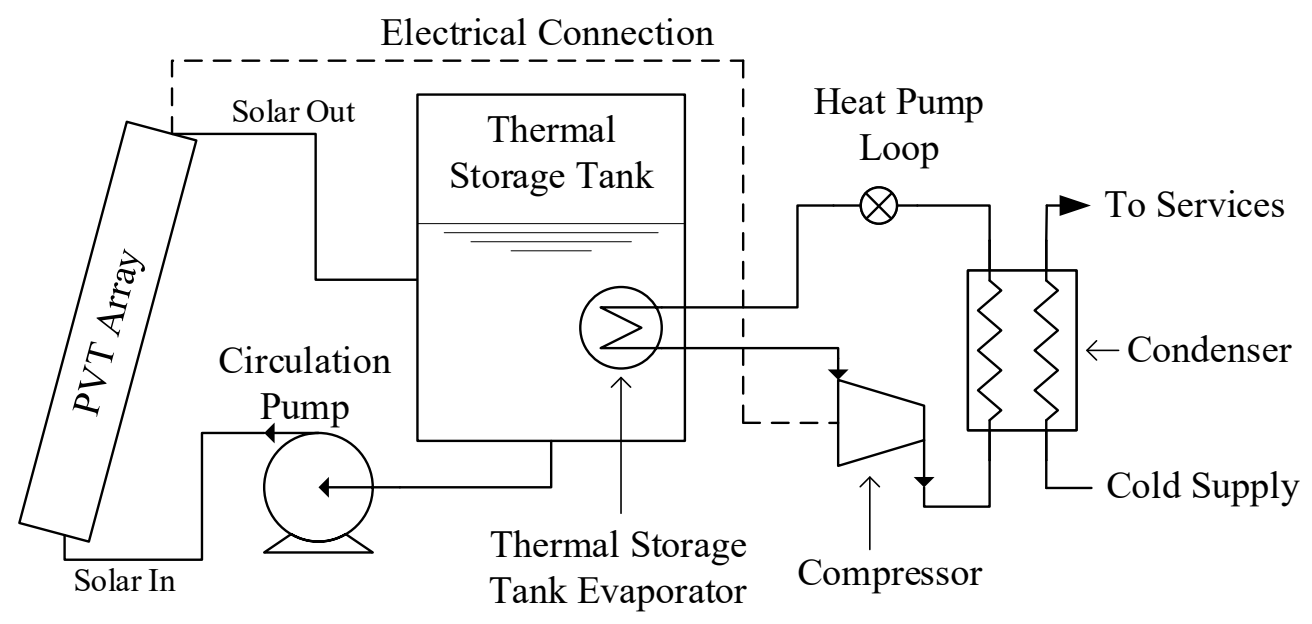

Figure 4-8: Simultaneous Consumption PVT Heat Pump System Schematic 
The panel tilt angle and the minimum thermal storage tank temperature were varied at each location to determine the combination of these two parameters that results in the system's maximum annual thermal energy output. An Emerson Climate ZB15KQE-PFJ variable capacity scroll compressor was used as the compressor in the heat pump loop [19]. REFPROP refrigerant property calculating software [64] was used to determine refrigerant state information for each of the trials, and Table 4-6 presents the parameters that were kept constant between each of these trials.

Table 4-4: Design Input Parameters for PVT System Case Study

\begin{tabular}{|l|c|}
\hline \multicolumn{1}{|c|}{ Parameter } & Value \\
\hline Time-step length & $60 \mathrm{~s}$ \\
\hline Total array absorber area & $8.4 \mathrm{~m}^{2}$ \\
\hline Thermal storage tank volume & $4 \mathrm{~m}^{3}$ \\
\hline Fluid mass flow rate through solar collector array & $0.18 \mathrm{~kg} / \mathrm{s}$ \\
\hline Panel azimuth angle & $0^{\circ}$ \\
\hline Heat Pump Evaporator Saturation Temperature & $30^{\circ} \mathrm{C}$ \\
\hline Heat Pump Condenser Saturation Temperature & $65^{\circ} \mathrm{C}$ \\
\hline $\begin{array}{l}\text { Design heat transfer rate of the heat exchanger in } \\
\text { the thermal storage tank }\end{array}$ & $1000 \mathrm{~W}[17]$ \\
\hline Heat pump refrigerant type & $\mathrm{R}-134 \mathrm{a}$ \\
\hline Specific heat capacity of solar panel cooling fluid & $4180 \frac{\mathrm{J}}{\mathrm{kgK}}$ \\
\hline
\end{tabular}

The optimization process was carried out by first setting the minimum thermal storage tank temperature to $35^{\circ} \mathrm{C}$, and varying the panel tilt angle, for each simulation location. Second, using the optimal panel tilt angle that was found during the first step in the optimization process, the minimum thermal storage tank temperature was varied to determine its optimal value for each location. Finally, to ensure that the optimal panel tilt angle did not change, the simulation for each 
location was re-run, varying the panel tilt angle while using the optimal minimum thermal storage tank temperature that was determined during the second step of the optimization process, to ensure that the optimal tilt angle did not change. A flowchart that represents this process is shown in Figure 4-9.

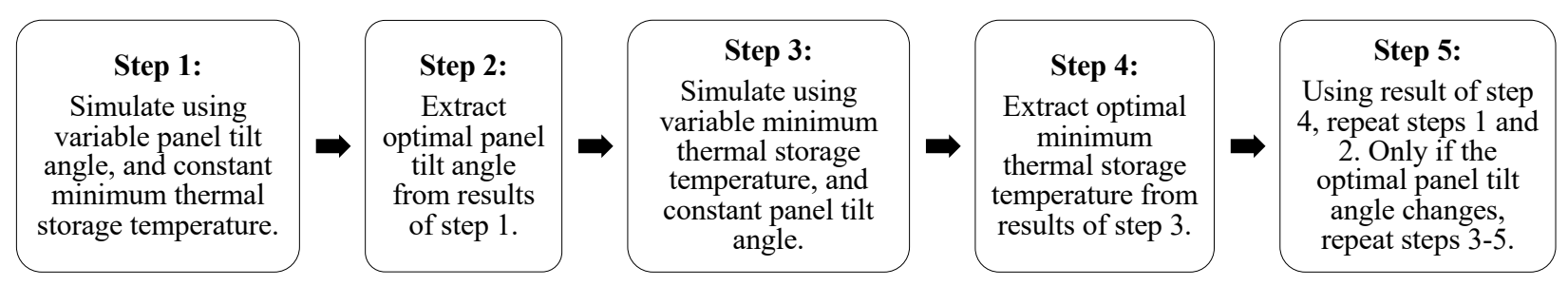

Figure 4-9: PVT Heat Pump System Optimization Process Flowchart

For illustration purposes, a sample plot showing the resulting thermal storage tank temperature for the simultaneous consumption PVT heat pump system over the simulated year in Toronto is shown in Figure 4-10, and the corresponding resulting thermal power output profile is shown in Figure 4-11. The plots in Figure 4-10 and Figure 4-11 were generated using a panel tilt angle of $31^{\circ}$, and a minimum thermal storage tank temperature of $24^{\circ} \mathrm{C}$. 


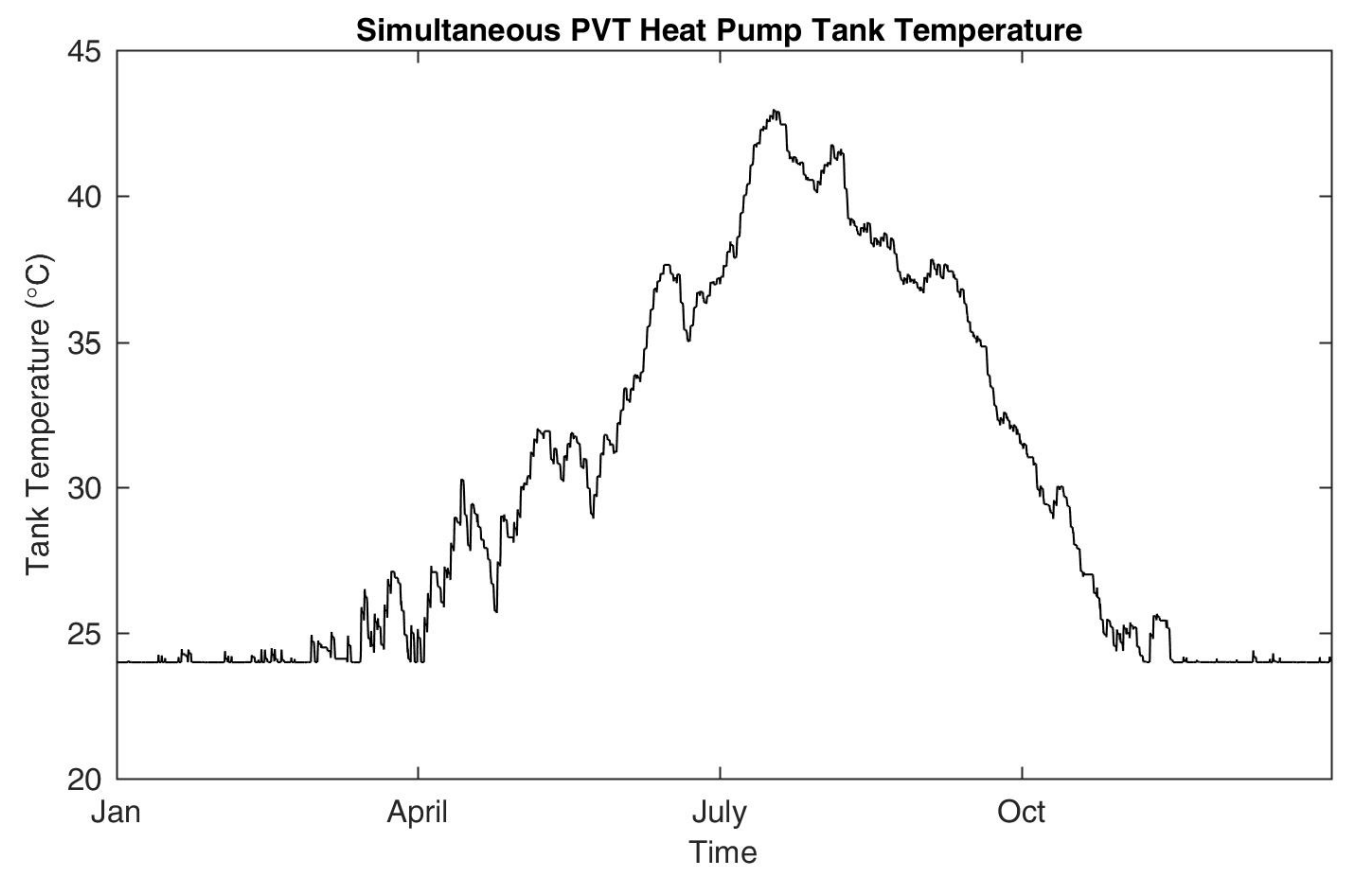

Figure 4-10: Simultaneous Consumption PVT Heat Pump Sample Thermal Storage Tank Temperature Profile for Toronto

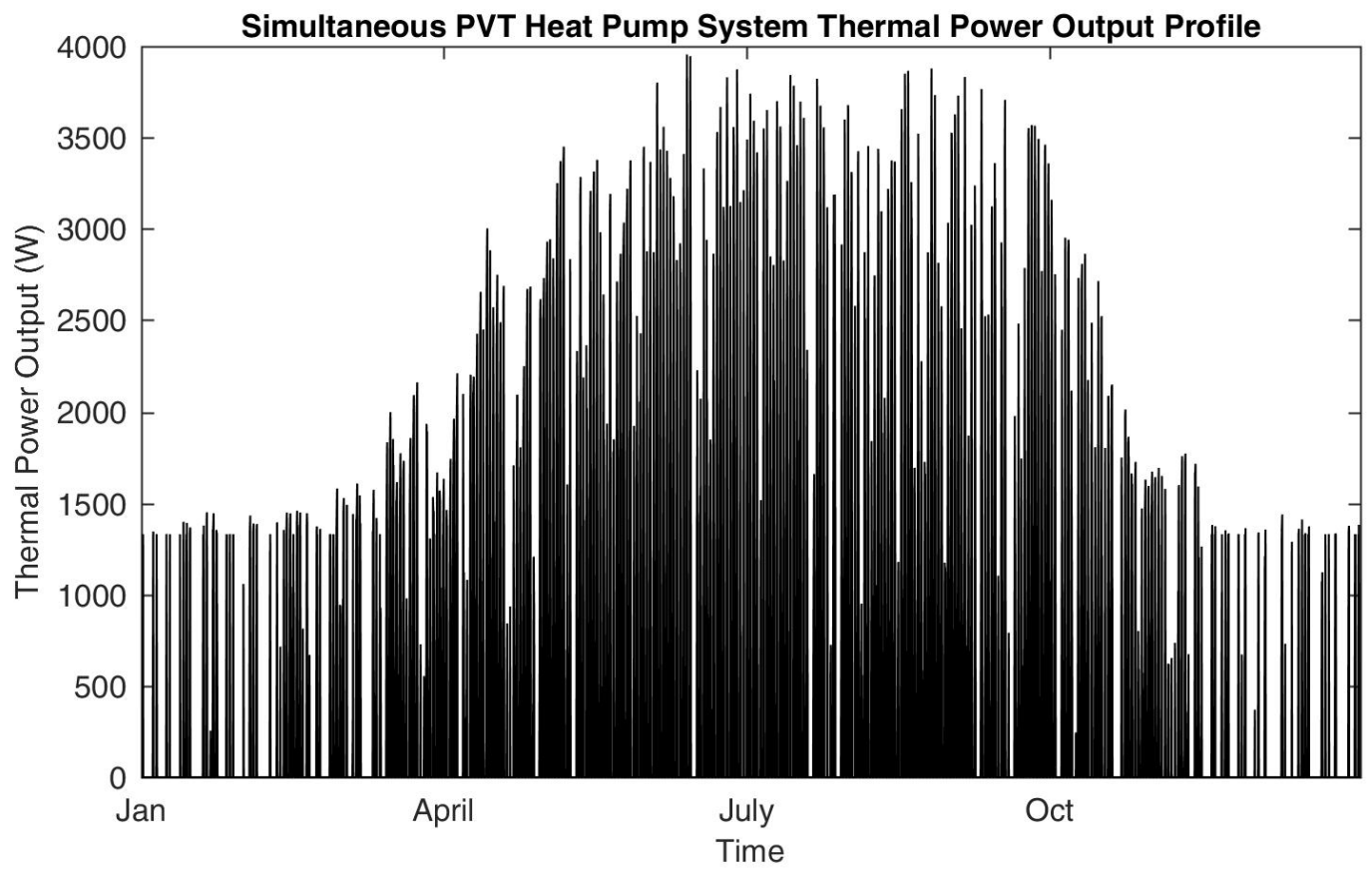

Figure 4-11: Simultaneous Consumption PVT Heat Pump Sample Thermal Power Output Profile for Toronto 
Based on the results shown in Figure 4-10, one can conclude that the system operates more frequently from April-October since the thermal storage tank is above the minimum temperature more frequently than in other months. This result is also verified by the higher density thermal power production profile shown in Figure 4-11 during the months of April-October.

A plot of the results from the panel tilt optimization process is shown in Figure 4-12a, and a plot of the results from the minimum thermal storage tank optimization process is shown in Figure 4-12b.

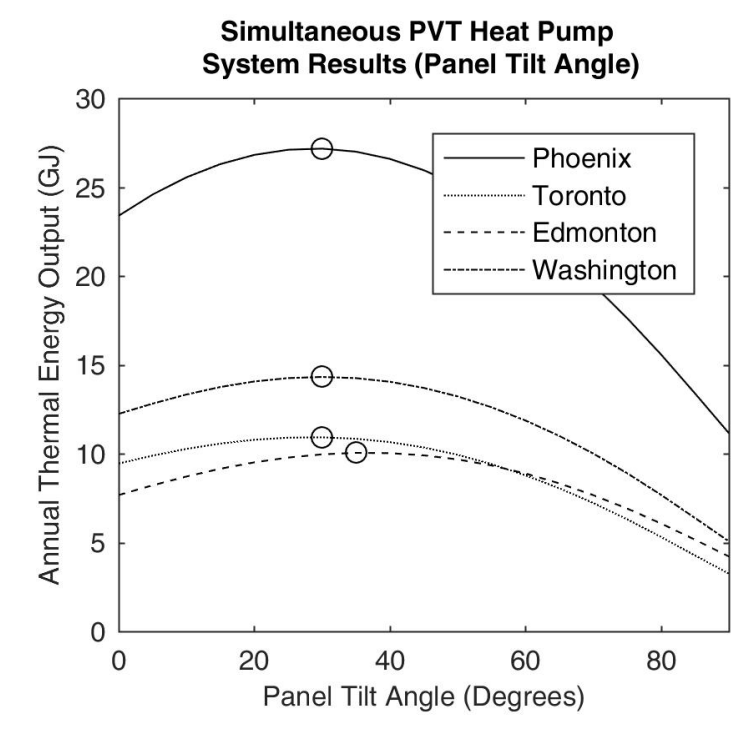

(a)

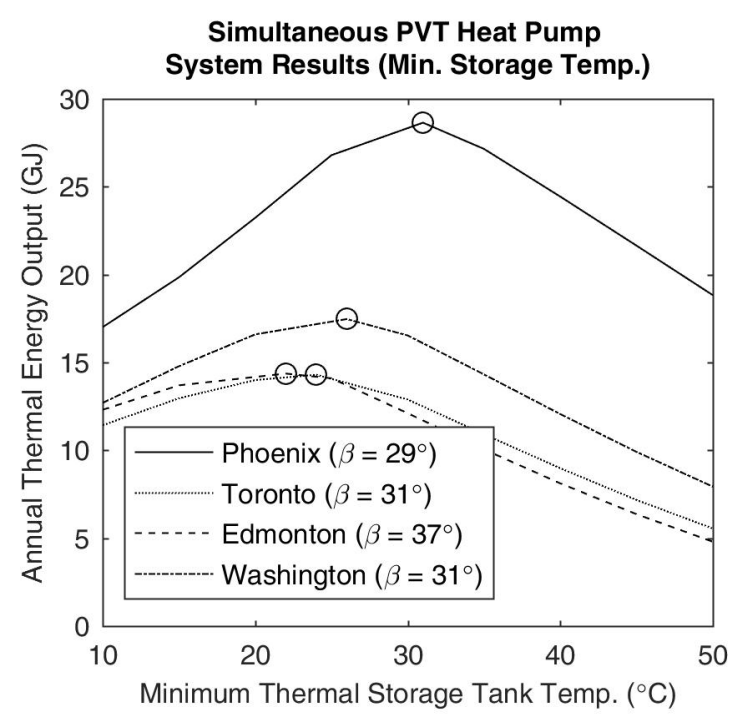

(b)

Figure 4-12: Simultaneous Consumption PVT Heat Pump Annual Energy Output Plots - (a) Panel Tilt Angle Study, (b) Minimum Thermal Storage Tank Study

Each curve in Figure 4-12a was generated using a variable panel tilt angle, and a constant thermal storage tank temperature of $35^{\circ} \mathrm{C}$. Therefore, the local maxima of each curve in Figure 4-12a, which is marked on each curve, corresponds to the annual thermal energy output when the 
optimal panel tilt angle for each simulation location is used, and the thermal storage tank temperature is set to $35^{\circ} \mathrm{C}$.

Each curve in Figure 4-12b was generated using a variable thermal storage tank temperature, and the optimal panel tilt angle for each location, which was found using Figure 4-12a. Therefore, the local maxima of each curve in Figure 4-12b, which is marked on each curve, corresponds to the annual thermal energy output when both the optimal thermal storage tank temperature is used, along with the optimal panel tilt angle, and is defined as the optimized value.

A summary of the optimal panel tilt angle, optimal minimum thermal storage tank temperature, and the optimized annual thermal energy output of the simultaneous PVT heat pump system for each location is presented in Table 4-5.

Table 4-5: Simultaneous Consumption PVT Heat Pump System Optimization Results

\begin{tabular}{|c|c|c|c|}
\hline $\begin{array}{c}\text { Location } \\
\text { (City, Country) }\end{array}$ & $\begin{array}{c}\text { Optimal } \\
\text { Tilt Angle }\end{array}$ & $\begin{array}{c}\text { Optimal Minimum } \\
\text { Thermal Storage } \\
\text { Tank Temperature }\end{array}$ & $\begin{array}{c}\text { Corresponding } \\
\text { Annual Thermal } \\
\text { Energy Output (GJ) }\end{array}$ \\
\hline Edmonton, Canada & $37^{\circ}$ & $22^{\circ} \mathrm{C}$ & 13.8 \\
\hline Toronto, Canada & $31^{\circ}$ & $24^{\circ} \mathrm{C}$ & 13.5 \\
\hline Washington DC, USA & $31^{\circ}$ & $26^{\circ} \mathrm{C}$ & 16.5 \\
\hline Phoenix, USA & $29^{\circ}$ & $31^{\circ} \mathrm{C}$ & 27.7 \\
\hline
\end{tabular}

These optimized results will be used for comparison against the evacuated tube system and the PVT cascade heat pump system annual energy outputs in Section 4.5.5. 


\subsubsection{PVT Cascade Heat Pump System}

Several simulations of the PVT cascade heat pump system were carried out to determine the operating parameters that result in the highest annual thermal energy output for each simulation location. The panel tilt angle and the minimum thermal storage tank temperature were varied at each location to determine the combination of these two parameters that results in the system's maximum annual thermal energy output. An Emerson Climate ZB15KQE-PFJ variable capacity scroll compressor was used as the compressor in the heat pump loop [19]. REFPROP refrigerant property calculating software [64] was used to determine refrigerant state information for each of the trials, and Table 4-6 presents the parameters that were kept constant between each of these trials.

Table 4-6: Design Input Parameters for PVT Cascade Heat Pump System Case Study

\begin{tabular}{|l|c|}
\hline \multicolumn{1}{|c|}{ Parameter } & Value \\
\hline Time-step length & $60 \mathrm{~s}$ \\
\hline Total array absorber area & $8.4 \mathrm{~m}^{2}$ \\
\hline Thermal storage tank volume & $4 \mathrm{~m}^{3}$ \\
\hline Fluid mass flow rate through solar collector array & $0.18 \mathrm{~kg} / \mathrm{s}$ \\
\hline Panel azimuth angle & $0^{\circ}$ \\
\hline Heat Pump A Evaporator Saturation Temperature & $5^{\circ} \mathrm{C}$ \\
\hline Heat Pump A Condenser Saturation Temperature & $35^{\circ} \mathrm{C}[17]$ \\
\hline Heat Pump B Evaporator Saturation Temperature & $30^{\circ} \mathrm{C}$ \\
\hline Heat Pump B Condenser Saturation Temperature & $65^{\circ} \mathrm{C}$ \\
\hline $\begin{array}{l}\text { Design heat transfer rate of the heat exchanger in } \\
\text { the thermal storage tank }\end{array}$ & $1000 \mathrm{~W}[17]$ \\
\hline Heat pump refrigerant type & $\mathrm{R}-134 \mathrm{a}$ \\
\hline Specific heat capacity of solar panel cooling fluid & $4180 \frac{\mathrm{J}}{\mathrm{kgK}}$ \\
\hline
\end{tabular}


The optimization process was carried out using the same method that was described in Section 4.5.3 for the simultaneous consumption PVT heat pump system. First, the minimum thermal storage tank temperature was set to $35^{\circ} \mathrm{C}$, and the panel tilt angle was varied for each simulation location. Second, using the optimal panel tilt angle that was found during the first step in the optimization process, the minimum thermal storage tank temperature was varied to determine its optimal value for each location. Finally, to ensure that the optimal panel tilt angle did not change, the simulation for each location was re-run, varying the panel tilt angle while using the optimal minimum thermal storage tank temperature that was determined during the second step of the optimization process, to ensure that the optimal tilt angle did not change.

For illustration purposes, a sample plot showing the resulting thermal storage tank temperature for the PVT cascade heat pump system over the simulated year in Toronto is shown in Figure 4-13, and the corresponding resulting thermal power output profile is shown in Figure 4-14. The plots in Figure 4-13 and Figure 4-14 were generated using a panel tilt angle of $34^{\circ}$, and a minimum thermal storage tank temperature of $28^{\circ} \mathrm{C}$. 


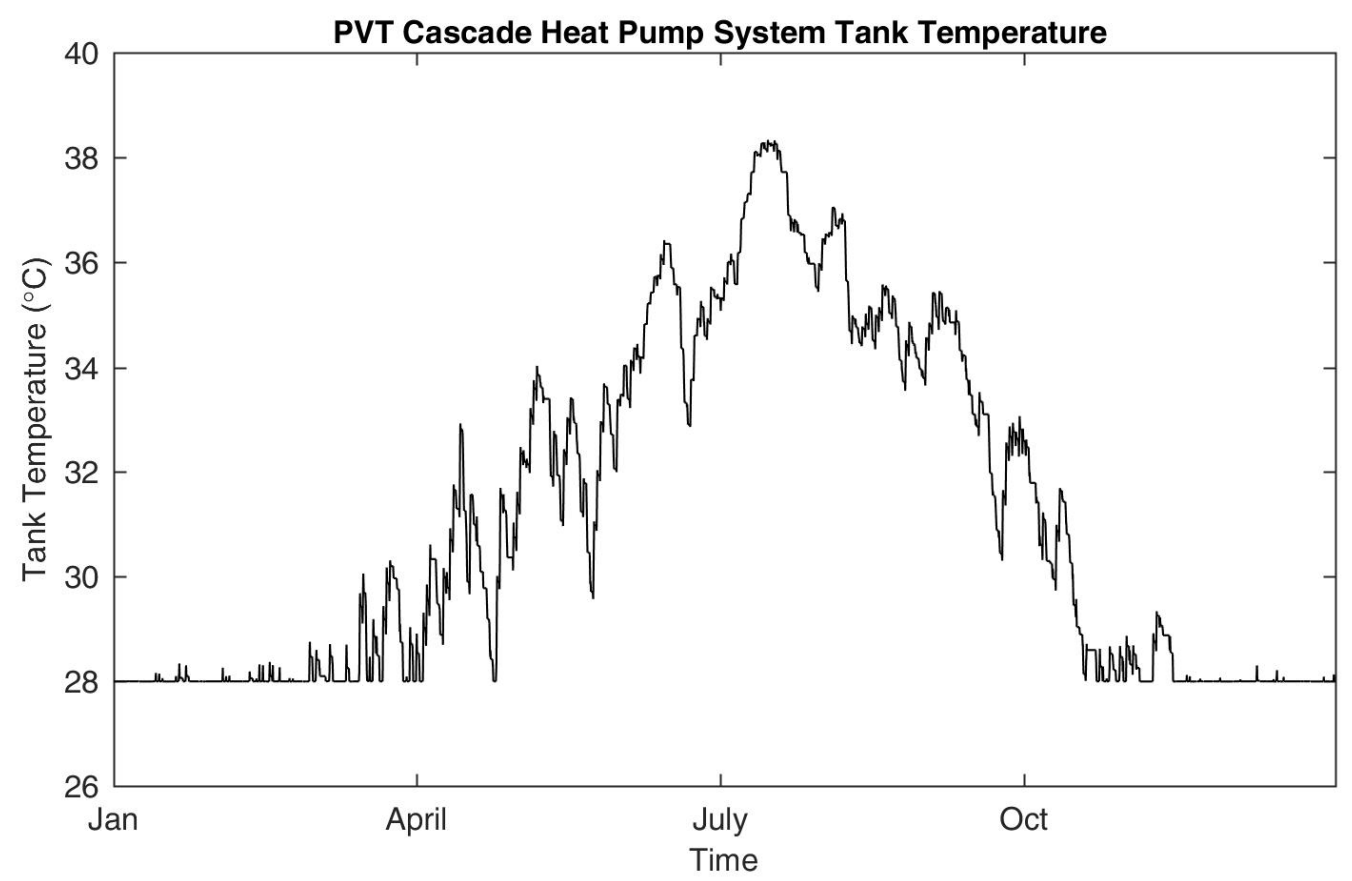

Figure 4-13: PVT Cascade Heat Pump Sample Thermal Storage Tank Temperature Profile for Toronto

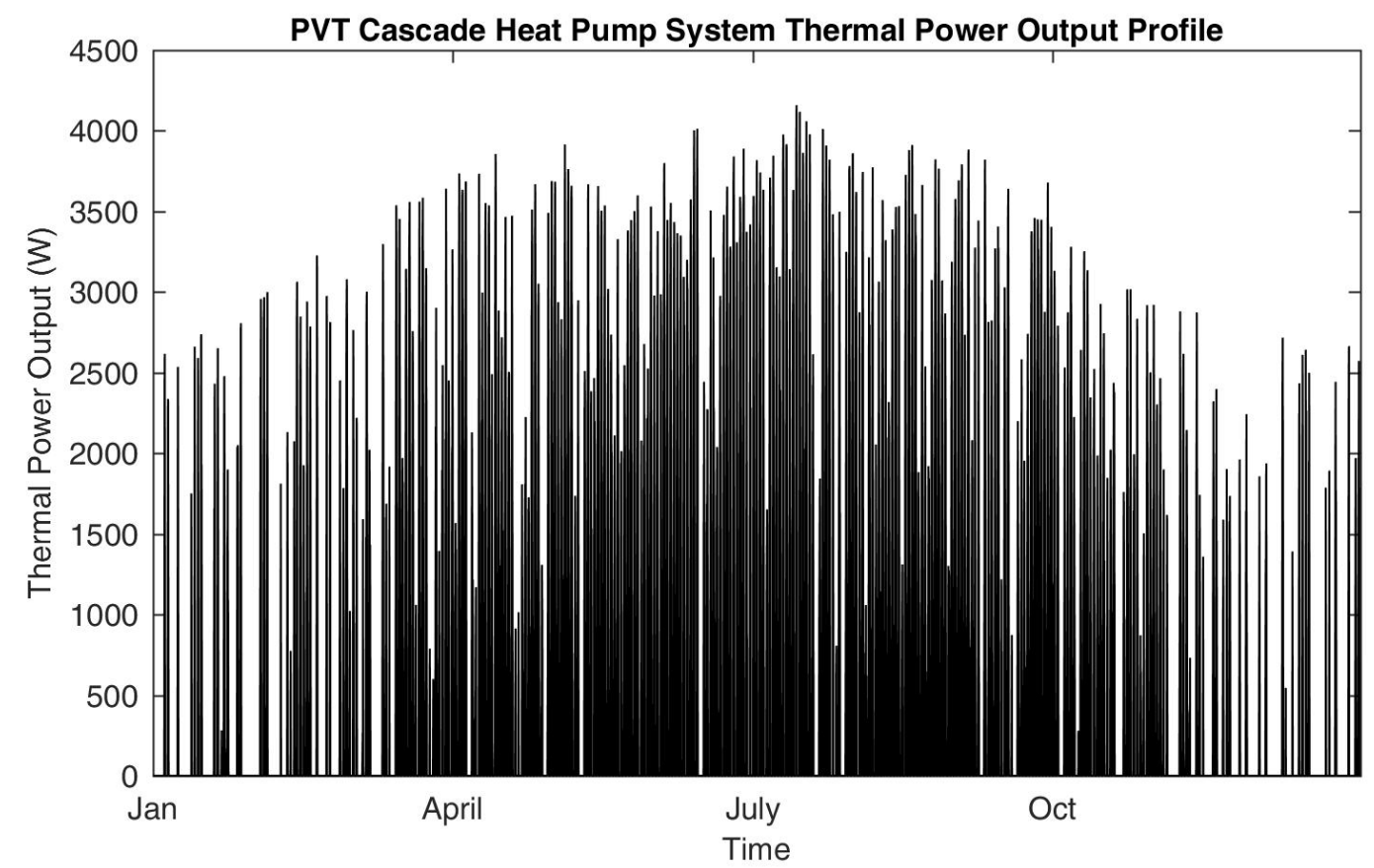

Figure 4-14: PVT Cascade Heat Pump Sample Thermal Power Output Profile for Toronto 
Using results shown in Figure 4-13 and Figure 4-14, and comparable results for the other locations, the total annual thermal energy production based on different panel tilt angles, and minimum thermal storage tank temperatures, was determined for each location. A plot of the results from the panel tilt optimization process is shown in Figure 4-15a, and a plot of the results from the minimum thermal storage tank optimization process is shown in Figure 4-15b.

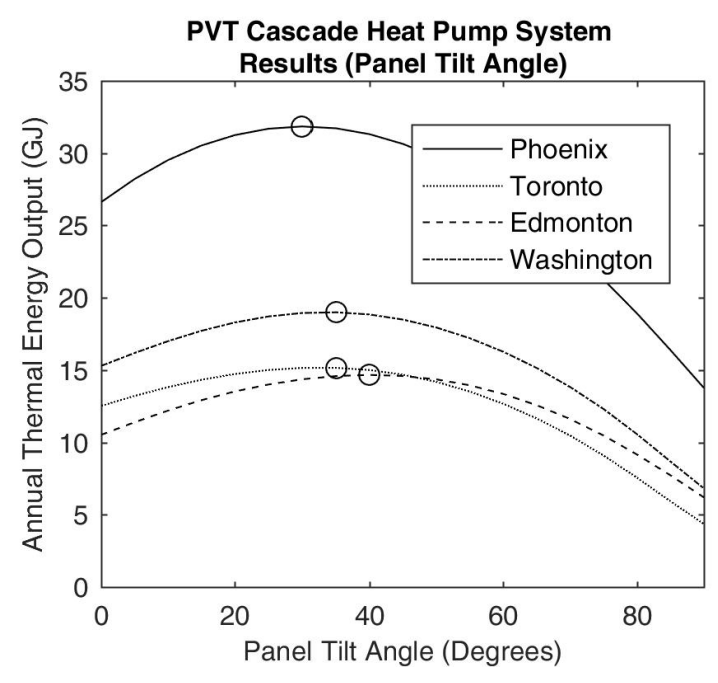

(a)

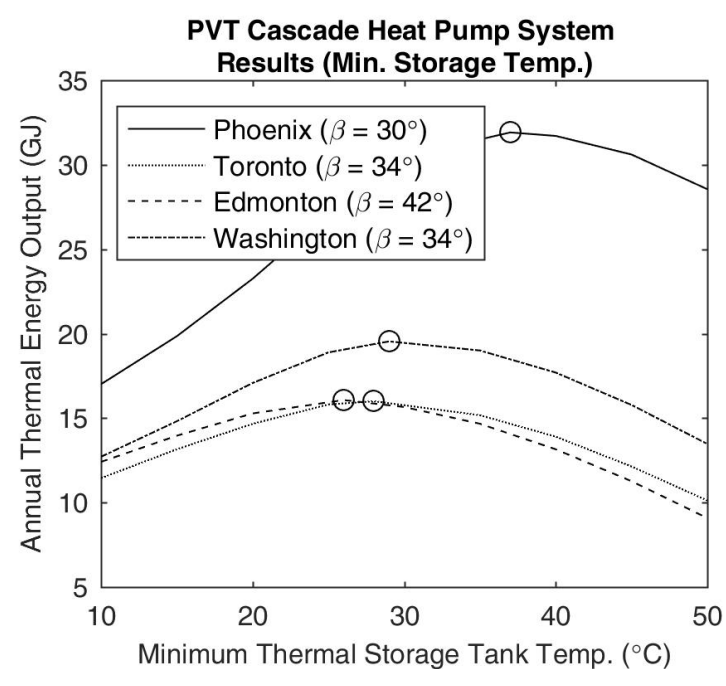

(b)

Figure 4-15: PVT Cascade Heat Pump System Annual Energy Output Plots - (a) Panel Tilt Angle Study, (b) Minimum Thermal Storage Tank Study

Since the PVT cascade heat pump system has two operational modes, which are with either one or two heat pumps being active, it is of interest to determine the number of hours spent in each state annually. Table 4-8 presents these results for the optimized system in each simulation location. 
Table 4-7: PVT Cascade Heat Pump Operating Mode Characteristics

\begin{tabular}{|c|c|c|c|}
\hline $\begin{array}{c}\text { Location } \\
\text { (City, Country) }\end{array}$ & $\begin{array}{c}\text { Total Annual } \\
\text { Operating } \\
\text { Hours }\end{array}$ & $\begin{array}{c}\text { Dual Heat Pump } \\
\text { Loop Operating } \\
\text { Hours }\end{array}$ & $\begin{array}{c}\text { Dual Heat Pump } \\
\text { Loop Operating } \\
\text { Fraction }\end{array}$ \\
\hline Edmonton, Canada & 2401 & 951 & $40 \%$ \\
\hline Toronto, Canada & 2083 & 930 & $45 \%$ \\
\hline Washington DC, USA & 2828 & 1067 & $38 \%$ \\
\hline Phoenix, USA & 3429 & 2024 & $59 \%$ \\
\hline
\end{tabular}

A summary of the optimal panel tilt angle, optimal minimum thermal storage tank temperature, and the optimized annual thermal energy output of the PVT heat pump system for each location is presented in Table 4-8.

Table 4-8: PVT Cascade Heat Pump System Optimization Results

\begin{tabular}{|c|c|c|c|c|c|}
\hline $\begin{array}{c}\text { Location } \\
\text { (City, Country) }\end{array}$ & $\begin{array}{c}\text { Optimal } \\
\text { Tilt } \\
\text { Angle }\end{array}$ & $\begin{array}{c}\text { Optimal } \\
\text { Minimum } \\
\text { Thermal Storage } \\
\text { Tank } \\
\text { Temperature }\end{array}$ & $\begin{array}{c}\text { Thermal } \\
\text { Energy } \\
\text { from Low } \\
\text { Grade } \\
\text { Source } \\
\text { (GJ) }\end{array}$ & $\begin{array}{c}\text { Solar } \\
\text { Radiation } \\
\text { Available } \\
\text { (GJ) }\end{array}$ & $\begin{array}{c}\text { Annual } \\
\text { Thermal } \\
\text { Energy } \\
\text { Output (GJ) }\end{array}$ \\
\hline Edmonton, Canada & $42^{\circ}$ & $26^{\circ} \mathrm{C}$ & 1.53 & 41.9 & 15.3 \\
\hline Toronto, Canada & $34^{\circ}$ & $28^{\circ} \mathrm{C}$ & 1.58 & 38.8 & 15.1 \\
\hline Washington DC, USA & $34^{\circ}$ & $29^{\circ} \mathrm{C}$ & 1.76 & 44.0 & 18.6 \\
\hline Phoenix, USA & $30^{\circ}$ & $37^{\circ} \mathrm{C}$ & 3.97 & 63.4 & 31.0 \\
\hline
\end{tabular}

These optimized results will be used for comparison against the evacuated tube system and the simultaneous PVT heat pump system annual energy outputs in Section 4.5.5. 


\subsubsection{Discussion and Comparison of System Performances}

A comparison between the annual energy outputs of the evacuated tube, simultaneous consumption PVT heat pump, and PVT cascade heat pump systems was carried out using the optimized system parameters, as detailed in Sections 4.5.2, 4.5.3, and 4.5.4. Table 4-9 presents a comparison of these results on both an annual and seasonal basis. Each of these simulation cases assume that the useful energy produced by each system can be entirely consumed at each timestep. This assumption was used such that the maximum performance of each of the systems could be compared, and the effects of different load profiles were outside the scope of this study. 
Table 4-9: Seasonal Comparison Between the PVT Heat Pump and Evacuated Tube systems

\begin{tabular}{|c|c|c|c|c|c|c|}
\hline \multirow[b]{2}{*}{ Location } & \multirow[b]{2}{*}{ Date Range } & \multicolumn{3}{|c|}{ Thermal Energy Output (GJ) } & \multicolumn{2}{|c|}{$\begin{array}{c}\% \text { Difference } \\
100 \% \times\left(\frac{E-E_{\text {evac }}}{E_{\text {evac }}}\right)\end{array}$} \\
\hline & & $\begin{array}{c}\text { Evacuated } \\
\text { Tube } \\
\left(E_{\text {evac }}\right)\end{array}$ & $\begin{array}{c}\text { Simultaneous } \\
\text { PVT Heat } \\
\text { Pump }\end{array}$ & $\begin{array}{c}\text { PVT } \\
\text { Cascade } \\
\text { Heat Pump }\end{array}$ & $\begin{array}{c}\text { Simultaneous } \\
\text { PVT Heat } \\
\text { Pump }\end{array}$ & $\begin{array}{c}\text { PVT } \\
\text { Cascade } \\
\text { Heat } \\
\text { Pump }\end{array}$ \\
\hline \multirow{5}{*}{$\begin{array}{l}\text { Edmonton, } \\
\text { Canada }\end{array}$} & Jan. $1^{\text {st }}-$ Mar. $31^{\text {st }}$ & 2.68 & 1.84 & 2.39 & $-31 \%$ & $-11 \%$ \\
\hline & April $1^{\text {st }}-$ June $30^{\text {th }}$ & 3.84 & 5.36 & 5.78 & $40 \%$ & $50 \%$ \\
\hline & July $1^{\text {st }}-$ Sept. $30^{\text {th }}$ & 3.75 & 5.17 & 5.54 & $38 \%$ & $48 \%$ \\
\hline & Oct. $1^{\text {st }}-$ Dec. $31^{\text {st }}$ & 1.66 & 1.42 & 1.59 & $-15 \%$ & $-4 \%$ \\
\hline & Annual & 11.9 & 13.8 & 15.3 & $16 \%$ & $28 \%$ \\
\hline \multirow{5}{*}{$\begin{array}{l}\text { Toronto, } \\
\text { Canada }\end{array}$} & Jan. $1^{\text {st }}-$ Mar. $31^{\text {st }}$ & 2.06 & 1.43 & 1.88 & $-31 \%$ & $-9 \%$ \\
\hline & April $1^{\text {st }}-$ June $30^{\text {th }}$ & 3.24 & 4.97 & 5.51 & $53 \%$ & $70 \%$ \\
\hline & July $1^{\text {st }}-$ Sept. $30^{\text {th }}$ & 3.69 & 5.50 & 5.94 & $49 \%$ & $61 \%$ \\
\hline & Oct. $1^{\text {st }}-$ Dec. $31^{\text {st }}$ & 1.60 & 1.57 & 1.74 & $-2 \%$ & $9 \%$ \\
\hline & Annual & 10.6 & 13.5 & 15.1 & $27 \%$ & $42 \%$ \\
\hline \multirow{5}{*}{$\begin{array}{l}\text { Washington } \\
\text { DC, USA }\end{array}$} & Jan. $1^{\text {st }}-$ Mar. $31^{\text {st }}$ & 3.04 & 2.70 & 3.51 & $-11 \%$ & $16 \%$ \\
\hline & April $1^{\text {st }}-$ June $30^{\text {th }}$ & 2.84 & 5.22 & 5.61 & $84 \%$ & $97 \%$ \\
\hline & July $1^{\text {st }}-$ Sept. $30^{\text {th }}$ & 3.35 & 5.52 & 5.84 & $65 \%$ & $74 \%$ \\
\hline & Oct. $1^{\text {st }}-$ Dec. $31^{\text {st }}$ & 3.02 & 3.07 & 3.59 & $2 \%$ & $19 \%$ \\
\hline & Annual & 12.3 & 16.5 & 18.6 & $35 \%$ & $51 \%$ \\
\hline \multirow{5}{*}{$\begin{array}{l}\text { Phoenix, } \\
\text { USA }\end{array}$} & Jan. $1^{\text {st }}-$ Mar. $31^{\text {st }}$ & 5.24 & 5.28 & 6.48 & $1 \%$ & $24 \%$ \\
\hline & April $1^{\text {st }}-$ June $30^{\text {th }}$ & 3.44 & 7.95 & 8.58 & $131 \%$ & $149 \%$ \\
\hline & July $1^{\text {st }}-$ Sept. $30^{\text {th }}$ & 4.35 & 8.48 & 9.01 & $95 \%$ & $107 \%$ \\
\hline & Oct. $1^{\text {st }}-$ Dec. $31^{\text {st }}$ & 5.89 & 5.98 & 6.95 & $2 \%$ & $18 \%$ \\
\hline & Annual & 18.9 & 27.7 & 31.0 & $46 \%$ & $64 \%$ \\
\hline
\end{tabular}

Based on the results presented in Table 4-9, one can see that in all simulation locations both the simultaneous consumption PVT heat pump, and PVT cascade heat pump system produced more thermal energy than the evacuated tube system, on both a seasonal and annual basis. The PVT cascade heat pump system shows the greatest improvement over both the evacuated tube system, and the simultaneous consumption PVT heat pump system, in locations and during times with higher dry-bulb temperatures. 
For example, in Edmonton, which is the simulation location with the lowest annual average dry-bulb temperature, the annual energy output was increased compared to the evacuated tube system by $37 \%$. However, in Toronto, which is the simulation location with the second lowest annual average dry-bulb temperature, the annual energy output was increased compared to the evacuated tube system by $51 \%$. This further increase in performance continues as the annual average dry-bulb temperature increases for the other simulation locations. Similar trends with the improving annual thermal energy output are seen when comparing the simultaneous consumption PVT heat pump system with the PVT cascade heat pump system. Therefore, based on this trend, the PVT cascade heat pump system offers the most improvement compared to the other two systems in locations with higher dry-bulb temperatures.

A similar result is found when comparing seasons in the same location. For example, in Edmonton, during the Winter months (i.e. January - March) the PVT cascade heat pump system has the same thermal energy output as the evacuated tube system. However, during the Spring months (i.e. April - June), the PVT cascade heat pump system offers an increase in thermal energy output of $62 \%$. This result further supports that the PVT cascade heat pump system offers the greatest improvement during months with higher dry-bulb temperatures. This result also demonstrates that even in a cold climate location, where the dry-bulb temperature and solar insolation are at their lowest annual values (i.e. during the Winter), the PVT cascade heat pump system still generates more thermal energy than the evacuated tube system and simultaneous consumption PVT heat pump system.

A cost estimation was also completed to compare the simultaneous consumption PVT heat pump system to the PVT cascade heat pump system. Since the difference between the equipment required for these two systems is the additional heat pump loop, an incremental cost analysis was 
completed. The incremental equipment cost associated with adding the secondary heat pump loop is approximately $\$ 988 \mathrm{CAD}[65,66,67,68]$. Assuming that natural gas instantaneous water heaters are used in each location with an energy factor of 0.90 [69], and assuming that the additional energy generated by the cascade system compared to the single heat pump system must be compensated for using natural gas, the annual cost savings shown in Table 4-10 were calculated.

Table 4-10: Annual Savings Cost Breakdown

\begin{tabular}{|c|c|c|c|c|}
\hline $\begin{array}{c}\text { Location } \\
\text { (City, Country) }\end{array}$ & $\begin{array}{c}\text { Additional } \\
\text { Energy } \\
\text { Requirement } \\
(\mathrm{GJ})\end{array}$ & $\begin{array}{c}\text { Utility Energy } \\
\text { Cost } \\
(\mathrm{CAD} / \mathrm{GJ})\end{array}$ & $\begin{array}{c}\text { Yearly } \\
\text { Savings } \\
(\mathrm{CAD})\end{array}$ & $\begin{array}{c}\text { Simple } \\
\text { Payback } \\
\text { Period (years) }\end{array}$ \\
\hline Edmonton, Canada & 1.67 & $3.55[70]$ & $\$ 5.92$ & 167 \\
\hline Toronto, Canada & 1.78 & $3.51[71]$ & $\$ 6.24$ & 158 \\
\hline Washington DC, USA & 2.33 & $15.41[68,72]$ & $\$ 35.96$ & 27 \\
\hline Phoenix, USA & 3.67 & $20.97[68,72]$ & $\$ 76.89$ & 13 \\
\hline
\end{tabular}

Based on the estimated payback periods presented in Table 4-10, and assuming a system lifetime of 20 years [10], the incremental cost of the added heat pump loop is only justified in Phoenix. The long payback periods in Edmonton, Toronto, and Washington are mostly due to the lower cost of natural gas in those locations compared Phoenix. However, the payback periods in all locations may be reduced if the system is mass-produced, and equipment costs can be reduced. 


\subsection{Conclusion}

A novel PVT cascade heat pump domestic water heating system was presented, along with computer simulation case studies. The system utilizes two heat pump loops, instead of a single heat pump loop, such that system optimization can be carried out to maximize thermal energy output, and consuming all of the electrical energy generated by the PVT panel. The study was carried out to determine and compare the annual and seasonal energy outputs of the PVT cascade heat pump system with the next leading conventional solar water heating technology, the evacuated tube system, along with a simultaneous consumption PVT heat pump system. The analysis of these systems was carried out using a time-stepping method and manufacturer data. Engineering weather data sets, and heat exchanger temperatures were used as inputs to the model, which yielded thermal power production and temperature profile outputs. Simulations were run using weather data for four different locations, which were Phoenix, Washington, Toronto, and Edmonton. These locations were selected because they provide a range in annual average dry-bulb temperature and total annual solar insolation.

Based on the simulations that were completed, it was found that the annual thermal energy output from the PVT cascade heat pump system exceeds the annual thermal energy output of the other two systems at each simulation location. It was also found that at each location, the PVT cascade heat pump system produces equal or more thermal energy than the other two systems during the spring and summer months. Finally, the PVT cascade heat pump system shows the greatest improvement over the other two systems in locations, and during seasons, with higher drybulb temperatures and greater solar insolation. Future research should focus on the development of a prototype, small-scale PVT heat pump apparatus for experimental testing and verification. 


\section{Chapter 5 A Methodology for Predicting Hybrid Solar Panel Performance in Different Operating Modes}

This chapter is based on the following journal manuscript:

J. P. Fine, S.B. Dworkin, J. Friedman, " A Methodology for Predicting Hybrid Solar Panel

Performance in Different Operating Modes," Renewable Energy, no. 130, pp. 1198-1206, 2019.

\subsection{Introduction}

\subsubsection{Research Motivation}

The use of solar panels is becoming more popular as concerns of GHG emissions increase, and because solar energy is renewable and increasingly affordable. There is a wide variety of solar panel types that are commercially available, which can produce thermal energy (converting solar radiation into heating a working fluid), electrical energy (by photovoltaic conversion), or both. Photovoltaic-thermal (PVT) panels can produce both forms of energy, and are often referred to as 'hybrid panels'. These hybrid panels will be the focus of this article.

When testing and characterizing the performance of solar panels, standard testing procedures are often used, and one popular choice is ISO:9806-2017 [18]. Using this standard testing procedure, the thermal performance of a panel is characterized as a function of operating conditions, using second-order thermal efficiency parameters [73]. This thermal efficiency characterization is often published by manufacturers such that engineers and researchers can estimate the panel performance for a given application. However, one drawback of this standard testing and characterization procedure is encountered when a hybrid panel is being considered. The testing standard only requires that the thermal performance of the panel be characterized when 
electricity is, or is not, being produced. Therefore, this can lead to scenarios where the thermal performance of the panel has been characterized in a different operating mode than the test condition. This paper will focus on investigating the implications that this different operating mode characterization can have on hybrid panel thermal performance. A modification methodology that uses manufacturer-provided thermal and electrical performance parameters, but can account for the different operating mode conditions, is also presented. This modification methodology is supported by experimental test results, which were generated using an indoor solar simulator.

\subsubsection{Overview of hybrid solar panels}

Hybrid solar panels offer the option to produce both heat and electricity from one panel, which can be necessary when there are space constraints for a given project. When looking to purchase a hybrid panel, there are options related to the fluid that can be used to extract heat from the panel. When a liquid is used, the fluid is often water, or a water-antifreeze mixture if cold temperatures are expected during operation. When a gas is used, air is often utilized as the fluid in either an open or closed loop system. Testing of both types of hybrid panels has shown that electrical performance improvements of up to $7 \%$ can be achieved compared to conventional photovoltaic (PV) panels [74]. This increase in electrical performance is due to lower PV cell temperatures caused by heat removal, which is another benefit of using hybrid panels [75].

Liquid-based hybrid panels can offer efficiency improvements compared to air-based panels, with typical thermal efficiencies of $45 \%$ to $79 \%$ [76], since water is a better heat-carrying fluid than air [77]. This improved performance allows for increased system operating temperatures, and better heat transfer to system thermal loads. Some applications of liquid-based 
hybrid panels include space heating [76], water heating [78], and water distillation [17]. However, some drawbacks of liquid-based systems include the maintenance required to ensure leaks do not develop in the piping network, along with the degradation of water-antifreeze mixtures at times when there are temperatures that exceed $121^{\circ} \mathrm{C}$ [79]. A schematic of a liquid-based hybrid panel is presented in Figure 5-1.

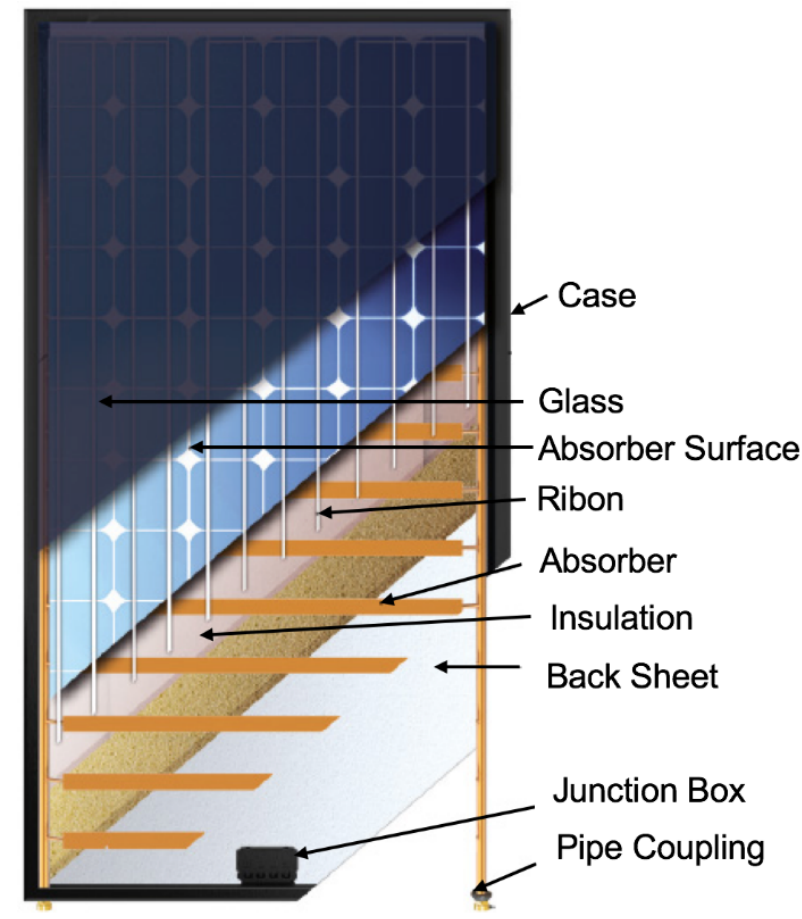

Figure 5-1: Hybrid Liquid-Based Panel Schematic [10]

Air-based hybrid panels operate similarly to liquid-based panels, but use air to transport heat from the panel to the thermal load. While these panels operate less efficiently than liquidbased panels, with a thermal efficiency range of $24 \%$ to $34 \%$ [76], they offer advantages related to low construction and maintenance costs [77]. Air-based hybrid panels can be constructed as 
individual units or as continuous arrays. Individual units must be connected by a ducting network, which can be connected in series or in parallel [12]. Alternatively, a panel array with no ductwork between panels can be constructed, which has a continuous airgap that runs underneath the panels, and can be constructed using off-the-shelf PV modules with a mounting system [80]. These continuous arrays may also act as the exterior surface of a building, and in that case can be referred to as a building integrated PVT (BIPVT) system [81]. These systems are often used to preheat ventilation air for buildings [82], and can also be used in conjunction with heat pumps to boost overall system operating efficiency in cold-climates [83]. Today, much of the research for airbased hybrid panels is related to heat transfer enhancements to improve the ability of air to remove heat from the panel [76]. A schematic of a typical air-based hybrid panel is presented in Figure

\section{$5-2$.}

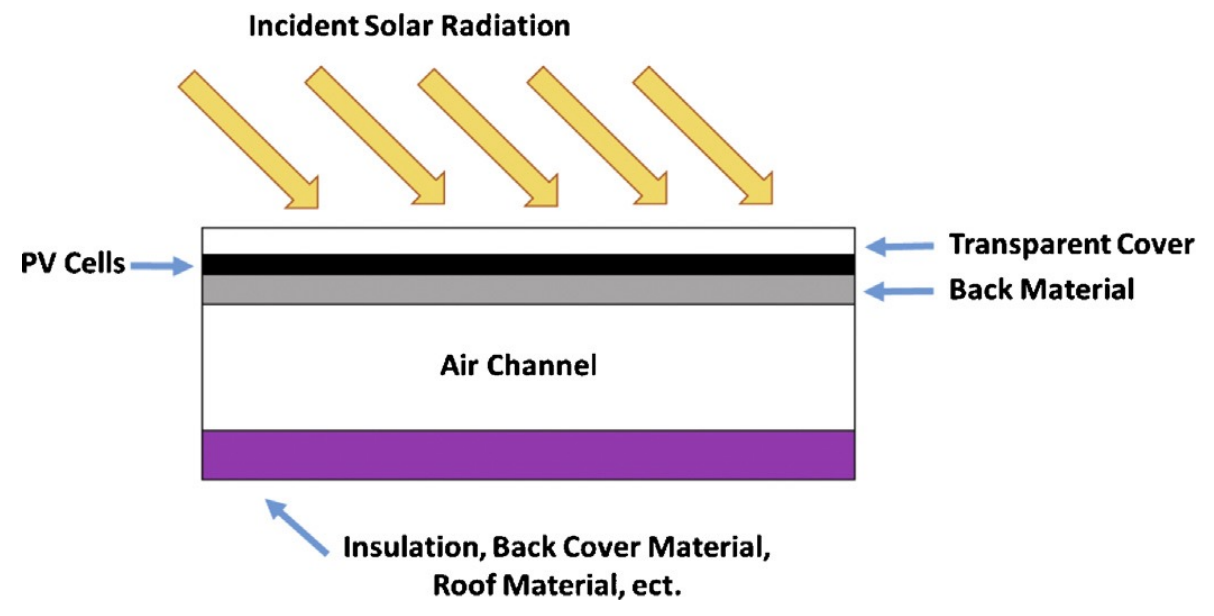

Figure 5-2: Hybrid Air-Based Panel Schematic [83] 


\subsubsection{Electrical performance modelling}

The electrical performance of a hybrid panel is assumed to be a function of the PV cell temperature. Typically for hybrid panels, the average of the panel inlet and outlet fluid temperatures are used since they are in close proximity to the PV, although the PV cell temperature is often higher than this value [17]. The general form of the electrical efficiency equation is given by Equation (5-1).

$$
\eta_{e}=\eta_{e_{\text {ref }}}-\alpha\left(T_{\text {panel }}-T_{\text {ref }}\right)=\frac{\dot{E}}{G A_{\text {panel }}}
$$

where $\eta_{e}$ is the electrical efficiency of the panel at the panel temperature $\left(T_{\text {panel }}\right)$ of interest, $\eta_{e_{r e f}}$ is the panel electrical power produced at the panel reference temperature $\left(T_{\text {ref }}\right), \alpha$ is the panel temperature coefficient, $\dot{E}$ is the electrical power generated by the panel, $G$ is the incident solar irradiation on the panel, and $A_{\text {panel }}$ is the panel area used in the thermal efficiency parameter determination. The panel reference efficiency, panel reference temperature, and the panel temperature coefficient are all typically provided by the manufacturer.

\subsubsection{Thermal performance modelling}

The thermal performance of hybrid panels is typically modelled using one of three different approaches. These approaches will be discussed in Sections 5.1.5 to 5.1.7. 


\subsubsection{Detailed finite element models}

The first approach is based upon a detailed finite element model of the panel, wherein each of the components in the panel is broken into small elements, and the interaction between each of these elements is accounted for numerically. These interactions include conductive, convective, and radiative heat exchange between elements, and between elements and the environment. The fluid flow within the panel can also be modelled using computational fluid dynamics (CFD), to ensure that the effects of variable fluid temperature, variable fluid flow velocity, and non-uniform panel temperature are considered [84]. This modelling technique requires that the detailed construction of the panel is known, and often requires highly specialized software. Estimation of panel performance has been within $2 \%$ of experimental values [85], which can be useful when designing a new solar panel, or when trying to learn about the detailed performance of a single panel component. However, the detail in this type of model is not always necessary to accurately estimate overall panel performance; a simplified component-level model may suffice.

\subsubsection{Component-level models}

The second modelling approach is based upon an energy balance for each of the major components in the panel $[86,87,88]$. Each of the components, such as the cover glass, insulation, fluid tubes, absorber plate, and PV cells, are given averaged material, optical, and geometric properties. The fluid within the panel is also given averaged characteristics, including specific heat capacity, temperature, density, and convection coefficient. The panel performance is then modelled based upon the interaction between each of these major components, the fluid, and the 
environment. This modelling technique has allowed for the overall performance of the panel to be estimated within $4.3 \%$ of experimental values [74], and can account for the selection of different panel components and operating conditions. However, while this technique can estimate panel performance for a wide variety of conditions and panel designs, manufacturers often do not release such detailed panel information, and instead only release the second-order efficiency parameters.

\subsubsection{Second-order efficiency models}

The third approach, which is also the focus of this paper, is the second-order efficiency model. This model is the most simplified of the models discussed to this point, and is used to estimate the thermal efficiency of the panel as a function of the fluid temperature within the panel, and the incident solar irradiation [18]. The general form of the second-order efficiency equation is presented in Equations (5-2) and (5-3), and is derived based upon a convective and radiative energy balance for a solar thermal panel [73].

$$
\begin{gathered}
\eta_{t h}=\eta_{0}+a_{1} T_{r}+a_{2} T_{r}^{2} G=\frac{\dot{Q}_{\text {panel }}}{G A_{\text {panel }}} \\
T_{r}=\frac{\left(T_{m}-T_{a}\right)}{G}
\end{gathered}
$$

where $T_{r}$ is the panel reduced temperature, $\eta_{0}, a_{1}$, and $a_{2}$ are the panel performance coefficients, $\dot{Q}_{\text {panel }}$ is the thermal power generated by the panel, $T_{a}$ is the ambient temperature, and $T_{m}$ is the mean of the panel inlet fluid temperature $\left(T_{\text {in }}\right)$ and outlet fluid temperature $\left(T_{\text {out }}\right)$. The panel 
performance coefficients are derived from standard test condition results, and by performing a regression curve fit to Equation (5-2).

Using the panel thermal efficiency, the temperature change of the fluid as it passes through the panel can be found using Equation (5-4).

$$
\dot{Q}_{\text {panel }}=\eta_{t h} G A_{\text {panel }}=\dot{m} c_{p}\left(T_{\text {out }}-T_{\text {in }}\right)
$$

where $\dot{m}$ is the mass flow rate of the fluid in the panel, and $c_{p}$ is the specific heat capacity of the fluid in the panel.

This overall solar panel thermal characterization method is widely accepted in the literature, and in industry, to estimate panel thermal performance. A study by Rad et al. [89] investigated using seasonal borehole energy storage with a solar array, and the second-order efficiency model was used to estimate solar energy generation. A study by Fine et al. [90] utilized the second-order efficiency model to determine the optimal quantity of solar panels for ground source heat pump systems. Another study by Khan et al. [91] used this analysis method to estimate solar panel performance when used with an absorption cooling system. This method is also referenced in the American Society of Heat Cooling and Refrigeration in their solar analysis standard [92], which is often used when designing solar energy systems. Lastly, hybrid panel manufacturers also use this method to characterize the thermal performance of their panels, and they typically publish the performance coefficients for use by system designers [41]. However, one major drawback compared to the more detailed models is that experimental data or detailed simulation data are required to generate the performance coefficients. Also, as previously mentioned, manufacturers are not required to provide thermal performance data when the panel is 
operating in hybrid mode, or thermal-only mode. Studies in the literature $[93,94,95,96]$ have shown that the thermal performance of a hybrid panel is different between these two modes. These differences will be discussed in Section 5.1.8.

\subsubsection{Effect of electrical energy generation on thermal performance}

Most studies in the literature that discuss the effect of electrical energy generation on hybrid panel thermal performance are in addition to the main topics of these articles. For example, a study by Dupeyrat et al. [93] performed characterization tests of a hybrid panel, with and without electrical energy generation, and found a difference in the panel thermal efficiency for the two cases. However, the purpose of this article was to assess the use of the panel with a solar water heating system, and an investigation into this generation difference was not presented. Similarly, a study by Yandri [94] mentioned that the thermal performance of a hybrid panel in these different operating modes can change by $4 \%$ to $12 \%$, depending on panel design and operating condition. This study by Yandri [94] also looked into how the thermal performance of a hybrid panel varied as a function of operating conditions, and included outdoor characterization tests. Yandri [94] found that at most panel reduced temperatures, the thermal efficiency of a hybrid panel will be higher when the panel is in thermal-only mode. However, Yandri [94] also found that at high irradiation levels, the thermal efficiency of a hybrid panel, when in hybrid mode, can exceed the thermal efficiency in thermal-only mode. Yandri [94] attributes this behavior at high irradiation levels to internal heating within the PV cells due to electrical current re-circulation, which improves heat transfer to the fluid circulating within the panel. 
As of January 2018, a task group has been set up by the International Energy Agency that focuses on PVT panels, and one of the goals of this group is to investigate the effect of electrical generation on the thermal performance of PVT panels [97]. However, the task group has not yet published a final report related to this study, but some information related to the method they will propose has been determined. When converting from hybrid manufacturer characterizations to thermal-only operation, their proposition is to add the theoretical electrical efficiency to the predicted thermal efficiency. Alternatively, when converting from thermal-only characterizations to hybrid mode operation, the proposition is to subtract the theoretical electrical efficiency from the predicted thermal efficiency. This methodology will be compared to the method proposed in this thesis in Section 5.3.3.

Furthermore, each of these studies supports the need to characterize the impact that the different operating modes have on the thermal performance of a hybrid panel. This paper will approach this need by presenting a modification method that can be used with the second-order efficiency model. This model was selected for use because of its wide-spread adoption, and ease of use. This modification method will provide a tool for designers and researchers to estimate the thermal performance of a hybrid panel when operating in a mode that differs from that used to generate the manufacturer-provided characterization parameters.

\subsection{Thermal efficiency modification methodology}

The proposed thermal efficiency modification methodology requires that both the thermal performance and electrical performance characteristics of a hybrid panel are known. The thermal performance is assumed to be given as the second-order efficiency parameters, which are typically 
provided by panel manufacturers. The electrical performance is assumed to be given as the panel temperature coefficient and reference temperature, which are also typically provided by the manufacturer.

There are two possible cases that must be investigated when modifying the thermal efficiency. The first case is when panel performance data is available from hybrid operation mode, but thermal-only operation is required. When this case occurs, it is proposed that the electrical power that would have been generated by the panel becomes an additional energy flux, which then becomes available to be converted by the panel into thermal energy. To complete this modification for the first operating case, a modified solar flux $\left(G_{1}{ }^{\prime}\right)$ must be determined using Equation (5-5).

$$
G_{1}^{\prime}=G+\eta_{e} G
$$

Next, a modified panel thermal efficiency $\left(\eta_{t h}{ }^{\prime}\right)$ and reduced temperature $\left(T_{r}{ }^{\prime}\right)$ can be found using Equations (5-6) and (5-7) respectively.

$$
\begin{gathered}
\eta_{t h}{ }^{\prime}=\eta_{0}+a_{1} T_{r}^{\prime}+a_{2} T_{r}^{\prime 2} G^{\prime} \\
T_{r}^{\prime}=\frac{\left(T_{m}-T_{a}\right)}{G^{\prime}}
\end{gathered}
$$

Lastly, the modified thermal power generated by the panel $\left(\dot{Q}_{\text {panel }}{ }^{\prime}\right)$ can be determined using Equation (5-8).

$$
\dot{Q}_{\text {panel }}{ }^{\prime}=\eta_{\text {th }}{ }^{\prime} G^{\prime} A_{\text {panel }}
$$


The second case occurs when panel performance data is available for thermal-only mode, but an application requires that the panel operate in hybrid mode. This modification process is similar to the first operating case, but instead of adding the estimated electrical power generation to the available solar flux, it must be subtracted. The calculation of the modified solar flux for the second operating case $\left(G_{2}^{\prime}\right)$ can be carried out using Equation (5-9), and is then used in Equations (5-6) through (5-8) to determine the modified thermal power output of the panel.

$$
G_{2}^{\prime}=G-\eta_{e} G
$$

This proposed modification methodology was used to analyze a hybrid panel that was tested using an indoor solar simulator. The details of this testing will be presented in Section 5.3.1, and the results from the modification technique will be presented in Section 5.3.3.

\subsection{Validation and implementation of the modification method}

5.3.1 Experimental testing description and test results

To validate the proposed modification methodology, an indoor solar simulator was used to generate thermal performance data for a hybrid panel in both operating modes. The hybrid panel that was studied during this testing campaign was the PowerTherm PVT panel from Solimpeks [10]. The PowerTherm is a flat plate, glazed, liquid-based hybrid solar panel. An image of the test setup is shown in Figure 5-3. 


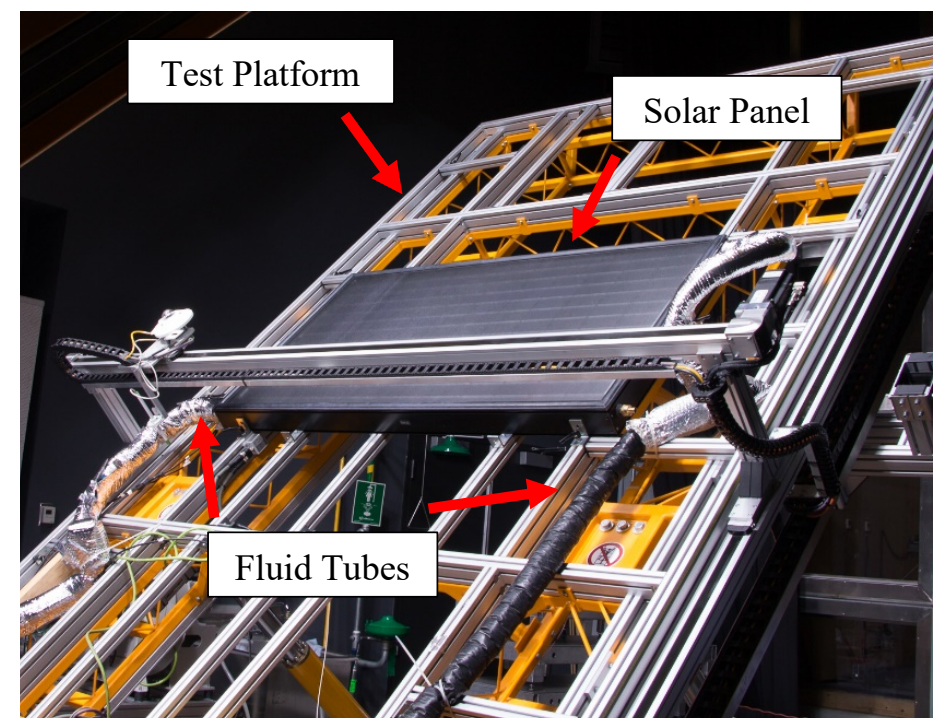

Figure 5-3: Photo of Panel on Solar Simulator Test Platform

The test campaign was carried out at the Concordia University Centre for Zero Energy Building Studies in Montreal, Canada. The solar simulator consists of eight special metal halide lamps that meet EN 12975:2006 and ISO 9806-1:1994 standards, with an artificial sky. The lamps produce radiation with collimation of approximately $80 \%$, have $97 \%$ spatial uniformity, and $+/-$ $1 \%$ temporal stability [98]. Temperature measurements were carried out using 1/10 DIN RTD's [98] with an average measurement accuracy of $+/-0.05 \mathrm{~K}$, and precision of $0.01 \mathrm{~K}$ [99]. Radiation measurements were carried out using a Kipp and Zonen CMP11 pyrometer, with a worst-case measurement accuracy of $+/-9 \mathrm{~W} / \mathrm{m}^{2}$ [100]. Water was used as the fluid within the panel, and mass flowrate measurements were carried out using an electromagnetic flow sensor with an accuracy of $+/-0.5 \%$ [98]. An air curtain was used to generate air motion at $2.6 \mathrm{~m} / \mathrm{s}$ [18], which flowed parallel to the lamp-facing surface of the panel, and wind speed measurements were carried out using an anemometer with an accuracy of $+/-0.1 \mathrm{~m} / \mathrm{s}$. Electrical energy was dissipated using a variable resistor at the peak power resistance for each test, and electrical performance data was recorded 
using the DS-100C I-V curve tracer, which has a peak power measurement accuracy of $+/-1 \%$ [101].

Using the specifications for each sensor, the maximum and minimum of each calculated parameter as a function of measurement uncertainty was determined. The maximum reduced temperature $\left(T_{r_{\max }}\right)$ and minimum reduced temperature $\left(T_{r_{\min }}\right)$ were calculated using Equations (5-10) and (5-11), which are derived from Equation (4-33) and use measured input data.

$$
\begin{gathered}
T_{r_{\text {max }}}=\frac{\left(T_{m}-T_{a}\right)_{\text {measured }}+0.1 \mathrm{~K}}{G_{\text {measured }}-9 \mathrm{~W} / \mathrm{m}^{2}} \\
T_{r_{\text {min }}}=\frac{\left(T_{m}-T_{a}\right)_{\text {measured }}-0.1 \mathrm{~K}}{G_{\text {measured }}+9 \mathrm{~W} / \mathrm{m}^{2}}
\end{gathered}
$$

The maximum useful heat generated $\left(\dot{Q}_{\max }\right)$ and minimum useful heat generated $\left(\dot{Q}_{\min }\right)$ by the panel were calculated using Equations (5-12) and (5-13), which are derived from Equation $(5-4)$.

$$
\begin{gathered}
\dot{Q}_{\text {max }}=\frac{1.005 \dot{Q}_{\text {measured }}\left[\left(T_{\text {out }}-T_{\text {in }}\right)_{\text {mesaured }}+0.1 \mathrm{~K}\right]}{\left(T_{\text {out }}-T_{\text {in }}\right)_{\text {mesaured }}} \\
\dot{Q}_{\text {min }}=\frac{0.995 \dot{Q}_{\text {measured }}\left[\left(T_{\text {out }}-T_{\text {in }}\right)_{\text {mesaured }}-0.1 \mathrm{~K}\right]}{\left(T_{\text {out }}-T_{\text {in }}\right)_{\text {mesaured }}}
\end{gathered}
$$

The maximum thermal efficiency $\left(\eta_{t h_{\max }}\right)$ and minimum thermal efficiency $\left(\eta_{t h_{\min }}\right)$ were then found using Equations (5-14) and (5-15).

$$
\eta_{t h_{\text {max }}}=\frac{\dot{Q}_{\text {max }}}{G_{\text {min }} A_{\text {panel }}}
$$




$$
\eta_{t h_{\text {min }}}=\frac{\dot{Q}_{\text {min }}}{G_{\text {max }} A_{\text {panel }}}
$$

The maximum electrical efficiency $\left(\eta_{e_{\max }}\right)$ and minimum electrical efficiency $\left(\eta_{e_{\min }}\right)$ of the panel were then found using Equations (5-16) and (5-17).

$$
\begin{aligned}
& \eta_{e_{\text {max }}}=\frac{1.01 \dot{E}_{\text {measured }}}{G_{\text {min }} A_{\text {panel }}} \\
& \eta_{e_{\text {min }}}=\frac{0.99 \dot{E}_{\text {measured }}}{G_{\text {max }} A_{\text {panel }}}
\end{aligned}
$$

A total of 22 tests were carried out in which the panel was allowed to reach steady state. The steady state condition was defined as when the water outlet temperature from the panel changed by less than $0.01 \mathrm{~K}$ per minute, for at least two minutes. Upon test completion, an average of each measured parameter over the last 120 seconds of each test was used to generate a data point for each parameter for each test. A summary of the averaged test data is presented in

Table 5-1. Note that an electrical power production measurement was not recorded for test 5 , but peak power tracking was active. 
Table 5-1: Experiment Test Results

\begin{tabular}{|c|c|c|c|c|c|c|c|c|c|c|}
\hline Mode & $\begin{array}{c}\text { Test } \\
\text { Number }\end{array}$ & $\begin{array}{l}\text { Wind } \\
\text { Speed } \\
(\mathrm{m} / \mathrm{s})\end{array}$ & $\begin{array}{c}\text { Water } \\
\text { Mass } \\
\text { Flow } \\
\text { Rate } \\
(\mathrm{kg} / \mathrm{h})\end{array}$ & $\begin{array}{l}\text { Solar } \\
\text { Flux } \\
\left(\mathrm{W} / \mathrm{m}^{2}\right)\end{array}$ & $\begin{array}{l}\text { Water } \\
\text { Inlet } \\
\text { Temp. } \\
\left({ }^{\circ} \mathrm{C}\right)\end{array}$ & $\begin{array}{l}\text { Water } \\
\text { Outlet } \\
\text { Temp. } \\
\left({ }^{\circ} \mathrm{C}\right)\end{array}$ & $\begin{array}{l}\text { Mean } \\
\text { Fluid } \\
\text { Temp. } \\
\left({ }^{\circ} \mathrm{C}\right)\end{array}$ & $\begin{array}{l}\text { Ambient } \\
\text { Temp. } \\
\left({ }^{\circ} \mathrm{C}\right)\end{array}$ & $\begin{array}{l}\text { Useful } \\
\text { Heat } \\
\text { Gain } \\
\text { (W) }\end{array}$ & $\begin{array}{c}\text { Electrical } \\
\text { Power } \\
\text { Output } \\
\text { (W) }\end{array}$ \\
\hline \multirow{12}{*}{ Hybrid } & 1 & 2.6 & 102.6 & 1062 & 21.9 & 27.64 & 24.77 & 19.66 & 683.7 & 145 \\
\hline & 2 & 2.6 & 102.8 & 1062 & 13.57 & 19.86 & 16.72 & 19.72 & 751 & 149.5 \\
\hline & 3 & 2.6 & 102.6 & 1062 & 40.37 & 44.84 & 42.61 & 19.62 & 532.3 & 135.9 \\
\hline & 4 & 2.6 & 104.4 & 1062 & 59.23 & 62.46 & 60.85 & 20.3 & 391.6 & 127 \\
\hline & 5 & 2.6 & 102.7 & 899 & 13.16 & 18.34 & 15.75 & 19.13 & 618 & \\
\hline & 6 & 2.6 & 103.7 & 899 & 21.49 & 26.2 & 23.85 & 19.19 & 567.1 & 124.7 \\
\hline & 7 & 2.6 & 102.8 & 899 & 40.23 & 43.95 & 42.09 & 19.24 & 444.6 & 114.1 \\
\hline & 8 & 2.6 & 103.1 & 899 & 58.99 & 61.48 & 60.24 & 20.12 & 299.4 & 108.1 \\
\hline & 9 & 2.6 & 102.6 & 1301 & 40.77 & 46.44 & 43.61 & 20.02 & 675.2 & 163.8 \\
\hline & 10 & 2.6 & 103.2 & 1301 & 22.21 & 29.12 & 25.67 & 20.3 & 828.2 & 174.9 \\
\hline & 11 & 2.6 & 103.3 & 1301 & 13.87 & 21.23 & 17.55 & 20.47 & 883.8 & 180.2 \\
\hline & 12 & 2.6 & 103 & 1301 & 59.46 & 63.98 & 61.72 & 21.01 & 540.7 & 151.9 \\
\hline \multirow{10}{*}{$\begin{array}{c}\text { Thermal- } \\
\text { Only }\end{array}$} & 13 & 2.6 & 102.6 & 1062 & 13.9 & 21.12 & 17.51 & 19.97 & 860.8 & 0 \\
\hline & 14 & 2.6 & 102.5 & 1062 & 22.18 & 28.79 & 25.49 & 19.8 & 786.6 & 0 \\
\hline & 15 & 2.6 & 102.5 & 1062 & 21.98 & 28.38 & 25.18 & 19.79 & 760.8 & 0 \\
\hline & 16 & 2.6 & 103.1 & 1062 & 40.64 & 45.87 & 43.26 & 19.95 & 625.6 & 0 \\
\hline & 17 & 2.6 & 103.2 & 899 & 13.34 & 19.26 & 16.30 & 19.18 & 709.9 & 0 \\
\hline & 18 & 2.6 & 103.7 & 899 & 21.67 & 27.07 & 24.37 & 19.16 & 650 & 0 \\
\hline & 19 & 2.6 & 102.8 & 899 & 40.3 & 44.59 & 42.45 & 19.2 & 511.4 & 0 \\
\hline & 20 & 2.6 & 102.7 & 1301 & 40.96 & 47.6 & 44.28 & 20.22 & 791.2 & 0 \\
\hline & 21 & 2.6 & 103.4 & 1301 & 22.45 & 30.39 & 26.42 & 20.24 & 952 & 0 \\
\hline & 22 & 2.6 & 102.9 & 1301 & 14.06 & 22.46 & 18.26 & 20.59 & 1004.5 & 0 \\
\hline
\end{tabular}

Using the measured test data, the resulting panel reduced temperatures, thermal efficiencies, and electrical efficiencies were calculated. The results shown in Table 5-2 summarize these calculated efficiencies, along with the uncertainties for each of these results which were derived based upon the maximum and minimum values found using Equations (5-10) to (5-17). 
Table 5-2: Resulting Thermal and Electrical Efficiencies

\begin{tabular}{|c|c|c|c|c|}
\hline Mode & $\begin{array}{c}\text { Test } \\
\text { Number }\end{array}$ & $\begin{array}{c}\text { Reduced } \\
\text { Temperature } \\
\left(\mathrm{Km}^{2} / \mathrm{W} \times 1000\right)\end{array}$ & $\begin{array}{l}\text { Thermal } \\
\text { Efficiency } \\
(\%)\end{array}$ & Electrical (\%) \\
\hline \multirow{12}{*}{ Hybrid } & 1 & $4.81+/-0.14$ & $46.0+/-1.4$ & $9.75+/-0.18$ \\
\hline & 2 & $-2.83+/-0.07$ & $50.5+/-1.5$ & $10.06+/-0.19$ \\
\hline & 3 & $21.64+/-0.28$ & $35.8+/-1.3$ & $9.14+/-0.17$ \\
\hline & 4 & $38.18+/-0.42$ & $26.3+/-1.2$ & $8.54+/-0.16$ \\
\hline & 5 & $-3.76+/-0.07$ & $49.1+/-1.7$ & \\
\hline & 6 & $5.18+/-0.16$ & $45.1+/-1.7$ & $9.91+/-0.20$ \\
\hline & 7 & $25.42+/-0.37$ & $35.3+/-1.5$ & $9.07+/-0.18$ \\
\hline & 8 & $44.62+/-0.56$ & $23.8+/-1.3$ & $8.59+/-0.17$ \\
\hline & 9 & $18.13+/-0.20$ & $37.1+/-1.1$ & $8.99+/-0.15$ \\
\hline & 10 & $4.12+/-0.11$ & $45.5+/-1.2$ & $9.60+/-0.16$ \\
\hline & 11 & $-2.24+/-0.06$ & $48.5+/-1.2$ & $9.89+/-0.17$ \\
\hline & 12 & $31.29+/-0.30$ & $29.7+/-1.0$ & $8.34+/-0.14$ \\
\hline \multirow{10}{*}{$\begin{array}{c}\text { Thermal- } \\
\text { Only }\end{array}$} & 13 & $-2.32+/-0.08$ & $57.9+/-1.6$ & 0 \\
\hline & 14 & $5.35+/-0.14$ & $52.9+/-1.5$ & 0 \\
\hline & 15 & $5.08+/-0.14$ & $51.2+/-1.5$ & 0 \\
\hline & 16 & $21.94+/-0.28$ & $42.1+/-1.4$ & 0 \\
\hline & 17 & $-3.20+/-0.08$ & $56.4+/-1.8$ & 0 \\
\hline & 18 & $5.80+/-0.17$ & $51.6+/-1.8$ & 0 \\
\hline & 19 & $25.86+/-0.37$ & $40.6+/-1.6$ & 0 \\
\hline & 20 & $18.49+/-0.21$ & $43.4+/-1.2$ & 0 \\
\hline & 21 & $4.75+/-0.11$ & $52.3+/-1.3$ & 0 \\
\hline & 22 & $-1.79+/-0.06$ & $55.1+/-1.3$ & 0 \\
\hline
\end{tabular}

Panel thermal and electrical efficiencies as functions of panel temperatures and are shown in Figure 5-4, along with regression fits to each of the data sets. 


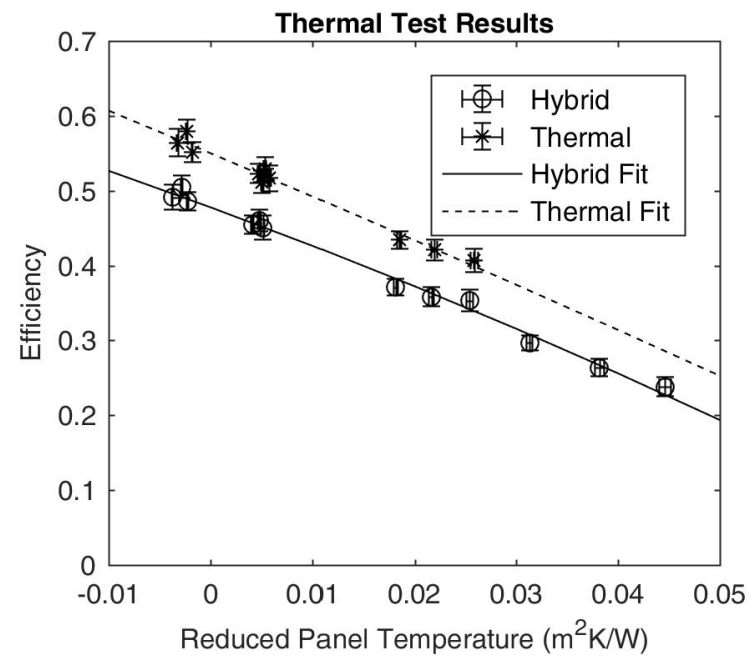

(a)

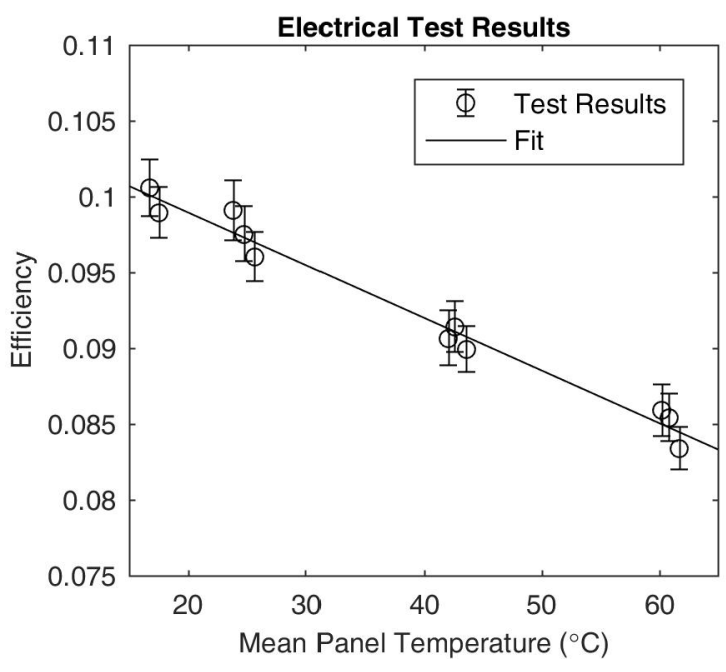

(b)

Figure 5-4: Thermal Test Results (a), Electrical Test Results (b)

It can be seen from Figure 5-4 that both the panel thermal and electrical efficiencies decrease with increasing panel temperature. The thermal efficiency results support that the panel operating mode does have an impact on the panel thermal performance, which will be discussed in more detail in Section 5.3.3. As the reduced temperature of the panel increases, the thermal efficiency decreases, which is expected based upon other results found in the literature [89, 90, 91]. Similarly, the electrical performance of the solar panel decreases as the mean panel temperature increases, which is also expected based upon typical PV panel performance [17].

The regression analysis was completed using the method of least squares to determine the most suitable set of coefficients for an equation of interest [102]. The coefficients for the secondorder thermal efficiency curve and the coefficients for the electrical efficiency curve are presented in Table 5-3. The resulting R-square and root mean square error (RMSE) for each of the fits are also presented in Table 5-3. 
Table 5-3: Panel Efficiency Equation Coefficients from Test Results

\begin{tabular}{|c|c|c|c|}
\hline Data Set & Equation & R-Square & RMSE \\
\hline Hybrid - Thermal Data & $\eta_{t h}=0.478-5.00 T_{r}-0.0136 T_{r}^{2} G$ & 0.9935 & 0.008 \\
\hline Thermal-Only - Thermal Data & $\eta_{t h}=0.550-5.73 T_{r}-0.00433 T_{r}^{2} G$ & 0.9814 & 0.010 \\
\hline Hybrid - Electrical Data & $\eta_{e}=0.1059-0.000347 T_{m}$ & 0.9796 & 0.001 \\
\hline
\end{tabular}

\subsubsection{Comparison to Manufacturer Published Characterization Curves}

A comparison of the test results to manufacturer supplied data was also carried out. The correlations supplied by the manufacturer are for the hybrid operating mode, and these correlations were used to estimate the panel thermal and electrical performance as a function of the different test conditions. The plots presented in Figure 5-5 include the experimentally derived characterization curves, along with the curves produced using manufacturer correlations. The coefficients for the manufacturer supplied thermal and electrical efficiency curves are presented in Table 5-4. The results of the comparative analysis are presented in Table 5-5, with differences being calculated with respect to the measured data. 


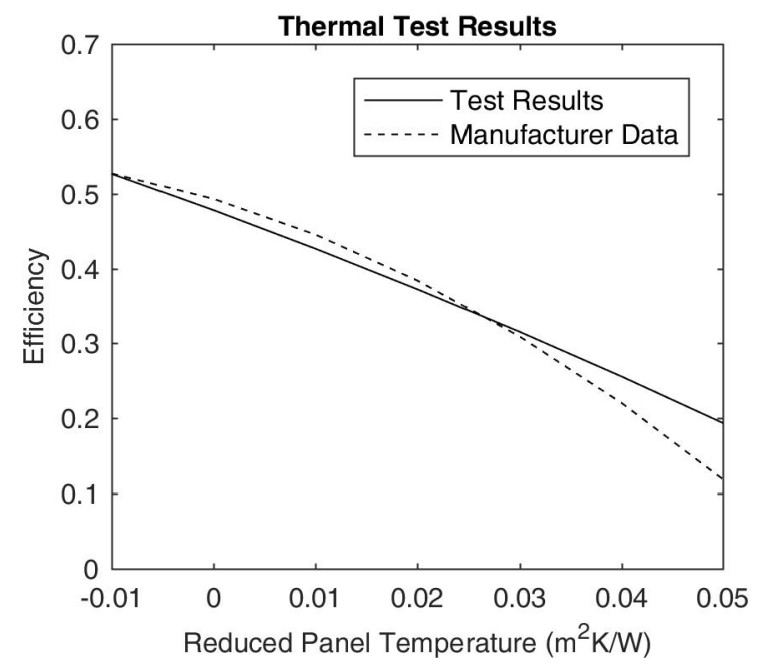

(a)

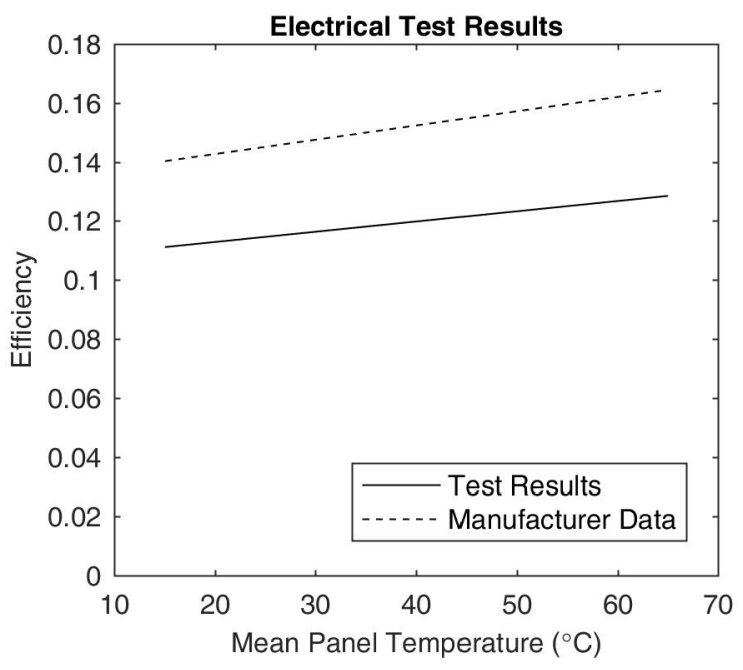

(b)

Figure 5-5: Manufacturer and Experimentally Produced Characterization Curves. (a) Thermal Curves for Hybrid Operating Case, (b) Electrical Curves

Table 5-4: Manufacturer Supplied Panel Efficiency Correlations [9, 41]

\begin{tabular}{|c|c|}
\hline Correlation & Equation \\
\hline Thermal & $\eta_{t h}=0.493-4.086 T_{r}-0.068 T_{r}^{2} G$ \\
\hline Electrical & $\eta_{e}=0.133-(0.6771 / 1400) T_{m}$ \\
\hline
\end{tabular}

Table 5-5: Comparison of Measured Data to Estimates using Manufacturer Correlations

\begin{tabular}{|c|c|c|c|c|c|c|}
\cline { 2 - 7 } \multicolumn{1}{c|}{} & \multicolumn{3}{c|}{ Useful Heat Gain } & \multicolumn{3}{c|}{ Electrical Power Produced } \\
\hline $\begin{array}{c}\text { Test } \\
\text { Number }\end{array}$ & Measured (W) & $\begin{array}{c}\text { Estimated } \\
(\mathrm{W})\end{array}$ & Error (\%) & Measured (W) & $\begin{array}{c}\text { Estimated } \\
(\mathrm{W})\end{array}$ & Error (\%) \\
\hline 1 & 684 & 701 & 2.6 & 145 & 180 & 24 \\
\hline 2 & 751 & 749 & -0.2 & 150 & 186 & 24 \\
\hline 3 & 532 & 551 & 3.5 & 136 & 167 & 23 \\
\hline 4 & 392 & 344 & -12.0 & 127 & 154 & 21 \\
\hline 5 & 618 & 639 & 3.4 & & 158 & \\
\hline 6 & 567 & 592 & 4.3 & 125 & 153 & 23 \\
\hline 7 & 445 & 440 & -1.0 & 114 & 142 & 24 \\
\hline 8 & 299 & 238 & -20.6 & 108 & 131 & 21 \\
\hline 9 & 675 & 710 & 5.2 & 164 & 204 & 24 \\
\hline 10 & 828 & 864 & 4.4 & 175 & 220 & 26 \\
\hline 11 & 884 & 914 & 3.4 & 180 & 227 & 26 \\
\hline 12 & 541 & 507 & -6.2 & 152 & 188 & 24 \\
\hline
\end{tabular}


Based on the results shown in Table 5-5, the average thermal performance estimation difference is approximately $5.6 \%$, with the largest differences occurring at elevated reduced temperatures. Since outdoor testing was used by the manufacturer, it is possible that steady-state operation may not have been as well established, which can lead to correlation inaccuracies. Similarly, outdoor testing introduces many uncontrolled parameters including variable wind speed, variable ambient temperature, and variable solar incidence angle. These parameters are not well accounted for by the second-order efficiency correlation, which can lead to additional inaccuracies. Therefore, given the general trends of both characterizations, the limits in available data, and the limits of the second-order efficiency correlation, the thermal characteristics of the panel have been determined to reasonably match the manufacturer provided specifications.

For the electrical performance, based on the results shown in Table 5-5, the average estimation difference is approximately $22 \%$, which is higher than a typically accepted $5 \%$ difference. It is important to note that the data from the manufacturer does not specify which temperature was used to generate their electrical performance correlation, which can lead to estimation errors. For example, if the PV cell temperature was measured directly with a thermocouple or thermal imaging camera, the temperatures used to derive the correlation would be different than if the fluid mean temperature was used.

To determine if this difference in selected correlation temperature was the cause of these large performance estimation differences, an investigation into the panel temperatures required to achieve the power outputs from each of the tests carried out for study was completed. This investigation involved using the electrical correlation from the manufacturer with the measured power outputs from each test, and backing out the temperature needed to balance the equation. These backed out temperatures were compared to the measured mean fluid temperatures for each 
test, and the average difference from all tests was found to be $44^{\circ} \mathrm{C}$. This result implies that if the manufacturer used a direct measurement of the PV cell temperature to produce their correlation, that their measurements were on average $44^{\circ} \mathrm{C}$ higher than the fluid mean temperature.

To determine if this difference should be expected, a review of the literature was carried out. A study by Aste et al. [103] focused on detailed monitoring of a glazed hybrid solar collector, similar in construction to the panel used in this experiment. While the construction of their panel was not identical, the measurements reported in the study showed a temperature difference of no more than $10^{\circ} \mathrm{C}$ between the PV cells and the mean fluid temperature. Therefore, it was concluded that the test results from this testing campaign do not align well with manufacturer data, even if the difference in the temperature used for the correlation is accounted for. However, since the electrical results from this testing campaign exhibit the expected trends, and show a strong correlation to panel temperature under different operating conditions, the test results are considered adequate for use given the purpose of this study.

\subsubsection{Application of the thermal performance modification technique}

Using the resulting correlations, and the environmental conditions from the testing campaign, the modification technique described in Section 5.2 was utilized to generate modified thermal performance data for validation purposes. The first validation case was carried out using hybrid mode measured environmental test data as inputs to Equations (5-6) with coefficients that were determined from thermal-only mode test data. Then, using the modification process, a prediction of hybrid mode thermal performance was completed and compared to the measured 
hybrid mode thermal performance test data. The results of this first validation case are presented in Table 5-6.

Table 5-6: Results of First Validation Case

\begin{tabular}{|c|c|c|c|c|c|}
\hline $\begin{array}{c}\text { Test } \\
\text { Number }\end{array}$ & $\begin{array}{c}\text { Measured } \\
\text { Useful } \\
\text { Heat } \\
\text { Gain (W) }\end{array}$ & $\begin{array}{c}\text { Estimated } \\
\text { Electrical } \\
\text { Efficiency from } \\
\text { Correlation }(\%)\end{array}$ & $\begin{array}{c}\text { Modified } \\
\text { Solar } \\
\text { Flux } \\
\left(\mathrm{W} / \mathrm{m}^{2}\right)\end{array}$ & $\begin{array}{c}\text { Modified } \\
\text { Useful } \\
\text { Heat Gain } \\
(\mathrm{W})\end{array}$ & $\begin{array}{c}\text { Relative } \\
\text { Error with } \\
\text { Modification } \\
(\%)\end{array}$ \\
\hline 1 & 683.7 & 9.73 & 959 & 697 & 1.95 \\
\hline 2 & 751 & 10.0 & 956 & 760 & 1.19 \\
\hline 3 & 532.3 & 9.11 & 965 & 556 & 4.39 \\
\hline 4 & 391.6 & 8.48 & 972 & 413 & 5.51 \\
\hline 5 & 618 & 10.0 & 809 & 650 & 5.14 \\
\hline 6 & 567.1 & 9.76 & 811 & 587 & 3.54 \\
\hline 7 & 444.6 & 9.13 & 817 & 443 & -0.46 \\
\hline 8 & 299.4 & 8.50 & 823 & 302 & 0.81 \\
\hline 9 & 675.2 & 9.08 & 1183 & 718 & 6.38 \\
\hline 10 & 828.2 & 9.70 & 1175 & 861 & 4.01 \\
\hline 11 & 883.8 & 9.98 & 1171 & 925 & 4.68 \\
\hline 12 & 540.7 & 8.45 & 1191 & 581 & 7.36 \\
\hline & & \multicolumn{5}{|c|}{ Average of Absolute Errors } & 3.79 \\
\hline
\end{tabular}

Based on the results presented in Table 5-6 for the first validation case, it can be seen that when the modification process is used to estimate hybrid mode performance with the thermal-only curve, estimates can be obtained with an average absolute relative error of $3.7 \%$. The minimum absolute error of $0.46 \%$ resulted from test 7 , which operated with a mean panel temperature of $42^{\circ} \mathrm{C}$, and a solar flux of $900 \mathrm{~W} / \mathrm{m}^{2}$. Alternatively, the maximum absolute error was $7.36 \%$ for test 12 , which operated with a mean panel temperature of $62^{\circ} \mathrm{C}$, and a solar flux of $1,300 \mathrm{~W} / \mathrm{m}^{2}$. Aside from test 7 , each of the estimations using the modification technique over-predicted the thermal power output of the solar panel. 
The second validation case was carried out using thermal-only mode measured environmental test data as inputs to Equations (5-6) with coefficients that were determined from hybrid mode test data. Then, using the modification process, a prediction of thermal-only mode thermal performance was completed and compared to the measured thermal-only mode test data. The results of this second validation case are presented in Table 5-7.

Table 5-7: Results of Second Validation Case

\begin{tabular}{|c|c|c|c|c|c|}
\hline $\begin{array}{c}\text { Test } \\
\text { Number }\end{array}$ & $\begin{array}{c}\text { Measured } \\
\text { Useful } \\
\text { Heat } \\
\text { Gain (W) }\end{array}$ & $\begin{array}{c}\text { Estimated } \\
\text { Electrical } \\
\text { Efficiency from } \\
\text { Correlation }(\%)\end{array}$ & $\begin{array}{c}\text { Modified } \\
\text { Solar } \\
\text { Flux } \\
\left(\mathrm{W} / \mathrm{m}^{2}\right)\end{array}$ & $\begin{array}{c}\text { Modified } \\
\text { Useful } \\
\text { Heat Gain } \\
(\mathrm{W})\end{array}$ & $\begin{array}{c}\text { Relative } \\
\text { Error with } \\
\text { Modification } \\
(\%)\end{array}$ \\
\hline 13 & 860.8 & 9.98 & 1168 & 813 & -5.50 \\
\hline 14 & 786.6 & 9.71 & 1165 & 754 & -4.15 \\
\hline 15 & 760.8 & 9.72 & 1165 & 756 & -0.61 \\
\hline 16 & 625.6 & 9.09 & 1159 & 616 & -1.47 \\
\hline 17 & 709.9 & 10.0 & 989 & 694 & -2.19 \\
\hline 18 & 650 & 9.74 & 987 & 636 & -2.20 \\
\hline 19 & 511.4 & 9.12 & 981 & 496 & -3.05 \\
\hline 20 & 791.2 & 9.05 & 1419 & 788 & -0.42 \\
\hline 21 & 952 & 9.67 & 1427 & 929 & -2.43 \\
\hline 22 & 1004.5 & 9.96 & 1431 & 992 & -1.29 \\
\hline \multicolumn{5}{|r|}{ Average of Absolute Errors } & 2.33 \\
\hline
\end{tabular}

Based on the results presented in Table 5-7 for the second validation case, it can be seen that when the modification process is used to estimate thermal-only performance with the hybrid curve, estimates can be obtained with an average absolute relative error of $2.33 \%$. The minimum absolute error of $0.42 \%$ resulted from test 20 , which operated with a mean panel temperature of $44^{\circ} \mathrm{C}$, and a solar flux of $1,300 \mathrm{~W} / \mathrm{m}^{2}$. Alternatively, the maximum absolute error of $5.5 \%$ resulted from test 13 , which operated with a mean panel temperature of $62^{\circ} \mathrm{C}$, and a solar flux of 1,300 
$\mathrm{W} / \mathrm{m}^{2}$. Each of the estimations using the modification technique for the second validation case under-predicted the thermal power output of the solar panel, which is an opposite result compared to the first validation case.

For additional insight, a calculation of the estimated thermal performance of the panel using the unmodified thermal performance correlations was also completed. The unmodified thermal-only correlation was used with the hybrid mode test data (case 1), and the unmodified hybrid mode correlation was used with the thermal-only test data (case 2). A summary of the resulting relative errors between these estimations and the measured test data is presented in Table $5-8$, along with the previously presented relative errors using the modification process for comparison. 
Table 5-8: Unmodified Performance Estimations for Comparison

\begin{tabular}{|c|c|c|c|}
\hline $\begin{array}{c}\text { Validation } \\
\text { Case }\end{array}$ & $\begin{array}{c}\text { Test } \\
\text { Number }\end{array}$ & $\begin{array}{l}\text { Absolute Relative } \\
\text { Error with } \\
\text { Modification (\%) }\end{array}$ & $\begin{array}{l}\text { Absolute Relative } \\
\text { Error Without } \\
\text { Modification }(\%)\end{array}$ \\
\hline \multirow{13}{*}{1} & 1 & 1.95 & 13.6 \\
\hline & 2 & 1.19 & 12.1 \\
\hline & 3 & 4.39 & 18.4 \\
\hline & 4 & 5.51 & 23.2 \\
\hline & 5 & 5.14 & 16.4 \\
\hline & 6 & 3.54 & 15.5 \\
\hline & 7 & 0.46 & 13.8 \\
\hline & 8 & 0.81 & 20.5 \\
\hline & 9 & 6.38 & 19.8 \\
\hline & 10 & 4.01 & 15.7 \\
\hline & 11 & 4.68 & 16.0 \\
\hline & 12 & 7.36 & 23.0 \\
\hline & Average & 3.79 & 17.3 \\
\hline \multirow{11}{*}{2} & 13 & 5.50 & 15.5 \\
\hline & 14 & 4.15 & 14.8 \\
\hline & 15 & 0.61 & 11.6 \\
\hline & 16 & 1.47 & 14.1 \\
\hline & 17 & 2.19 & 12.4 \\
\hline & 18 & 2.20 & 13.1 \\
\hline & 19 & 3.05 & 16.2 \\
\hline & 20 & 0.42 & 12.6 \\
\hline & 21 & 2.43 & 13.2 \\
\hline & 22 & 1.29 & 11.7 \\
\hline & Average & 2.33 & 13.5 \\
\hline
\end{tabular}

Based on the results presented in Table 5-8, it was found that using the modification technique improves opposing mode thermal performance estimations for all tests. Using the unmodified thermal-only curve to estimate hybrid performance data results in an average estimation error of $17.3 \%$, compared to an average estimation error of $3.8 \%$ when using the modification technique. Similarly, using the unmodified hybrid mode curve to estimate thermalonly performance data results in an average estimation error of $13.5 \%$, compared to an average estimation error of $2.3 \%$ when using the modification technique. Furthermore, these experimental results validate that the modification technique is an effective method in predicting alternate mode thermal performance for a hybrid panel. 
Lastly, correlations between relative error estimates using the modification technique and reduced temperature, solar flux, fluid temperature increase across the panel, and panel mean temperature were also investigated. However, the R-square results for each of these correlations did not exceed 0.12 . Therefore, it was determined that there is no significant correlation between panel operating conditions and the error that results when using the modification technique.

\subsubsection{Comparing the Proposed Method to an Alternative Modification Method}

As mentioned in the literature review in Section 5.1.8, the International Energy Agency (IEA) has proposed an alternative method for predicting thermal performance in different operating modes. The method they propose involves directly adding or subtracting the electrical efficiency of the solar collector, depending on the modification case, to the estimated thermal efficiency. This modification methodology can be summarized by Equation (5-18) when performing the hybrid to thermal-only modification, and Equation (5-19) when performing the thermal-only to hybrid modification. Based on this methodology, Equations (5-1) through (5-4) are used to determine the efficiency, unmodified thermal efficiency, and energy outputs from the panel.

$$
\begin{gathered}
\eta_{t h}^{\prime}=\eta_{t h}+\eta_{e} \\
\eta_{t h}^{\prime}=\eta_{t h}-\eta_{e}
\end{gathered}
$$

To compare the efficacy of the IEA method with the proposed method, the experimental data set was also postprocessed using the IEA method. The results of utilizing the IEA 
methodology are presented in Table 5-9 for the first validation case, which represents using a thermal-only mode correlation to estimate hybrid performance. The results of utilizing the IEA modification methodology are presented in Table 5-10 for the second validation case, which represents using a hybrid mode correlation to estimate thermal-only performance. The relative error in both tables represents the error in estimating the useful heat gain of the panel, when comparing the estimate to the measured test data for each operating point.

Table 5-9: First Validation Case Modification Results Using the IEA Method

\begin{tabular}{|c|c|c|c|c|c|c|}
\hline $\begin{array}{c}\text { Test } \\
\text { Number }\end{array}$ & $\begin{array}{l}\text { Measured } \\
\text { Useful } \\
\text { Heat } \\
\text { Gain (W) }\end{array}$ & $\begin{array}{c}\text { Estimated } \\
\text { Thermal } \\
\text { Efficiency from } \\
\text { Correlation }(\%)\end{array}$ & $\begin{array}{c}\text { Estimated } \\
\text { Electrical } \\
\text { Efficiency from } \\
\text { Correlation }(\%)\end{array}$ & $\begin{array}{c}\text { Modified } \\
\text { Thermal } \\
\text { Efficiency } \\
(\%)\end{array}$ & $\begin{array}{l}\text { Modified } \\
\text { Useful } \\
\text { Heat } \\
\text { Gain (W) }\end{array}$ & $\begin{array}{c}\text { Relative } \\
\text { Error with } \\
\text { Modification } \\
(\%)\end{array}$ \\
\hline 1 & 683.7 & 52.2 & 9.73 & 42.5 & 631.9 & -7.57 \\
\hline 2 & 751 & 56.6 & 10.0 & 46.6 & 692.9 & -7.73 \\
\hline 3 & 532.3 & 42.4 & 9.11 & 33.3 & 494.6 & -7.07 \\
\hline 4 & 391.6 & 32.5 & 8.48 & 24.0 & 356.4 & -8.98 \\
\hline 5 & 618 & 57.1 & 10.0 & 47.1 & 592.9 & -4.07 \\
\hline 6 & 567.1 & 52.0 & 9.76 & 42.3 & 531.8 & -6.22 \\
\hline 7 & 444.6 & 40.2 & 9.13 & 31.1 & 390.9 & -12.1 \\
\hline 8 & 299.4 & 28.7 & 8.50 & 20.2 & 253.7 & -15.3 \\
\hline 9 & 675.2 & 44.4 & 9.08 & 35.3 & 643.8 & -4.65 \\
\hline 10 & 828.2 & 52.6 & 9.70 & 42.9 & 781.9 & -5.60 \\
\hline 11 & 883.8 & 56.3 & 9.98 & 46.3 & 843.3 & -4.58 \\
\hline 12 & 540.7 & 36.5 & 8.45 & 28.1 & 511.3 & -5.44 \\
\hline \multicolumn{6}{|c|}{ Average of Absolute Errors } & 7.44 \\
\hline
\end{tabular}


Table 5-10: Second Validation Case Modification Results Using the IEA Method

\begin{tabular}{|c|c|c|c|c|c|c|}
\hline $\begin{array}{c}\text { Test } \\
\text { Number }\end{array}$ & $\begin{array}{l}\text { Measured } \\
\text { Useful } \\
\text { Heat } \\
\text { Gain (W) }\end{array}$ & $\begin{array}{c}\text { Estimated } \\
\text { Thermal } \\
\text { Efficiency from } \\
\text { Correlation }(\%)\end{array}$ & $\begin{array}{c}\text { Estimated } \\
\text { Electrical } \\
\text { Efficiency from } \\
\text { Correlation (\%) }\end{array}$ & $\begin{array}{c}\text { Modified } \\
\text { Thermal } \\
\text { Efficiency } \\
(\%)\end{array}$ & $\begin{array}{l}\text { Modified } \\
\text { Useful } \\
\text { Heat } \\
\text { Gain (W) }\end{array}$ & $\begin{array}{c}\text { Relative } \\
\text { Error with } \\
\text { Modification } \\
(\%)\end{array}$ \\
\hline 13 & 860.8 & 49.0 & 9.98 & 58.9 & 876.2 & 1.79 \\
\hline 14 & 786.6 & 45.1 & 9.71 & 54.8 & 814.5 & 3.55 \\
\hline 15 & 760.8 & 45.2 & 9.72 & 54.9 & 816.9 & 7.37 \\
\hline 16 & 625.6 & 36.1 & 9.09 & 45.2 & 672.3 & 7.47 \\
\hline 17 & 709.9 & 49.4 & 10.0 & 59.4 & 747.8 & 5.34 \\
\hline 18 & 650 & 44.9 & 9.74 & 54.6 & 687.3 & 5.73 \\
\hline 19 & 511.4 & 34.1 & 9.12 & 43.2 & 543.3 & 6.24 \\
\hline 20 & 791.2 & 37.9 & 9.05 & 47.0 & 856.1 & 8.20 \\
\hline 21 & 952 & 45.4 & 9.67 & 55.1 & 1003 & 5.34 \\
\hline 22 & 1004.5 & 48.7 & 9.96 & 58.6 & 1068 & 6.34 \\
\hline \multicolumn{6}{|c|}{ Average of Absolute Errors } & 5.74 \\
\hline
\end{tabular}

To complete the comparison, the relative error results from the IEA method are presented along with the results from the proposed method in Table 5-11. 
Table 5-11: Results of Comparison between IEA Modification Method to Proposed Method

\begin{tabular}{|c|c|c|c|c|}
\hline $\begin{array}{l}\text { Validation } \\
\text { Case }\end{array}$ & $\begin{array}{c}\text { Test } \\
\text { Number }\end{array}$ & $\begin{array}{l}\text { Absolute } \\
\text { Relative from } \\
\text { Proposed } \\
\text { Method (\%) }\end{array}$ & $\begin{array}{c}\text { Absolute } \\
\text { Relative } \\
\text { from IEA } \\
\text { Method (\%) }\end{array}$ & $\begin{array}{l}\text { Improvement } \\
\text { using Proposed } \\
\text { Method (\%) }\end{array}$ \\
\hline \multirow{13}{*}{1} & 1 & 1.95 & 7.57 & 5.62 \\
\hline & 2 & 1.19 & 7.73 & 6.54 \\
\hline & 3 & 4.39 & 7.07 & 2.68 \\
\hline & 4 & 5.51 & 8.98 & 3.47 \\
\hline & 5 & 5.14 & 4.07 & -1.07 \\
\hline & 6 & 3.54 & 6.22 & 2.68 \\
\hline & 7 & 0.46 & 12.1 & 11.64 \\
\hline & 8 & 0.81 & 15.3 & 14.49 \\
\hline & 9 & 6.38 & 4.65 & -1.73 \\
\hline & 10 & 4.01 & 5.60 & 1.59 \\
\hline & 11 & 4.68 & 4.58 & -0.10 \\
\hline & 12 & 7.36 & 5.44 & -1.92 \\
\hline & Average & 3.79 & 7.44 & 3.65 \\
\hline \multirow{11}{*}{2} & 13 & 5.50 & 1.79 & -3.71 \\
\hline & 14 & 4.15 & 3.55 & -0.60 \\
\hline & 15 & 0.61 & 7.37 & 6.76 \\
\hline & 16 & 1.47 & 7.47 & 6.00 \\
\hline & 17 & 2.19 & 5.34 & 3.15 \\
\hline & 18 & 2.20 & 5.73 & 3.53 \\
\hline & 19 & 3.05 & 6.24 & 3.19 \\
\hline & 20 & 0.42 & 8.20 & 7.78 \\
\hline & 21 & 2.43 & 5.34 & 2.91 \\
\hline & 22 & 1.29 & 6.34 & 5.05 \\
\hline & Average & 2.33 & 5.74 & 3.41 \\
\hline \multicolumn{2}{|c|}{ Overall Average } & 3.21 & 6.67 & 3.54 \\
\hline
\end{tabular}

As shown in Table 5-11, when using the thermal-only correlation to estimate hybrid performance, the average absolute estimation error using the proposed method is $3.79 \%$ and the average absolute estimation error using the IEA method is $7.44 \%$. Therefore, the proposed method offers an average improvement of $3.66 \%$ for the first modification case. Similarly, when using the hybrid correlation to estimate thermal-only performance, the average absolute estimation error using the proposed method is $2.33 \%$ and the average absolute estimation error is $5.74 \%$ when using the IEA method. Therefore, the proposed method offers an average improvement of 3.41\% 
for the second modification case. Finally, based on an average for all of the tests that were carried out, the proposed method offers an estimation improvement of $3.54 \%$ compared to the IEA method, which further supports utilizing the proposed method to improve performance estimated in alternate operating modes.

\subsection{Conclusions}

Hybrid panel manufactures typically publish the second-order efficiency parameters for their products, which are often used by researchers and engineers to estimate overall panel thermal performance. However, based upon standard testing procedures, manufacturers are only required to characterize the thermal performance of hybrid panels in hybrid mode, or thermal-only mode. Due to this widespread use, and because of the need for alternate mode performance prediction, a modification technique for the second-order efficiency model was selected as the focus for this study.

The proposed modification method involves adjusting the available solar flux based upon the theoretical electrical efficiency of the panel. This modified flux is then used to determine a modified panel reduced temperature, and these two modified parameters can then be used with the manufacturer provided efficiency correlation. Using this modification method, the average estimating error was found to be $3.71 \%$ when using the modified thermal-only correlation to estimate hybrid mode performance, which results in a $13.5 \%$ performance estimation improvement compared to not using the modification process. Similarly, when using the modification method with the hybrid mode correlation to estimate thermal-only performance, an average error of $2.33 \%$ was found, with an average improvement of $11.2 \%$ compared to not using the modification 
method. No strong correlation was found between estimation error and panel mean temperature, solar flux, or panel reduced temperature. Therefore, based upon the results of this study, the proposed modification method has been validated as an effective tool for estimating alternate mode hybrid solar panel thermal performance. 


\section{Chapter 6 Conclusion}

\subsection{Summary and Conclusions}

This thesis focused on the development of a novel solar heating system. The system was made up of a hybrid solar panel coupled with a cascade heat pump, such that heat output from the system could be optimized. In Chapter 1, the thesis began by introducing the challenges being faced worldwide with respect to climate change, and outlining the need for sustainable heating systems. A high-level overview of solar and heat pump technologies was then presented, such that the technologies being built upon with the development of this system were well defined. It was concluded from this overview that combining heat pumps with hybrid solar panels offered the ability to optimize the combined system. This combination also took advantage of the operating characteristics of both individual systems, to improve overall system performance.

Next, the initial development of the hybrid solar heating system was detailed in Chapter 2, which illustrated the motivation for selecting the final system layout. An initial design iteration was presented in Section 2.1, which utilized a single heat pump that was coupled with a hybrid solar collector. Plots of system heat output as a function panel temperature illustrated that system performance was sensitive to panel temperature. To improve system performance, and decrease performance sensitivity to panel temperature, design iterations were carried out and the final iteration was presented in Section 2.2. This design included a second heat pump loop, and thermal storage. Plots of system performance as a function of panel temperature were presented in Figure 2-5, which also compared the performance of the final design to that of the initial iteration. This

final design was selected as the focus for the thesis project because of improved peak heat output, and because of reduced sensitivity to panel operating temperature. 
Following the design development, a first manuscript-based chapter was presented in Chapter 3. This chapter focused on utilizing the proposed solar heating system for water distillation. An analysis methodology for a multi-effect distillation system was presented, along with the analysis methodology for the hybrid solar cascade heat pump heating system. Case studies were presented that compared the proposed solar heating system with a solar still for four different locations. The final conclusion from this chapter was that using the hybrid solar heating system offered performance improvements up of to $780 \%$ compared to a basic solar still, and a $65 \%$ improvement compared to the next leading thermally driven distillation technology.

A second manuscript-based study was then presented in Chapter 4, which primarily focused on utilizing the proposed solar heating system for domestic hot water production. An analysis methodology that improves heat pump performance estimates, compared to the methods used in Chapter 3, was also presented as part of this chapter. Case studies were carried out which compared the proposed cascade hybrid solar heating system to an evacuated tube heating system, and a single heat pump hybrid solar heating system. One conclusion from this study was that the cascade solar heating system exceeded the performance of both other systems for each of the test locations that were investigated. A second conclusion was that the improvements compared to the other two systems were maximized during seasons with higher average dry-bulb temperatures, and increased solar irradiation.

The final manuscript-based study for the thesis was presented in Chapter 5, which focused on improving alternate mode thermal performance estimates for hybrid solar panels. This study focused on the development of the alternate mode thermal performance estimation methodology, and also focused on experimental testing that was carried out at Concordia University. The conclusion from this study was that the proposed methodology can successfully estimate thermal 
performance within $5 \%$ of actual values. The study also demonstrated that the proposed methodology exhibited improved performance estimates for all test cases when compared to not using the methodology for alternate mode performance estimation. Each of these studies contributed to the goal of developing a novel solar energy heating system, and a list of the resulting scientific contributions is presented in Section 6.2.

\subsection{Novel Scientific Contributions}

A summary of the novel scientific contributions that resulted from this doctoral thesis is presented below:

1. A novel solar heating system was developed that includes a cascade heat pump and hybrid solar panels. This system offers performance improvement compared to other solar heating systems, and is less sensitive to panel temperature than comparable systems. Analysis methodologies for this system were disseminated to the scientific community, which also contain the algorithms needed to simulate a wide variety of other systems. The system and these algorithms have increased the scientific community's understanding of solar technologies, and have provided additional analysis tools.

2. A heat pump analysis technique was formalized that uses the industry-standard tencoefficient polynomial, and also accounts for different levels of superheating and subcooling. Standard testing methods only require that one level of superheating and subcooling be used to characterize the performance of heat pumps. However, these levels may differ from those used in an application, which will alter system 
performance. Therefore, the analysis methodology that was developed will allow the scientific community to improve the accuracy of their simulations.

3. A simple technique that can estimate alternate mode hybrid solar panel thermal performance was developed. This technique only uses manufacturer-supplied data, which ensures that it is widely accessible to engineers and system designers. Manufacturers are only required to provide thermal performance of hybrid solar panels in one operating mode, but there may be times that systems operate in an alternate mode. Therefore, this technique can be used by the scientific community to improve alternate mode performance estimates for hybrid solar panels.

4. High-quality experimental data has been analyzed and disseminated to the scientific community for a liquid-based hybrid solar panel. This data was a result of the successful experimental testing campaign that was developed and carried out as part of this doctoral thesis work. This data can be used by the scientific community for model validation, which is critical when developing new analysis techniques.

\subsection{Recommendations for Future Work}

Additional tasks that are beyond the scope of this thesis, that can further develop the included topics are herein discussed in the list below:

1. Investigations into additional applications for the hybrid solar heat pump system should be carried out. As shown throughout the thesis, the temperatures that are used with this system affect performance. Since many applications require different temperatures, the efficacy of 
the system for these different applications should be investigated. These applications include space heating, and ground source heat pump thermal balancing.

2. Investigations into the effect of different load profiles on the efficiency of the hybrid solar heat pump system should be completed. Since the previous simulations of the system assume that all energy being output from the high pressure condenser could be immediately used, there may be changes to system efficiency if energy storage is required. This analysis will more clearly illustrate the practicality of the system, and will permit more realistic economic assessments.

3. Bench testing of a cascade heat pump system with thermal storage should be carried out to validate the analysis algorithms that were developed as part of this thesis. This system should include a variable speed compressor, variable electrical input, and variable heat input such that the cascade heat pump system with thermal storage can be independently tested. The use of a solar collector is not needed for this validation, but should be added after initial testing.

4. Following the independent validation of the cascade heat pump with thermal storage, the addition of hybrid solar collectors to the system should be carried out. Outdoor and longterm testing should be completed to determine real-world performance, and to determine the best control strategies for the installation.

5. Testing of additional hybrid solar panels using the same testing campaign that was detailed in Chapter 5 should be carried out. This test data should then be used along with the alternate mode thermal performance analysis methodology to determine the efficacy of the technique for different solar collector designs. Air-based and liquid-based collectors should be considered. 


\section{Appendix A Derivation of Equation (2-7)}

The derivation begins by defining the following fundamental equations for the cascade heat pump system:

$$
\begin{gathered}
\operatorname{COP}_{A}=\frac{\dot{Q}_{\text {out }_{A}}}{\dot{W}_{A}} \\
\operatorname{COP}_{B}=\frac{\dot{Q}_{\text {out }_{B}}}{\dot{W}_{B}} \\
\operatorname{COP}_{\text {cascade }}=\frac{\dot{Q}_{\text {out }_{B}}}{\dot{W}_{A}+\dot{W}_{B}} \\
\dot{Q}_{\text {out }_{A}}=\dot{Q}_{\text {in }_{B}} \\
\dot{Q}_{\text {out }_{A}}=\dot{Q}_{\text {in }_{A}}+\dot{W}_{A} \\
\dot{Q}_{\text {out }_{B}}=\dot{Q}_{\text {in }_{B}}+\dot{W}_{B}
\end{gathered}
$$

Next, re-arranging Equation (6) and inputting Equations (1), (2), and (4):

$$
\begin{gathered}
\dot{Q}_{o u t_{B}}=\dot{Q}_{\text {in }_{B}}+\dot{W}_{B} \\
\dot{Q}_{o u t_{B}}=\dot{Q}_{o u t_{A}}+\dot{W}_{B} \\
C O P_{B} \dot{W}_{B}=C O P_{A} \dot{W}_{A}+\dot{W}_{B} \\
\dot{W}_{B}\left(C O P_{B}-1\right)=C O P_{A} \dot{W}_{A} \\
\frac{\dot{W}_{A}}{\dot{W}_{B}}=\frac{C O P_{B}-1}{C O P_{A}}
\end{gathered}
$$

Finally, rearranging Equation (3) and inputting Equations (2) and (7): 


$$
\begin{gathered}
C O P_{\text {cascade }}=\frac{\dot{Q}_{\text {out }_{B}}}{\dot{W}_{A}+\dot{W}_{B}} \\
C O P_{\text {cascade }}=\frac{\dot{Q}_{o u t_{B}} / \dot{W}_{B}}{\dot{W}_{A} / \dot{W}_{B}+1} \\
C O P_{\text {cascade }}=\frac{C O P_{B}}{\frac{C O P_{B}-1}{C O P_{A}}+1} \\
C O P_{\text {cascade }}=\frac{C O P_{A} C O P_{B}}{C O P_{A}+C O P_{B}-1}
\end{gathered}
$$




\section{Appendix B Solimpeks PowerTherm Panel Manufacturer Specifications}

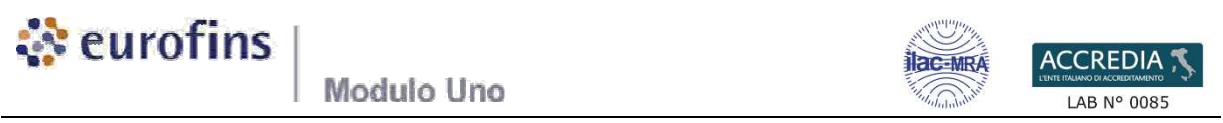

\begin{tabular}{|c|c|c|c|c|c|c|c|c|c|c|c|c|c|}
\hline$\S$ & & \multicolumn{12}{|c|}{ TAB. 11A: Thermal performance - Measurements' results / Prestazioni termiche - Risultati delle misure } \\
\hline \multicolumn{4}{|c|}{$\begin{array}{l}\text { Test start [YYYY/MM/DD] } \\
\text { Data inizio prova [AAAA/MM/GG] }\end{array}$} & \multicolumn{4}{|c|}{ 2011/05/10 } & \multicolumn{3}{|c|}{$\begin{array}{l}\text { Test end [YYYY/MM/DD] } \\
\text { Data fine prova [AAAA/MM/GG] }\end{array}$} & \multicolumn{3}{|c|}{ 2011/07/27 } \\
\hline \multicolumn{4}{|c|}{ Test method / Metodo di prova } & \multicolumn{4}{|c|}{ 6.1 Outdoor - Steady state $\bigotimes$} & \multicolumn{3}{|c|}{6.1 Indoor - Steady state method $\square$} & \multicolumn{3}{|c|}{ 6.3 Outdoor-quasi-dynamic $\square$} \\
\hline \multicolumn{4}{|c|}{ Latitude / Latitudine: } & \multicolumn{4}{|c|}{$44^{\circ} 52^{\prime} \mathrm{N}$} & \multicolumn{3}{|c|}{ Longitude / Longitudine: } & \multicolumn{3}{|c|}{$08^{\circ} 48^{\prime} \mathrm{E}$} \\
\hline \multicolumn{4}{|c|}{$\begin{array}{l}\text { Collector tilt / Inclinazione del } \\
\text { collettore [ }]\end{array}$} & \multicolumn{4}{|c|}{45} & \multicolumn{3}{|c|}{$\begin{array}{l}\text { Collector azimuth /Orientamento } \\
\text { azimutale del collettore }\end{array}$} & \multicolumn{3}{|c|}{ South / sud } \\
\hline \multicolumn{11}{|c|}{ Orientation of absorber tubes during testing / Orientamento dei tubi del collettore durante la prova } & \multicolumn{3}{|c|}{45} \\
\hline \multicolumn{11}{|c|}{ Flow rate used for performance testing (average) / Flusso utilizzato per il test (valore medio) $\left[\mathrm{kg} / \mathrm{s} / \mathrm{m}^{2}\right]$} & \multicolumn{3}{|c|}{0.021} \\
\hline \multicolumn{14}{|c|}{ Test results / Risultati di prova } \\
\hline & & \multicolumn{6}{|c|}{ Measured } & \multicolumn{6}{|c|}{ Derived } \\
\hline & \# & $\begin{array}{r}\text { Ta } \\
{\left[{ }^{[} \mathrm{C}\right]}\end{array}$ & $\mathrm{G}\left[\mathrm{W} / \mathrm{m}^{2}\right]$ & $\begin{array}{c}u \\
{[\mathrm{~m} / \mathrm{s}]}\end{array}$ & $\begin{array}{l}\text { Tin } \\
{\left[{ }^{\circ} \mathrm{C}\right]}\end{array}$ & $\begin{array}{l}\text { Tout } \\
{\left[{ }^{\circ}\right]}\end{array}$ & $\begin{array}{l}\text { Flow } \\
\text { rate } \\
{[1 / \mathrm{min}}\end{array}$ & $\begin{array}{l}\Delta \mathbf{T} \\
{[\mathrm{K}]}\end{array}$ & $\begin{array}{l}\mathrm{Tm} \\
{\left[{ }^{[} \mathrm{C}\right]}\end{array}$ & $\begin{array}{c}\mathbf{Q} \\
{[\mathbf{W}]}\end{array}$ & $\mathbf{T}_{\mathrm{m}}{ }^{*}$ & $\eta_{\mathrm{A}}$ & $\eta_{a}$ \\
\hline & 1 & 22.2 & 983 & 1.63 & 15.00 & 20.70 & 1.72 & 5.70 & 17.85 & 4.1835 & -0.004 & 0.50 & 0.49 \\
\hline & 2 & 22.4 & 977 & 1.57 & 15.08 & 21.02 & 1.72 & 5.94 & 18.05 & 4.1833 & -0.004 & 0.52 & 0.51 \\
\hline & 3 & 22.3 & 951 & 1.96 & 15.09 & 20.60 & 1.73 & 5.51 & 17.85 & 4.1835 & -0.005 & 0.50 & 0.49 \\
\hline & 4 & 22.6 & 944 & 1.99 & 15.12 & 20.80 & 1.73 & 5.67 & 17.96 & 4.1834 & -0.005 & 0.52 & 0.51 \\
\hline & 5 & 23.8 & 918 & 2.09 & 26.00 & 31.22 & 1.71 & 5.22 & 28.61 & 4.1789 & 0.005 & 0.48 & 0.48 \\
\hline & 6 & 24.2 & 934 & 2.18 & 26.10 & 31.20 & 1.73 & 5.11 & 28.65 & 4.1789 & 0.005 & 0.47 & 0.46 \\
\hline & 7 & 24.8 & 957 & 2.23 & 26.28 & 31.64 & 1.71 & 5.37 & 28.96 & 4.1788 & 0.004 & 0.48 & 0.47 \\
\hline . & 8 & 23.9 & 893 & 1.57 & 26.05 & 30.91 & 1.72 & 4.86 & 28.48 & 4.1789 & 0.005 & 0.47 & 0.46 \\
\hline 음 & 9 & 23.1 & 1006 & 1.51 & 38.81 & 43.44 & 1.72 & 4.63 & 41.12 & 4.1795 & 0.018 & 0.39 & 0.39 \\
\hline 苋 & 10 & 22.8 & 976 & 1.41 & 37.96 & 42.49 & 1.73 & 4.53 & 40.23 & 4.1793 & 0.018 & 0.40 & 0.39 \\
\hline & 11 & 22.7 & 893 & 1.78 & 37.40 & 41.50 & 1.72 & 4.10 & 39.45 & 4.1792 & 0.019 & 0.39 & 0.39 \\
\hline & 12 & 23.3 & 925 & 1.58 & 38.18 & 42.31 & 1.74 & 4.13 & 40.25 & 4.1793 & 0.018 & 0.39 & 0.38 \\
\hline & 13 & 27.4 & 964 & 1.33 & 53.03 & 56.79 & 1.72 & 3.75 & 54.91 & 4.1833 & 0.029 & 0.33 & 0.33 \\
\hline & 14 & 26.0 & 948 & 2.31 & 51.69 & 55.19 & 1.72 & 3.50 & 53.44 & 4.1827 & 0.029 & 0.32 & 0.31 \\
\hline & 15 & 26.8 & 973 & 2.36 & 52.96 & 56.55 & 1.73 & 3.60 & 54.76 & 4.1832 & 0.029 & 0.32 & 0.31 \\
\hline & 16 & 28.0 & 992 & 1.10 & 54.21 & 57.86 & 1.73 & 3.66 & 56.04 & 4.1837 & 0.028 & 0.32 & 0.31 \\
\hline & 17 & -- & -- & -- & - & - & - & - & - & - & - & - & -- \\
\hline & 18 & -- & - & -- & - & - & - & - & - & - & - & - & -- \\
\hline & 19 & -- & - & -- & - & - & - & - & - & - & - & - & - \\
\hline & 20 & -- & - & -- & - & - & -- & - & - & - & - & - & - \\
\hline Rer & & Dsservaz & & & & & & & & & & & \\
\hline $\begin{array}{l}\text { The } \\
\text { istar }\end{array}$ & & $\begin{array}{l}\text { leous e } \\
\text { efinita col }\end{array}$ & iency is d & ined a & / L'effic & & & & & $=\frac{Q}{A_{A} G} \quad \eta$ & $a_{a}=\frac{Q}{A_{a} G}$ & & \\
\hline $\begin{array}{l}\text { The } \\
\text { is } g \\
\text { in } b \text {. }\end{array}$ & $\sec$ & $\begin{array}{l}\text { order } \\
\text { he equ } \\
\text { dell'ass }\end{array}$ & $\begin{array}{l}\text { data bas } \\
\text { n/La regre } \\
\text { ore }(A) \text { è da }\end{array}$ & $\begin{array}{l}\text { d on th } \\
\text { sione lin } \\
\text { dalla se }\end{array}$ & $\begin{array}{l}\text { absor } \\
\text { re del se } \\
\text { ruente ec }\end{array}$ & $\begin{array}{l}\text { er area } \\
\text { ondo ord } \\
\text { azione }\end{array}$ & & & $=\eta_{0.1}$ & $a_{L A}\left(\frac{t_{m}-t_{a}}{G}\right)$ & $-a_{2 A} G(\stackrel{t}{t}$ & $\left.\frac{-t_{a}}{7}\right)^{2}$ & \\
\hline $\begin{array}{l}\text { The } \\
\text { is } g \\
\text { in } b \text {. }\end{array}$ & & $\begin{array}{l}\text { order f } \\
\text { he equ } \\
\text { dell'ape }\end{array}$ & $\begin{array}{l}\text { data bas } \\
\text { n La regre } \\
\text { (a) è data c }\end{array}$ & $\begin{array}{l}\text { d on th } \\
\text { sione lin } \\
\text { alla segu }\end{array}$ & $\begin{array}{l}\text { apert } \\
\text { re del se } \\
\text { nte equa }\end{array}$ & $\begin{array}{l}\text { e area } \\
\text { ondo ord } \\
\text { one }\end{array}$ & & & $\eta_{o a}$ & $t_{i a}\left(\frac{t_{m}-t_{a}}{G}\right)$ & $-a_{2 a} G(\stackrel{t}{-}$ & $\frac{-t_{a}}{G}$ & \\
\hline $\begin{array}{l}\text { The } \\
\text { me } \\
\text { rela }\end{array}$ & on $f$ & $\begin{array}{l}\text { e therm } \\
\text { nt reco } \\
\text { outdoor }\end{array}$ & $\begin{array}{l}\text { capacity is } \\
\text { of tin, } \Delta T \\
\text { sting / La c }\end{array}$ & $\begin{array}{l}\text { calcul } \\
\text { ta , G } \\
\text { pacità te }\end{array}$ & $\begin{array}{l}\text { ed fron } \\
\text { and by } \\
\text { mica effe }\end{array}$ & $\begin{array}{l}\text { the } \\
\text { e follov } \\
\text { iva è }\end{array}$ & & 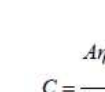 & 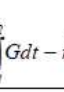 & $\int_{t i}^{t 2} \Delta T d t-A U$ & {$\left[\int_{t i}^{t 2}\left(t_{i n}\right.\right.$} & $-\frac{1}{2} \int_{t i}^{t 2}$ & \\
\hline & & registra & $\begin{array}{l}\text { misurate di } \\
\text { t all'aperto: }\end{array}$ & in, $\Delta T, t$ & G utiliz & ndo la & & & & $t_{m 2}-$ & & & \\
\hline & & & perator / & eratore & & & & & & Giovanni Bell & lenda & & \\
\hline
\end{tabular}




\section{åseurofins}

Modulo Unōo

\section{§ 6 TAB. 11B: Thermal performance - Test results / Prestazioni termiche - Risultati della prova}

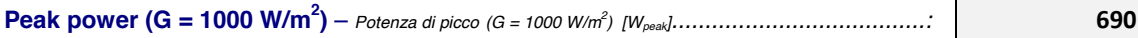
Power output per collector unit/ Potenza di uscita per unità di collettore

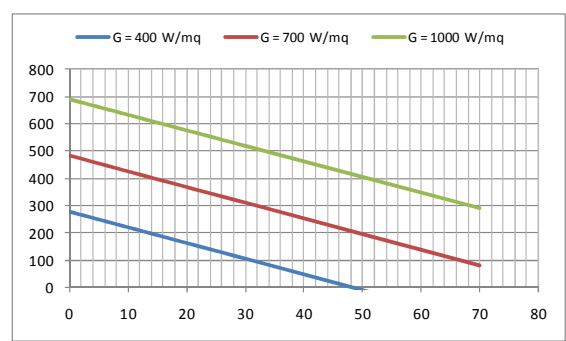

\begin{tabular}{|c|c|c|c|}
\cline { 2 - 4 } & \multicolumn{3}{|c|}{ Irradiance - Irraggiamento } \\
\hline $\mathrm{T}_{\mathrm{m}}-\mathrm{T}_{\mathrm{a}}[\mathrm{K}]$ & $\mathbf{4 0 0 \mathrm { W } / \mathrm { m } ^ { 2 }}$ & $\mathbf{7 0 0} \mathrm{W} / \mathrm{m}^{2}$ & $\mathbf{1 0 0 0} \mathrm{W} / \mathrm{m}^{2}$ \\
\hline $\mathbf{0}$ & $\mathbf{2 7 6}$ & $\mathbf{4 8 3}$ & $\mathbf{6 9 0}$ \\
\hline $\mathbf{1 0}$ & 219 & 425 & 633 \\
\hline $\mathbf{3 0}$ & 104 & 311 & 518 \\
\hline $\mathbf{5 0}$ & $<0$ & 196 & 404 \\
\hline $\mathbf{7 0}$ & $<0$ & 82 & 289 \\
\hline
\end{tabular}

Remarks / Osservazioni: The reported values are for normal incidence - I valori riportati si riferiscono ad incidenza normale

Istantaneous efficency curve / Curva di efficienza istantanea

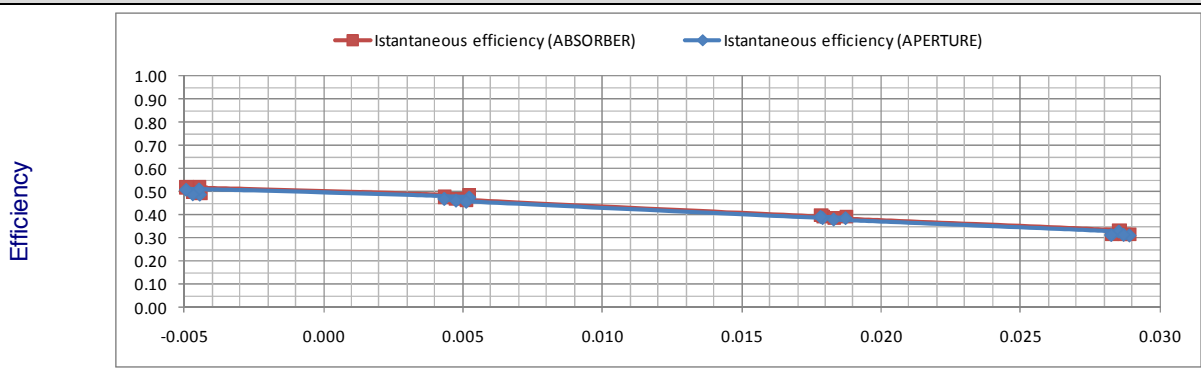

Reduced temperature difference $\left(T_{m}-T_{a}\right) / G\left[K \times m^{2} N\right]$

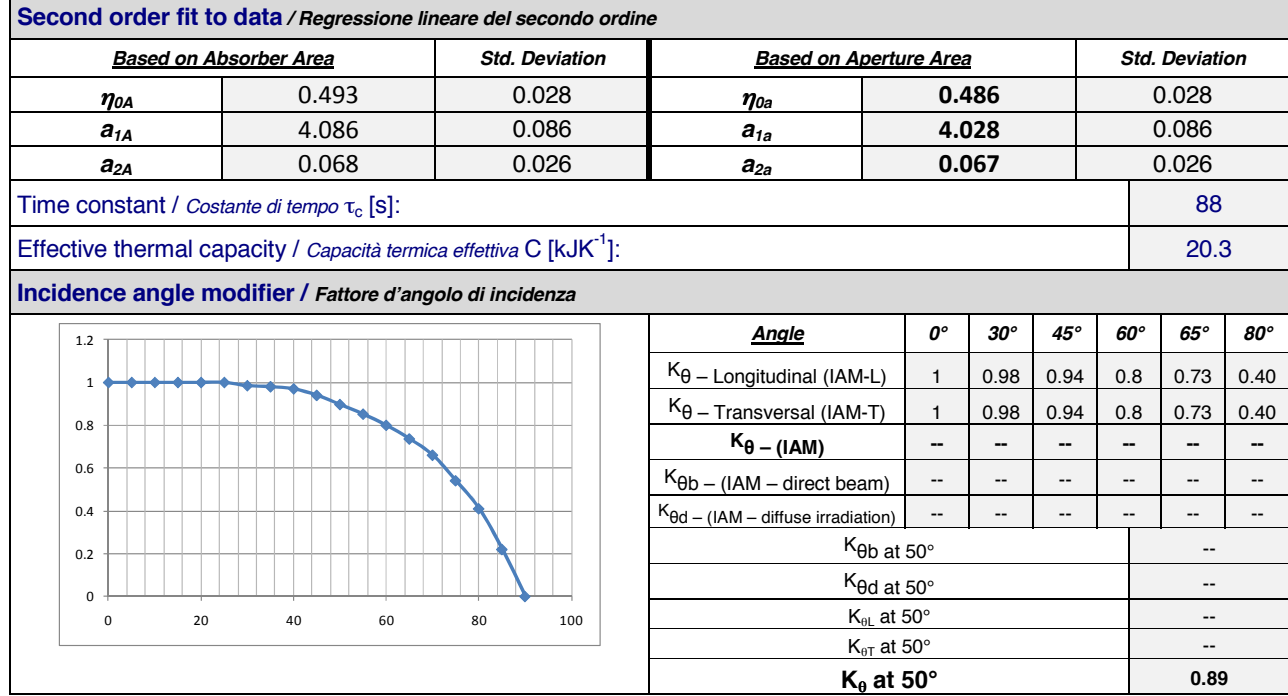


eurofins

Modulo Uno

ACCREDIA ?

जIAC-MIRA

LAB No 0085

RAPPORTO DI PROVA N ${ }^{\circ}$ Test Report $\mathrm{n}^{\circ}$

M1.11.NRG.0317/43724

Pag. 27 di 90

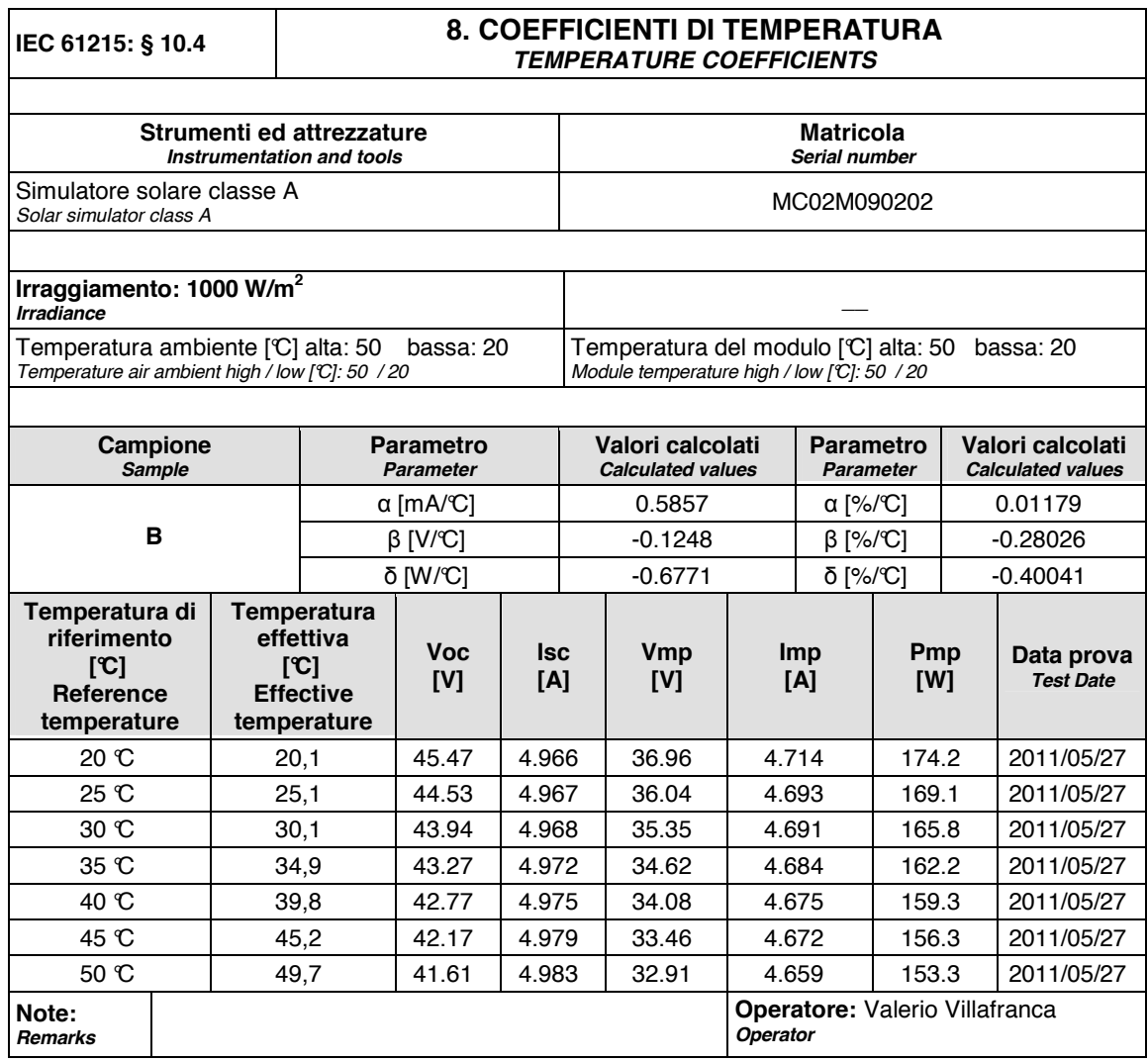




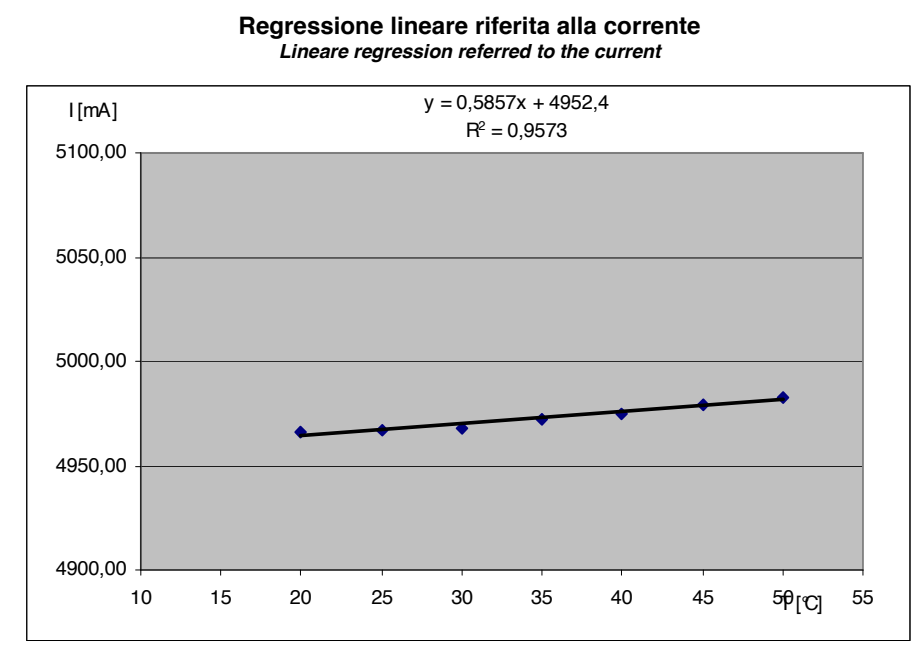

Regressione lineare riferita alla tensione

Linear regression referred to the voltage

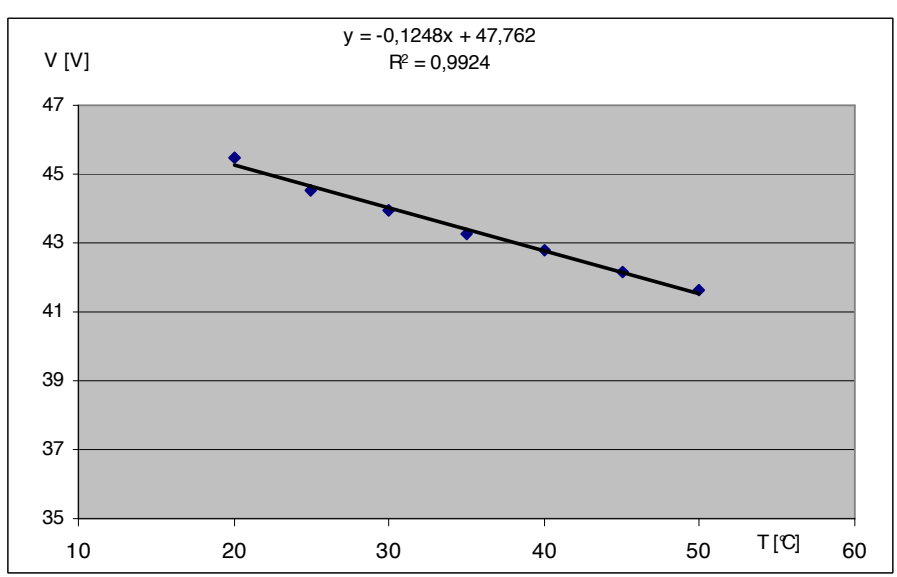




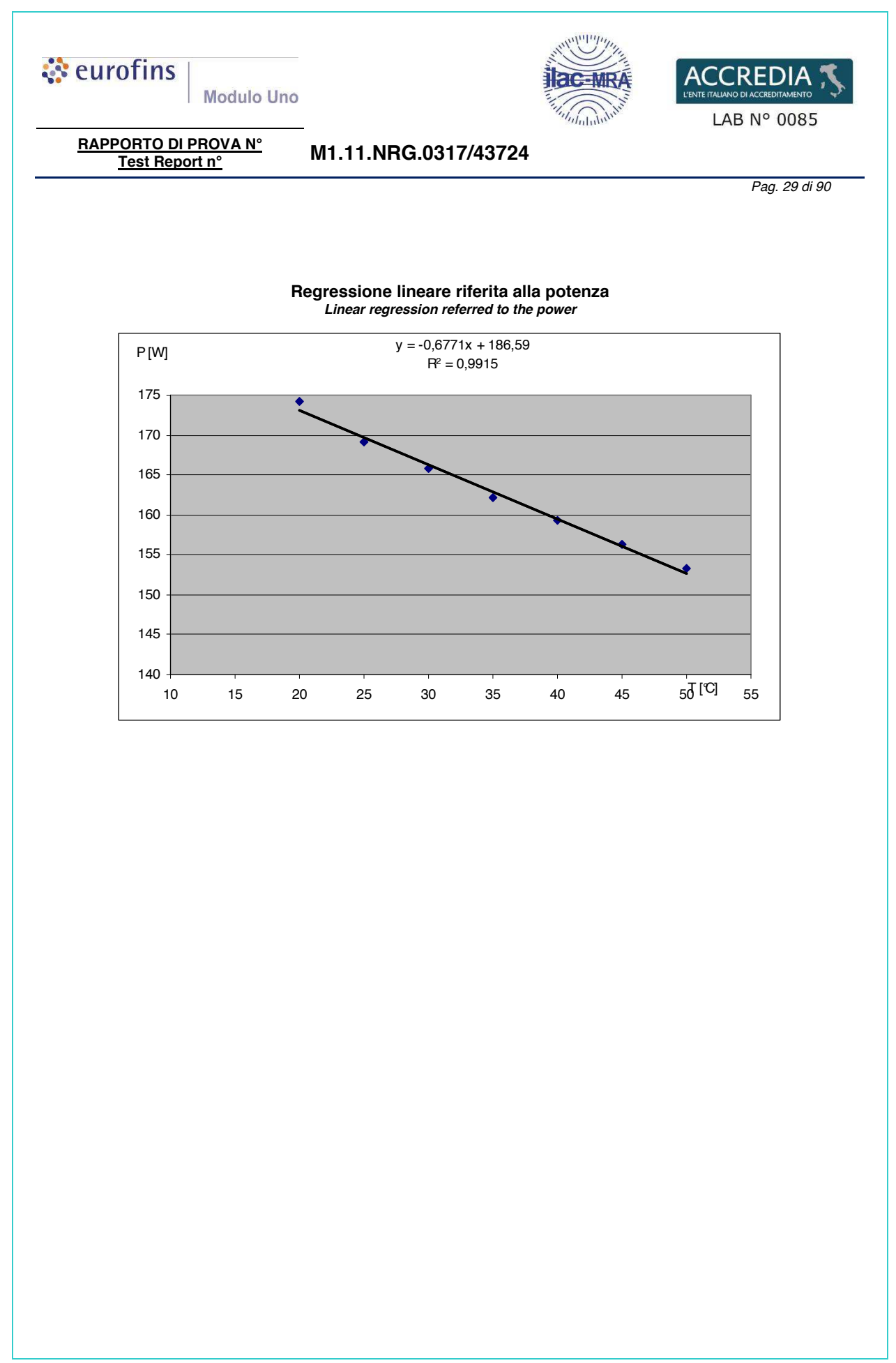




\section{Bibliography}

[1] United States Environmental Protection Agency, "Solar Heating and Cooling Technologies," [Online]. Available: https://19january2017snapshot.epa.gov/rhc/solarheating-and-cooling-technologies_html. [Accessed 17 April 2018].

[2] R. S. Kamel, A. S. Fung and P. R. Dash, "Solar systems and their integration with heat pumps: A review," Energy and Buildings, vol. 87, pp. 395-412, 2015.

[3] J. S. Wallace, Alternative Energy Systems - Solar Collector Types and Performance, Toronto: University of Toronto, 2015.

[4] ASHRAE TC 6.7, Solar Energy Utilization, ASHRAE Systems and Equipment Handbook - Chapter 37, ASHRAE, 2016.

[5] International Energy Agency, "Snapshot of Global Photovoltaic Markets," International Energy Agency, 2016.

[6] Roofway Inc., "Photovoltaic Performance," [Online]. Available:

http://www.roofway.com/en/solucao/sustainable-generation-energy-performance. [Accessed 17 April 2018].

[7] J. S. Wallace, Alternative Energy Systems - Band gap energy and efficiency, Toronto: University of Toronto, 2015.

[8] S. Angrist, "Direct Energy Conversion, 3rd Edition," Allyn and Bacon, Boston, 1976.

[9] G. Bellenda, "Powertherm Electrical Test Data, Test Report No. M1.11.NRG.0317/43724," Eurofins, Torino, 2011.

[10] Solimpeks Solar Energy Corp., "Volther PowerTherm \& PowerVolt Datasheet," Solimpeks, Konya, 2016.

[11] R. Moss, P. Henshall, F. Arya, G. Shire, T. Hyde and P. Eames, "Performance and operational effectiveness of evacuated flat plate solar collectors compared with conventional thermal, PVT and PV panels," Applied Energy, vol. 216, pp. 588-601, 2018.

[12] V. Tomar, G. Tiwari and T. Bhatti, "Performance of different photovoltaic-thermal (PVT) configurations integrated on prototype test cells: An experimental approach," Energy Conversion and Management, vol. 154, pp. 394-419, 2017.

[13] M. Izquierdo and P. d. Agustín-Camacho, "Solar heating by radiant floor: Experimental results and emission reduction obtained with a micro photovoltaic-heat pump system," Applied Energy, vol. 147, pp. 297-307, 2015.

[14] Z. M. Amin and M. Hawlader, "Analysis of solar desalination system using heat pump," Renewable Energy, vol. 74, pp. 116-123, 2015.

[15] M. J. Moran, H. N. Shapiro, D. D. Boettner and M. B. Bailey, Fundamentals of Engineering Thermodynamics 7ed, John Wiley \& Sons, Inc., 2010.

[16] Ecologix Inc., "Air to Water Cold Climate Heat Pump," Ecologix Inc, Cambridge, 2012.

[17] J. P. Fine, J. Friedman and S. B. Dworkin, "Transient analysis of a photovoltaic thermal heat input process with thermal storage," Appied Energy, vol. 160, pp. 308-320, 2015. 
[18] ISO/TC 180 Solar energy, "ISO 9806:2017 Solar energy -- Solar thermal collectors -test methods," International Organization for Standardization, 2017.

[19] Emerson Climate Technologies, "ZB15KQE-PFJ Ratings Coefficients," 2010.

[20] N. Ghaffour, S. Lattemann, T. Missimer, K. C. Ng, S. Sinha and G. Amy, "Renewable energy-drive innovative energy-efficient desalination technologies," Applied Energy, vol. 136, pp. 1155-1165, 2014.

[21] E. Antipova, D. Boer, L. F. Cabeza, G. Guillén-Gosálbez and L. Jiménez, "Multiobjective design of reverse osmosis plants integrated with solar Rankine cycles and thermal energy storage," Applied Energy, vol. 102, pp. 1137-1147, 2013.

[22] Z. A. Suleimani and V. R. Nair, "Desalination by solar-powered reverse osmosis in a remote area of the Sultanate of Oman," Applied Energy, vol. 65, pp. 367-380, 2000.

[23] A. Colangelo, D. Marano, G. Spagna and V. Sharma, "Photovoltaic powered reverse osmosis sea-water desalination systems," Applied Energy, vol. 64, pp. 289-305, 1999.

[24] M. Shatat, M. Worall and S. Riffat, "Opportunities for solar water desalination worldwide: Review," Sustainable Cities and Society, vol. 9, pp. 67-80, 2013.

[25] S. A. Kalogirou, Solar Energy Engineering - Processes and Systems, Elsevier, 2010, pp. 421-468.

[26] M. A. Eltawil, Z. Zhengming and L. Yuan, "A review of renewable energy technologies integrated with desalination systems," Renewable and Sustainable Energy Reviews, vol. 13, pp. 2245-2262, 2009.

[27] M. George, A. Ayoub and L. Malaebb, "Economic feasibility of a solar still desalination system with enhanced productivity," Desalination, vol. 335, pp. 27-32, 2014.

[28] Z. Liu, H. Song, D. Ji, C. Li, A. Cheney, Y. Liu, N. Zhang, X. Zeng, B. Chen, J. Gao, Y. Li, X. Liu, D. Aga, S. Jiang, Z. Yu and Q. Gan, "Extremely Cost-Effective and Efficient Solar Vapor Generation under Nonconcentrated Illumination Using Thermally Isolated Black Paper," 30 January 2017. [Online]. Available: https://doi.org/10.1002/gch2.201600003. [Accessed 6 June 2018].

[29] G. Singh, S. Kumar and G. Tiwari, "Design, fabrication and performance evaluation of a hybrid photovoltaic thermal (PVT) double slope active solar still," Desalination, vol. 277, pp. 399-406, 2011.

[30] A. Chafidz, S. Al-Zahrani, M. N. Al-Otaibi, C. F. Hoong, T. F. Lai and M. Prabu, "Portable and integrated solar-driven desalination system using membrane distillation for arid remote areas in Saudi Arabia," Desalination, vol. 345, 2014.

[31] A. M. Bilton, R. Wiesman, A. Arif, S. M. Zubair and S. Dubowsky, "On the feasibility of community-scale photovoltaic-powered reverse osmosis," Renewable Energy, vol. 36, pp. 3246-3256, 2011.

[32] H. Chena, S. B. Riffata and Y. Fu, "Experimental study on a hybrid photovoltaic/heat pump system," Applied Thermal Engineering, vol. 31, pp. 4132-4138, 2011.

[33] G. Xu, S. Deng, X. Zhang, L. Yang and Y. Zhang, "Simulation of a photovoltaic/thermal heat pump system having a modified collector/evaporator," Solar Energy, vol. 83, pp. 1967-1976, 2009.

[34] J. Jie, L. Keliang, C. Tin-tai, P. Gang, H. Wei and H. Hanfeng, "Performance analysis of a photovoltaic heat pump," Applied Energy, vol. 85, pp. 680-693, 2008. 
[35] G. Xu, X. Zhang and S. Deng, "Experimental study on the operating characteristics of a novel low-concentrating solar photovoltaic/thermal integrated heat pump water heating system," Applied Thermal Engineering, vol. 31, pp. 3689-3695, 2011.

[36] X. Zhang, X. Zhao, J. Shen, J. Xu and X. Yu, "Dynamic performance of a novel solar photovoltaic/loop-heat-pipe heat pump system," Applied Energy, vol. 114, pp. 335-352, 2014.

[37] X. Zhang, X. Zhao, J. Xu and X. Yu, "Characterization of a solar photovoltaic/loop-heatpipe heat pump water heating system," Applied Energy, vol. 102, pp. 1229-1245, 2013.

[38] X. Zhang, J. Shen, P. Xu, X. Zhao and Y. Xu, "Socio-economic performance of a novel solar photovoltaic/loop-heat-pipe heat pump water heating system in three different climatic regions," Applied Energy, vol. 135, pp. 20-34, 2014.

[39] L. A. Bromley, D. Singh, P. Ray, S. Sridhar and S. M. Read, "Thermodynamic Properties of Sea Salt Solutions," AIChE Journal, vol. 20, no. 2, pp. 326-335, 1974.

[40] National Renewable Energy Laboratory, "Hourly Data Files, Compressed by Site," September 1992. [Online]. Available: http://rredc.nrel.gov/solar/old_data/nsrdb/19611990/hourly/compressed/23183.tar.gz. [Accessed 16 March 2015].

[41] G. Bellenda, "Powertherm Thermal Test Report, Test Report Number M1.11.NRG.0319/43724," Torino, 2011.

[42] S. C. Chapra, Applied Numerical Methods with MATLAB, New York: McGraw Hill, 2008.

[43] M. Darwish, F. Al-Juwayhel and H. K. Abdulraheim, "Multi-effect boiling systems from an energy viewpoint," Desalination, vol. 194, pp. 22-39, 2006.

[44] U.S. Department of Energy, "EnergyPlus Energy Simulation Software Weather Data," U.S. Department of Energy, 15 July 2013. [Online]. Available:

http://apps1.eere.energy.gov/buildings/energyplus/weatherdata_about.cfm. [Accessed 2 July 2015].

[45] Copeland Climate Technology, "Copeland Scroll ZSKA Refrgrigeration Compressor Information Package," [Online]. Available: http://www.emersonclimate.com/enus/Products/Compressors/Scroll_Compressors/copeland_scroll_refrigeration/Documents /ZSKA_Customer_Launch_Package.pdf. [Accessed $25 \overline{11}$ 2014].

[46] S. Jenkins, J. Paduan, P. Roberts, D. Schlenk and J. Weis, "Management of Brine Discharges to Coastal Waters Recommendations of a Science Advisory Panel," Costa Mesa, 2012.

[47] K. Tanha, A. S. Fung and R. Kumar, "Performance of two domestic solar water heaters with drain water heat recovery units: Simulation and experimental investigation," Applied Thermal Engineering, vol. 90, pp. 444-459, 2015.

[48] M. S. Buker and S. B. Riffat, "Solar assisted heat pump systems for low temperature water heating applications: A systematic review," Renewable and Sustainable Energy Reviews, vol. 55, pp. 399-413, 2016.

[49] Z. Wang, W. Yang, F. Qiu, X. Zhang and X. Zhao, "Solar water heating: From theory, application, marketing and research," Renewable and Sustainable Energy Reviews, vol. 41, pp. 68-84, 2015. 
[50] S. S. Bertsch and E. A. Groll, "Two-stage air-source heat pump for residential heating and cooling applications in northern U.S. climates," International Journal of Refrigeration, vol. 31, pp. 1282-1292, 2008.

[51] H. W. Jung, H. Kang, W. J. Yoon and Y. Kim, "Performance comparison between a single-stage and a cascade multi-functional heat pump for both air heating and hot water supply," International Journal of Refrigeration, vol. 36, pp. 1431-1441, 2013.

[52] H. Fathabadi, "Increasing energy efficiency of PV-converter-battery section of standalone building integrated photovoltaic systems," Energy and Buildings, vol. 101, pp. 1-11, 2015.

[53] C. J. Banister and M. R. Collins, "Development and performance of a dual tank solarassisted heat pump system," Applied Energy, vol. 149, pp. 125-132, 2015.

[54] ANSI/AHRI , "Standard 540 - Standard for Performance Rating of Positive Displacement Refrigerant Compressors and Compressor Units," ANSI, 2004.

[55] R. Soltani and M. R. I. Dincer, "Comparative performance evaluation of cascaded airsource hydronic heat pumps," Energy Conversion and Management, vol. 89, pp. 577$587,2015$.

[56] A. Dabiri and C. Rice, "A compressor simulation model with corrections for the level of suction gas superheat," ASHRAE Transactions, vol. 87, p. 771-780, 1981.

[57] D. Goswani, F. Kreith and J. Kreider, Principles of Solar Engineering, 2nd Edition, Taylor and Frances, 2003.

[58] T. Markvart, Practical handbook of photovoltaics: Fundamentals and applications, New York: Elsevier Advanced Technology, 2003.

[59] Thermal Energy System Specialists, LLC, "TRNSYS 17 a TRaNsient SYstem Simulation program - Volume 4 Mathematical Reference Solar," University of Wisconsin-Madison, Wisconsin, 2012.

[60] National Renewable Energy Lab, "NSRDB: 1991- 2005 Update: TMY3," NREL, 2016.

[61] Meteorological Service of Canada and The National Research Council of Canada, "Canadian Weather Energy and Engineering Data Sets (CWEEDS Files)," The National Research Council of Canada, Ottawa, 2008.

[62] Solar Rating and Certification Corporation, "Solar Panels Plus SPP-30 Thermal Performance Rating," Solar Rating and Certification Corporation, 2009.

[63] Natural Resources Canada-Canmet ENERGY, "The RETScreen Clean Energy Project Analysis Software 4.0".

[64] E. Lemmon, M. Huber and M. McLinden, "NIST Standard Reference Database 23: Reference Fluid Thermodynamic and Transport Properties-REFPROP, Version 9.1," National Institute of Standards and Technology, Gaithersburg, 2013.

[65] Guangzhou Qilin Environmental Technology Firm, "Copeland Scroll Compressor Prices," [Online]. Available: http://www.alibaba.com/product-detail/Copleand-ScrollCompressor-ZB15KQE-PFJ-558_1118991563.html. [Accessed 2016].

[66] POKKA Automotive air conditioning parts export co., LTD, "Conditioner Expansion Valve Prices," [Online]. Available: http://www.aliexpress.com/item/Free-ShippingFujikoki-Thailand-Expansion-valve-9-16-OR-3-8-OR-Air-conditioner-expansionvalve/32647847244.html?spm. 
[67] McMaster-Carr, "Heat Exchanger Price," [Online]. Available: http://www.mcmaster.com/\#35115k61/=135z2ja. [Accessed 2016].

[68] The World's Trusted Currency Authority, "Exchange Rates," [Online]. Available: http://www.xe.com/currencyconverter/convert/?Amount=1. [Accessed 7 July 2016].

[69] Natural Resources Canada, "Water heater guide," Ottawa, 2012.

[70] Ontario Energy Board, "Natural Gas Rate Updates," [Online]. Available: http://www.ontarioenergyboard.ca/OEB/Consumers/Natural Gas/Natural Gas Rates. [Accessed 8 Juy 2016].

[71] EPCOR, "Historical Natural Gas Rates," [Online]. Available: http://www.epcor.com/power-natural-gas/energy-plans/energy-plans/Pages/historicalnatural-gas-rates.aspx. [Accessed 8 July 2016].

[72] U.S. Energy Information Administration, "Independent Statistics and Analysis," [Online]. Available: https://www.eia.gov/naturalgas/. [Accessed 8 July 2016].

[73] J. A. Duffie and W. A. Beckman, Solar Engineering of Thermal Processes - Second Edition, New York: Wiley-Interscience, 1991.

[74] R. Nasrin, M. Hasanuzzaman and N. Rahim, "Effect of high irradiation and cooling on power, energy and performance of a PVT system," Renewable Energy, vol. 116, pp. 552$569,2018$.

[75] H. Ibrahim and N. Anani, "Variations of PV module parameters with irradiance and temperature," Energy Procedia, vol. 134, pp. 276-285, 2017.

[76] T. M. Sathe and A. Dhoble, "A review on recent advancements in photovoltaic thermal techniques," Renewable and Sustainable Energy Reviews, vol. 76, pp. 645-672, 2017.

[77] A. Kumar, P. Baredar and U. Qureshi, "Historical and recent development of photovoltaic thermal (PVT) technologies," Renewable and Sustainable Energy Reviews, vol. 42, pp. 1428-1436, 2015.

[78] J. P. Fine, J. Friedman and S. B. Dworkin, "Detailed modeling of a novel photovoltaic thermal cascade heat pump domestic water heating system," Renewable Energy, vol. 101, pp. 500-513, 2017.

[79] DOW Chemical, "Engineering and Operating Guide for Dowtherm SR-1 and Dowtherm 4000 Inhibited Ethylene Glycol-based Heat Transfer Fluids," DOW Chemical, Midland, 2008.

[80] S. Bambrook and A. Sproul, "Maximising the energy output of a PVT air system," Solar Energy, vol. 86, pp. 1857-1871, 2012.

[81] M. Debbarma, K. Sudhakar and P. Baredar, "Comparison of BIPV and BIPVT: A review," Resource-Efficient Technologies, vol. 3, pp. 263-271, 2017.

[82] S. Tiwari and G. Tiwari, "Energy and exergy analysis of a mixed-mode greenhouse-type solar dryer, integrated with partially covered N-PVT air collector," Energy, vol. 128, pp. 183-195, 2017.

[83] R. S. Kamel and A. S. Fung, "Modeling, simulation and feasibility analysis of residential BIPV/T+ASHP system in cold climate - Canada," Energy and Buildings, vol. 82, pp. 758-770, 2014. 
[84] S. Hussain and S. J. Harrison, "Evaluation of thermal characteristics of a flat plate solar collector with a back mounted air channel," Applied Thermal Engineering, vol. 123, pp. 940-952, 2017.

[85] M. Lammle, T. Kroyer, S. Fortuin, M. Wiese and M. Hermann, "Development and modelling of highly-efficient PVT collectors with low-emissivity coatings," Solar Energy, vol. 130, pp. 161-173, 2016.

[86] S. Bambrook and A. Sproul, "A solvable thermal circuit for modelling PVT air collectors," Solar Energy, vol. 138, pp. 77-87, 2016.

[87] A. Fudholi, K. Sopian, M. H. Yazdi, M. H. Ruslan, A. Ibrahim and H. A. Kazem, "Performance analysis of photovoltaic thermal (PVT) water collectors," Energy Conversion and Management, vol. 78, pp. 641-651, 2014.

[88] J. Antonanzas, A. d. Amo, A. Martinez-Gracia, A. Bayod-Rujula and F. AntonanzasTorres, "Towards the optimization of convective losses in photovoltaic-thermal panels," Solar Energy, vol. 116, pp. 323-336, 2015.

[89] F. M. Rad, A. S. Fung and M. A. Rosen, "An integrated model for designing a solar community heating system with borehole thermal storage," Energy for Sustainable Development, vol. 36, pp. 6-15, 2017.

[90] J. P. Fine, H. V. Nguyen, J. Friedman, W. H. Leong and S. B. Dworkin, "A Simplified Ground Thermal Response Model for Analyzing Solar-Assisted Ground Source Heat Pump Systems," Energy Conversion and Management, vol. 165, pp. 276-290, 2018.

[91] M. S. A. Khana, A. W. Badarb, T. Talha, M. W. Khan and F. S. Butt, "Configuration based modeling and performance analysis of single effect solar absorption cooling system in TRNSYS," Energy Conversion and Management, vol. 157, pp. 351-363, 2018.

[92] ASHRAE, ASHRAE Standard 93-2003 - Methods of testing to determine the performance of solar collectors, Atlanta: American Society of Heating Cooling and Refrigeration, 2003.

[93] P. Dupeyrat, C. Ménézo and S. Fortuin, "Study of the thermal and electrical performances of PVT solar hot water system," Energy and Buildings, vol. 68, pp. 751$755,2014$.

[94] E. Yandri, "The effect of Joule heating to thermal performance of hybrid PVT collector during electricity generation," Renewable Energy, vol. 111, pp. 344-352, 2017.

[95] T. Chow, W. He and J. Ji, "Hybrid photovoltaic-thermosyphon water heating system for residential application," Solar Energy, vol. 80, pp. 298-306, 2006.

[96] A. Ghoneim, M. Aljanabi, A. Al-Hasan and M. A. M., "Yields Analysis and Environmental Evaluation of Combined Photovoltaic-Thermal Collector in Kuwait Climate," in Global Conference on Global Warming, Istanbul, 2008.

[97] Internation Energy Agency, "Task 60: PVT SYSTEMS Application of PVT collectors and new solutions in HVAC systems - Work Plan Information Plan," Internation Energy Agency, Switzerland, 2018.

[98] K. Kapsis, "Modelling, Design and Experimental Study of Semi-Transparent Photovoltaic Windows for Commercial Building Applications - PhD Thesis," Concordia University, Montreal, 2016. 
[99] Temperature Controls Ltd., "RTD accuracy - Class A, Class B, 1/3 DIN, 1/10 DIN," Temperature Controls Ltd., Sydney, 2018.

[100] Kipp and Zonen, "CMP Series Pyranometer Instruction Manual," Delft, 2016.

[101] DayStar Inc., "DS-100C I-V CURVE TRACER User Manual," Daystar Inc., Albuquerque, 2011.

[102] MathWorks, Inc, "Curve Fitting Toolbox Help Documentation," MathWorks, 2016.

[103] N. Aste, F. Leonforte and C. D. Pero, "Design, modeling and performance monitoring of a photovoltaic-thermal (PVT) water collector," Solar Energy, vol. 112, pp. 85-99, 2015. 